\title{
HIGH CYCLE (FATIGUE) RESISTAṄCE OF \\ REINFORCED CONCRETE BEAMS WITH LAP SPLICES
}

\author{
A Thesis Submitted to the College of \\ Graduate Studies and Research \\ in Partial Fulfilment of the Requirements \\ for the Degree of Master of Science \\ in the Department of Civil Engineering \\ University of Saskatchewan \\ Saskatoon, Saskatchewan
}

By

Jeffrey G. Afseth

August 1993

C Copyright Jeffrey G. Afseth, 1993. All rights reserved. 


\section{PERMISSION TO USE}

In presenting this thesis in partial fulfilment of the requirements for a Postgraduate degree from the University of Saskatchewan, I agree that the Libraries of this University may make it freely available for inspection. I further agree that permission for copying of this thesis in any manner, in whole or part, for scholarly purposes may be granted by the professor or professors who supervised my thesis work or, in their absence, by the Head of the Department or the Dean of the College in which my thesis work was done. It is understood that any copying or publication or use of this thesis or parts thereof for financial gain shall not be allowed without my written permission. It is also understood that due recognition shall be given to me and to the University of Saskatchewan in any scholarly use which may be made of any material in my thesis.

Requests for permission to copy or to make other use of material in this thesis in whole or in part should be addressed to:

Head of the Department of Civil Engineering University of Saskatchewan Saskatoon, Saskatchewan S7N OW0 


\section{ABSTRACT}

The development of current design standards for reinforced concrete beams containing lap splices has been mainly aimed at preventing failures due to static (monotonic) loading, or low cycle, high intensity (seismic) loading. However, little consideration has been given in these standards or in previous research to the performance of lap splices when subjected to high cycle, low intensity (fatigue) loading. Also, recently proposed design equations for lap splices under static loading will permit shorter lap lengths. For these reasons, a study was initiated to investigate the fatigue resistance of reinforced concrete beams with lap splices. A principal variable in this research program was the degree of transverse reinforcement (stirrups) which was provided along the lap splice.

The specimens used in this experimental program were seven meters in length, with a cross section $330 \mathrm{~mm}$ wide and $508 \mathrm{~mm}$ deep, and were reinforced with two No. 30 Grade 400 bars, top and bottom. A lap splice was provided in the bottom tension bars situated in a constant moment region created by a symmetrical two point loading system. The lap splice length and confinement were designed according to ACI Committee 408 recommendations for static loading.

Two different lap splice configurations were provided for the test specimens. The first used the maximum number of stirrups that were deemed to be effective for static loading, permitting a shorter lap length. In the second configuration nominal stirrups were provided to the splice at a spacing of one half the effective beam depth, requiring a longer lap length. Failure of the specimens with the heavier stirrups occurred from fatigue of the tensile reinforcing steel and showed similar fatigue resistance to beams containing continuous reinforcement. The specimens with nominal stirnups usually resulted in a splice failure after fewer load cycles, after splitting and delamination of the concrete confining the lap had occurred.

Both beams had a similar static bond resistance; however, the beams with the heavier stirrup confinement (shorter lap length) displayed a greater fatigue resistance than the beams with lighter stirrups (longer lap length). These results are in agreement with conclusions reached for seismic loading conditions, which found that splice confinement provided by a high degree of transverse reinforcement is required under cyclic loading to offset the rapid deterioration of the concrete cover confinement. 


\section{ACKNOWLEDGMENTS}

The author would like to acknowledge the following people for their invaluable assistance towards completion of this thesis: Professor T. Rezansoff for his guidance, expertise and patience during the writing of this report; and Mr. D. Stott for his experienced assistance in completing the experimental testing for this study. 


\section{DEDICATION}

This Master of Science Thesis is dedicated to the following people for their much appreciated encouragement, support and assistance: my mother and father, Ross and Noreen Afseth, and Niki Burfitt. 


\section{TABLE OF CONTENTS}

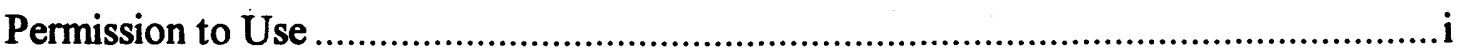

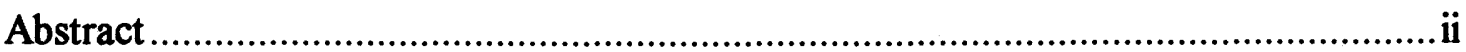

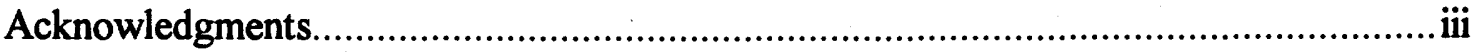

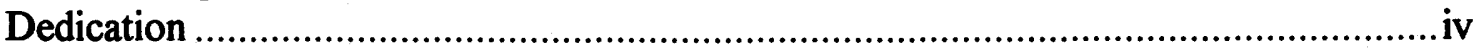

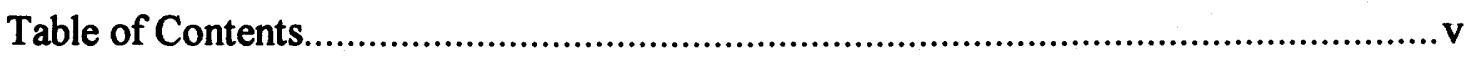

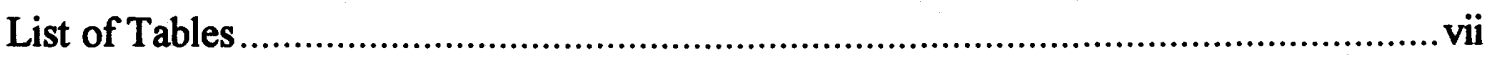

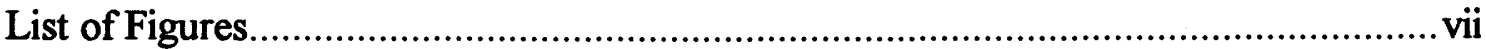

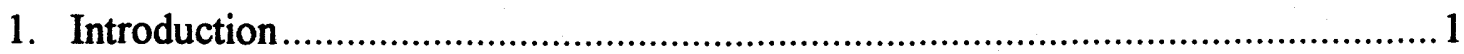

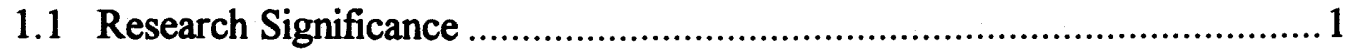

1.2 Lap Splice Design Background ........................................................2

1.2.1 ACI Committee 408 Recommendations................................2

1.2.2 Research into Seismic Loading ...........................................5

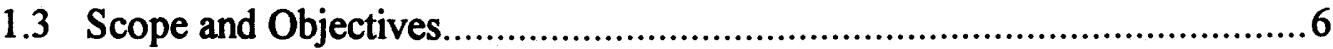

1.4 Report Overview ...................................................................... 8

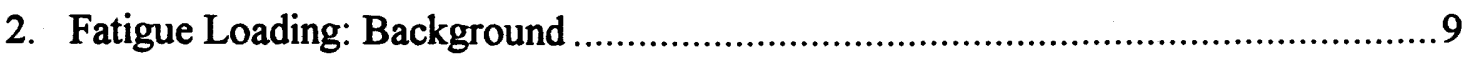

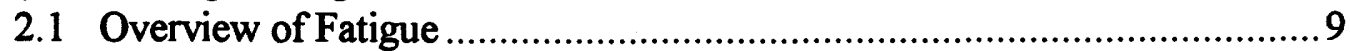

2.1.1 Analysis of Fatigue - S-N Relations .................................... 10

2.1.2 Analysis of Fatigue - Fracture Mechanics ............................ 12

2.1.2.1 Linear Elastic Fracture Mechanics........................... 13

2.1.2.2 Non-Linear Fracture Mechanics.............................20

2.1.3 Variable Amplitude Loading................................................22

2.2 Fatigue of Concrete .................................................................23

2.2.1 Factors Influencing Fatigue Strength of Concrete ...................23

2.2.2 Influence of Loading Rate .................................................. 25

2.2.3 Influence of Stress Gradient .............................................27

2.2.4 Influence of Varying Stress Range......................................27

2.3 Analysis of Concrete Fatigue Strength .............................................30

2.3.1 S-N Relationships for Concrete .......................................... 30

2.3.1.1 Stress and Stress Range Dependence ........................30

2.3.1.2 Time Dependence ................................................... 31

2.3.1.3 Statistical Evaluation ...............................................33

2.3.2 Fracture Mechanics for Concrete ........................................ 33

2.3.2.1 Nature of Concrete Fracture .................................. 33

2.3.2.2 Application of Fracture Mechanics to Concrete............35

2.3.2.3 Fracture Mechanics and Concrete Fatigue...................39

2.4 Fatigue of Reinforcing Steel.............................................................43 
2.4.1 Analysis of Reinforcing Steel Fatigue .......................................45

2.4.1.1 S-N Relationships for Reinforcing Steel .....................45

2.4.1.2 Fracture Mechanics for Reinforcing Steel......................46

2.5 Fatigue of Reinforced Concrete Beams ...................................................49

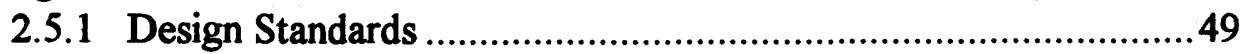

2.5.2 Bond in Reinforced Concrete ...................................................50

2.5.2.1 Fracture Mechanics of Bond ......................................52

2.5.3 Overview of Lap Splices ........................................................53

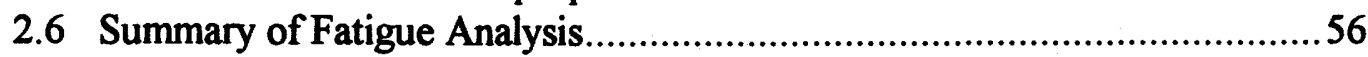

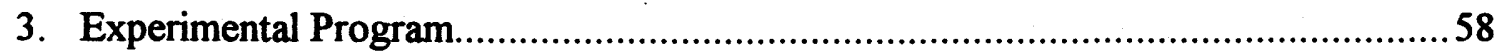

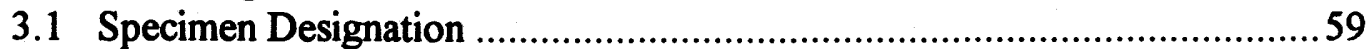

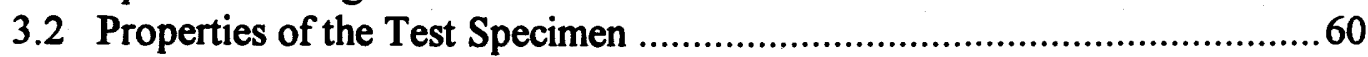

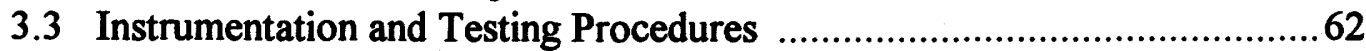

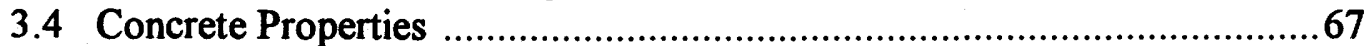

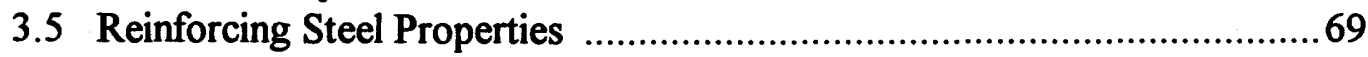

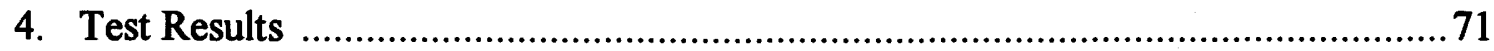

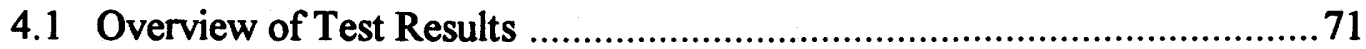

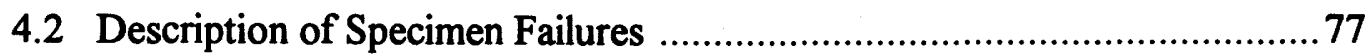

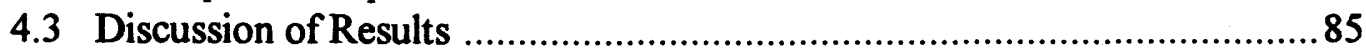

4.3.1 Bond Failure Results ............................................................87

4.3.1.1 Influence of Transverse Reinforcement

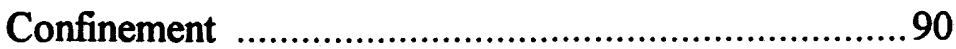

4.3.1.2 Influence of Concrete Strength ...................................91

4.3.2 Steel Failure Results ............................................................93

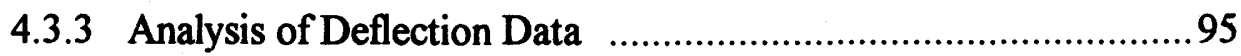

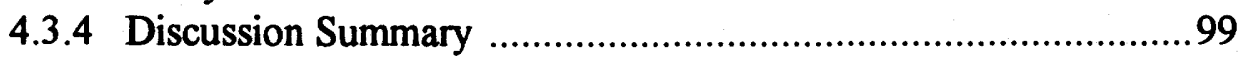

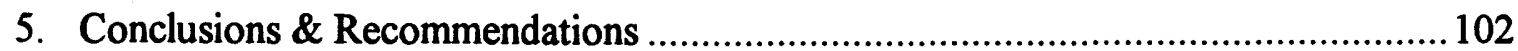

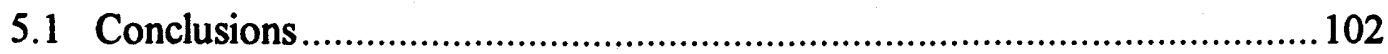

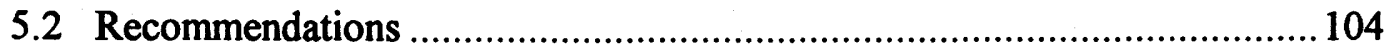

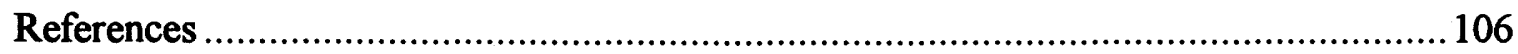

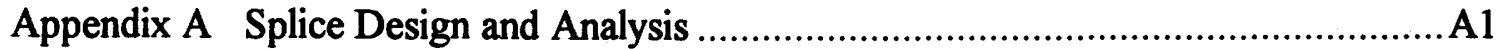

Appendix B Regression Analysis of Bond Failures.................................................... B1

Appendix C Moment - Curvature Program..............................................................

Appendix D MTS Load - Deflection Plots................................................................

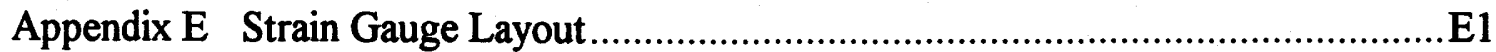

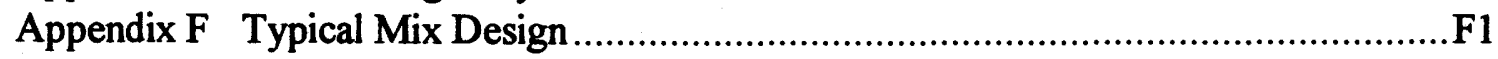

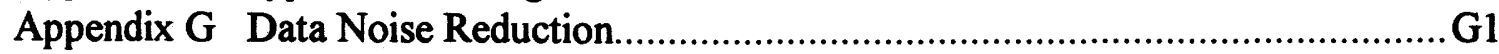

Appendix H LVDT Deflection Data ..................................................................... 


\section{LIST OF TABLES}

Table 1.1 Comparison of Lap Splice Design Lengths ............................................4

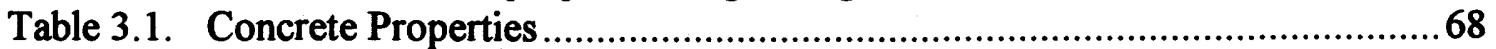

Table 3.2. Reinforcing Steel Properties .............................................................69

Table 4.1. Test Data based on Static Strength ........................................................... 72

Table 4.2. Test Data based on Steel Strength ...........................................................74

\section{LIST OF FIGURES}

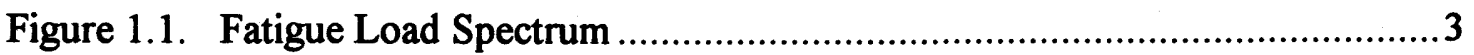

Figure 1.2. Comparison of ACI 318-89 Design Equations and ACI 408

Recommendations: Lap Splice Lengths vs. Total Confinement

Provided to Splice.

Figure 2.1. Schematic of Typical S-N Curve...........................................................11

Figure 2.2. Modified Goodman Diagram (Mallet 1991).............................................11

Figure 2.3. Goodman Diagram for Determination of Fatigue Strength of Plain Concrete According to Swedish Regulations BBK 79 (Gylltoft

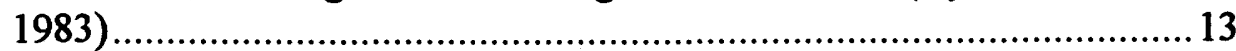

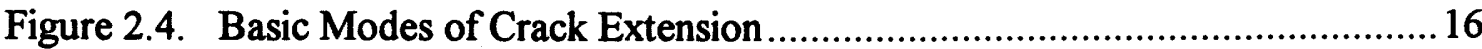

Figure 2.5. Stress Distribution in Front of a Crack Tip (Broek 1984).........................17

Figure 2.6. Schematic Diagram for Fatigue Crack Growth Rate Log (da/dN) vs. the Stress Intensity Factor Range $\log (\Delta \mathrm{K})($ Gylltoft 1983) .................20

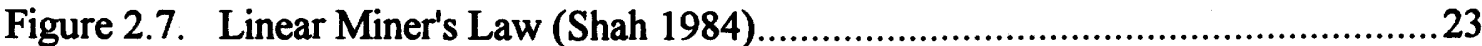

Figure 2.8. Non-Linear Miner's Law (Shah 1984) ..............................................29

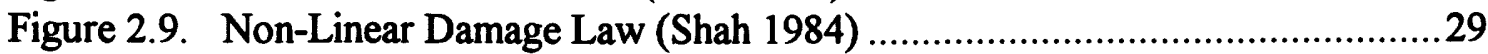

Figure 2.10. S-N Curves of Different Values of $R$ (Tepfers and Kutti 1979) ................32

Figure 2.11. Stress-Strain Diagram of Hardened Cement Paste, Aggregate and Concrete (Ziegeldorf) ..........................................................................34

Figure 2.12. Stress-Strain Curve for Concrete Showing Different Regions of Crack Growth (Mindess 1983)..............................................................34

Figure 2.13. The Conditions Around a Crack Tip in Different Types of Materials ........37

Figure 2.14. Stress Distribution in Front of Crack Tip Before and After Cracking; Material Properties (Hillerborg 1983) ....................................38

Figure 2.15. Stress-Deformation Curves of a Notched Beam During Fatigue Life (Glucklich 1965) 
Figure 2.16 Stress-Strain Curve of Concrete Subjected to Repeated Loading (Mindess and Young 1981)

Figure 2.17. Experimental Load Histories in Cyclic Tension (Elfgren 1989) ...............43

Figure 2.18 Lug Height and Base Radius..........................................................4

Figure 2.19 Woods Model for Fatigue Crack Initiation (Broek 1982) .......................48

Figure 2.20 Fatigue Crack Growth (Broek 1982) ...............................................48

Figure 2.21 A Typical Crack Around a Deformed Bar (Goto 1971)...........................51

Figure 2.22 Schematic Representation of the Radial Components of the Bond Forces Balanced Against Tensile Stress Rings in the Concrete at a Zone of Anchorage (Tepfers) ........................................................52

Figure 3.1. Specimen Details and Loading Arrangement ...........................................61

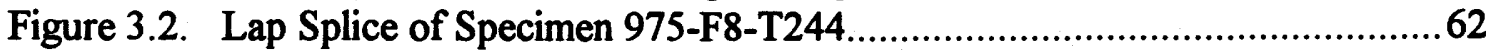

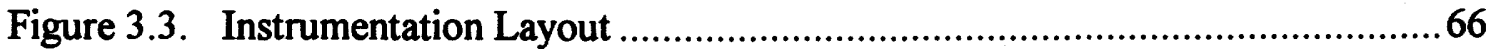

Figure 3.4. Stress-Strain Diagram for Tensile Reinforcement Batch \#1 .....................70

Figure 3.5. Stress-Strain Diagram for Tensile Reinforcement Batch \#2 ....................70

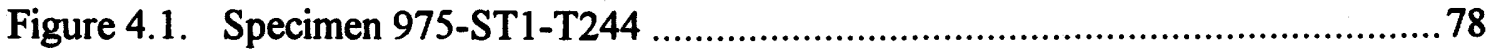

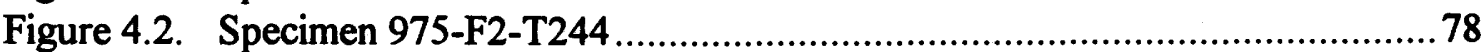

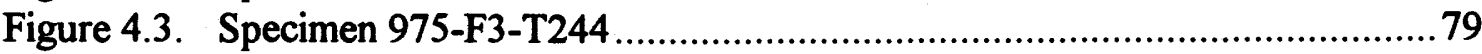

Figure 4.4. Reinforcing Steel Fatigue Crack - 900-F4-T129 .....................................8

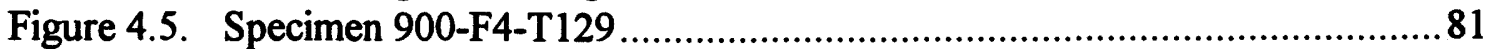

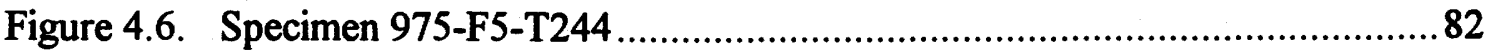

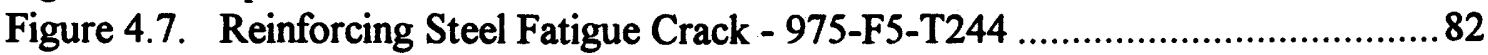

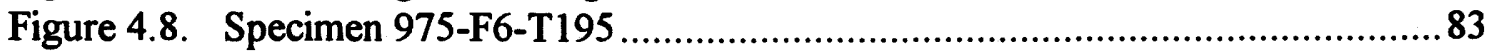

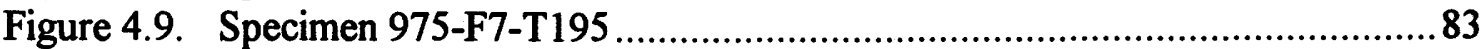

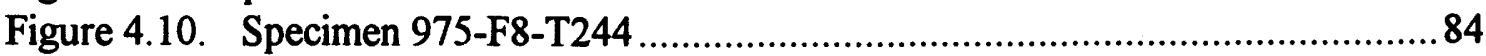

Figure 4.11. Reinforcing Steel Fatigue Crack - 900-F9-T129 ……….......................86

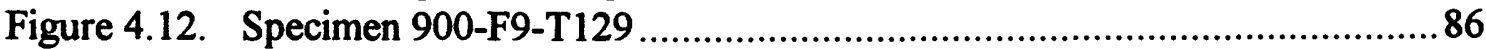

Figure 4.13. Maximum Stress vs. Number of Cycles to Failure ..................................88

Figure 4.14. Concrete Compressive Strength vs. Number of Cycles to Failure ............92

Figure 4.15. Stress Range vs. Number of Cycles to Failure......................................94

Figure 4.16. Specimens' Deflections: Maximum Midspan Deflection vs. $\log (\mathrm{N}) \ldots \ldots . . .97$

Figure 4.17. Bond Failure Deflections: Maximum Midspan Deflection vs. Load

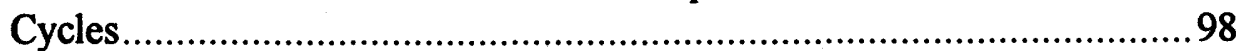

Figure 4.18. Steel Failure Deflections: Maximum Midspan Deflection vs. Load Cycles. 98

Figure 4.19. Stress Range (\% of Static Lap Splice Strength) vs. Number of Cycles to Failure 100 


\section{INTRODUCTION}

\subsection{Research Significance:}

The appearance of lighter and stronger materials for use in the design and construction of civil engineered structures have enabled such structures to become lighter and more slender. Also, advances in engineering design standards are allowing higher stresses and stress ranges to be applied to the materials of these structures (Gylltoft 1983). Such advancements in engineering technology have created a situation where the potential for a fatigue failure to occur is increasing.

In addition, older structures are often called upon to resist heavier loading than they were initially designed for. This occurs with traffic bridges, where heavier tractor-trailers with larger payloads are being used to realize savings in transportation costs. The current world economy hardly permits the maintenance and rehabilitation of the available infrastructure, let alone permitting the replacement of existing structures.

The study of longitudinal reinforcement lap splices or development lengths in reinforced concrete has mainly been directed towards failure from static or low cycle (approximately 1 cycle to 1000 cycles), high intensity (seismic) loading. From this extensive research, equations for the design of lap splices under these types of loadings have been developed. These have been incorporated into the design practices of current design standards and will result in more accurate design approaches in future codes. The ACI Committee 408 
(1979 and 1990) recommendations have proposed some of the more current design equations and practices for static loading of lap splices. The recommendations put forth by researchers at Cornell University (Fagundo, Gergely, and White 1979; Tocci, Gergely, and White 1981; and Hungspreug 1981) consider the situation of seismic loading of splices, and the related design equations.

Information is somewhat limited in the area of high cycle (approximately 1000 to $10,000,000$ cycles), low or moderate intensity (fatigue) loading. The present research program was undertaken to provide information on lap splice tensile resistance in concrete beams subjected to a high cycle fatigue loading. Figure 1.1 shows a classification diagram defining the approximate boundaries for various types of fatigue loading applications.

\subsection{Lap Splice Design Background:}

\subsubsection{ACI Committee 408 Recommendations:}

Extensive research in the area of tensile lap splices and tensile development lengths in beams subjected to static loading has resulted in more accurate approaches to design such as the one presented in the recommendations by ACI Committee 408 (1979 and 1990).

The procedures presented by ACI 408 for lap splice design take into account the spacing of the main tensile reinforcement, and the amount of confinement provided to the lap splice. Therefore, unlike the approaches taken by earlier design codes, ACI 408 has recognized the advantages which can be provided to a tensile lap splice by the confinement contributed from concrete cover and transverse reinforcement. Enhanced 


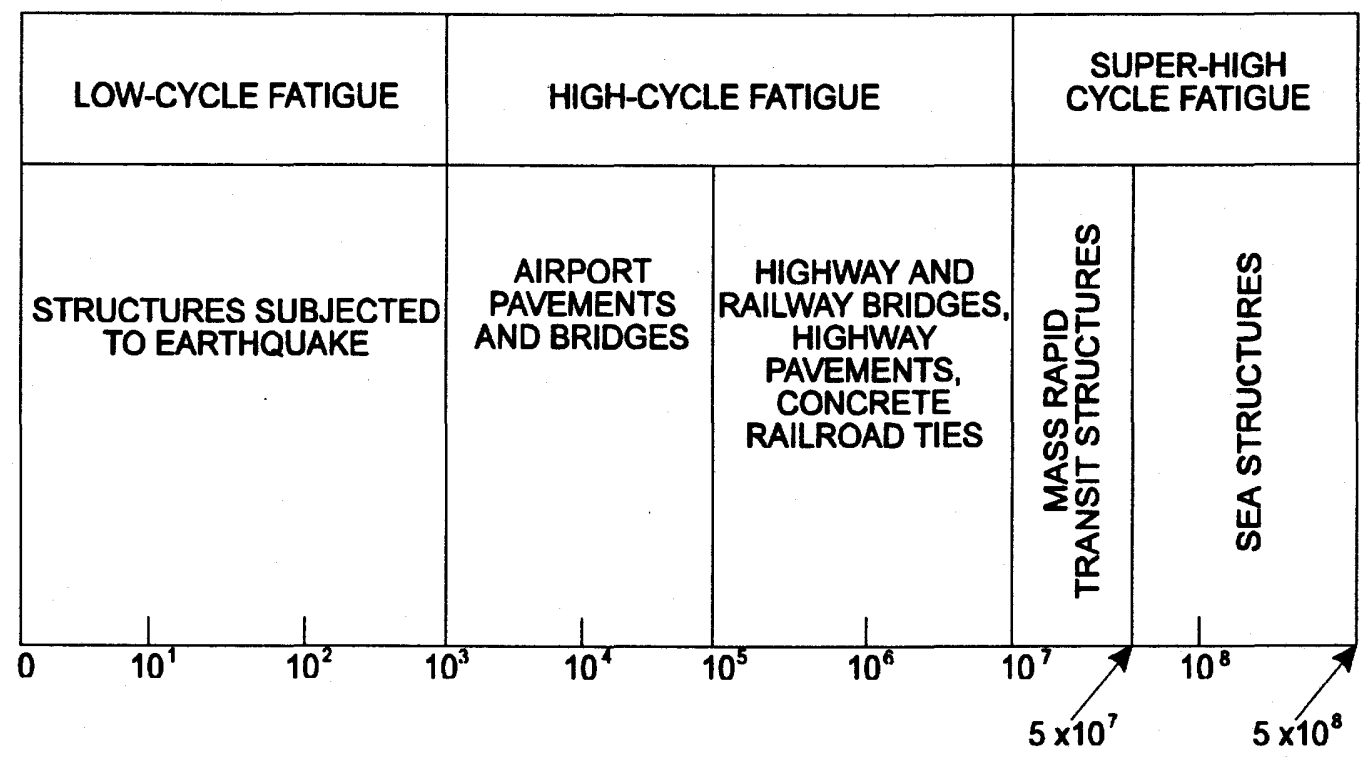

NUMBER OF CYCLES

Figure 1.1. Fatigue Load Spectrum (Hsu 1981).

confinement can reduce the length of the lap splice considerably. The ACI 408 design equations provide for shorter lap lengths with more confinement and longer lap lengths with less confinement. Therefore, a splice design based on the ACI 408 procedures will be significantly different from one designed according to the Canadian standard, CSA CAN3-A23.3-M84, which does not adequately consider the benefits of lap splice confinement.

The ACI 408 Committee has proposed in its recommendations that splice length and development length can be designed using the same equations. This is unlike the lap splice requirements of the Canadian design standard, CSA CAN3-A23.3-M84, in which a required class factor is to be applied to the basic development length depending on the stress level in the reinforcing bar and the percentage of reinforcement being spliced at the lap location. 
Table 1.1. Comparison of Lap Splice Design Lengths

Transverse Reinforcement

\begin{tabular}{llll}
\cline { 2 - 4 } \multicolumn{1}{c}{ Standard } & None & Nominal & Heavy \\
\hline CSA CAN3-A23.3-M84 & $1872 \mathrm{~mm}$ & $1872 \mathrm{~mm}$ & $1872 \mathrm{~mm}$ \\
ACI 408 & $1239 \mathrm{~mm}$ & $972 \mathrm{~mm}$ & $895 \mathrm{~mm}$ \\
\hline
\end{tabular}

To compare the lap splice designs, based on the ACI 408 Committee's recommendations and CSA CAN3-A23.3-M84, calculations were performed, as shown in Appendix A and summarized in Table 1.1, to determine the required lap lengths under static loading for the beam cross section of the current study. The lengths were established for different quantities of stirrup confinement.

The lap splice lengths determined by the Canadian standard are much longer than the lengths designed according to ACI 408. This is partly due to the fact that the Canadian standard does not account for the benefits that have been identified with stirrup confinement and only crudely accounts for concrete cover confinement. In addition, a class factor needs to be applied to the basic development length in the Canadian standard to obtain a required splice length. The class factor that is required by the Canadian standard is 1.7 for the current study where 100 percent of the bars are spliced at a lap location within a high stress region. Work by Orangun, Jirsa and Breen (1977) has shown that lap splices designed by the Canadian standard are often excessively conservative for static loading. Therefore shorter lengths were recommended by the ACI 408 Committee. 


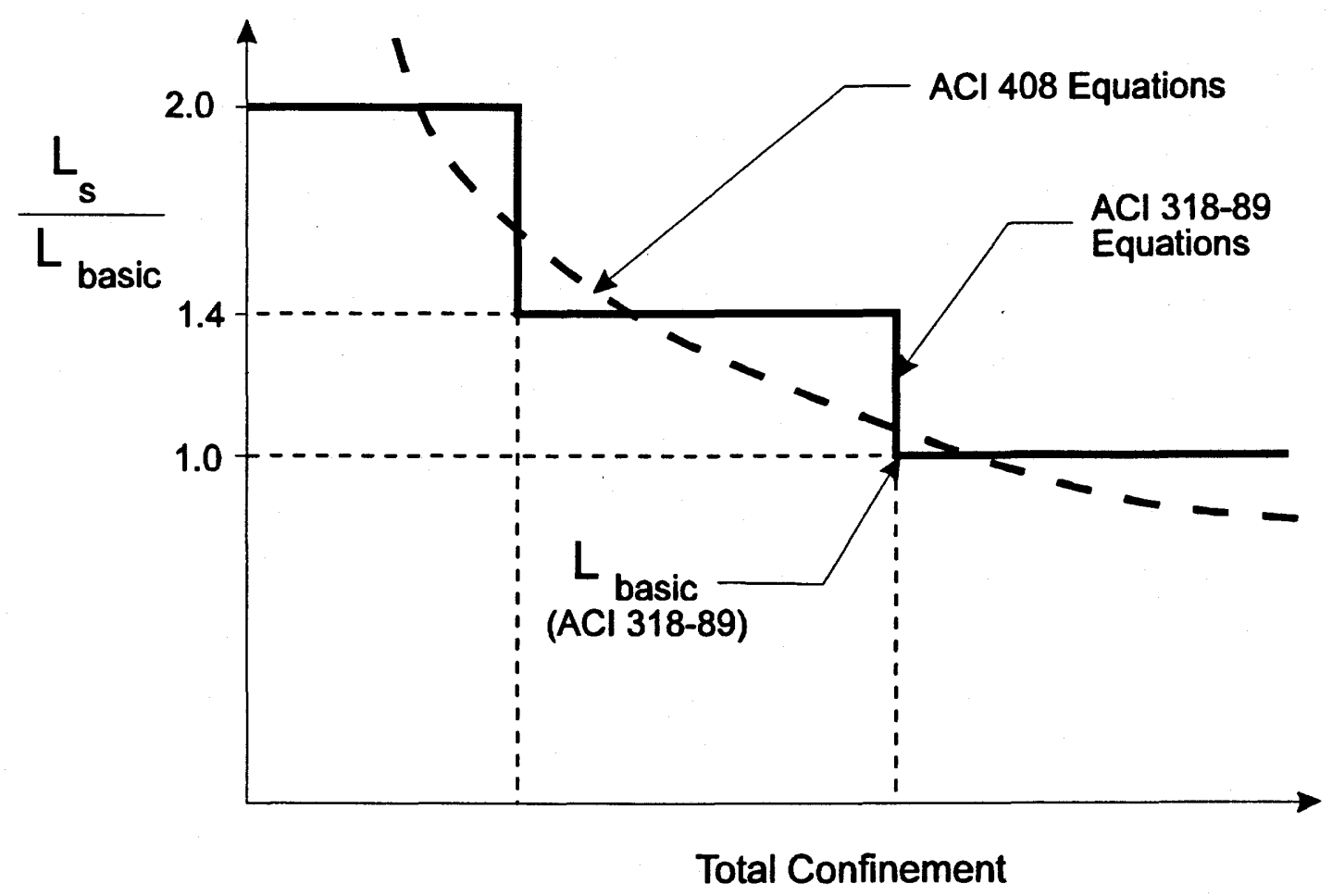

Figure 1.2. Comparison of $\mathrm{ACl}$ 318-89 Design Equations and $\mathrm{ACl} 408$ Recommendations : Lap Splice Length vs. Total Confinement Provided to Splice.

Some present and newly proposed codes have attempted to apply the recommendations set forth by the ACI 408 Committee. However, due to the complexity of the ACI 408 equations, some method of simplification has been considered necessary for the design equations of these codes. The ACI 318-89 code, for example, has attempted to include the influence of confinement into its design equations by adopting a step-wise approach to the ACI 408 equations (see Fig. 1.2). The procedure involves determining a basic splice length which is then increased by a factor depending on the amount of confinement provided to the splice.

The splices in Table 1.1 designed according to ACI 408 recommendations show a significant reduction in lap splice length because of the considerations given to the benefits associated with confinement of the splice. The shorter lengths permitted by 
ACI 408 have been developed using static loading studies. Their performance under high cycle fatigue load is not well documented. Since splices designed for static loading are also assumed to be adequate for fatigue loading, experimental confirmation of this assumption is necessary.

\subsubsection{Research into Seismic Loading:}

Most of the studies in the area of seismic loaded lap splices have concentrated on the difference in the performance with respect to statically designed splices. At Cornell University, a number of studies by Fagundo, Gergely, and White (1979), Tocci, Gergely, and White (1981), and Hungspreug (1981), were completed on lap splices in the area of seismic loading. They concluded from their investigations that the confinement provided by the concrete cover deteriorated rapidly with high intensity loading. Therefore it was determined that heavy stirrup confinement is required to offset this loss of concrete confinement.

\subsection{Scope and Objectives:}

The objectives of this program are as follows:

1) to determine if tensile lap splices designed according to the ACI 408 recommendations for static loading would perform adequately under fatigue loading;

2) to evaluate the effects that different proportions of confinement provided to the tensile lap splices by the concrete cover and steel transverse reinforcement may have on the fatigue resistance of the reinforced concrete beams. 
To address these objectives, nine specimens were tested to failure under repeated uni-directional loading; one specimen was also failed statically. Two configurations of lap splices were utilized within these test specimens. The first used the maximum number of stirrups that were deemed to be effective for static loading by the recommendations of ACI 408, while the second used nominal stirrups and a longer lap length (Table 1.1). The current program did not consider lap splices without stirrup confinement. Only one size of longitudinal reinforcement was used for all specimens. To ensure a relatively consistent concrete strength for all specimens, one ready-mix supplier was employed to provide all the concrete. The maximum and minimum stresses, and the stress ranges were held constant for all tests in an attempt to limit the number of variables involved.

To provide a larger database by which to reach the above objectives, two other series of test data were examined along with the information from this program. The first additional series considered was obtained from the results of a Master of Science program previously completed at the University of Saskatchewan (Zacaruk 1990). The specimens' configuration and mode of testing were similar to those of the current program. Stirrups provided a larger portion of the lateral confinement to the lap splice in Zacaruk's study while in the current study a majority of specimens utilized lighter stirrups along the lap. The second supplementary series was part of a study on the performance of lap splices completed by Tepfers (1973). The information obtained from this investigation was presented here to increase the database to include results of tests on lap splices without confinement from transverse reinforcement.

\subsection{Report Overview:}

This report is divided into five (5) chapters. The first chapter introduces the topic to the reader and provides the objectives and scope of the testing program. In the second 
chapter a literature review dealing with fatigue of concrete, reinforcing steel and reinforced concrete is presented. The third chapter outlines the testing program itself. The discussion of the test results is presented in the fourth chapter and the final chapter summarizes the conclusions resulting from this study. 


\section{FATIGUE LOADING: BACKGROUND}

\subsection{Overview of Fatigue:}

Fatigue is the result of a process that begins with a crack initiating in a weak area of a material. Under repetitive loading, the crack continues to propagate. If enough cycles of stress of sufficient intensity are completed, failure will occur due to complete fracture of the material. This point of failure marks the fatigue strength of the material. The fatigue strength is defined by a level or range of stress and the number of load cycles required to cause failure of the material.

There is a level or range of stress that exists for some materials below which fatigue failure will not occur even after an infinite number of load cycles. This stress is called the endurance limit of a material. Some materials do not exhibit an endurance limit and will undergo a fatigue failure no matter how low the stress is, if enough cycles are applied.

The process of fatigue is divided into three different stages, crack initiation, crack propagation, and final unstable crack extension which results in fracture. The failure of a material from fatigue is a brittle fracture (i.e. small deformations) and occurs suddenly without warning. The applied cyclic stress range that can lead to the fatigue failure of a material may be well below its static yield strength (Ramakrishnan and Lokvik 1991; Mallet 1991).

There are a number of different approaches used in assessing the fatigue performance of 
a material, including S-N (stress level or range vs. number of cycles to failure) relations, statistical (empirical-probabilistic) analysis, damage mechanics and fracture mechanics (linear and non-linear). Two approaches, S-N relations and fracture mechanics, are considered in detail here.

\subsubsection{Analysis of Fatigue - S-N Relations:}

The most common analysis of fatigue uses $\mathrm{S}-\mathrm{N}$ relationships. From these relations, a semi-logarithmic S-N or Wöhler curve can be plotted to present the fatigue data in a graphical representation. From this curve, either the fatigue strength or the endurance limit for a specified number of load applications can be determined for the material. Fig. 2.1 shows a representative Wöhler curve.

Another plot that is used to present fatigue data, and is often utilized for fatigue design, is the modified Goodman diagram. A typical diagram representing the stress ranges permitted for a specified number of load cycles before fatigue failure occurs is illustrated in Fig. 2.2 (Mallet 1991). These diagrams are usually determined from experimental results. The modified Goodman diagram presents the maximum stress, $\sigma_{\max }$, of the applied stress range, $\sigma_{r}$ versus the corresponding minimum stress, $\sigma_{\min }$. All stresses are expressed as proportions of the ultimate static strength of the material, $f_{u}$ (Mallet 1991). Use of the modified Goodman diagram begins by entering the diagram along the abscissa at the minimum stress value, then moving vertically until intersecting with the $45^{\circ}$ line and the maximum stress curve, therewith the maximum stress which can be endured is read from the ordinate. Thus, the allowable stress range or the endurance limit, $\sigma_{r}$ is determined from the vertical distance between the $\sigma_{\max } / f_{u}$ and $\sigma_{\min } / f_{u}$ curves.

Empirical equations (Mallet 1991) have been developed which can be used for 


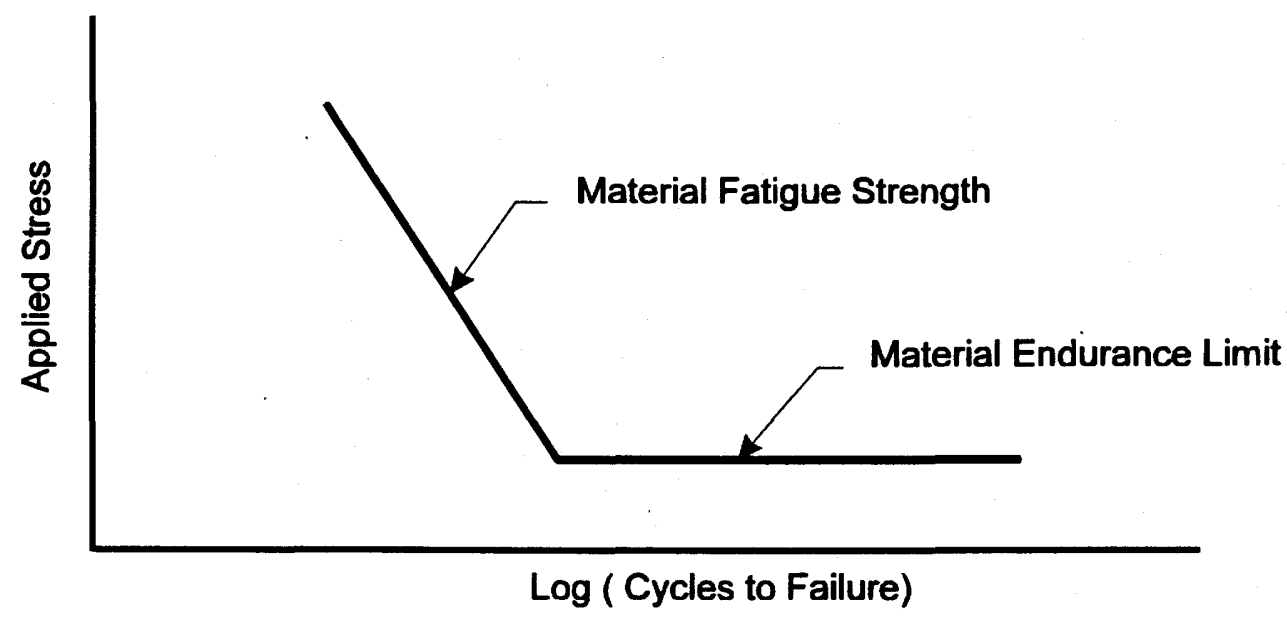

Figure 2.1. Schematic of Typical S-N Curve.

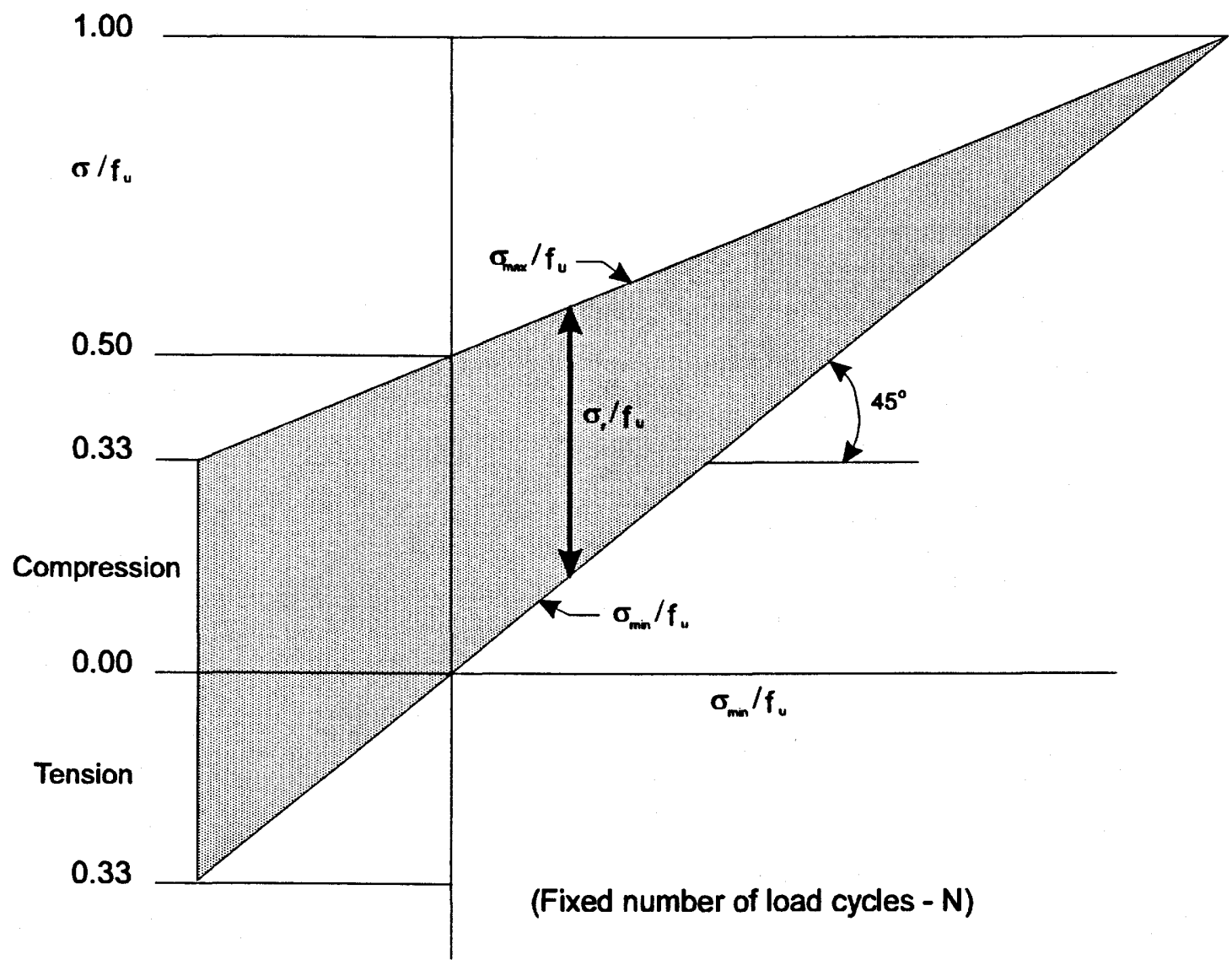

Figure 2.2. Modified Goodman Diagram (Mallet 1991). 
determining the allowable stress range in place of the experimentally formulated Goodman diagram. Two of these empirical equations are as follows:

Gerber's Law

$$
\sigma_{\mathrm{r}}=\sigma_{\mathrm{ro}}\left(1-\left(\frac{\sigma_{\mathrm{rm}}}{\mathrm{f}_{\mathrm{u}}}\right)^{2}\right)
$$

$$
\text { Modified Goodman Law } \quad \sigma_{\mathrm{r}}=\sigma_{\mathrm{r}}\left(1-\frac{\sigma_{\mathrm{rm}}}{\mathrm{f}_{\mathrm{u}}}\right)
$$

where:

$$
\begin{aligned}
& \sigma_{\mathrm{r}}=\text { allowable stress range or endurance limit; } \\
& \sigma_{\mathrm{rm}}=\text { constant mean stress; } \\
& \sigma_{\mathrm{ro}}=\text { value of } \sigma_{\mathrm{r}} \text { for } \sigma_{\mathrm{m}}=0 \\
& \mathrm{f}_{\mathrm{u}}=\text { ultimate static strength }
\end{aligned}
$$

The Swedish Regulations for concrete structures BBK 79 utilizes a modified Goodman diagram to form the basis of fatigue design of plain concrete (Gylltoft 1983). Fig. 2.3 as reproduced from Gylltoft (1983) is an example of the diagram used by BBK 79. The minimum and maximum stress levels are represented in the diagram by $\sigma_{1}$ and $\sigma_{2}$, respectively. The Swedish code indicates that no risk of fatigue failure at $\mathrm{N}$ load cycles, between the stress limits $\sigma_{1}$ and $\sigma_{2}$, exists if $\sigma_{1}$ and $\sigma_{2}$ form a point in Fig. 2.3 which is located within the curves representing a particular N (Tepfers 1982).

\subsubsection{Analysis of Fatigue - Fracture Mechanics:}

Failures in structures due to fatigue are associated with the initiation and propagation of cracks. Cracking occurs when the applied stresses within a material exceed the tensile strength. Fracture mechanics is the study of the conditions around and in front of a crack 


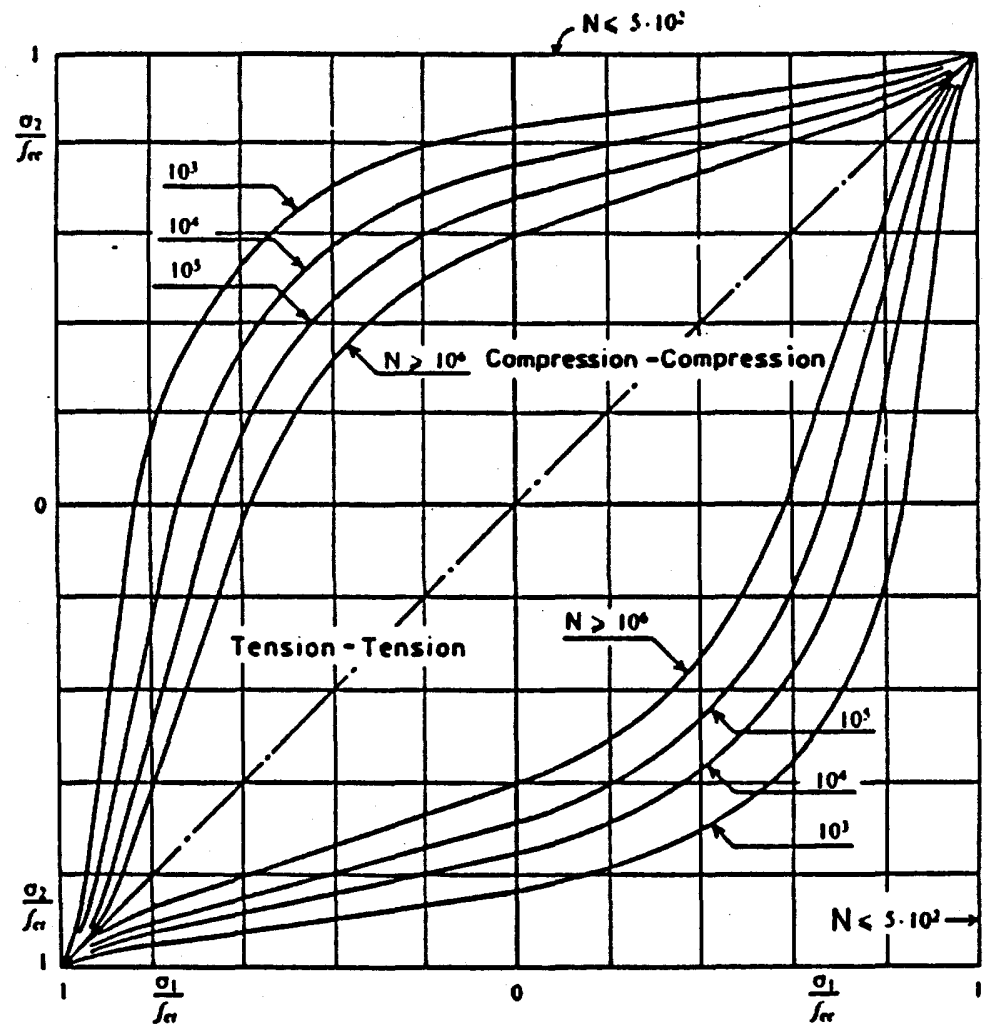

Figure 2.3. Goodman Diagram for Determination of Fatigue Strength of Plain Concrete According to Swedish Regulations BBK 79 (Gylltoft 1983).

tip (Elfgren 1989). Therefore, it would seem natural that fracture mechanics would be an appropriate approach for assessment of fatigue failure. There are two methods of study in fracture mechanics, linear elastic and non-linear analysis.

\subsubsection{Linear Elastic Fracture Mechanics:}

Linear Elastic Fracture Mechanics (LEFM) assumes that the material being considered is fully elastic and that no fracture zone exists in front of the crack tip. LEFM relates the magnitude and distribution of the stresses near the crack tip to the nominal stress applied, to material properties, and to the size, shape and orientation of the crack (Rolfe and Barsom 1977). When the material can not resist the applied stresses, crack growth takes place. 
In 1920, Griffith, as described by Kaplan (1961), developed an energy-balance theory of crack propagation based on the very brittle properties of glass. His theory suggested that a brittle material contains many randomly distributed flaws or cracks of various sizes that were formed during fabrication or from application of load. These numerous small cracks cause high stress concentrations within the material, with the largest flaw being the most significant and the one which invariably greatly affects the material's fracture strength. Griffith proposed an energy theory for an ideally brittle material. He suggested that as load is applied a material possesses an amount of potential energy, U. For a crack to propagate a certain amount of energy, $\mathrm{W}$, will be consumed at the crack tip. When the rate of increase in the potential energy per infinitesimal extension of a cracked area is equivalent to the rate of decrease in the strain energy, then crack propagation will occur causing rapid crack extension and ultimately failure due to fracture (Kaplan 1961). This condition may be stated as:

or

$$
\begin{aligned}
\frac{d W}{d A}=\frac{d U}{d A} \quad \text { where: } & U=\text { potential energy; } \\
W & =\text { surface energy required for crack extension; } \\
& A=\text { infinitesimal extension of a cracked area; }
\end{aligned}
$$

Griffith's proposed condition has been shown to be equivalent to:

$$
\begin{array}{ll}
G=R \quad \text { where: } \quad & G=\text { energy-release rate }=d W / d A \\
& R=\text { fracture resistance }=d U / d A .
\end{array}
$$

$$
\begin{aligned}
& \mathrm{G}=\frac{\pi \sigma^{2} \mathrm{a}}{\mathrm{E}} \quad \text { where: } \mathrm{E}=\text { Modulus of Elasticity; } \\
& \mathrm{a}=\text { crack length; } \\
& \sigma=\text { uniform tensile stress normal to plane of } \\
& \text { crack. }
\end{aligned}
$$


Instability of a crack occurs when $G=R$. The crack length at this point is called the critical crack length and the value of the strain energy-release rate during this unstable crack growth is called the critical strain-energy release rate, $G_{c}$ (Kaplan 1961).

Kaplan (1961) indicates that Griffith's formula was modified in 1948 by Irwin and Orowan to account for fracture in ductile materials or materials that were not ideally brittle in nature. In these materials, it was found that a certain amount of plastic deformation takes place at the tip of the crack. The energy required to produce this zone of plasticity was not considered in Griffith's ideal model. It was therefore determined that the total resistance $(R)$ of these non-ideal materials to cracking should be described by the sum of both the elastic-strain-energy and the plastic-strain-energy occurring at the crack tip (Rolfe and Barsom 1977).

This is the basis of the energy-balance approach. However, limitations of this approach do exist. For example, the strain energy-release rate has been found to be influenced by various factors including load application magnitude and rate (Kaplan 1961). Also, this energy criterion for fracture was developed to define conditions for instability of an ideally sharp crack. Such conditions are not always applicable.

As an alternative to the energy-balance approach, Rolfe and Barsom (1977) describes how Irwin proposed a criterion for fracture based on the stress intensity in the vicinity of the crack tip. Three modes of relative displacements of the two crack surfaces defined by Irwin were: Mode I-opening mode; Mode II-sliding mode; Mode III-tearing mode (see Fig. 2.4, reproduced from Broek (1982)). Irwin showed that the distribution of the stress in the vicinity of the crack tip when subjected to the three modes of deformation 


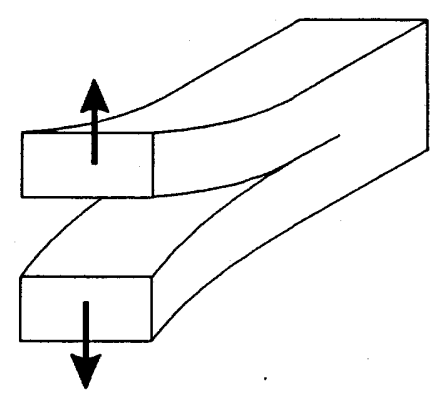

I

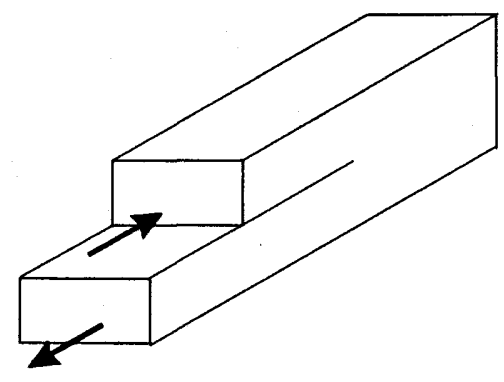

II

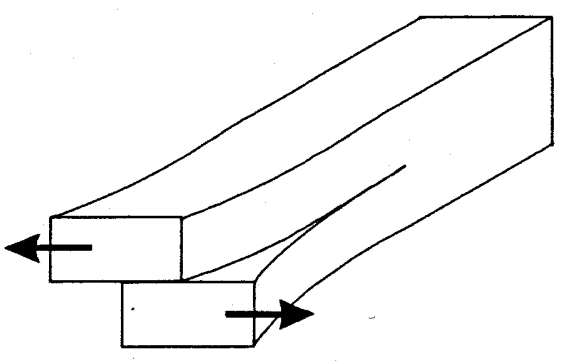

III

Figure 2.4. Basic Modes of Crack Extension (Broek 1982):

I opening mode

II sliding mode

III tearing mode.

may be expressed as:

$$
\begin{aligned}
& \sigma=\frac{\mathrm{K}}{\sqrt{2 \pi \mathrm{r}}} \mathrm{f}(\theta) \quad \text { where: } \quad \sigma=\text { stress in vicinity of crack tip; } \\
& \mathbf{K}=\text { stress intensity factor; } \\
& r, \theta=\text { polar coordinates of stress element } \\
& \text { from origin at crack tip; } \\
& f(\theta)=\text { function with corresponding } \\
& \text { expression for each component of } \\
& \text { stress and each mode of failure (I, } \\
& \text { II, III). }
\end{aligned}
$$

Crack growth will not take place if the material can carry the stresses. However, by assuming the above stress distribution the stresses at the crack tip are allowed to become infinite (see Fig. 2.5, Broek (1982)). This in reality can not occur because in any real material some localized yielding must be present. Therefore, the criterion for crack growth can not be based on a value of stress or strength but rather a more appropriate value, such as a measure of the material's toughness (Hillerborg 1983).

In Equation [2.6], $\mathrm{K}$ quantifies the elastic stresses near the crack tip and is called the 


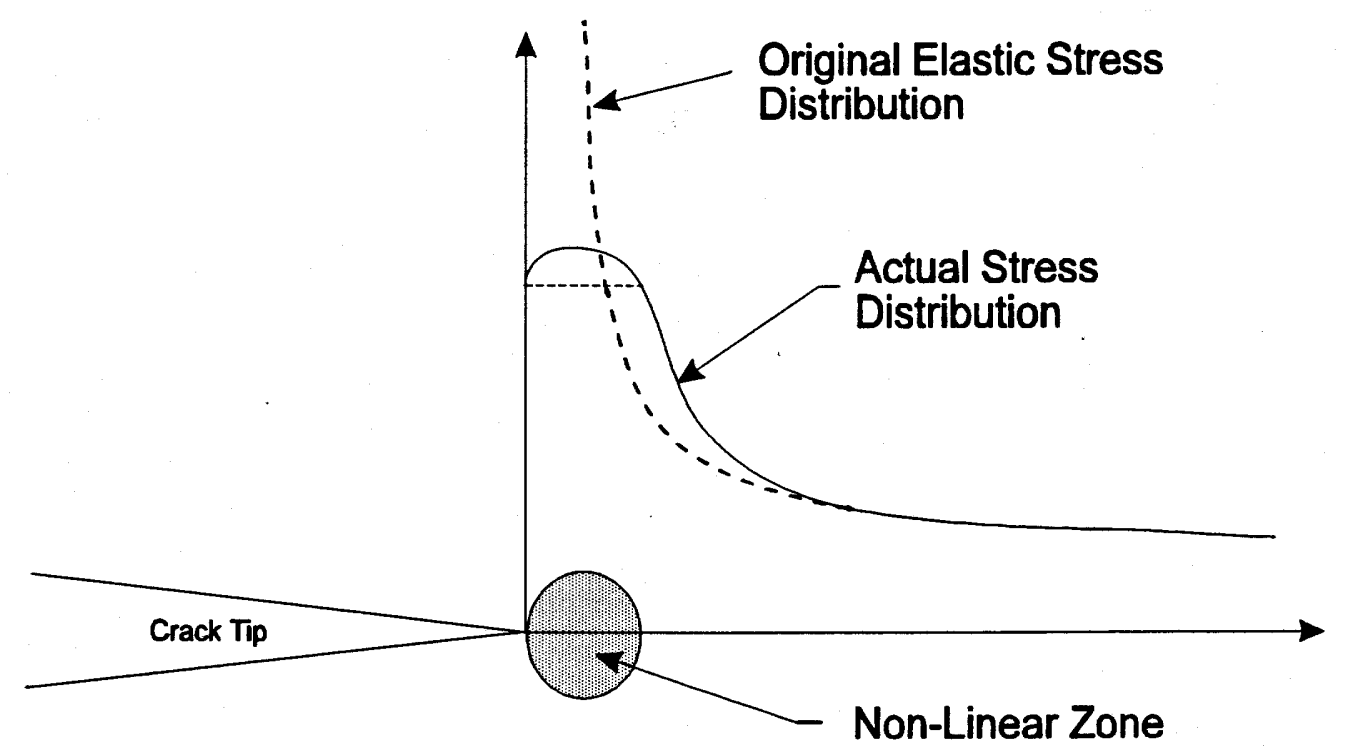

Figure 2.5. Stress Distribution in Front of a Crack Tip (Broek 1982).

stress intensity factor. This stress intensity factor is a measure of the material's toughness and is dependent on the mode of failure. The value of $\mathrm{K}$ is usually expressed as (Hillerborg 1983):

$$
\begin{aligned}
& \mathrm{K}=\mathrm{Y} \sigma_{\mathrm{o}} \sqrt{\pi \mathrm{a}} \quad \text { where: } \mathrm{Y}=\text { parameter which varies depending on } \\
& \text { specimen geometry, crack } \\
& \text { configuration and load type (Numerous } \\
& \text { publications have presented different } \\
& \text { values for this parameter); } \\
& \mathrm{a}=\text { crack length; } \\
& \sigma_{o}=\text { stress which should act if crack were } \\
& \text { not present. }
\end{aligned}
$$

When the value of $\sigma_{0}$ reaches a critical value, then crack propagation initiation occurs. The value of $\mathrm{K}$ at this point is designated as $\mathrm{K}_{\mathrm{c}}$, and is called the "fracture toughness" of a material. The values of $K_{c}$ and $G_{c}$ are regarded as crack resisting parameters and have been proven to be properties of the material they describe (Elfgren 1989). 
For fracture Mode $\mathrm{I}$, it has been shown that $\mathrm{K}$ and $\mathrm{G}$ are equivalent methods of presenting the condition of stress at a crack tip as a quantity (Gylltoft 1983). Their equivalence is represented by the following (Gylltoft 1983; Mallet 1991):

$$
\begin{aligned}
& G=\frac{K^{2}}{E} \quad \text { plane stress (thin sections); } \\
& \mathrm{G}=\frac{\mathrm{K}^{2}}{\mathrm{E}}\left(1-\mu^{2}\right) \quad \text { plane strain (thick sections); } \\
& \text { where: } \quad \mathrm{E}=\text { Young's modulus; } \\
& \mu=\text { Poisson's ratio. }
\end{aligned}
$$

Since $\mathrm{K}_{\mathrm{c}}$ is considered a material property, it would seem reasonable that its value would remain constant as the crack length, a, increases. Though this may be true for a very brittle material, recent research has shown that this may not be true for less brittle materials. It has been observed that $\mathrm{K}_{\mathrm{c}}$ may actually increase with an increasing crack extension. This observation may be the result of an increasing zone of plasticity in front of the crack tip.

When applying LEFM to fatigue problems, the stress intensity factor, $\mathrm{K}$, is often used to describe crack propagation. A common empirical crack propagation law is the Paris equation:

$$
\begin{aligned}
\frac{\mathrm{da}}{\mathrm{dN}}=\mathrm{C}(\Delta \mathrm{K})^{\mathrm{n}} \quad \text { where: } \quad & \mathrm{N}=\text { number of cycles; } \\
\mathrm{C}= & \text { material constant; } \\
\mathrm{n}= & \text { exponent constant; } \\
\mathrm{a} & =\text { crack length; } \\
\Delta \mathrm{K}= & \mathrm{K}_{\max }-\mathrm{K}_{\min }, \text { stress factor intensity } \\
& \text { range. }
\end{aligned}
$$


The values of $\mathrm{C}$ and $\mathrm{n}$ are found experimentally from monitored constant amplitude crack growth tests (Mallet 1991). When a crack growth rate resulting from constant stress amplitude loading is plotted versus $\Delta \mathrm{K}$ on a logarithmic plot, a linear curve will result.

The Paris equation has been shown to give inaccurate crack growth rates near $\mathrm{K}_{\mathrm{c}}$; therefore, Forman, Kearney and Engle, in 1967, proposed an improved formula (Gylltoft 1983):

$$
\frac{\mathrm{da}}{\mathrm{dN}}=\frac{\mathrm{C}(\Delta \mathrm{K})^{\mathrm{n}}}{\left((1-\mathrm{R}) \mathrm{K}_{\mathrm{c}}-\Delta \mathrm{K}\right)} \quad \text { where: } \quad \mathrm{R}=\mathrm{K}_{\min } / \mathrm{K}_{\max }
$$

It has been observed that there exists a critical stress intensity factor below which cracks do not grow under cyclic loading. This value is called the threshold stress intensity factor range, $\Delta \mathrm{K}_{\text {th }}$ (Gylltoft 1983). Fig. 2.6, reproduced from Gylltoft (1983), shows a schematic plot of the complete relationship between fatigue crack growth rate and the stress intensity factor range. Gylltoft notes an analogy between the shape of this plot and a traditional S-N curve. He suggests that the threshold stress intensity may qualitatively correspond to the endurance limit commonly found on an S-N curve.

Since LEFM is only an ideal description of the behaviour of a real material (Hillerborg 1983), it can never correctly describe the true cracking process. For in any real material there exists finite stresses and a fracture zone of finite size storing plastic stresses in front of a crack. Although LEFM does not truly describe a real material, it can be used to approximate one and will give results for $\mathrm{K}$ or $\mathrm{G}$ within the correct order of magnitude, even though the stress level is unrealistic. For LEFM to be applicable in determining an appropriate value for the fracture criterion $\left(\mathrm{K}_{\mathrm{c}}\right.$ or $\left.\mathrm{G}_{\mathrm{c}}\right)$ of a particular material, the nonlinear effects should be sufficiently small compared to the size of the crack. This will 


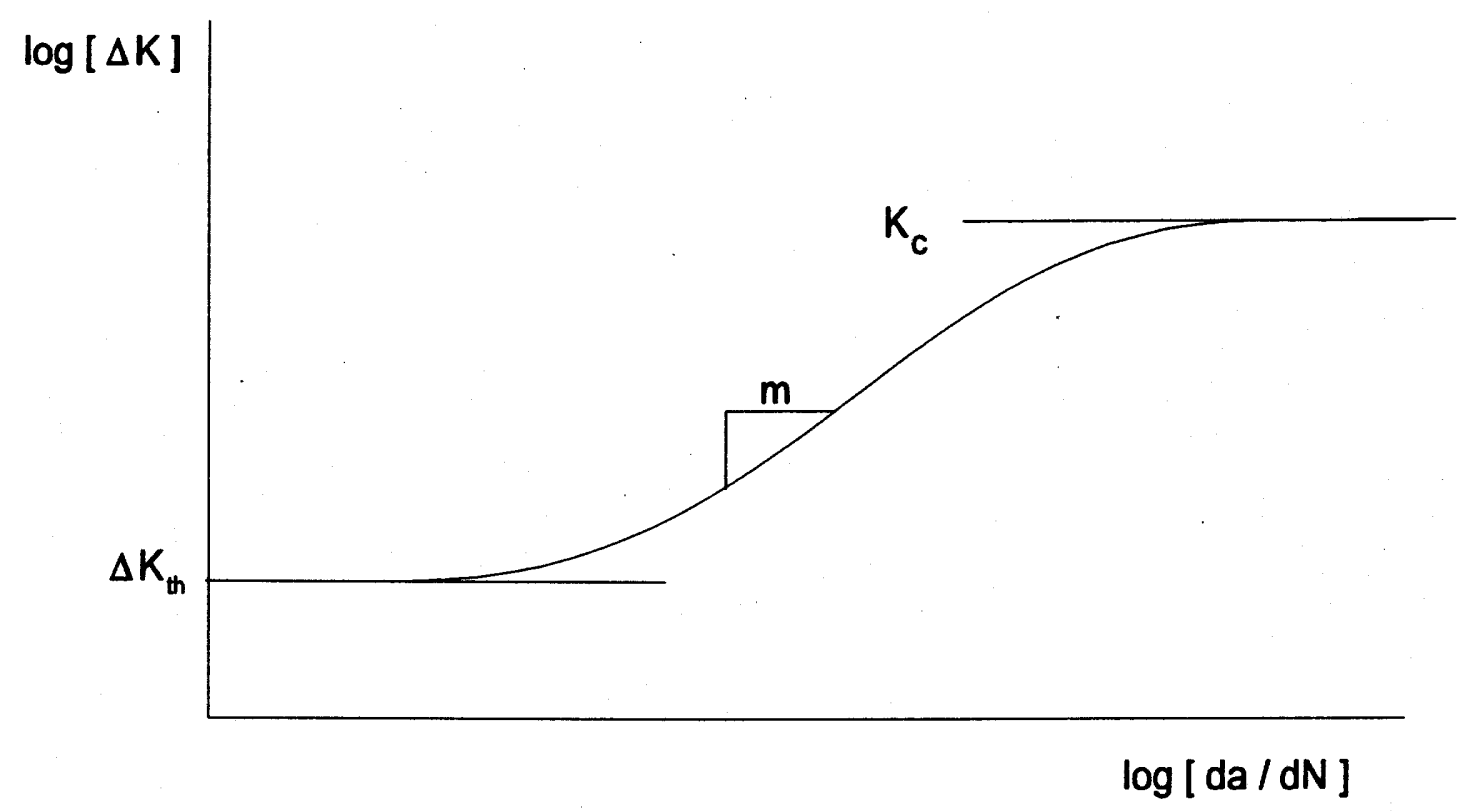

Figure 2.6. Schematic Diagram for Fatigue Crack Growth Rate Log (da/dN) vs. the Stress Intensity Factor Range Log ( $\Delta K$ ) (Gylltoft 1983).

reduce the non-linear effects that occur at the crack tip in a real material.

\subsubsection{Non-Linear Fracture Mechanics:}

Numerous non-linear material models have been proposed to describe the fracture criterion for situations where the conditions of stress at the crack tip fall between fully elastic and fully plastic (Rolfe and Barsom 1977). Gylltoft (1983) describes models proposed by Dugdale, in 1960, and Barenblatt, in 1962, in which the stresses at the crack tip were kept within finite limits, below the tensile strength of the material. In both models an assumption of a narrow non-linear zone was made.

Gylltoft (1983), in summarizing work completed by Rice in 1968, observed that in metals a wide plastic zone exists at the crack tip and so he proposed the J-integral approach, 
which is a path independent contour integral. The J-integral path is taken outside the fracture zone from one crack face stress free point to another on the other crack face. The J-integral has been shown to be equivalent to the energy-release rate, G, in LEFM and similar to $G_{c}$, when the J-integral reaches a critical value, $J_{c}$. However, the J-integral is valid only for linear and non-linear elastic materials. Therefore, the loading and unloading of the material within the integration path must follow the same stress-strain curve. Similar to LEFM, the J-Integral is only an approximate model since no material is purely elastic. Because of these limitations, the usefulness of this method for certain materials, such as concrete, and for conditions of cyclic loading is questionable.

Broek (1982) describes a crack opening displacement (COD) model that was introduced in 1961 by Wells. When a crack tip reaches a maximum value of strain, then crack extension will take place. The COD approach measures the crack opening displacement that occurs when this extension takes place. This measurement can then be related to the value of strain at the crack tip. The COD method requires measurement of a fracture toughness parameter, $\delta_{c}$, similar to $K_{c}$ or $G_{c}$ for LEFM, to set a value to the fracture criterion.

As was previously mentioned, the fracture toughness, $K_{c}$, does not remain constant throughout crack propagation for plastic materials. Rather, $\mathrm{K}_{\mathrm{c}}$ will increase in value as the crack propagates. R-curve or resistance curve analysis is a method established to determine the value of $\mathrm{K}_{\mathrm{c}}$ as crack propagation occurs. The $\mathrm{R}$-curve is then just a curve representing the change in $\mathrm{K}_{\mathrm{c}}$ as the crack length varies. The $R$-curve is not a pure material property and thus can not be used for design purposes (Broek 1982). 


\subsubsection{Variable Amplitude Loading:}

The fatigue process is affected by several different factors. Some of these variables are the amplitude, specimen geometry and environmental conditions.

For most experimental testing a constant stress range is used. However, in reality, the stresses will vary in a random manner over the life of the structure. In 1945, Miner, as explained by Mallet (1991), developed a hypothesis for estimating the cumulative damage that occurs to a material due to variable fatigue loading. Miner developed this concept based on fatigue test results on high strength aluminum alloy. However, it has also been shown to be relevant to other material types. The concept of Miner's rule is that for a single stress cycle, ranging from $S_{\max i}$ to $S_{\min i}$, there is a magnitude of fatigue damage, $1 / N_{i}$, where $N_{i}$ is the number of cycles which results in failure under a constant amplitude of stress $S_{i}$. Therefore, for a number of stress cycles, $c$, the total fatigue damage, $M$, is the resultant of the sum of the fatigue damage caused from each of the individual cycles. This may be represented as follows:

$$
M=\sum_{i=1}^{c} \frac{1}{N_{i}} \quad \text { where: } \quad c=\text { number of cycles at stress range } S_{i}
$$

According to Miner's rule, at the state of failure the total damage, $M$, is assumed to equal unity and may be presented in the following form:

$$
\begin{aligned}
& \sum_{i=1}^{k} \frac{n_{i}}{N_{i}}=1 \\
& \text { where: } \quad n_{i}=\text { number of constant amplitude } \\
& \text { cycles for stress range } S_{i} \text {; } \\
& \mathrm{k}=\text { number of constant amplitude stress } \\
& \text { ranges. }
\end{aligned}
$$




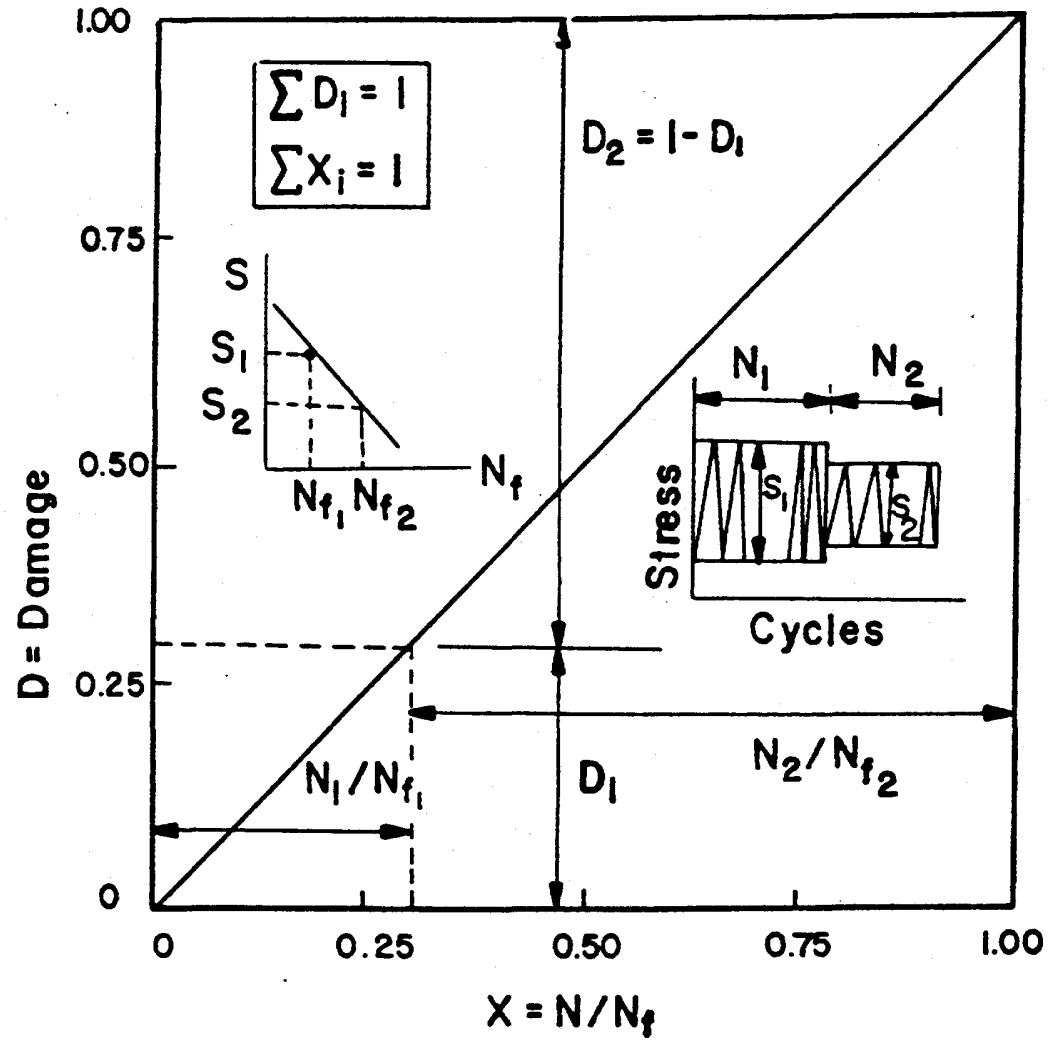

Figure 2.7. Linear Miner's Law (Shah 1984).

This damage rule proves to be linear when plotted and is reproduced from Shah (1984) in Fig. 2.7.

\subsection{Fatigue of Concrete:}

Fatigue of concrete can be divided into separate types of failures. The different forms of fatigue failure in concrete structures are, bending (flexural), shear, compression, tension and bond failures. Flexural failure might be considered as a combination of failures due to tension and compression, while bond and shear fatigue are similar to tension failures.

\subsubsection{Factors Influencing Fatigue Strength of Concrete:}

The fatigue of concrete results from the progressive microcracking that occurs within the 
concrete matrix under loading. It has been found in past research that internal microcracking under a fatigue loading will increase significantly more than under a static load (Gylltoft 1983). The process of failure due to microcracking is one of crack initiation followed by propagation of the microcrack leading to macrocracking due to the accumulation of many microcracks, followed by a complete failure due to fracture. This cracking process is largely influenced by the non-homogeneous nature of concrete (Mallet 1991), since it is the breakdown of bond between the cement and aggregates that causes the initiation of fatigue cracking. Then as the crack propagates through the cement matrix, it is arrested by the coarse aggregate until bond breakdown occurs again and the process continues (Mallet 1991).

Research in the field of concrete fatigue has not been as extensive as the work completed for fatigue of metals. However, limited research has shown that the fatigue strength of concrete is dependent on a number of factors, some of which are:

1) ultimate static strength;

2) load history;

3) rate of loading;

4) material properties;

5) environmental conditions.

In 1958, Norby reviewed the research that had been performed with respect to concrete behaviour under repeated loading and the theories emerging from the research. Some of the results of the investigations completed were as follows:

1) an endurance limit was not found for concrete subjected to under $10,000,000$ load cycles; however, to establish a rough value for the endurance limit of concrete, it was determined that at 10 million cycles, the fatigue strength is around $50-55 \%$ of the ultimate static strength; 
2) rest periods increased the concrete's resistance to fatigue;

3) a decrease in the range of stress caused an increase in the fatigue strength.

The fact that concrete does not exhibit an endurance limit has been confirmed by a number of investigators and is an important realization. Unlike steel which reaches a limit of stress below which an infinite fatigue life exists, concrete may fail in fatigue at a very low stress range, well below any current limits set forth within governing standards.

Material properties such as cement content, water-cement ratio, age at loading, air content, curing conditions, and type of aggregates are variables affecting the fatigue strength of concrete in a similar manner to which they affect its ultimate static strength. (ACI 215 1974; Ramakrishnan and Lokvik 1991). Ramakrishnan and Lokvik (1991) noted that past research indicates that air content decreases fatigue life and a decrease in water-cement ratio causes a significant increase in the fatigue strength.

\subsubsection{Influence of Loading Rate:}

The rate of loading of a concrete fatigue specimen has been shown to be a variable in the determination of its fatigue strength. During fatigue experiments, it is often required to accelerate the test because completion of the test at realistic loading rates would take too long (Sparks and Menzies 1973). The question often arises as to whether this accelerated rate of loading provides realistic results when compared to the true fatigue life of concrete in service under a lower rate of loading. Hsu (1981) indicates that for the two regions of study, high cycle (cycles $>10^{3}$ ) and low cycle (cycles $<10^{3}$ ) testing, investigators have conflicting conclusions in regard to the effects of the rate of loading. The high cycle region is generally associated with moderate stress levels, while low cycle tests commonly suggest high levels of stress. 
Awad and Hilsdorf (1963) concluded from their investigation on 300 concrete prisms that a decrease in the rate of loading by one order of magnitude would result in a reduction in the number of cycles to failure by almost an order of magnitude. Their experiment was based on a high compressive cyclic loading with the maximum stress ranging from 80 to $95 \%$ of the static compressive strength and the stress range varying between 0 to $95 \%$ of the compressive strength. Sparks and Menzies (1973) also completed high compression fatigue testing of concrete prisms and concluded that the number of cycles to failure increases tenfold with increases in rate of loading between 0.6 $\mathrm{Hz}$ and $6 \mathrm{~Hz}$.

Conversely, Kesler in 1958 and Raithby and Whiffen in 1968, as described by Mallet (1991), determined that for a rate of loading between $0.5 \mathrm{~Hz}$ and $7.5 \mathrm{~Hz}$ there is no significant differences in regard to the fatigue life. Mallet (1991) also notes that Galloway and Raithby, in 1973, concluded from flexural fatigue testing of small beams, that any differences found in fatigue life were not due to the rate of loading. The above conclusions were subject to a condition of the maximum stress held to a moderate stress level of less than $75 \%$ of the static strength.

Therefore, from the testing completed to date, it has been concluded that the frequency of loading has a minor effect on the fatigue strength for the high cycle (moderate stress level) case. While for low cycle (high stress level) cases, the rate of loading is a significant variable in determining the fatigue strength of concrete (ACI 215 1974). Therefore, as Hsu (1981) suggests, different approaches may need to be taken in deriving theories and equations for each region of study.

Rest periods during cyclic testing have been shown to extend the fatigue life of plain concrete. Hilsdorf and Kesler (1966) concluded from tests on specimens subjected to 
rest periods while sustaining a constant loading that intermittent rest periods will increase the fatigue strength of plain concrete when subsequently subjected to repeated flexural loads.

However, rest periods beyond 5 minutes did not seem to further increase the fatigue strength of the concrete. ACI 215 (1974) noted that although the effects of rest periods and sustained loads on fatigue have not been sufficiently explored, if the sustained stress during the rest period is held below $75 \%$ of the static strength there is a tendency for the fatigue strength to increase. However, if the sustained load is held above this value, then detrimental effects on the fatigue life may occur due to an increase in microcracking.

\subsubsection{Influence of Stress Gradient:}

Within flexural members the compressive and tensile regions of the concrete are exposed to a stress gradient. In 1966, Ople and Hulsbos conducted tests in an attempt to describe the effect that stress gradients have on the fatigue life of concrete in compression. From their results it was found that stress gradients cause an increase in the fatigue life of the concrete specimen. ACI 215 (1974) noted that such conclusions were consistent with results completed for static tests which indicated that the stress gradient impaired the growth of internal microcracks. Therefore, using the lower bound results of tests performed on uniformly stressed concrete to estimate the fatigue life of flexural members, may be a safe assumption (ACI 215 1974; Ople and Hulsbos 1968).

\subsubsection{Influence of Varying Stress Range:}

Miner's rule when applied to concrete has been shown to be non-conservative due to the nonlinear nature of concrete. Therefore, Shah (1984) presented a nonlinear cumulative 
damage law. Shah explains that the process of damage in concrete has three stages of growth when subjected to fatigue loading. These stages, as shown in Fig. 2.8, are 1) rate of increase of damage decreases, 2) rate of damage is constant, 3) rate of damage increases. The following equation was developed by Shah to describe the above stages of damage growth:

$$
\begin{array}{ll}
\sum D_{i}=a \sum x_{i}^{3}+b \sum x_{i}^{2}+c \sum x_{i}=1 \quad \text { where: } & x_{i}=n_{i} / N_{i} \\
& a, b, c=\text { constants; } \\
& D_{i}=\text { damage parameter. }
\end{array}
$$

The constants $\mathrm{a}, \mathrm{b}$, and $\mathrm{c}$, are determined from the following conditions:
1) $\mathrm{D}=1, \mathrm{x}=1$
2) $x=\xi, d D / d x=\tan \theta$
3) $x=\xi, d^{2} D / d x^{2}=0$.

The values of $\theta$ and $\xi$, are determined from the curve, reproduced from Shah (1984) in Fig. 2.8, at the inflection point, and are considered material properties.

The validity of Equation [2.14] was confirmed by data from numerous fatigue tests on reinforced concrete beams. In Fig. 2.9, reproduced from Shah (1984), the test data is compared with Shah's non-linear damage law and Miner's law. It is apparent from this plot that the non-linear cumulative law removes the non-conservatism associated with Miner's law when applied to concrete. 


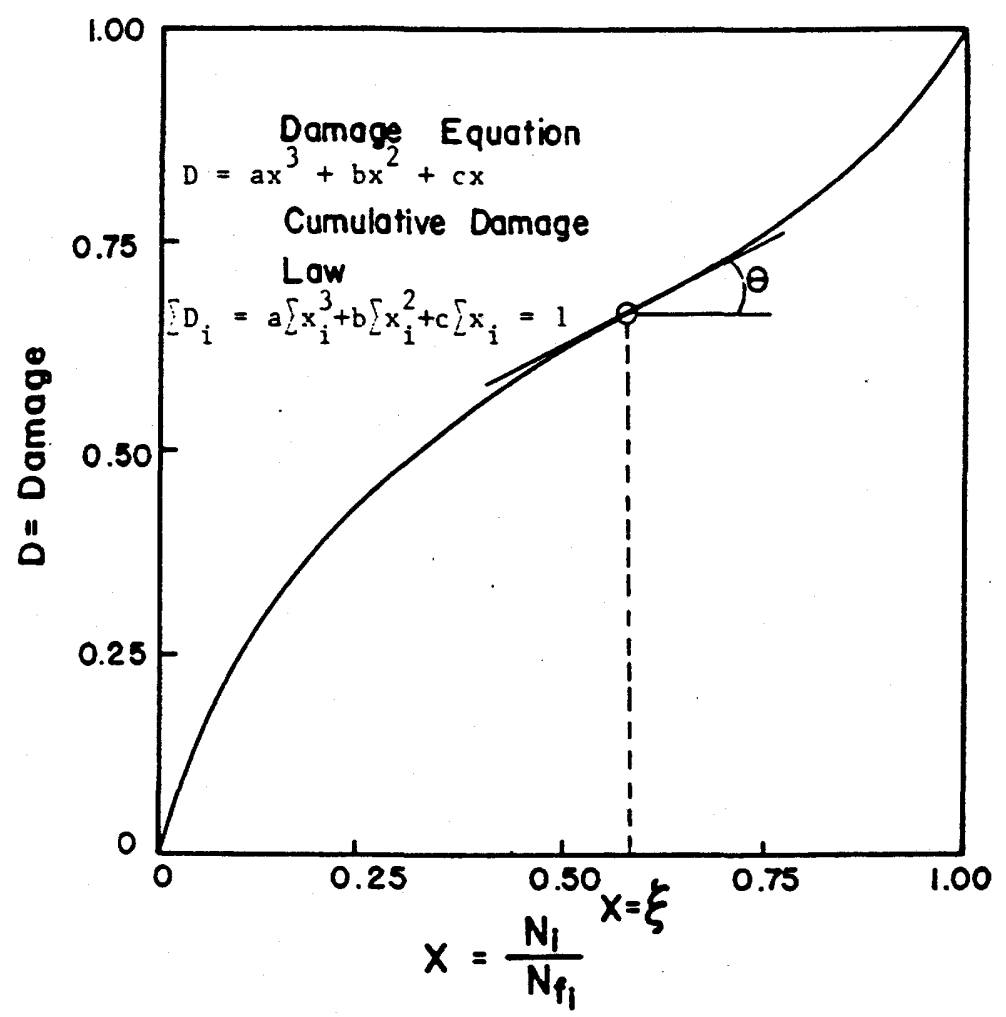

Figure 2.8. Non-Linear Miner's Law (Shah 1984).

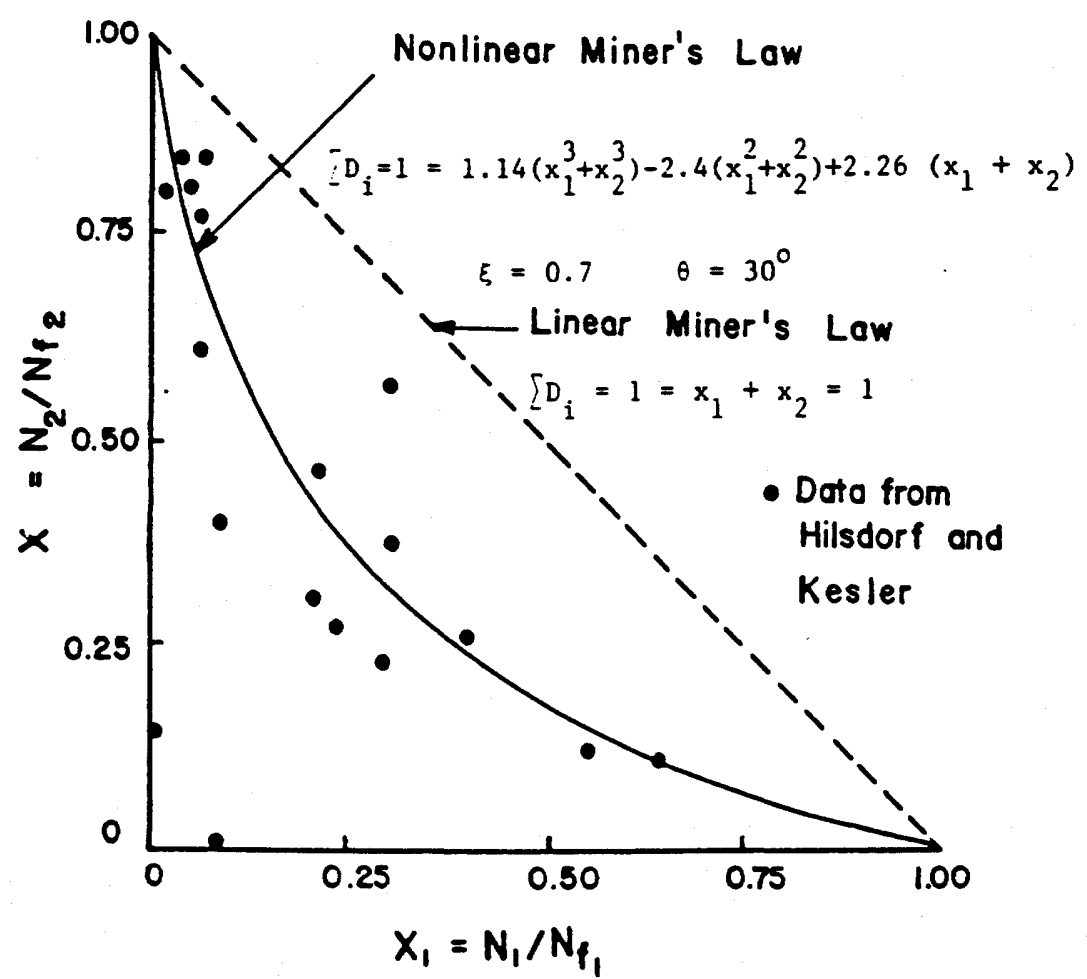

Figure 2.9. Non-Linear Damage Law (Shah 1984). 


\subsection{Analysis of Concrete Fatigue Strength:}

Different approaches used in determining the fatigue performance of reinforced concrete are S-N relations, statistical evaluations, damage mechanics, and fracture mechanics.

\subsubsection{S-N Relationships for Concrete:}

\subsubsection{Stress and Stress Range Dependence:}

It has been shown in past investigations that the fatigue life of concrete is affected by such applied-fatigue stress parameters as $\sigma_{\min } / \sigma_{\max }, \sigma_{\text {mean }} / \sigma_{\max }, \sigma_{\text {mean }} / \mathrm{f}^{\prime}$, and $\left(\sigma_{\max }\right.$ $\left.\sigma_{\min }\right) / f^{\prime}{ }_{c}$, etc. (Park 1990). Therefore, the fatigue strength of concrete has traditionally been analyzed using an S-N relationship. The most common of the S-N curves (or Wöhler curves) to be used in presenting the fatigue strength of concrete utilizes the proportional stress relationship of $\sigma_{\max } / f_{c}^{\prime}$. Hsu (1981) states that, when the appliedfatigue stress $(\sigma)$ is non-dimensionalized by the static strength $\left(f^{\prime}{ }_{c}\right)$ of an identical specimen, this non-dimensionalized S-N curve becomes independent of conditions such as specimen shape, concrete age and moisture content at the time of loading. It is believed that this curve provides an actual representation of the susceptibility of concrete to fatigue.

In 1967, Bennett and Muir investigated the influence of static strength on the fatigue strength of concrete under an axial compressive loading. They presented the results of their testing on a semi-logarithmic S-N curve, along with a regression line which indicates that the fatigue strength of concrete decreases linearly with an increase in the number of cycles to failure: 


$$
\frac{\sigma_{\max }}{f_{c}^{\prime}}=0.93-0.043 \log (\mathrm{N})
$$

Aas-Jakobsen (1970) notes that how on the basis of investigations completed by Graf and Brenner in 1934 and 1936, it was observed that for a fixed maximum stress, $\sigma_{\max }$, the life of concrete under compressive fatigue loading was dependent on the minimum stress, $\sigma_{\min }$, applied. Aas-Jakobsen (1970) further studied the effects that $\sigma_{\min }$ has on the fatigue strength of concrete in compression. He concluded that a linear dependence of the fatigue life on $\sigma_{\min }$ exists and can be related by:

$$
\begin{array}{ll}
\frac{\sigma_{\max }}{f_{c}^{\prime}}=1-\beta(1-R) \log (N) \quad \text { where: } \quad & \beta=\text { regression constant } \\
& R=\sigma_{\min } / \sigma_{\max }
\end{array}
$$

Fig. 2.10, reproduced from Tepfers and Kutti (1979), shows S-N curves based on Equation [2.16], with each line determined for a constant value of $R$. This plot shows that for a given number of cycles, an increase in $\sigma_{\min }$ results in an increase in $\sigma_{\max }$ (Mallet 1991). In 1979, Tepfers and Kutti, based on their own test data, acknowledged this equation and determined a value for $\beta$ to be 0.0685 for fatigue strength of concrete in compression. In 1973, Tepfers stated that Equation [2.16] was applicable to concrete in tension if $f^{\prime}{ }_{c}$ was replaced with the ultimate tensile strength of the concrete, $f_{u}$.

\subsubsection{Time Dependence:}

Hsu (1981) extended Equation [2.16] to include the effects of time. He suggested the addition of the variable $T$, the period of repetitive loads, to simultaneously account for the effect of time and the effect of rate of loading. The following equations were 


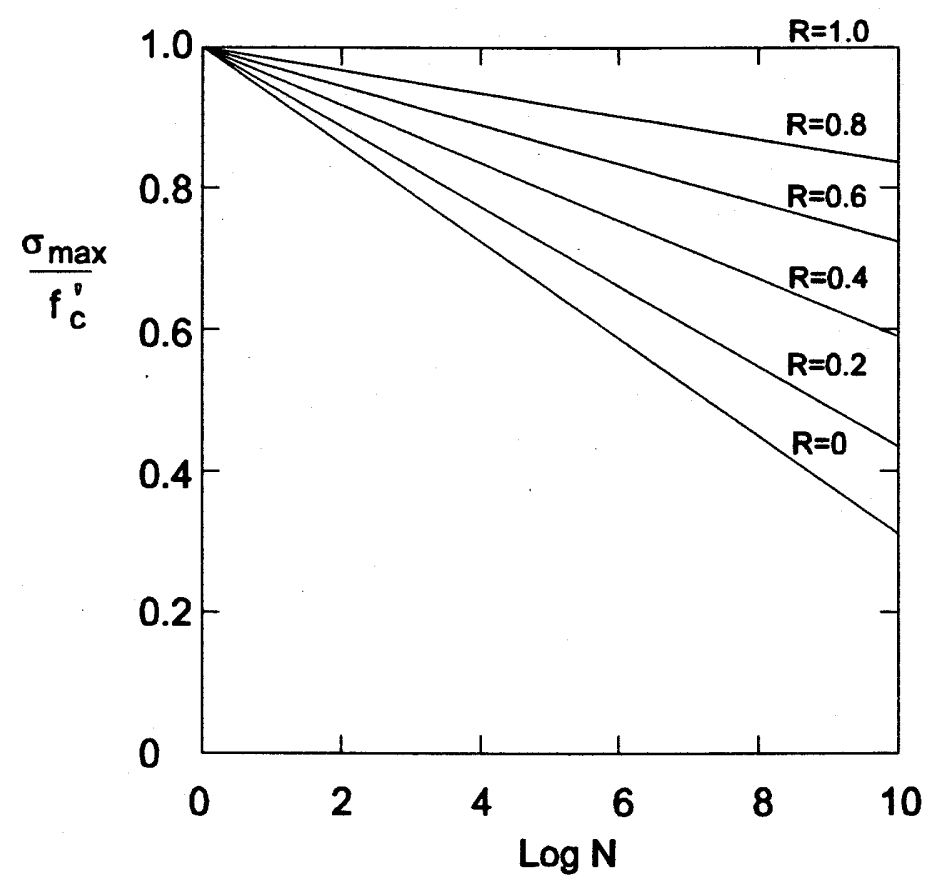

Figure 2.10. S-N Curves for Different Values of R (Tepfers and Kutti 1979).

proposed by Hsu, one pertaining to high-cycle fatigue and one involving low-cycle fatigue:

[2.17] High-Cycle Fatigue $\frac{\sigma_{\max }}{f_{c}^{\prime}}=1-0.0662(1-0.552 R) \log (\mathrm{N})-0.0294 \log (\mathrm{T})$

$$
\text { Low-Cycle Fatigue } \quad \begin{aligned}
\frac{\sigma_{\max }}{f_{c}^{\prime}}= & 1.20-0.20 \mathrm{R}-0.113(1-0.779 \mathrm{R}) \log (\mathrm{N}) \\
& -0.0534(1-0.445 \mathrm{R}) \log (\mathrm{T})
\end{aligned}
$$

The effects of the time variable proved to be more pronounced for the low-cycle region (Gylltoft 1983). The validity of the Equation [2.17] concerning the high-cycle region may be questioned for certain ranges of loading frequency since it has been shown that the loading rate has minor effects on the fatigue strength of concrete within the range $0.5 \mathrm{~Hz}$ to $7.5 \mathrm{~Hz}$. Hsu (1981) substantiated the proposed equations for both 
compression and flexural fatigue with a large number of test data reported in the literature. He claims that the equations are valid for both compression and tension stresses.

\subsubsection{Statistical Evaluation:}

Due to the considerable scatter of data that commonly results in S-N curves for concrete, it has been suggested that a statistical evaluation of the test data may be appropriate. Mallet (1991) indicates that McCall, in 1958, suggested that fatigue data be represented by the probability of failure $(\mathrm{P})$ as well as stress $(\mathrm{S})$ and cycles to failure $(\mathrm{N})$. Research has generally acknowledged that statistical variability result from such factors as material strengths and applied loads (Hwan Oh 1986). In 1983, Siemes, as noted by Mallet (1991), showed that the scatter of data in S-N curves may be attributed to the variable nature of $f^{\prime}{ }_{c}^{\prime}$ (static strength of concrete). Research has shown this to be true for compression fatigue, flexural fatigue, tension and tension-compression fatigue (Mallet 1991).

\subsubsection{Fracture Mechanics for Concrete:}

\subsubsection{Nature of Concrete Fracture:}

Concrete may be defined as a heterogeneous material made up of two different phases, hydrated cement paste (hcp) and aggregate. Shown in Fig. 2.11, adapted from Ziegeldorf (1983), the stress-strain curves of these two materials differ significantly. Both materials fail in a brittle manner, and are linear, with the cement paste becoming nonlinear at $90-95 \%$ of its ultimate strength. Concrete, however, is highly nonlinear, which is partly due to the poor bond between the two material phases and to the 


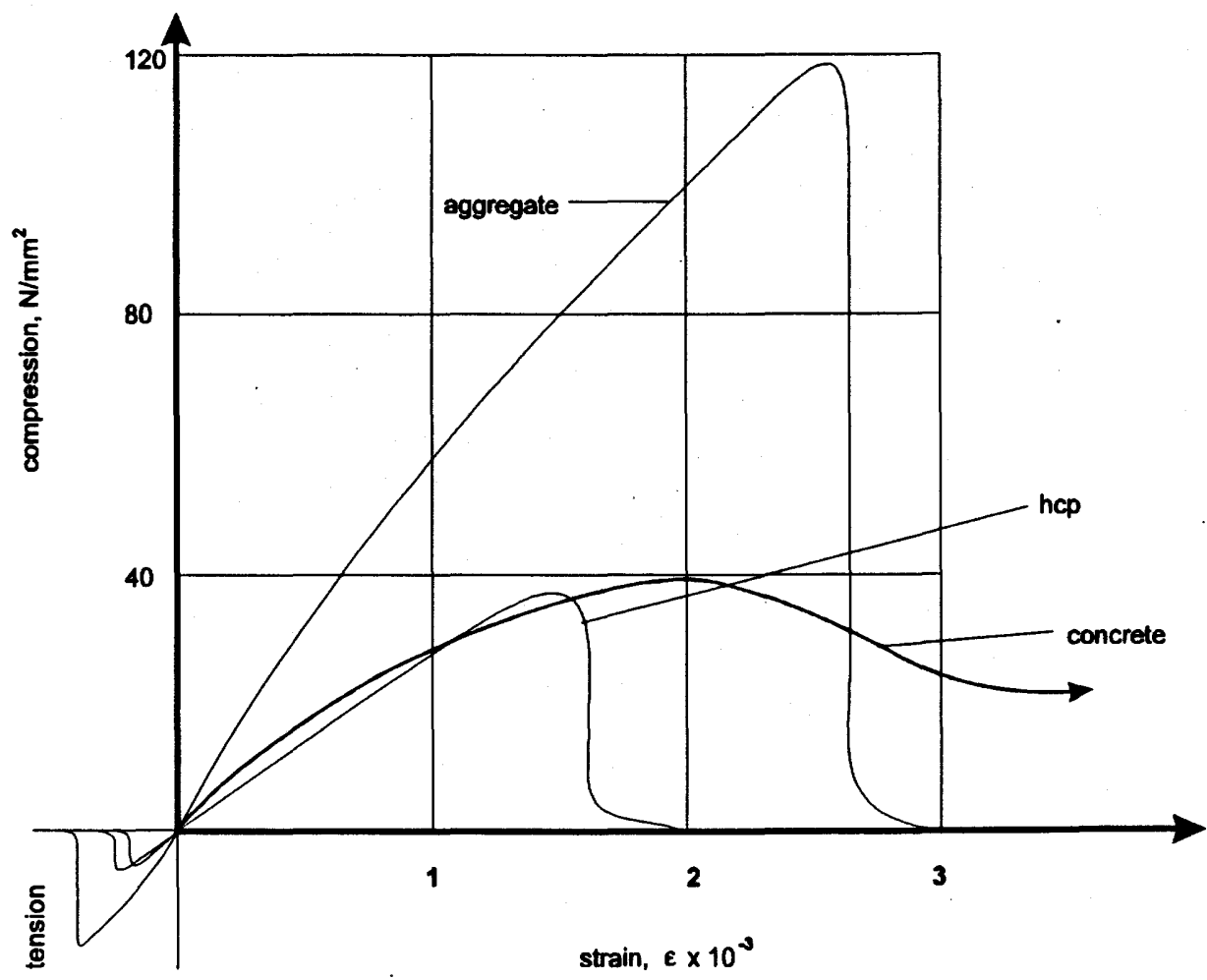

Figure 2.11. Stress-Strain Diagram of Hardened Cement Paste, Aggregate and Concrete (Ziegeldorf 1983).

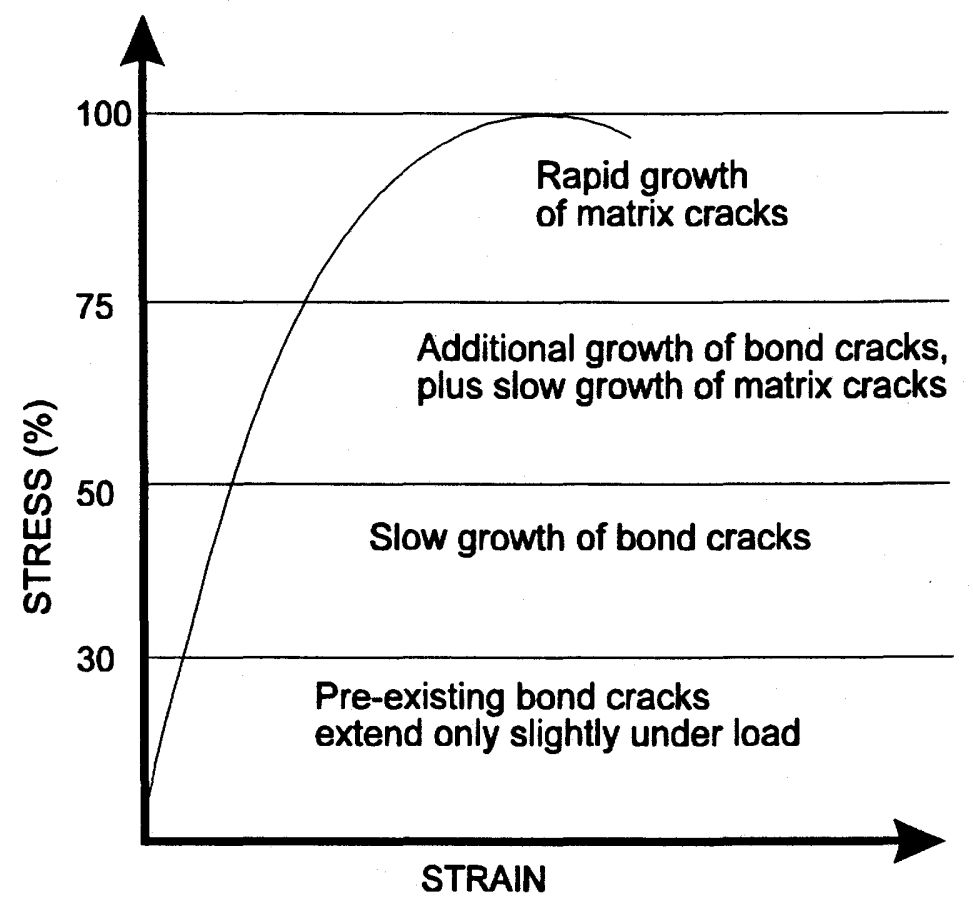

Figure 2.12. Stress-Strain Curve for Concrete Showing Different Regions of Crack Growth (Mindess 1983). 
considerable cracking which occurs throughout the medium. The growth history of the cracking in relation to the stress-strain curve is adapted from Mindess (1983) in Fig. 2.12. It has been suggested that the cracking of concrete occurs initially at the interfacial bond between the aggregate and the cement paste. This may take place prior to the loading of the concrete and is usually due to shrinkage of the cement paste. Cracking in concrete is not smooth as in other materials such as metals, but highly tortuous. This is because the crack tends to pass around the hard aggregate particles which, due to their high strength, act as arrestors as the crack propagates through the cement paste matrix (Bazant 1985; Mindess 1983). The energy demand for crack growth increases when the crack is stopped at an aggregate particle, and higher stress levels are required to reactivate the crack growth thus leading to a step-wise growth of the crack. It has been observed that even within the cement paste, on the microscopic level, cracking is quite complex (Ziegeldorf 1983).

\subsubsection{Application of Fracture Mechanics to Concrete:}

The application of fracture mechanics, specifically Griffith's Theory, to concrete was first experimentally attempted by Kaplan (1961). He conducted tests on notched beams that were used to determine the critical strain energy release rate , $G_{c}$. Mindess (1983) notes that Kaplan concluded, based on his research, "... that the Griffith concept of a critical strain-energy-release rate being a condition for rapid crack propagation and consequent fracture, is applicable to concrete". Glucklich, as noted by Mindess (1983), agreed that fracture mechanics was applicable to concrete, but he suggested that fracture was not limited to the propagation of a single crack; rather, a multitude of microcracks formed in the highly stressed zone.

Unlike ductile materials such as metal, in which fracture is preceded by yielding, in 
concrete, microcracking occurs prior to fracture. This is because concrete in tension can not deform plastically (Bazant 1985). These discontinuous microcracks form in what is called the fracture process zone, which is a zone of strain softened material located at the tip of the crack. In ductile materials such as metals, the strain softened region is small in relation to the nonlinear (plastic) zone where yielding occurs, while in concrete the majority of the nonlinear zone will contain strain softened material (fracture zone) (Bazant 1985). Fig. 2.13, adapted from Bazant (1985), compares the conditions which exist at the crack tip for different types of materials. Within the fracture zone in concrete, the visible microcracks which form are still able to provide some stress resistance by such mechanisms as aggregate interlock (Ingraffea, Gerstle, Gergely and Saouma 1984).

There is very little contraction resulting in the fracture of concrete, due to the low Poisson's ratio of concrete, and so there is little difference between plane strain and plane stress conditions, unlike the conditions in metals under yielding. Therefore, the width of the concrete specimen is not a concern and this simplifies the fracture mechanics in regard to concrete (Hillerborg 1983).

The applicability of LEFM is often questioned in regard to concrete because of the large amount of non-linearity which results in the fracture process zone. Therefore, many different nonlinear models of fracture have been suggested and experimented with for concrete.

According to Hillerborg, the crack opening displacement (COD) analysis is not applicable to concrete. This is because concrete does not have a well-defined crack tip so that crack propagation and crack opening will not occur simultaneously (Swamy 1983). 
(a) Linear Elastic

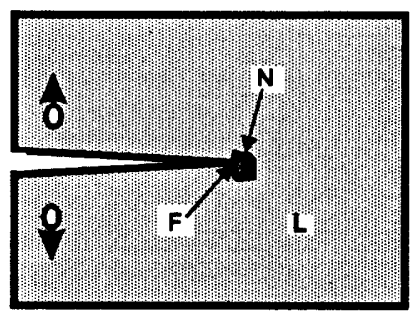

(b) Metals

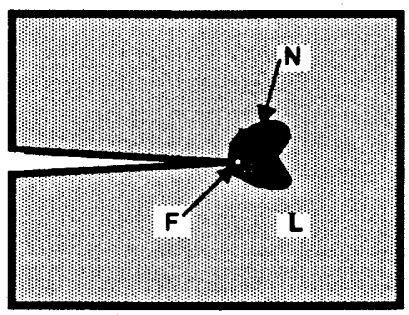

(c) Concrete

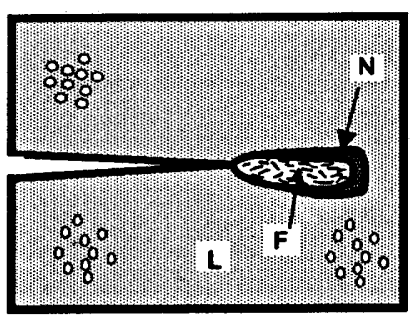

Figure 2.13. The Conditions Around a Crack Tip in Different Types of Materials (Bazant 1985):

$$
\begin{aligned}
& \mathrm{L}=\text { Linear Zone } \\
& \mathbf{N}=\text { Non-linear Zone } \\
& \mathrm{F}=\text { Fracture Zone. }
\end{aligned}
$$

R-curve analysis, according to Hillerborg (1983), has limited applicability to concrete.

He states that because R-curve analysis is based on observation of crack growth and since, in concrete, a well-defined crack tip can not truly be determined, this model for fracture is impractical for concrete.

As discussed early, the J-integral approach is only applicable to elastic materials and the loading-unloading curves must be identical. Therefore, since concrete and it's constituents demonstrate a brittle failure, the J-integral is not a useful model.

The fictitious crack model (FCM) is a nonlinear fracture mechanics model developed by Hillerborg (1983) for concrete and takes into account the large fracture zone ahead of the crack tip. This approach is based on an energy criterion. Because the many microcracks which form throughout the fracture zone in concrete are still able to transfer stresses across the zone, this zone of discontinuous cracks is not considered to be a real crack, but is described as a 'fictitious crack'. Two diagrams are required to describe the deformation properties of the material at the crack tip: the stress-strain $(\sigma-\varepsilon)$ curve up to the tensile strength, $f_{t}$, and the stress-deformation $(\sigma-w)$ curve, for $\sigma>f_{t}$ (see Fig. 2.14, $\mathrm{c}$ and d, adapted from Hillerborg (1983)). This zone or 'fictitious crack' is 


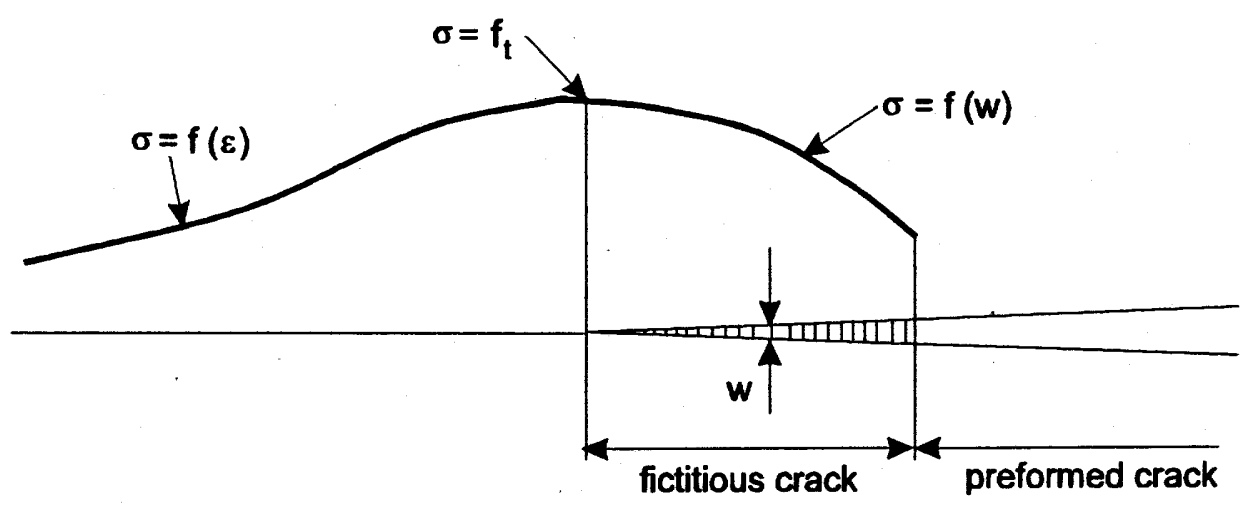

(a)

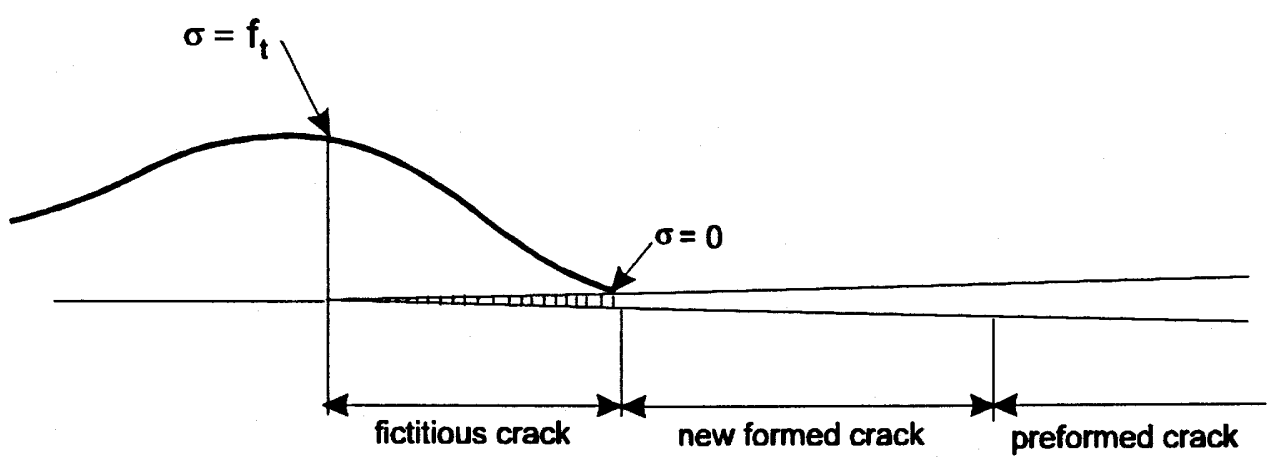

(b)

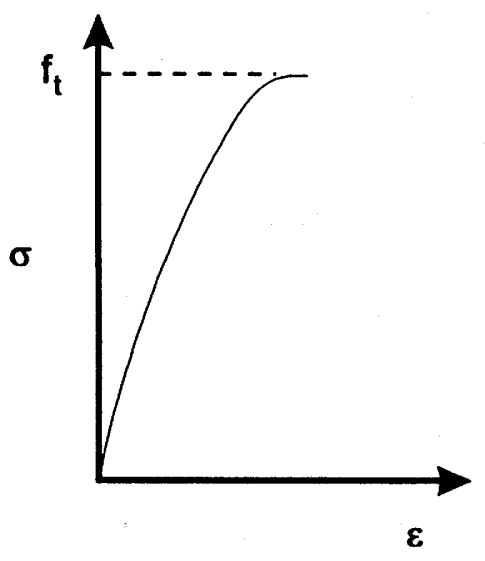

(c)

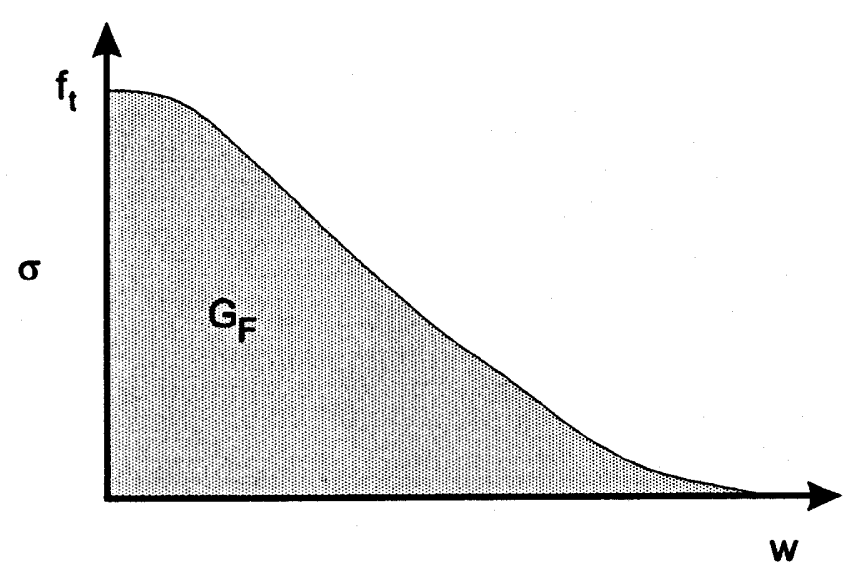

(d)

Figure 2.14. Stress Distribution in Front of Crack Tip Before and After Cracking; Material Properties (Hillerborg 1983). 
suggested to arise when the stresses across the process zone reach the tensile strength (i.e. $\sigma=f_{t}$ ). So prior to the formation of the fictitious crack, the normal $\sigma-\varepsilon$ curve may be used to describe the material (Gylltoft 1983). As the fictitious crack width increases, the stress in the material decreases to zero at which point the crack width, $w$, reaches the ultimate crack width, $w_{c}$, and a real crack is created (Gylltoft 1983). Everywhere within the fictitious crack area, the $\sigma$-w curve describes the unloading of the material. Outside

the 'fictitious crack', the material may be described by the normal $\sigma-\varepsilon$ curve (see Fig. 2.14 $a$ and $b)$. The area underneath the $\sigma-w$ curve is the fracture energy $G_{F}$ which is the energy absorbed in forming one unit area of crack (Gylltoft 1983).

Analysis of the FCM, as with most recent fracture mechanic models, is most suitable to numerical analysis utilizing the Finite Element Method. For simplicity, the normal $\sigma-\varepsilon$ curve is often assumed to be linear up to $f_{t}$ and the unloading curve, $\sigma-w$, is usually assumed as either a linear curve at its purest simplification or a step wise linearity.

\subsubsection{Fracture Mechanics and Concrete Fatigue:}

The amount of research directed towards fracture mechanics of concrete under fatigue loading has been limited. However, there are a few studies completed which attempt to explain the processes occurring during fatigue and to formulate models to describe the cracking of concrete under fatigue loading. Glucklich (1965) described from his observations of fatigue bending of mortar beams, how cracking might occur in concrete during fatigue loading. He found that the plots of the stress-deformation curves (see Fig. 2.15, reproduced from Glucklich (1965)) showed a general pattern which may be explained by cracking of the concrete. During the first load cycle, the stress-strain curves were convex to the stress axis. This was considered to be the result of cracking corresponding to the stress level applied. For the cycles that followed within the same 


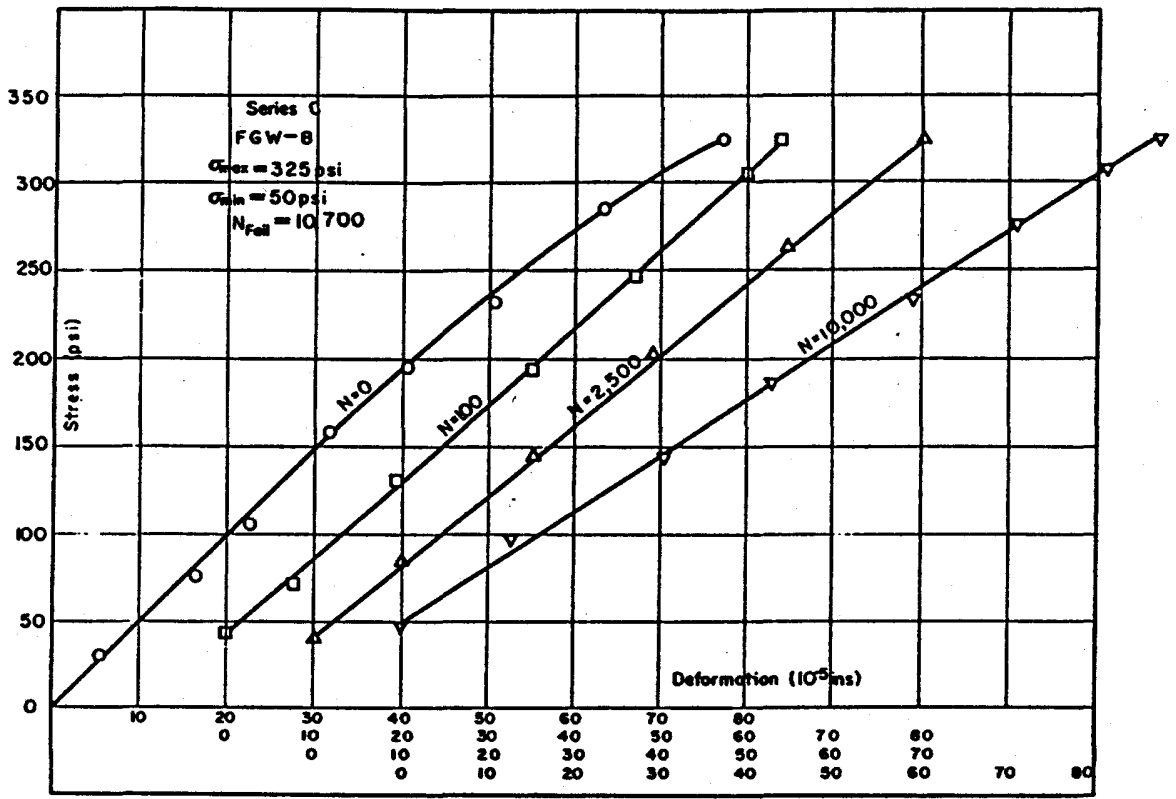

Figure 2.15. Stress-Deformation Curves of Notched Beam During Fatigue Life (Glucklich 1965).

stress range, the stress-deformation curves were linear, thus indicating that the cracking for that range of stress was complete. Also, Glucklich found that, with an increasing number of cycles, the slope of the stress-deformation curve decreased. He concluded from his observations of this stress-strain phenomenon that "... the cracking, which has stopped when the stress reached its maximum value in the first cycle, is continued due to the repeated cycles. In other words, a certain amount of cracking can be brought about by either a relatively high stress applied once, or a lower stress repeated many times." He determined that such observations may also explain what is believed to be the endurance limit of concrete at approximately 50 to $60 \%$ of static ultimate strength since no cracking occurs before this stress during static loading. Thus, there are no cracks present which can be advanced by the cyclic loading.

The mechanisms responsible for fatigue failure, which were observed by Glucklich, can be explained using the concepts of stress concentration and fracture mechanics as 


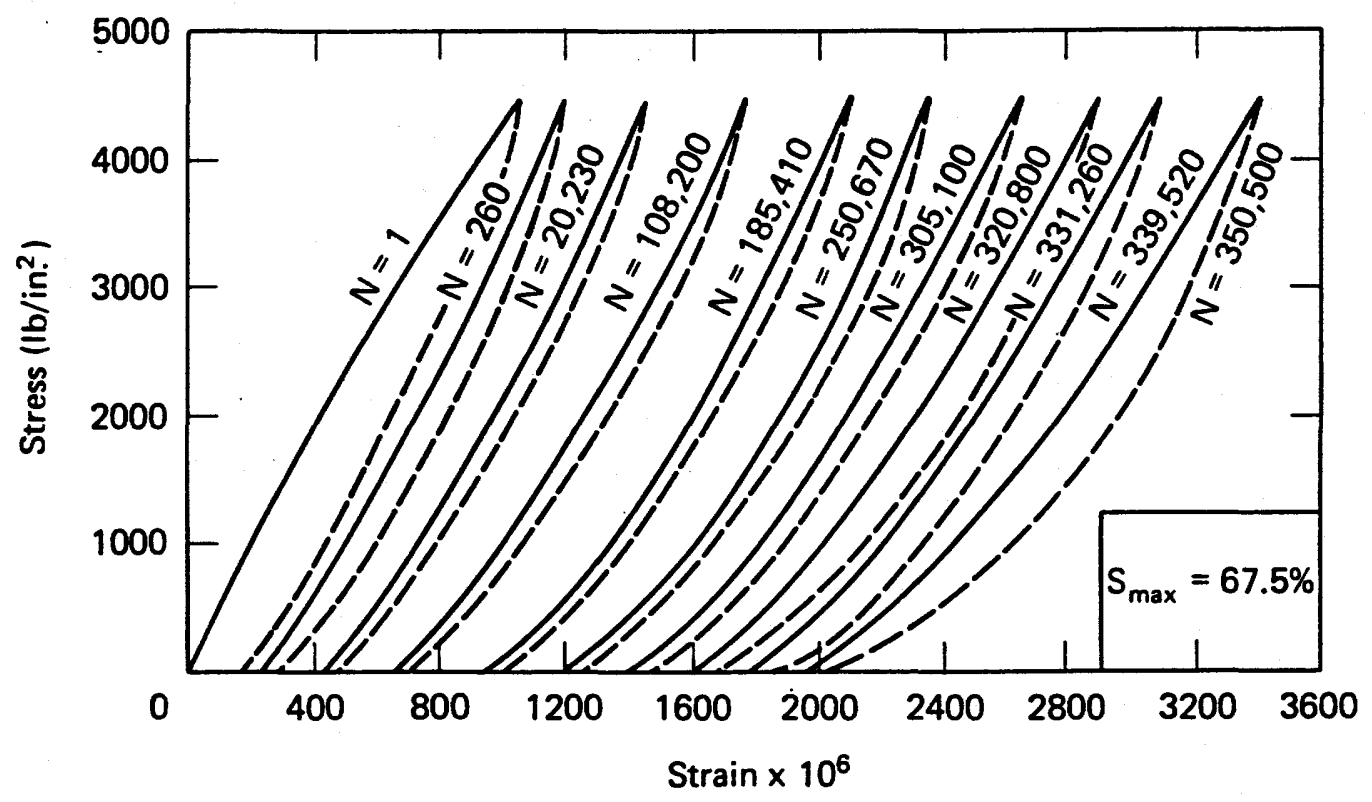

Figure 2.16. Stress-Strain Curve of Concrete Subjected to Repeated Loading (Mindess and Young 1981).

described by Mindess and Young (1981). The internal flaws and cracks which form in concrete during hydration at the interface between the cement and the aggregate have a very high level of stress at their tips. This stress can exceed the cohesive strength of the cement-aggregate bond even though the nominal stress in the concrete is quite low, thus causing the cracks to propagate under repeated load. This growth process is shown by the stress strain curve of concrete under a fatigue loading in Fig. 2.16, reproduced from Mindess and Young (1981). The area within the hysteresis loops, which result during the cycling process, is equivalent to the "...irreversible energy of deformation, energy that becomes available to propagate the cracks" (Mindess and Young 1981). At the start of testing, Fig. 2.16 shows the area of the loops decreasing with increasing load cycles, but then near failure they begin to increase. Such a response can explain the crack growth of the concrete under cyclic loads. At the beginning, crack growth is gradual and viscous flow may also be taking place. There is a tendency for the developing microcracks to be stabilized through interaction with the aggregate, thus hindering large crack growth. Nevertheless, the repeated loading will eventually have supplied enough energy to make 
damage at the crack tips worse, and the cracks will then propagate until failure occurs.

Shah and Chandra (1970) studied the effects of cyclic and sustained loading on the fracture of concrete. For cyclic loading of concrete in compression they found that "... the repetitive nature of loading played a predominate role in crack propagation". They also observed that the microscopic fatigue fracture surfaces showed "... well defined crack front arrest lines, each of which was caused by a single load. These are called fatigue striations and the number of striations generally equals the number of loading cycles."

Gylltoft (Elfgren 1989) reviewed the work completed towards the effort of fracture mechanic modeling of concrete under cyclic loading. He indicates that a large number of models have been formed to describe the behaviour under compressive loading based on theories of elasticity or plasticity; however, there has been considerably less research on models for tension loading. Many of the tension models describe possible envelope curves while others present a simplified representation of the loading-reloading cycle. Fig. 2.17, reproduced from Elfgren (1989), are examples of the load histories studied by researchers at the Stevin laboratory, showing a case of a monotonic loading and three cases with the unloading stresses varying between low tensile stresses, low compressive stresses, and high compressive stresses. All cyclic load histories were found to be similar to the monotonic tension load case. Gylltoft (1983) presented a fracture mechanics model he developed to describe the above observations for concrete in tension under either monotonic or cyclic loading. The model describes gradual increasing damage occurring in the fracture zone as microcracking increases. The damage is measured as the energy consumed during each loading-reloading cycle, with the ultimate failure occurring when the total energy consumed equals the fracture energy, $G_{F}$. The monotonic and the cyclic load ultimate failure criteria are considered to be equivalent for 


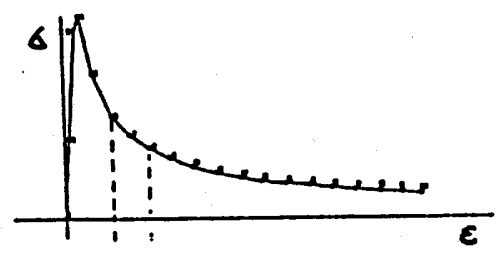

type I

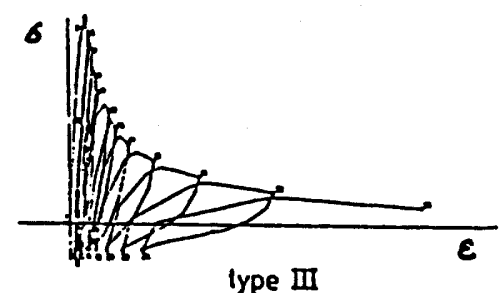

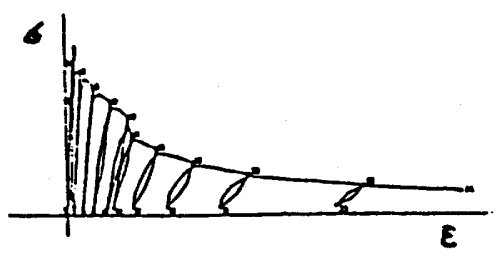

type II

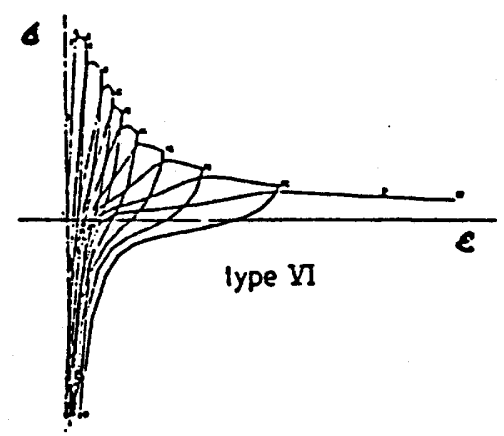

Figure 2.17. Experimental Load Histories in Cyclic Tension (Elfgren 1989).

this model. Gylltoft indicates that the fracture mechanic models he presented have only been applied to "low-cycle fatigue" problems, however he believes that the models will also be applicable to "high-cycle fatigue" problems.

\subsection{Fatigue of Reinforcing Steel:}

The failure of reinforcing steel due to fatigue loading is governed by several factors, the most significant of these being surface geometry, applied stress ranges, and environmental conditions. Stress concentrations due to an irregular surface or discontinuities in the geometry will result in microcracks initiating in the material. The propagation of the microcracks from repetitive loading results in ultimate failure of the material. 


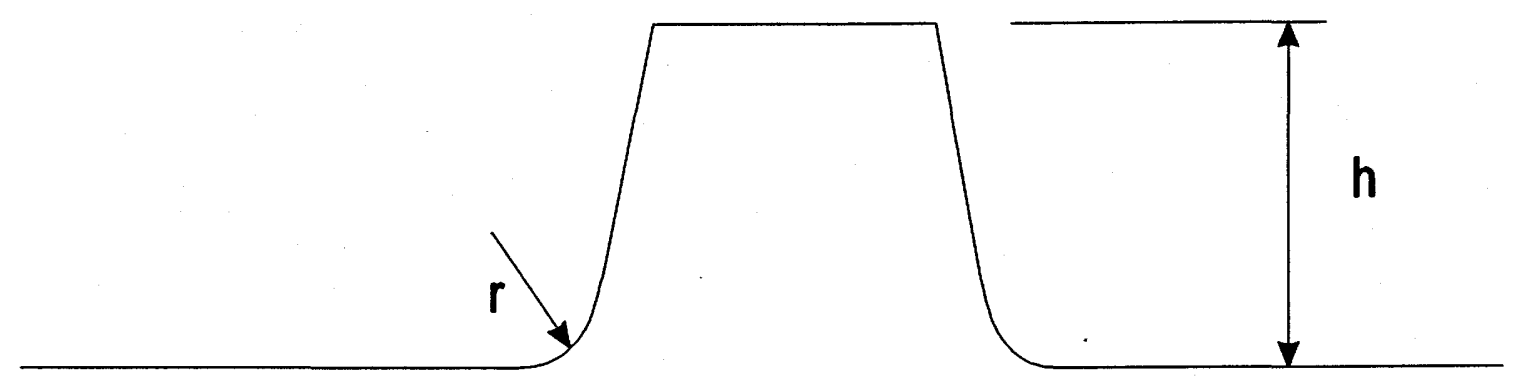

Figure 2.18. Lug Height and Base Radius.

For deformed reinforcing bars, the most important characteristic is the ribs or patterns which are provided to improve bond between the bar and the surrounding concrete. These deformations cause stress concentrations within the bar which will reduce its fatigue strength (Mallet 1991). It was shown by Jhamb and Mac Gregor (1963a and 1963b) and Soretz (1964) that the height of the lug and the radius of the lug root (see Fig. 2.19) were significant in determining the effect the deformations had on the strength. They also showed that a larger radius at the base of the lug would not be as detrimental to the fatigue strength as a sharper radius.

Jhamb and Mac Gregor (1963a) noted that the grade of steel did not seem to influence the fatigue strength for deformed bars. Two grades of steels were considered in their study, Grade 40 and 60 (ksi). In 1948, Bullens indicated that an increase in fatigue strength was not evident in notched steel specimens when an increase in tensile strength was provided. This conclusion was based on a study using high strength steels.

Another characteristic of reinforcing bars that has been shown to influence their fatigue strength is the bar diameter. With an increase in bar diameter, it has been noted that a reduction in fatigue strength results (Tilly 1979). Mallet (1991) suggests the reason for this reduction is that for a larger surface area there is a greater likelihood of flaws. 


\subsubsection{Analysis of Reinforcing Steel Fatigue:}

Analysis of steel fatigue has been well researched. Reinforcing steel subjected to fatigue has been proven to maintain similar characteristics to that of structural steel when submitted to fatigue loading.

\subsubsection{S-N Relationships for Reinforcing Steel:}

The most common parameter used in presenting the fatigue strength of reinforcing steels is the applied stress range $\sigma_{\mathrm{r}}$, which is the difference between the maximum and minimum stresses. Fig. 2.1, as presented earlier, is a schematic diagram of an S-N curve for a reinforcing steel bar. Typically, steel displays a distinct endurance limit, which is a level of the stress range below which an infinite number of cycles may be applied without fatigue failure occurring. The reason for this condition is the material's capacity for strain hardening with repeated load (Gylltoft 1983).

Rabbat and Corley (1984) tested a number of reinforced concrete beams under fatigue stress ranges between $21 \mathrm{ksi}(144.8 \mathrm{MPa})$ and $26.5 \mathrm{ksi}(182.8 \mathrm{MPa})$. They presented the following equations, based on their test results, to describe the fatigue strength of the main reinforcing steel within a reinforced concrete beam:

$$
\begin{array}{cc}
\sigma_{\mathrm{r}}=21-0.31 \sigma_{\min }+8\left(\frac{\mathrm{r}}{\mathrm{h}}\right) \quad \text { where: } \quad & \sigma_{\mathrm{r}}=\text { stress range }(\mathrm{ksi}) ; \\
& \sigma_{\min }=\text { minimum cyclic stress }(\mathrm{ksi}) ; \\
\mathrm{r} / \mathrm{h}=\text { ratio of base radius to height } & \text { of lug. }
\end{array}
$$




$$
\log (N)=6.1044-0.0407 \sigma_{r}-0.0138 \sigma_{\min }+0.0071 f_{s u}
$$

$$
-0.0566 \mathrm{~A}_{\mathrm{s}}+0.3233 \mathrm{D}\left(\frac{\mathrm{r}}{\mathrm{h}}\right)
$$

$$
\text { where: } \quad \begin{aligned}
& f_{\mathrm{su}}=\text { ultimate tensile stress }(\mathrm{ksi}) ; \\
& \mathrm{A}_{\mathrm{s}}=\text { area of reinforcing bar }\left(\mathrm{in}^{2}\right) \\
& \mathrm{D}=\text { diameter of reinforcing } \operatorname{bar}(\mathrm{in})
\end{aligned}
$$

Equation [2.19] represents the limiting stress range at which point the main tensile reinforcement will no longer fail from fatigue (i.e. infinite fatigue life). Equation [2.20] provides the number of cycles $(N)$ to failure based on fatigue of the main reinforcement, for a given stress range $\left(\sigma_{\mathrm{r}}\right)$ and a minimum stress $\left(\sigma_{\min }\right)$, of a reinforced concrete beam. This equation is only suitable for fatigue lives between 10000 and 1 million cycles.

\subsubsection{Fracture Mechanics for Reinforcing Steel:}

LEFM has been proven to be quite suitable for describing cracking in metals. This is because the process zone at the crack tip in which the metal is yielding contains only a small amount of plasticized (i.e. strain-softened) material. Because of its applicability, a lot of research has been directed towards LEFM for metals. ASTM has published a large amount of information regarding fracture mechanics and the testing methods for metals that provide a basis for the use of LEFM concepts.

In metals, conditions of either plane stress or plane strain will exist. Large plastic zones (i.e. high yielding) will result in conditions of plane stress. If the amount of yield deformation is small, plane strain conditions will prevail. The size of the specimen will thus dictate the condition of stress for metals and must be a consideration in design and testing (Broek 1982). 
Fatigue cracks develop at points of stress concentrations such as flaws or mechanical notches. Under cyclic loading, local stresses may be well above the yield strength of the material thus creating a situation for crack initiation. There are several models that may be used to describe crack initiation. Broek (1982) describes one such model developed by Wood (see Fig. 2.20, reproduced from Broek (1982)). During the initial cyclic load, the increasing load causes slip planes to develop. As the decreasing load completes the cycle, slip occurs in the reverse direction. This slipping can create intrusions or extrusions that provide a situation for high stress concentrations thus resulting in further crack growth by plastic flow.

Broek (1982) also presents a model used to describe the propagation of a crack after initiation has occurred. In Fig. 2.21, reproduced from Broek (1982), a sharp crack is highly stressed at its crack tip due to tension loading. Because of the high stress concentrations, slip occurs along a slip plane causing the crack to open and lengthen at the same time. When further slippage occurs along with work hardening, a blunt crack tip will result. As the load cycle reverses, the plasticized material at the end of the blunt crack will be placed under compressive stresses above the material yield strength from the surrounding elastic material. This forces the crack to re-sharpen at the end of the cycle at which time the crack has propagated a length of $\Delta \mathrm{a}$. This pattern continues under the cyclic loading causing microscopic striations along the fractured surface of the specimen which represent the position of the crack tip as it progresses through its cycle of blunting and re-sharpening.

It has been reported by some researchers that a change in the magnitude of the cyclic loading, such as an overload, may result in a retardation in the crack propagation (Rolfe and Barsom 1977). The occurrence of this slowdown behaviour has been attributed to crack tip blunting which retards crack growth until re-sharpening of the crack tip occurs, 


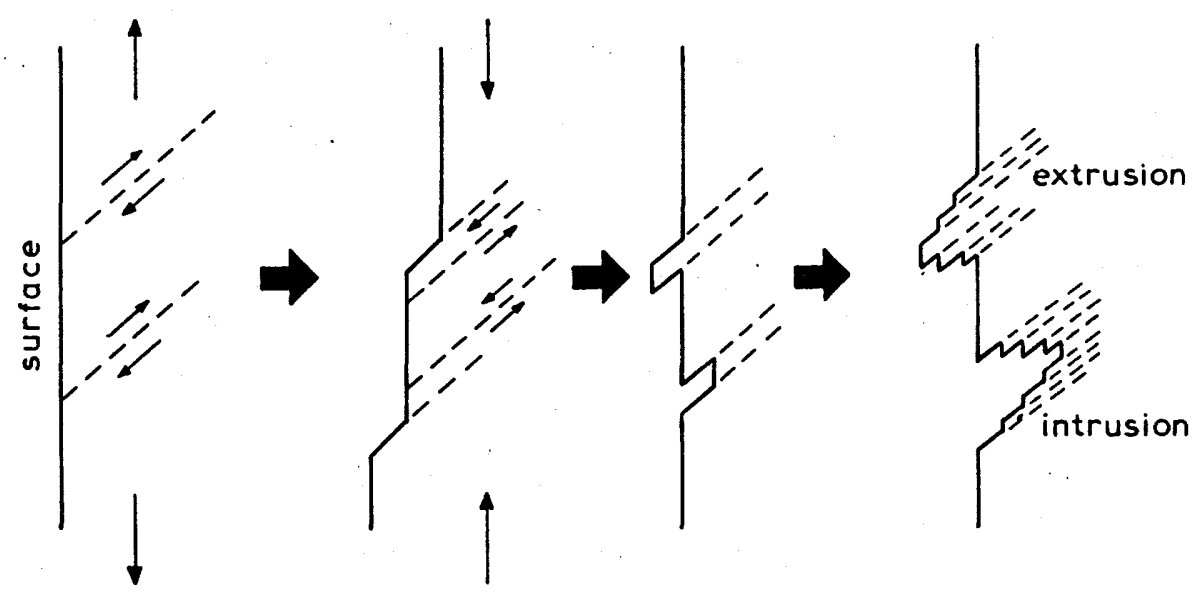

Figure 2.19. Woods Model for Fatigue Crack Initiation (Broek 1982).

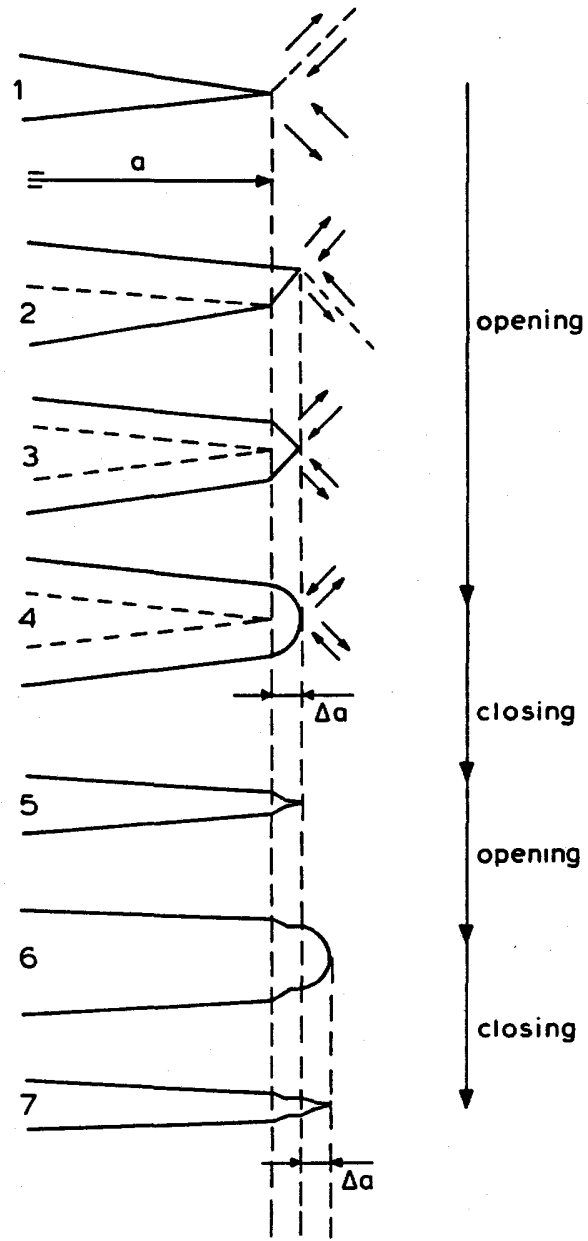

Figure 2.20. Fatigue Crack Growth (Broek 1982). 
and also to residual compressive stresses in the proximity of the crack tip that reduce the rate of fatigue crack growth.

\subsection{Fatigue of Reinforced Concrete Beams:}

\subsubsection{Design Standards:}

The Canadian bridge design code CAN/CSA-S6-88 (1988), provides equations for determining the allowable stresses in the steel and concrete of reinforced concrete structures when subjected to repetitive loading. The following design equations are expected to provide the structure with an infinite fatigue life if the applied stresses are held below the allowable values:

$$
\sigma_{c} \leq 0.5 f_{c}^{\prime}
$$

$$
\sigma_{r} \leq 145-0.33 \sigma_{\min }+55\left(\frac{r}{h}\right)
$$

where:

$\mathrm{r} / \mathrm{h}=$ ratio of base radius to height of rolled deformation. Use $\mathrm{r} / \mathrm{h}=0.3$ for design purposes, unless the value can be found for the bars to be used.

$\mathrm{f}_{\mathrm{c}}^{\prime}=$ concrete static compressive strength (MPa); $\sigma_{\mathrm{c}}=$ allowable concrete stress (MPa); $\sigma_{\mathrm{r}}=$ allowable stress range in reinforcing steel (MPa); $\sigma_{\min }=$ minimum service stress imposed on reinforcing steel (MPa).

Equation [2.22] is a metric version of Equation [2.19] as presented by Rabbat and Corley (1984). The above equation only applies to reinforcing bars which conform to the standard for billet-steel bars for concrete reinforcement, CSA G30.12-M1977. 


\subsubsection{Bond in Reinforced Concrete:}

Bond within reinforced concrete can be described as the shearing stress or force that exists between the reinforcing bar and the surrounding concrete. Bond is considered to be the result of three different mechanisms, chemical adhesion, friction and mechanical interaction between concrete and steel. Deformed reinforcing bars depend primarily on mechanical interlock to develop bond with the surrounding concrete (Lutz and Gergely 1967).

Flexural cracking results when longitudinal stresses in the concrete surrounding the longitudinal reinforcement bar exceeds the tensile capacity of the concrete. At the point where these primary cracks are formed, the bond stress is zero and the stress in the steel bars is at a local peak. Between these flexural surface cracks, the steel stress is lower due to part of the tension force being carried by the concrete. Internal cracks (secondary cracks) develop at the ribs of the reinforcing bars shortly after the primary cracks form, at bond stresses well below the bond capacity (Goto 1971). This internal transverse cracking produces a series of independent rings of uncracked concrete around the reinforcement (see Fig. 2.22, reproduced from Goto (1971)). The force transfer mechanism is then established by a compressive resultant bond force acting at the face of the rib through the concrete rings into the surrounding uncracked concrete (Goto 1971).

The resultant bond force can be divided into two components, radial and longitudinal forces (see Fig. 2.22). The longitudinal bond force combined with the reinforcement bar tensile stress is balanced against the tensile force which exists at the end of the bar. The radial component of the bond force is balanced with a circumferential tensile stress ring in the concrete (see Fig. 2.23, reproduced from Tepfers (1973)). These stress rings are 


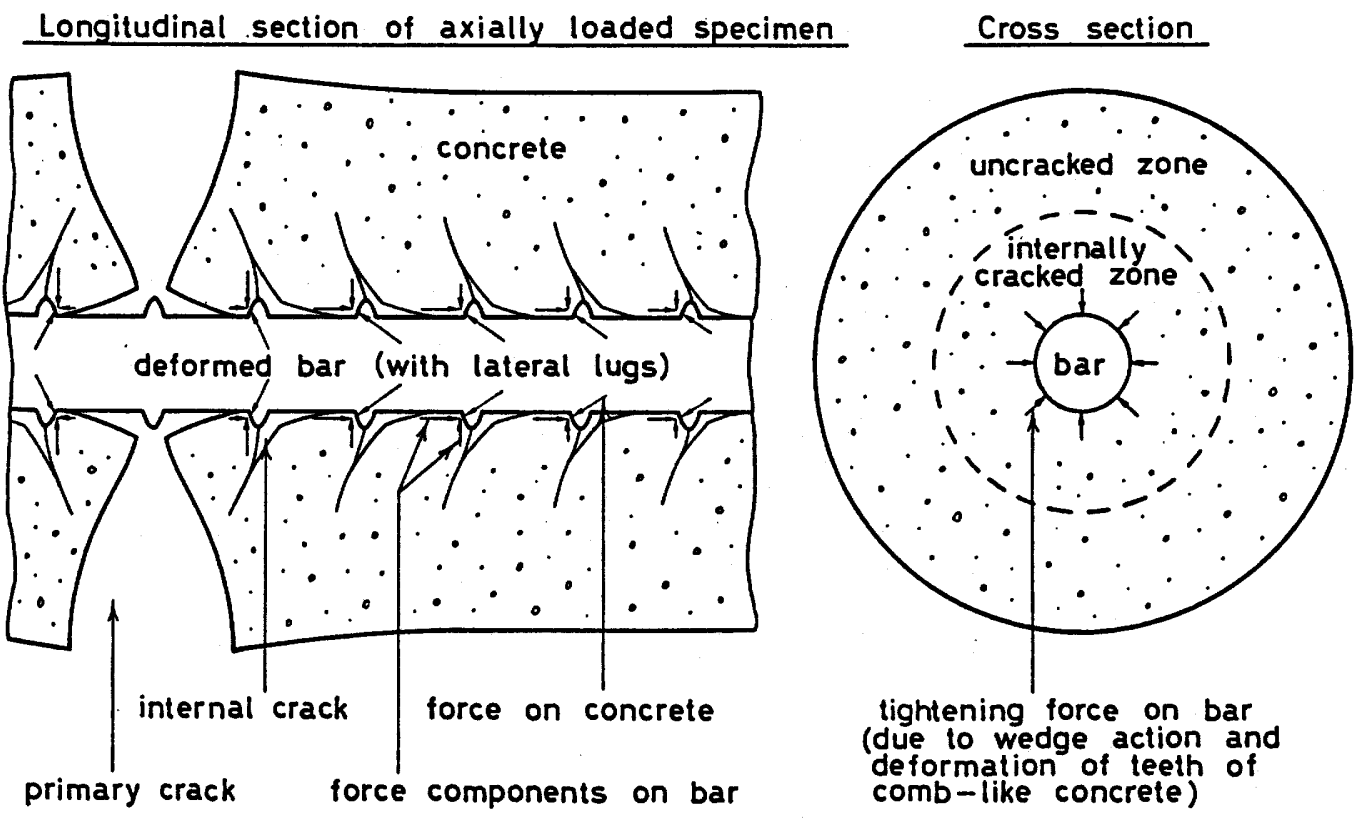

Figure 2.21. A Typical Crack Around a Deformed Bar (Goto 1971).

located at each bar rib where the bond forces exist. An analogy often considered for the radial stresses is to regard them as the pressure acting on a thick concrete cylinder causing tension forces within the cylinder wall (Tepfers 1973). The internal diameter of the cylinder is assumed to be equal to the bar diameter with a thickness equivalent to the thinnest cover on the bar. When the tensile stress exceeds the tensile capacity of the concrete, longitudinal splitting cracks will form in the wall of the cylinder, along the axis of the bar. The splitting of the concrete cover leads to spalling of the cover thus removing any mechanism for bond transfer; consequently, bond failure occurs.

The concepts of bond mechanisms under a cyclic loading are theoretically the same as that for monotonic loads as discussed above. 


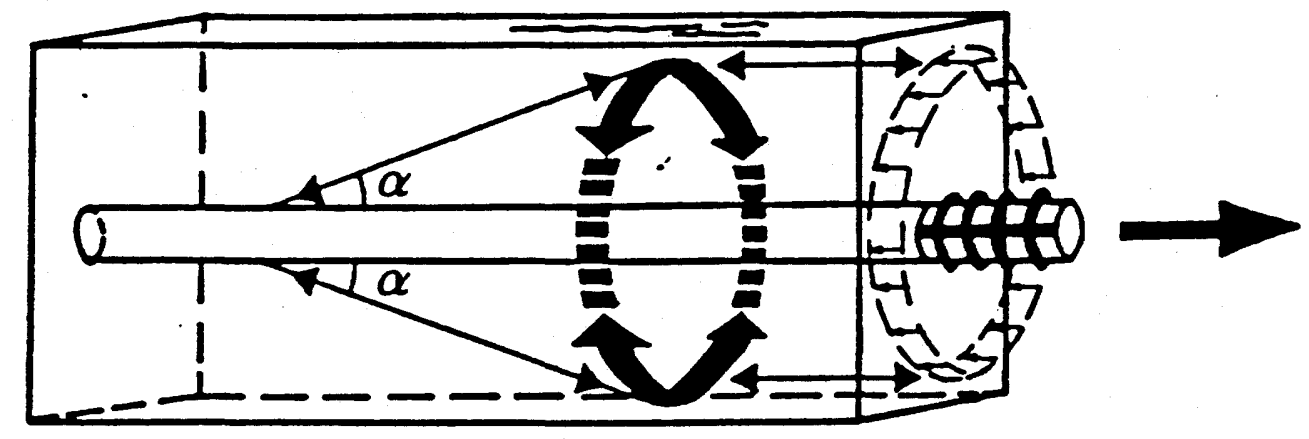

Figure 2.22. Schematic Representation of the Radial Components of the Bond Forces Balanced Against Tensile Stress Rings in the Concrete at a Zone of Anchorage (Tepfers 1973)

\subsubsection{Fracture Mechanics of Bond:}

Bond failure due to longitudinal splitting of the concrete cover is a crack propagation problem. Therefore the use of fracture mechanics, which is the study of crack growth, would only seem logical. With the use of the finite element method, a number of nonlinear fracture mechanics models have been developed for bond.

Holkmann Olsen (1990) completed testing on overlapped splices and determined that the fracture energy parameter of the concrete, $G_{F}$, was a more influential property governing the strength of the lap splices than either the compressive or splitting strengths of the concrete.

Ingraffea, Gerstle, Gergely, and Saouma (1984) presented a non-linear discrete, interface approach to model the effects of radial secondary cracking in an attempt to better understand and predict the bond-slip behaviour. On the basis of his fracture mechanics model for concrete in tension, Gylltoft (1983) created another model to describe bond 
problems between concrete and reinforcing steel for monotonic and uni-directional cyclic loading. The model considers cracking simultaneously in the shear direction and the direction perpendicular to the contact surface. Olsson (1985) utilized an extension of the Hillerborg fictitious crack model as well as a constitutive unloading model, similar to that provided by Gylltoft (1983), in an attempt to describe the splitting failure of the concrete cover in relation to anchorage of a reinforcing bar in concrete. The presence of transverse reinforcing is also considered in his model.

Studies such as the ones mentioned above have shown that fracture mechanics is applicable for analyzing the problem of bond in reinforced concrete.

\subsubsection{Overview of Lap Splices Fatigue:}

The fundamentals of bond transfer within reinforced concrete can also be applied to lap splices. Transfer of stress is accomplished through bond stresses along the lap length. The mechanics of this transfer of force is basically the same as for a single anchored bar. The analogy of stress rings may also be used for lap splices, with the cylinder having an oval shape surrounding both lapped bars (Tepfers 1973).

There are a number of factors which influence the bond strength of lap splices in reinforced concrete beams. Some of these parameters are:
1) splice length;
2) confinement;
3) concrete strength;
4) steel tensile strength;

The main purpose of splice design is to determine a proper length of splice for the design 
conditions which exist. Fagundo, Gergely, and White (1979) explained that past research has not developed any general agreement which indicates how an increase in splice length will affect the strength of the splice. They concluded that the length of the splice seems to affect the influence of the different splice parameters which control splitting and visa versa.

It is generally accepted that when confinement is provided, whether it be from the concrete cover or the transverse reinforcement, it is possible to reduce the splice length without a reduction in strength. However, there are limits to the advantages that are provided by the added confinement. The ACI 408 Committee (1979 and 1990) has found that above a certain amount of confinement, there is no increase in capacity of the splice. This is because the mode of failure changes. With smaller amounts of confinement a splitting failure will occur. With heavier confinement, a pullout failure results. Therefore, it may be concluded that confinement is only effective in improving splitting resistance; it does not increase pullout strength. Because of this limited effectiveness, restrictions on the amount of confinement provided by transverse reinforcement are often imposed in design equations. Transverse steel is provided to create a confining pressure for the concrete once cracking begins. Although transverse reinforcement will not prevent splitting failure, it will assist in containing the propagation and widening of the cracks in the concrete cover, consequently increasing the bond capacity of the anchored bars (Tocci, Gergely and White 1981). The amount of concrete cover present not only determines the mode of failure, but it will also influence the type of splitting failure which will occur.

Confinement is important for the cyclic load case because crack propagation and widths increase at a faster rate than when under static load (Tocci, Gergely and White 1981). Under the conditions of seismic loading, it has been shown that a large amount of stirrup 
confinement is required to compensate for rapid deterioration of concrete confinement (Fagundo, Gergely, and White 1979; Tocci, Gergely, and White 1981; and Hungspreug 1981). However, the relative effectiveness, of the two different types of confinement provided, is not yet known in when concerning lap splice performance under fatigue loading.

Bond mechanisms are greatly affected by the strength of the concrete. Force transfer occurs through bearing of the concrete on the reinforcement ribs, and bond failure is the result of tensile splitting. Therefore, concrete compressive strength and tensile strength are key factors affecting the strength of lap splices. Since tensile strength of concrete is not often established through measurement, a correlation with the compressive concrete strength is normally used to determine its value.

Bond stress in present codes is directly related to the static steel stress in the spliced reinforcement. Current static design procedures for obtaining statically loaded lap splice lengths are based on the assumption that the steel will develop 1.25 times its yield strength. However, for higher strength reinforcement, the yield strength and lap splice length are not directly proportional. This is because the bond stress distribution becomes more non-uniform for the longer lap length. Therefore, the bond resistance per unit length reduces.

Because a long anchorage is not as efficient as a short anchorage on a unit length basis, future static codes are being revised to utilize shorter lap lengths and at the same time maintain a high stress resistance from the splice by including the influence of confinement into the design. However, current design codes do not differentiate between lap splice requirements for static loading and fatigue loading. Instead, the codes, such as the Canadian highway bridge design standard, CAN/CSA-S6-88 (1988), require a reduction 
in the allowable stress in the reinforcing steel and concrete when subjected to cyclic loading. Problems may arise with this approach to fatigue splice design. As future static design is revised in the codes to take better advantage of confinement, permitting shorter lap lengths, the fatigue resistance of these statically designed lap splices will need to be verified.

\subsection{Summary of Fatigue Analysis:}

There are a number of different approaches used in assessing the fatigue performance of a material. Two approaches, $\mathrm{S}-\mathrm{N}$ relations and fracture mechanics, were considered in this chapter in detail.

Fatigue was shown to be a process causing the propagation of cracks within a structure that could eventually lead to failure of the structure due to fracture. Fracture mechanics was defined as the study of the conditions around and in front of the tip of a crack within a material. Therefore, fracture mechanics was shown to be a logical tool for fatigue analysis.

Currently a lot of research is being directed toward developing fracture mechanic models for concrete. However, research is still in its early stages and most of the studies have been concerned with static loading conditions, while very few have considered the conditions of fatigue loading. It is expected, however, that with further development of models and standards, fracture mechanics will become a very important procedure for analysis of concrete subjected to conditions of fatigue.

Fracture mechanics is a very complex mathematical analysis and requires the use of Finite Element Method to analyze its models. Therefore, because of its complexity and lack of 
any standard models for concrete subjected fatigue loading, fracture mechanics was not used to analyze the test results of the current test program.

S-N relations are the most traditional method of analyzing fatigue failures of materials. These empirical relations provide a visual analysis utilizing a semi-logarithmic Wöhler curve to present the fatigue data in a graphical representation. This procedure was used to examine the test results of the current program because of its simplicity and since it allowed the objectives of this study to be attained. 


\section{EXPERIMENTAL PROGRAM}

The experimental program was designed to address the role that the magnitude of transverse reinforcement confinement provided along the lap length has on the high cycle (fatigue) bond resistance of the splice. Prior work by Zacaruk (1991) showed that when a lap splice designed for static loading was confined with the maximum transverse reinforcement (stirrups) deemed to be effective by the design recommendations of ACI Committee 408 (1979 and 1990) for static loading, the splice was also adequate for fatigue loading. For the load cycling ranges used during testing in this prior work, failure occurred in fatigue of the reinforcing bars outside the lap, indicating that the splice design for static loads utilizing heavy stirrups was also sufficient for fatigue loading.

The majority of the test specimens in the current study used a lap splice design where the stirrups provided along the lap were spaced further apart, while several specimens duplicated the heavy stirrup conditions used in the previous study. The design with fewer stirrups required an increase in the lap splice length above the length used by Zacaruk to provide the necessary static lap splice resistance based on the ACI 408 recommendations.

The fatigue loading response of the splice design with fewer stirrups but a longer lap was expected to be inferior to the resistance obtained with heavy stirrups and a shorter lap, even though, under static loading, the two designs were expected to have the same strength. Studies on lap splice performance under seismic loading (high intensity-low cycle, rather than lower intensity - high cycle fatigue condition used in the current 
program) have shown that heavy transverse reinforcement is essential. With high intensity load cycling, the confinement provided by the concrete to the lapped bars along the splice length is rapidly degraded, making the use of heavy transverse reinforcement mandatory. The concrete confining the lapped bars was also expected to degrade under the fatigue loading considered in the current study, making confinement provided by the concrete less effective than the confinement provided to the lap length by the stirrups. Therefore, the design with less confinement coming from the stirrups was expected to be inferior under fatigue loading.

Design calculations for the two lap splice alternatives are provided in Appendix A. Details of the test specimens and program follows.

\subsection{Specimen Designation:}

To identify each specimen and its significance within the experimental program, a threepart designation was developed. The first part refers to the lap splice length, in millimeters. The second part refers to the method of test being performed, for example a fatigue (F) or static (ST) test, and numerically orders the beams under each of these test methods. The third part describes the type and quantity of confinement used along the lap splice. Only closed transverse stirrups are used in this experimental program. Therefore, the designation for the type of confinement will be a ' $\mathrm{T}$ ' followed by the centre to centre spacing of the stirrups.

An example of a specimen designation is 975-F1-T244. This beam has a tensile lap splice length of $975 \mathrm{~mm}$, it is the first (1) fatigue (F) test to be performed, and closed transverse stirrups (T) are spaced at $244 \mathrm{~mm}$ on centre along the splice length. 


\subsection{Properties of the Test Specimen:}

Ten specimens with a length of seven meters and a cross section $330 \mathrm{~mm}$ wide by $508 \mathrm{~mm}$ deep were tested (see Fig. 3.1). The main reinforcement within the beams consisted of two longitudinal No. 30, Grade 400 bars, along both the top and bottom faces of each beam. The top compression bars, continuous throughout the length of each beam, were provided to prevent failure of the compressive zone during testing and, at the same time, hold the specimen together after failure of the lap splice. The two tensile reinforcement bars were both spliced at the same location in the beam and the splices were centered at the mid-span of the beam. The tensile lap splice length and confinement were designed according to the recommendations reported by the ACI Committee 408 (see Appendix A). The spacing and the concrete cover of the longitudinal bars, shown in Fig. 3.1, were designed to allow the tensile reinforcement to yield before failure of the lap splice under static load conditions. The spliced region was confined by No. 10, Grade 400 , closed vertical stirrups. The two different beam configurations designed for testing had the following details:

1) Nominally confined with transverse reinforcement at a centre to centre spacing of approximately half the effective beam depth (d/2); a $975 \mathrm{~mm}$ lap length with either 5 transverse stirrups at $195 \mathrm{~mm}$ o.c. or 4 transverse stirrups at $244 \mathrm{~mm}$ o.c.

2) Heavily confined with transverse reinforcement based on the maximum amount deemed effective for a static load condition; a $900 \mathrm{~mm}$ lap length with 7 transverse stirrups at $129 \mathrm{~mm}$ o.c..

A view of a reinforcing cage along the length of a lap nominally confined with stirrups, is shown in Fig. 3.2. Waterproofing material which protects the electrical resistance strain 


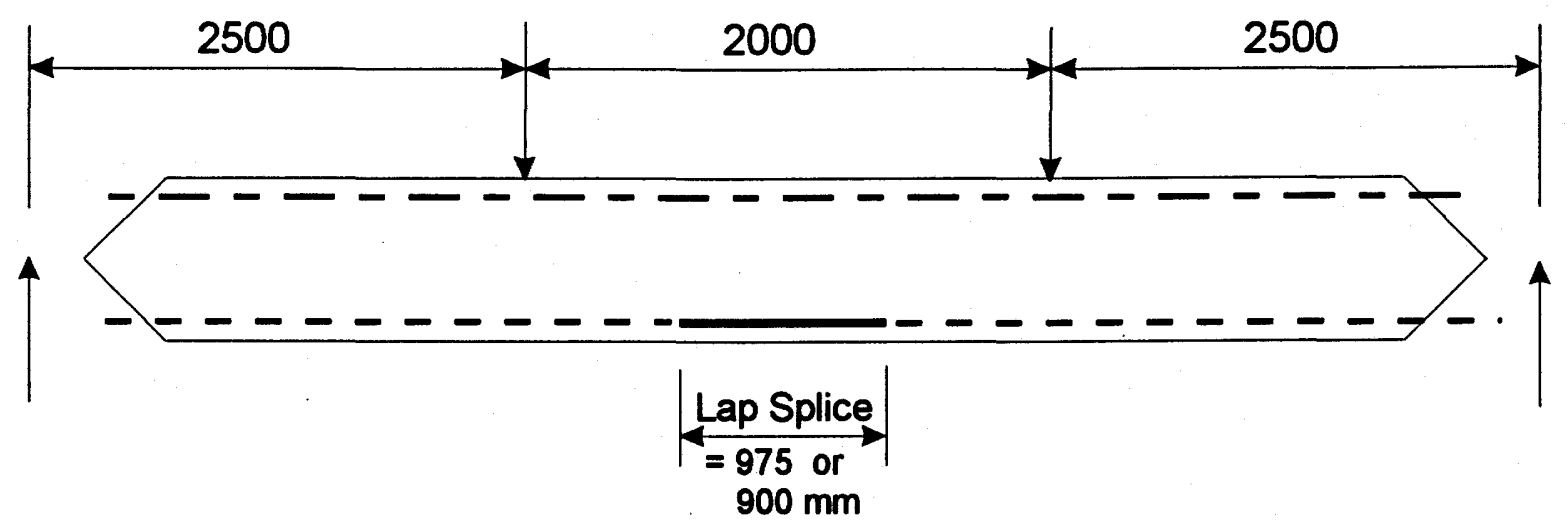

a) Elevation

b) Cross Section

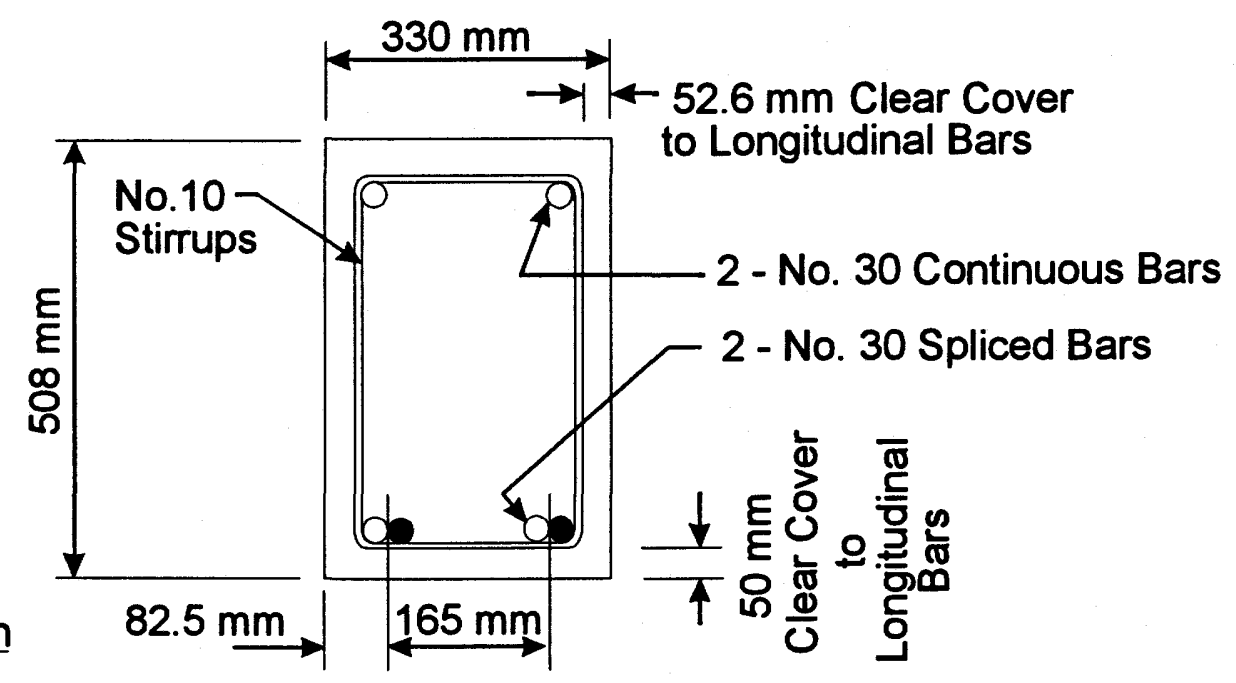

$(+)$

c) Shear Diagram (excluding self-weight)

\section{$(-)$}

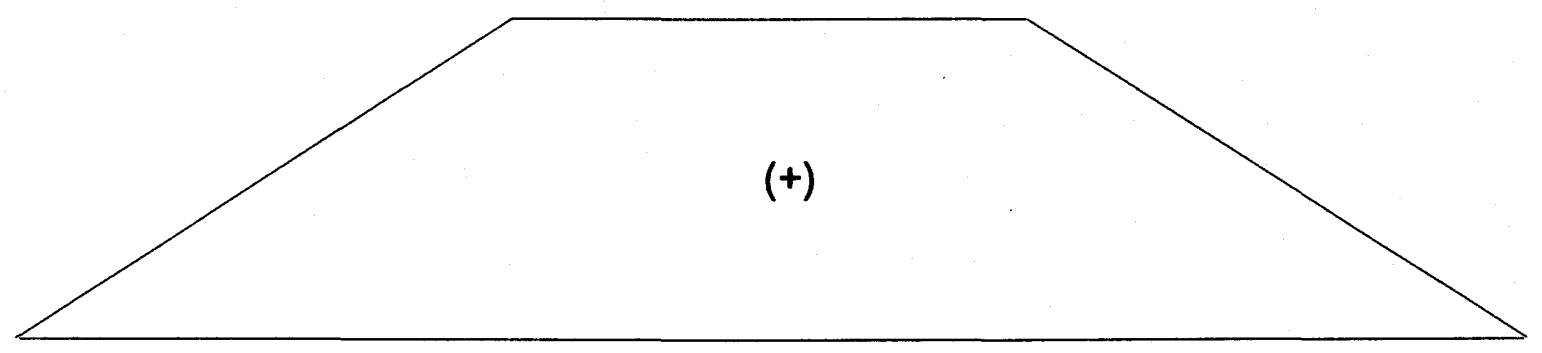

d) Moment Diagram (excluding self-weight)

Figure 3.1. Specimen Details and Loading Arrangement. 


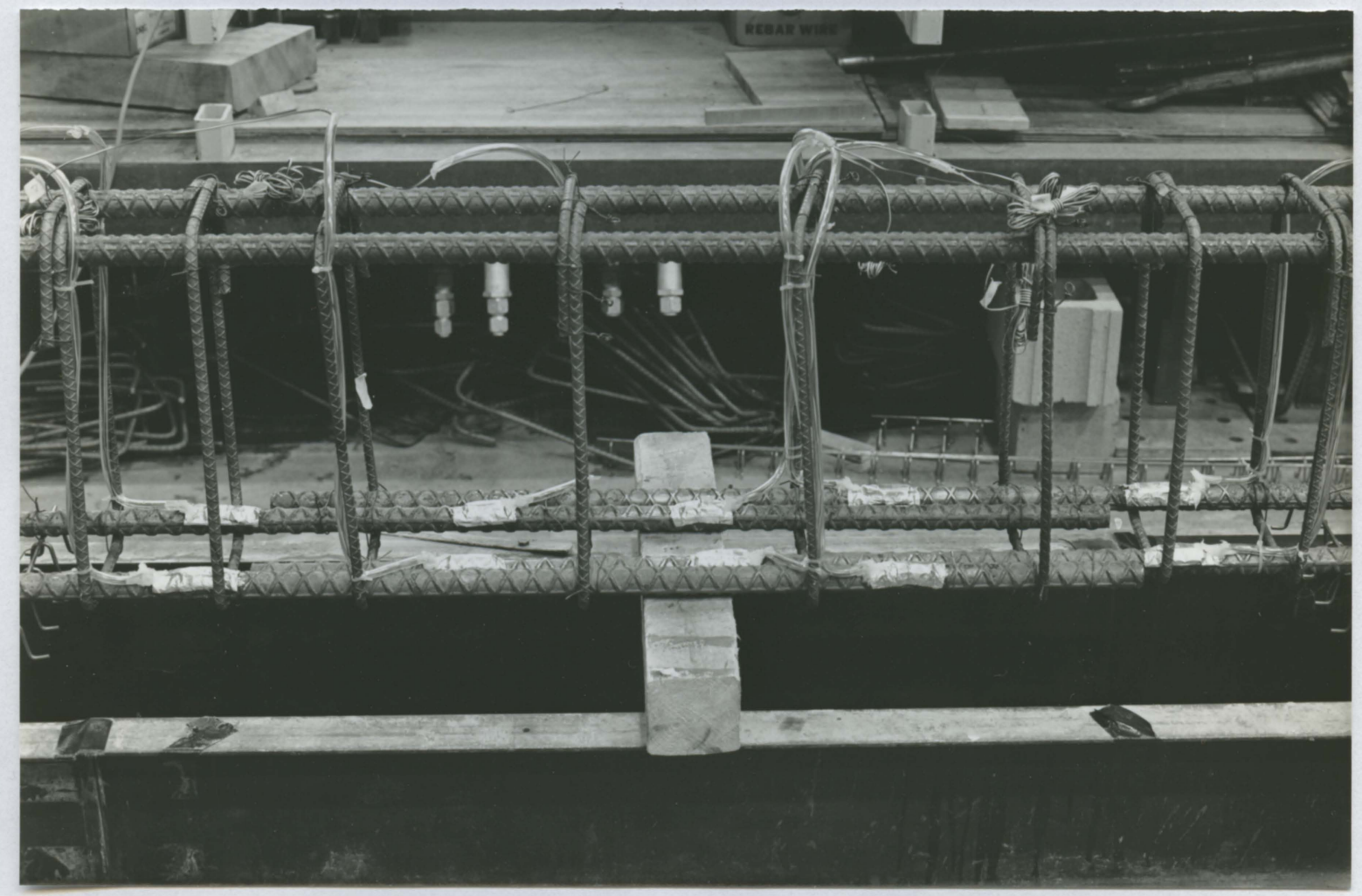

Figure 3.2. Lap Splice of Specimen 975-F8-244.

gauges is also visible.

The transverse reinforcement outside the splice zone was designed to prevent any shear failure under the load range being applied to the specimen during testing. The stirrups were spaced at a distance of $150 \mathrm{~mm}$ on centre.

It was expected that the static strength of the two different designs should be the same, however the fatigue performance for each was anticipated to be different.

\subsection{Instrumentation and Testing Procedures:}

Each specimen was held on hinged supports that were specially designed to model a theoretical simply supported end condition, thus eliminating any end moments and any 
significant axial loads within the beams. Point loads were applied to the specimen symmetrically, one meter on either side of the mid-span of the beam, by two, $500 \mathrm{kN}$ capacity, hydraulic actuators of a Material Testing System (MTS). The hydraulic rams were both regulated by a single control unit to assure a synchronized loading pattern. The combination of symmetrical loading, special support conditions and proportioning of the beam, created a zone of constant moment and zero shear between the point loads (see Fig. 3.1). It is within this isolated zone that the tensile lap splices were situated and therefore could be investigated under a controlled condition. Only the constant moment (zero shear) loading condition was investigated in this study. For static loading, this condition has been shown to represent the most serious case because both ends of the splice are stressed at the same value (Ferguson and Briceno 1969).

The dead load of the beam added an initial moment into the specimen. To include this effect directly, the parabolic moment curve caused by the self-weight could be approximated by two symmetrical point loads applied by the hydraulic rams of the MTS, and equal to $9.5 \mathrm{kN}$ each. By lifting up on the beam with these forces, the dead load moment is, in effect, removed from the specimen. The MTS control unit could then be set for an initial load and deflection of zero. Subsequently, the applied load which was recorded would then include the dead load of the beam.

One beam of the ten specimens tested, 975-ST1-T244, was failed by a static load to provide a basis for estimating the static strength of the other specimens failed by fatigue. The beam was loaded with monotonically increasing load increments until static failure of the lap splice occurred. For the remaining beams tested under fatigue conditions, the cyclic loads applied were sinusoidal in nature with constant values of the period and load range, which produced the maximum and minimum stresses in the tensile reinforcement 
of each specimen. The values used were as follows:

- Period $=0.33 \mathrm{~Hz}$;

- Maximum Stress $=75 \%$ of the measured tensile reinforcement yield strength;

- Minimum Stress $=25 \%$ of the measured tensile reinforcement yield strength.

The selection of these values was influenced by the loading limitations of the MTS when using dynamic conditions, as well as time constraints on the test program.

There were three (3) different measuring devices used in collecting data during testing of each specimen. To measure the strains that developed in the reinforcing steel during testing, a number of strain gauges were used within the lap splice area of some of the beams. The strain gauges were placed along the main tensile reinforcement and on the legs of the confining stirrups, all within the lap splice length. Two different types of gauges were put to use on four of the ten specimens tested. Two specimens, 975-F1-T244 and 975-F2-T244, were provided with FAE-25-12 S9 type strain gauges which had a gauge length of $6.35 \mathrm{~mm}, 120 \mathrm{ohm}(\Omega)$ resistance and a gauge factor of approximately 2.0. These gauges developed problems that resulted in the majority of them failing electrically prior to or during testing of the specimen; however, it is not known why these problems occurred. Each of the gauges was protected according to manufacturer's recommendations from mechanical damage and moisture. To waterproof them, each gauge was covered with a layer of butyl rubber. A piece of neoprene was then laid over each gauge to protect it from being damaged by the concrete. Finally, a piece of foil was taped over each gauge. Two other beams, 975-F8-T244 and 900-F9-T129, were supplied with WK-06-250BG-350 type strain gauges which had a resistance of 350 $\operatorname{ohm}(\Omega)$ and a gauge factor of approximately 2.03 . The damage and moisture protection was significantly lessened for these gauges in an attempt to reduce any detrimental effect 
it might have on the bond of the lap splices. The layout of the strain gauges for specimen 900-F9-T129 is shown in Fig. 3.3. Appendix E describes the strain gauge layout for the remaining specimens. Unfortunately, no meaningful data was obtained from the strain gauges because of premature failures and extreme noise in the signals recorded.

To measure the progressive change in the displacement of the beams, four SE 380/150 AC/AC Linear Variable Displacement Transducers (LVDT) were used on all the specimens. The LVDT's had a sensitivity of $3.54 \mathrm{mV} / \mathrm{V} / \mathrm{mm}$ and a calibrated travel of $\pm 150 \mathrm{~mm}$. The LVDT's were placed as shown in Fig. 3.3 in an attempt to obtain data on the curvature of the beam just outside the lap splice, and thus demonstrate the progressive softening effect of the concrete within the maximum moment region as cycling continued.

At both load points (Fig. 3.3), a $500 \mathrm{kN}$ load cell was built into the hydraulic actuators of the MTS system. They were used to measure the load being applied to the specimen at any point in time.

All of these instruments of measurement were connected to a data acquisition system, the Megadac 2000c. The system was adjusted to record the data from each instrument at a sampling rate of the 25 samples per second. To ensure that the data at failure was recorded, the system was set to begin recording once a preset deflection was reached. Readings were also recorded periodically throughout the test period to provide information on the progressive change of the beam curvature and the strain pattern along the spliced reinforcing bars. 

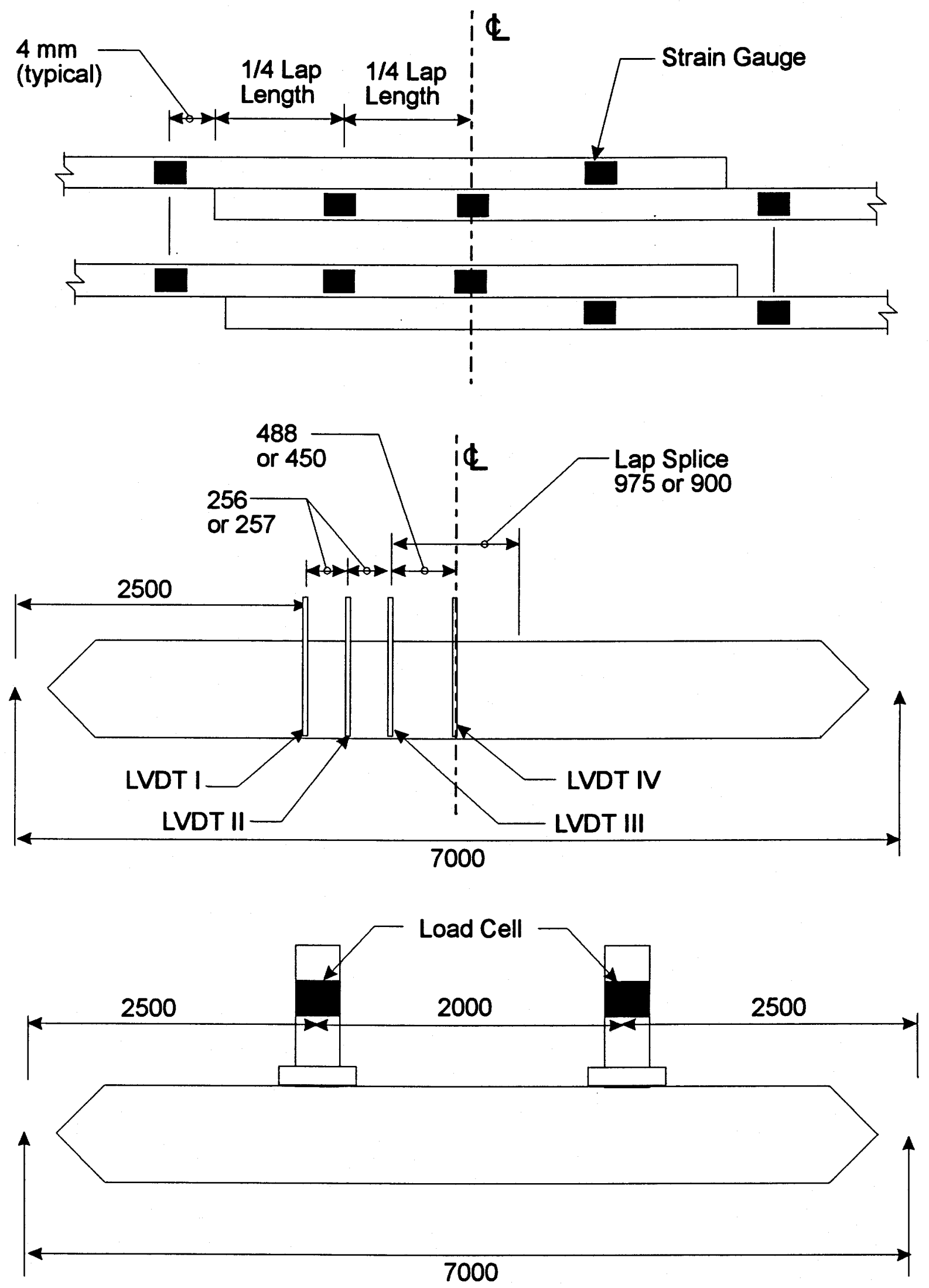

Figure 3.3. Instrumentation Layout. 


\title{
3.4 Concrete Properties:
}

The concrete used in this study was specified to have the same properties as the concrete used by Zacaruk (1990) in similar studies previously completed at the University of Saskatchewan. The resulting properties for each specimen are listed in Table 3.1.

\begin{abstract}
A local ready mix concrete supplier was used to prepare and deliver the concrete to the laboratory for pouring of the test specimens. The same plant was used for each pour in an attempt to obtain a consistency in the concrete properties. The concrete parameters which the plant was requested to provide are as follows:
\end{abstract}

- Cement Type: Portland-Normal Type 10;

- Compressive Strength $=30 \mathrm{MPa}$ at 28 days;

- Air Entertainment $=6 \% \pm 1 \%$;

- Slump $=75$ to $100 \mathrm{~mm}$.

The plant was also instructed not to add any other admixtures or cement replacements to the mix. A typical mix design for the concrete is listed in Appendix F.

The concrete strength at the start of the testing for some of the beams was not equal to the value of $30 \mathrm{MPa}$ that was targeted. This inaccuracy may be a fault of the ready-mix plant not providing the correct strength. Another reason, which might explain the specimens with high strengths, is that two beams were poured simultaneously. Since only one specimen may be tested at one time and the testing periods for some of these beams extended over weeks, the second specimen's strength had plenty of time to rise above the specified value of $30 \mathrm{MPa}$. 
Table 3.1. Concrete Properties.

\begin{tabular}{cccccccc}
$\begin{array}{c}\text { Beam } \\
\text { Description }\end{array}$ & $\begin{array}{c}\text { Date } \\
\text { Poured }\end{array}$ & $t_{1}$ & $t_{2}$ & $\mathbf{f}_{c 1}$ & $\mathbf{f}_{c 2}$ & $\begin{array}{c}\text { Slump } \\
(\mathbf{m m})\end{array}$ & $\begin{array}{c}\text { Air Content } \\
(\%)\end{array}$ \\
\hline $975-S T 1-T 244$ & $12 / 13 / 88$ & 41 & 41 & 28.2 & 28.2 & 100 & 7.00 \\
$975-F 1-T 244 *$ & $9 / 20 / 88$ & - & - & - & - & - & - \\
$975-F 2-T 244$ & $9 / 20 / 88$ & 55 & 55 & 30.0 & 30.0 & 100 & 5.00 \\
$975-F 3-T 244$ & $12 / 13 / 88$ & 30 & 30 & 25.7 & 25.7 & 100 & 7.00 \\
$900-F 4-T 129$ & $2 / 9 / 89$ & 32 & 46 & 33.9 & 36.9 & 90 & 6.25 \\
$975-F 5-T 244$ & $2 / 9 / 89$ & 49 & 60 & 37.4 & 38.8 & 90 & 6.25 \\
$975-F 6-T 195$ & $3 / 7 / 89$ & 36 & 38 & 24.8 & 25.1 & 115 & 5.80 \\
$975-F 7-T 195$ & $3 / 7 / 89$ & 41 & 42 & 25.7 & 25.8 & 115 & 5.80 \\
$975-F 8-T 244$ & $4 / 24 / 89$ & 31 & 33 & 30.4 & 30.4 & 100 & 5.10 \\
$900-F 9-T 129$ & $4 / 24 / 89$ & 49 & 69 & 31.8 & 34.0 & 100 & 5.10 \\
\hline
\end{tabular}

$\mathrm{f}_{\mathrm{c1}}=$ compressive strength from $150 \mathrm{~mm} \times 300 \mathrm{~mm}$ cylinders at start of testing (MPa)

$f_{c 2}=$ compressive strength from $150 \mathrm{~mm} \times 300 \mathrm{~mm}$ cylinders at end of testing (MPa)

$t_{1}=$ age of concrete at start of test (days)

$t_{2}=$ age of concrete at end of test (days)

* specimen disregarded due to accidental failure

The beams were constructed using metal forms treated with form oil. The concrete was poured in two separately vibrated layers with the top surface of the beams screeded and then covered with polyethylene sheets. The beams were removed from the forms seven days after pouring and set to air cure in the laboratory at $20^{\circ} \mathrm{C}$ for at least 21 days.

For each test specimen, 16 test cylinders $150 \mathrm{~mm} \times 300 \mathrm{~mm}$ were cast. The cylindrical specimens were used to determine the compressive strength of the concrete. The cylinders were water cured for seven days at which time they were removed, and covered with polyethylene to air cure next to the "stripped" test specimen. Two cylinders were tested at 7 days and two more at 21 days after the pour, with the remainder of the cylinders being tested at the beginning and end of each test. 
Table 3.2. Reinforcing Steel Properties.

\begin{tabular}{ccccccc} 
& & & & \multicolumn{2}{c}{$\%$ Elongation } \\
\cline { 6 - 7 } Batch & $f_{y}$ & $f_{u}$ & $E$ & $50 \mathrm{~mm}$ Gauge & $200 \mathrm{~mm}$ Gauge \\
\hline 1 & 459 & 678 & 207000 & 16 & 14 \\
2 & 464 & 684 & 202000 & 19 & 15 \\
\hline
\end{tabular}

$f_{y}=$ measured yield strength as determined from coupon tension test (MPa)

$f_{u}=$ measured ultimate strength as determined from coupon tension test (MPa)

$\mathrm{E}=$ Modulus of Elasticity (MPa)

\subsection{Reinforcing Steel Properties:}

The longitudinal reinforcement used for this program was a No. 30 , Grade 400 , steel deformed reinforcing bar. The first batch was the reinforcement remaining in the laboratory from a previous experimental program (Zacaruk 1990) completed at the University of Saskatchewan, and was used in the first 8 beams. The second batch of steel was ordered from a local steel supplier and was used as the reinforcement for the last two specimens tested. The closed transverse stirrups were No. 10, Grade 400 deformed bars and were ordered from the same local steel supplier as the longitudinal steel.

Coupons were cut from each batch of longitudinal steel and tensile tests were performed to determine their tensile properties. Table 3.2 lists the results from these tests. Fig. 3.4 and 3.5 are plots of the stress-strain diagrams for both batches of steel.

A coupon tensile test was also performed on the stirrups used along the lap splice of the specimens. The yield strength of the stirrups was determined from the test as $431 \mathrm{MPa}$. 


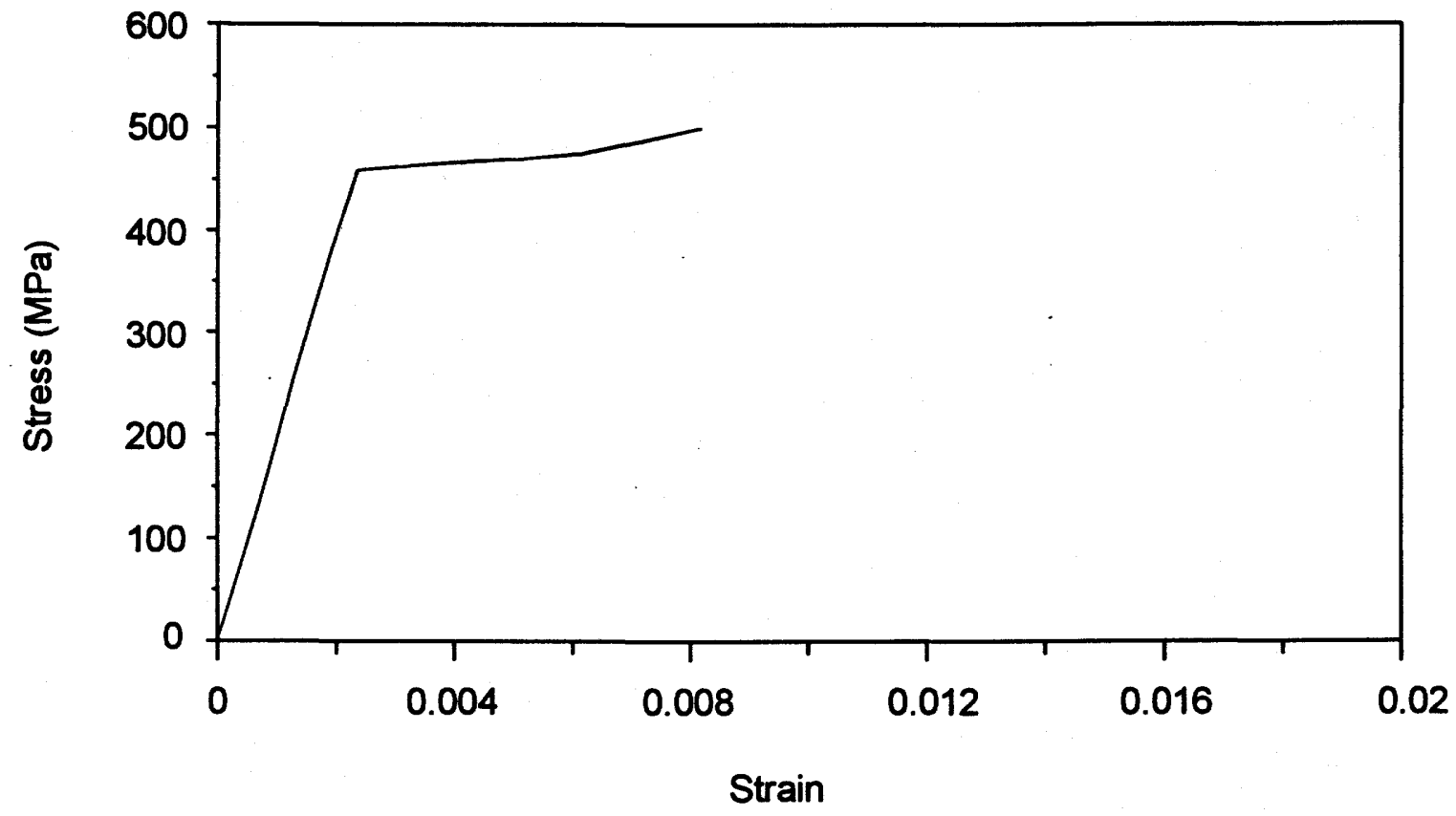

Figure 3.4. Stress - Strain Diagram for Tensile Reinforcement Batch \#1.

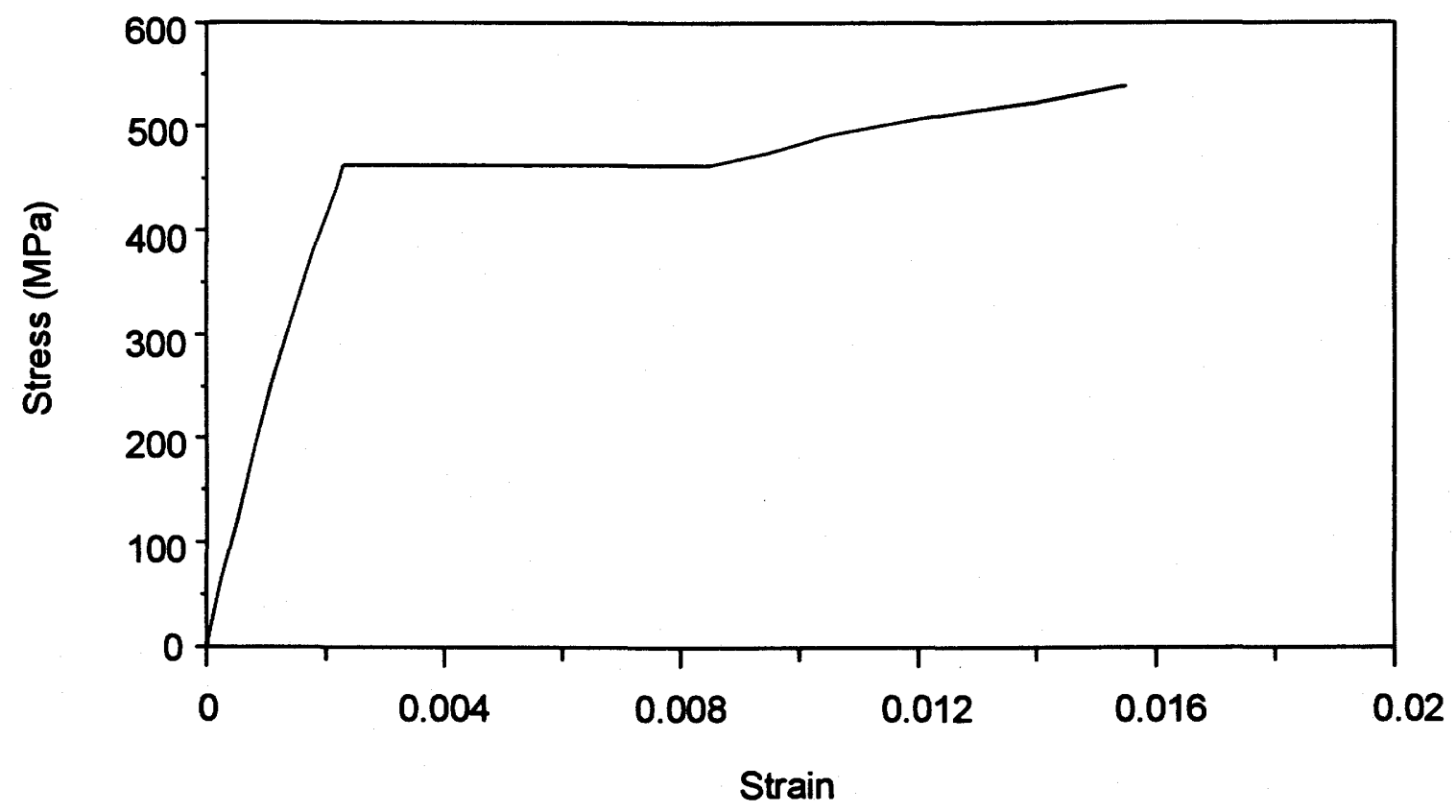

Figure 3.5. Stress - Strain Diagram for Tensile Reinforcement Batch \#2. 


\section{TEST RESULTS}

\subsection{Overview of Test Results:}

The test results for this program and a summary of the material properties are listed in Tables 4.1 and 4.2. The tables include three series of data. Series $A$ is the data resulting from the current testing program. Series B represents the test results obtained from another M.Sc. program previously completed at the University of Saskatchewan (Zacaruk, 1990) of which the current study is an extension. In addition, a third series of data from Tepfers' (1973) study of lap splice fatigue, is presented to increase the data base to include beams without transverse reinforcement.

The reinforcing steel stresses during testing, $\sigma_{\mathrm{s}}$, were obtained from the applied loading, using a computer program (Tsui and Rezansoff 1982) that provides a sectional analysis of a specimen's cross section at the maximum moment location by employing moment curvature principles and actual material properties. Moment arms as obtained from the computer program varied between realistic values of 0.91 and 0.93 of the effective depth for these moderately reinforced beams (reinforcing ratio $\rho=0.00983$ ).

To provide the necessary data for a typical S-N curve that is the traditional means of presenting test results from fatigue studies, the performance of all specimens were compared with two static strength reference bases. The most suitable reference depended on the mode of failure of the specimen. For those specimens for which failure 
Table 4.1. Test Data Based on Static Strength.

\begin{tabular}{|c|c|c|c|c|c|c|c|c|c|c|c|c|c|c|}
\hline \multirow[b]{2}{*}{ Series } & \multirow[b]{2}{*}{ Specimen } & \multicolumn{2}{|c|}{$\sigma_{8}$} & \multicolumn{2}{|c|}{ \% Resistance } & \multirow[b]{2}{*}{$f_{c}^{\prime}$} & \multirow[b]{2}{*}{$\sigma_{\text {static }}$} & \multicolumn{3}{|c|}{$\sigma_{s} / \sigma_{\text {static }} \%$} & \multirow[b]{2}{*}{$\mathbf{R}$} & \multirow[b]{2}{*}{$\mathbf{N}$} & \multirow[b]{2}{*}{$\log (N)$} & \multirow{2}{*}{$\begin{array}{c}\text { Failure } \\
\text { Mode }\end{array}$} \\
\hline & & $\max$ & $\min$ & stirr. & conc. & & & $\max$ & $\min$ & $\max -\min$ & & & & \\
\hline \multirow[t]{9}{*}{ A } & 975-ST1-T244 & 462 & 0 & 20.6 & 79.4 & 28.2 & - & 100.0 & 0.0 & 100.0 & 0.00 & 1 & 0.00 & Bond \\
\hline & 975-F2-T244 & 347 & 114 & 20.6 & 79.4 & 30.0 & 477 & 72.7 & 24.0 & 48.7 & 0.33 & 720 & 2.86 & Bond \\
\hline & 975-F3-T244 & 340 & 120 & 20.6 & 79.4 & 25.7 & 441 & 77.1 & 27.3 & 49.9 & 0.35 & 6600 & 3.82 & Bond \\
\hline & 900-F4-T129 & 346 & 113 & 32.9 & 67.1 & 33.9 & 553 & 62.5 & 20.3 & 42.1 & 0.33 & 334000 & 5.52 & Steel \\
\hline & 975-F5-T244 & 345 & 112 & 20.6 & 79.4 & 37.4 & 532 & 64.8 & 21.0 & 43.8 & 0.32 & 250000 & 5.40 & Steel \\
\hline & 975-F6-T195 & 349 & 115 & 24.5 & 75.5 & 24.8 & 455 & 76.6 & 25.3 & 51.3 & 0.33 & 49000 & 4.69 & Bond \\
\hline & 975-F7-T195 & 348 & 115 & 24.5 & 75.5 & 25.7 & 463 & 75.2 & 24.9 & 50.3 & 0.33 & 12000 & 4.08 & Bond \\
\hline & 975-F8-T244 & 348 & 115 & 20.6 & 79.4 & 30.4 & 480 & 72.5 & 24.0 & 48.5 & 0.33 & 46000 & 4.66 & Bond \\
\hline & 900-F9-T129 & 347 & 115 & 32.9 & 67.1 & 31.8 & 535 & 64.9 & 21.5 & 43.4 & 0.33 & 385000 & 5.59 & Steel \\
\hline \multirow[t]{9}{*}{ B } & 900-ST1-T129 & 473 & 0 & 32.9 & 67.1 & 36.0 & - & 100.0 & 0.0 & 100.0 & 0.00 & 1 & 0.00 & Bond \\
\hline & 900-F1-T129 & 355 & 114 & 32.9 & 67.1 & 35.9 & 473 & 75.1 & 24.2 & 50.9 & 0.32 & 196000 & 5.29 & Steel \\
\hline & 900-F2-T129 & 302 & 115 & 32.9 & 67.1 & 30.5 & 436 & 69.3 & 26.4 & 43.0 & 0.38 & 550000 & 5.74 & Steel \\
\hline & 900-F3-T129 & 245 & 72 & 32.9 & 67.1 & 31.2 & 441 & 55.5 & 16.3 & 39.2 & 0.29 & 838000 & 5.92 & Steel \\
\hline & $900-F 4 S-T 129$ & 189 & 49 & 32.9 & 67.1 & 38.3 & 488 & 38.8 & 10.0 & 28.8 & 0.26 & 3000000 & 6.48 & \\
\hline & & 520 & 0 & 32.9 & 67.1 & 40.5 & 502 & 103.6 & 0.0 & 103.6 & 0.00 & 1 & 0.00 & Flex \\
\hline & $900-F 5-T 129$ & 361 & 195 & 32.9 & 67.1 & 40.6 & 503 & 71.9 & 38.7 & 33.2 & 0.54 & 720000 & 5.86 & Steel \\
\hline & $900-F 6-T 129$ & 354 & 115 & 32.9 & 67.1 & 43.8 & 522 & 67.7 & 22.1 & 45.7 & 0.33 & 230000 & 5.36 & Steel \\
\hline & F1-CONT & 355 & 113 & 32.9 & 67.1 & 42.0 & 511 & 69.4 & 22.1 & 47.2 & 0.32 & 235000 & 5.37 & Steel \\
\hline
\end{tabular}

$\sigma_{\mathbf{s}}=$ stress in tensile reinforcement of specimen at maximum moment location; splice failure strength for static reference specimens (MPa) $\%$ Resistance = splice (bond) strength developed by confining stirrups and by concrete, based on $\mathrm{ACl} 408$ model

$f_{c}^{\prime}=$ compressive strength of concrete from $150 \mathrm{~mm} \times 300 \mathrm{~mm}$ cylinders (MPa)

$\sigma_{\text {static }}=$ stress in tensile reinforcement for predicted static lap splice strength of specimen based on results of the series static test (MPa)

$R=$ ratio of minimum $\sigma_{s}$ to maximum $\sigma_{s}$ during load cycle

$N=$ number of load cycles 
Table 4.1. Test Data Based on Static Strength (cont'd).

\begin{tabular}{|c|c|c|c|c|c|c|c|c|c|c|c|c|c|c|}
\hline \multirow[b]{2}{*}{ Series } & \multirow[b]{2}{*}{ Specimen } & \multicolumn{2}{|c|}{$\sigma_{s}$} & \multicolumn{2}{|c|}{ \% Resistance } & \multirow{2}{*}{$f_{c}^{\prime}$} & \multirow[b]{2}{*}{$\sigma_{\text {static }}$} & \multicolumn{3}{|c|}{$\sigma_{s} / \sigma_{\text {static }} \%$} & \multirow[b]{2}{*}{$\mathbf{R}$} & \multirow[b]{2}{*}{$\mathbf{N}$} & \multirow[b]{2}{*}{$\log (N)$} & \multirow{2}{*}{$\begin{array}{l}\text { Failure } \\
\text { Mode }\end{array}$} \\
\hline & & $\max$ & $\min$ & stirr. & conc. & & & $\overline{\max }$ & $\min$ & $\max -\min$ & & & & \\
\hline Tepfers & $732-23$ & 393 & 107 & 0.0 & 100.0 & 31.6 & 451 & 87.1 & 23.7 & 63.4 & 0.27 & 703 & 2.85 & Bond \\
\hline \multirow[t]{20}{*}{ (1973) } & $732-25$ & 371 & 148 & 0.0 & 100.0 & 31.6 & 412 & 90.0 & 35.9 & 54.1 & 0.40 & 5524 & 3.74 & Bond \\
\hline & $732-26$ & 376 & 159 & 0.0 & 100.0 & 31.6 & 491 & 76.6 & 32.4 & 44.2 & 0.42 & 246895 & 5.39 & Bond \\
\hline & $732-27$ & 373 & 158 & 0.0 & 100.0 & 32.7 & 539 & 69.2 & 29.3 & 39.9 & 0.42 & 76553 & 4.88 & Bond \\
\hline & $732-33$ & 301 & 130 & 0.0 & 100.0 & 29.9 & 496 & 60.7 & 26.2 & 34.5 & 0.43 & 46510 & 4.67 & Bond \\
\hline & 732-79 & 371 & 58 & 0.0 & 100.0 & 38.4 & 433 & 85.7 & 13.3 & 72.3 & 0.16 & 117743 & 5.07 & Bond \\
\hline & $732-81$ & 409 & 172 & 0.0 & 100.0 & 43.0 & 733 & 55.8 & 23.5 & 32.4 & 0.42 & 29720 & 4.47 & Bond \\
\hline & $732-82$ & 371 & 173 & 0.0 & 100.0 & 37.7 & 643 & 57.7 & 26.9 & 30.7 & 0.47 & 82953 & 4.92 & Bond \\
\hline & $732-83$ & 371 & 173 & 0.0 & 100.0 & 40.2 & 620 & 59.8 & 27.9 & 31.9 & 0.47 & 7145330 & 6.85 & Bond \\
\hline & 732-91 & 450 & 172 & 0.0 & 100.0 & 46.2 & 664 & 67.7 & 25.9 & 41.9 & 0.38 & 13320 & 4.12 & Bond \\
\hline & $732-92$ & 430 & 172 & 0.0 & 100.0 & 42.0 & 611 & 70.3 & 28.1 & 42.2 & 0.40 & 79090 & 4.90 & Bond \\
\hline & $732-93$ & 450 & 172 & 0.0 & 100.0 & 44.3 & 627 & 71.7 & 27.4 & 44.3 & 0.38 & 350 & 2.54 & Bond \\
\hline & $732-94$ & 432 & 173 & 0.0 & 100.0 & 43.2 & 642 & 67.2 & 26.9 & 40.3 & 0.40 & 520 & 2.72 & Bond \\
\hline & $732-95$ & 417 & 175 & 0.0 & 100.0 & 44.3 & 604 & 69.0 & 29.0 & 40.0 & 0.42 & 21970 & 4.34 & Bond \\
\hline & $732-96$ & 394 & 174 & 0.0 & 100.0 & 41.9 & 610 & 64.6 & 28.5 & 36.0 & 0.44 & 45610 & 4.66 & Bond \\
\hline & $732-97$ & 246 & 89 & 0.0 & 100.0 & 15.3 & 410 & 60.1 & 21.7 & 38.4 & 0.36 & 1250 & 3.10 & Bond \\
\hline & $732-99$ & 432 & 155 & 0.0 & 100.0 & 50.5 & 719 & 60.1 & 21.5 & 38.6 & 0.36 & 45960 & 4.66 & Bond \\
\hline & $732-162$ & 443 & 159 & 0.0 & 100.0 & 45.6 & 613 & 72.3 & 25.9 & 46.4 & 0.36 & 1680 & 3.23 & Bond \\
\hline & $732-164$ & 440 & 157 & 0.0 & 100.0 & 77.6 & 800 & 55.0 & 19.6 & 35.4 & 0.36 & 376520 & 5.58 & Steel \\
\hline & $732-165$ & 440 & 157 & 0.0 & 100.0 & 85.1 & 708 & 62.1 & 22.2 & 39.9 & 0.36 & 246890 & 5.39 & Bond \\
\hline & $732-166$ & 440 & 157 & 0.0 & 100.0 & 87.3 & 848 & 51.9 & 18.5 & 33.4 & 0.36 & 8920 & 3.95 & Bond \\
\hline
\end{tabular}

$\sigma_{\mathbf{3}}=$ stress in tensile reinforcement of specimen at maximum moment location; splice failure strength for static reference specimens (MPa) $\%$ Resistance $=$ splice (bond) strength developed by confining stimups and by concrete, based on $\mathrm{ACl} 408$ model

$f_{c}^{\prime}=$ compressive strength of concrete from $150 \mathrm{~mm} \times 300 \mathrm{~mm}$ cylinders (MPa)

$\sigma_{\text {static }}=$ stress in tensile reinforcement for predicted static lap splice strength of specimen based on results of the series static test (MPa)

$R=$ ratio of minimum $\sigma_{s}$ to maximum $\sigma_{s}$ during load cycle

$\mathrm{N}=$ number of load cycles 
Table 4.2. Load Data Based on Steel Strength.

\begin{tabular}{|c|c|c|c|c|c|c|c|c|c|c|c|}
\hline & \multirow[b]{2}{*}{ Specimen } & \multicolumn{2}{|c|}{$\sigma_{8}$} & \multirow[b]{2}{*}{$f_{y}$} & \multicolumn{2}{|c|}{$\sigma_{s} / f_{y}$} & $(\%)$ & \multirow[b]{2}{*}{$\mathbf{R}$} & \multirow[b]{2}{*}{$\mathbf{N}$} & \multirow[b]{2}{*}{$\log (N)$} & \multirow{2}{*}{$\begin{array}{l}\text { Failure } \\
\text { Mode }\end{array}$} \\
\hline Series & & $\max$ & $\min$ & & $\max$ & $\min$ & max-min & & & & \\
\hline A & 975-ST1-T244 & 462 & 0 & 459 & 100.7 & 0.0 & 100.7 & 0.00 & 1 & 0.00 & Bond \\
\hline & 975-F2-T244 & 347 & 114 & 459 & 75.5 & 24.9 & 50.6 & 0.33 & 720 & 2.86 & Bond \\
\hline & 975-F3-T244 & 340 & 120 & 459 & 74.1 & 26.2 & 47.9 & 0.35 & 6600 & 3.82 & Bond \\
\hline & $900-F 4-T 129$ & 346 & 113 & 459 & 75.3 & 24.5 & 50.8 & 0.33 & 334000 & 5.52 & Steel \\
\hline & 975-F5-T244 & 345 & 112 & 459 & 75.1 & 24.3 & 50.8 & 0.32 & 250000 & 5.40 & Steel \\
\hline & 975-F6-T195 & 349 & 115 & 459 & 76.0 & 25.1 & 50.8 & 0.33 & 49000 & 4.69 & Bond \\
\hline & 975-F7-T195 & 348 & 115 & 459 & 75.9 & 25.1 & 50.8 & 0.33 & 12000 & 4.08 & Bond \\
\hline & 975-F8-T244 & 348 & 115 & 464 & 75.0 & 24.8 & 50.1 & 0.33 & 46000 & 4.66 & Bond \\
\hline & 900-F9-T129 & 347 & 115 & 464 & 74.8 & 24.8 & 50.1 & 0.33 & 385000 & 5.59 & Steel \\
\hline \multirow[t]{9}{*}{ B } & 900-ST1-T129 & 473 & 0 & 463 & 102.2 & 0.0 & 102.2 & 0.00 & 1 & 0.00 & Bond \\
\hline & $900-F 1-T 129$ & 355 & 114 & 463 & 76.7 & 24.7 & 52.0 & 0.32 & 196000 & 5.29 & Steel \\
\hline & 900-F2-T129 & 302 & 115 & 463 & 65.2 & 24.8 & 40.4 & 0.38 & 550000 & 5.74 & Steel \\
\hline & $900-F 3-T 129$ & 245 & 72 & 463 & 52.8 & 15.5 & 37.3 & 0.29 & 838000 & 5.92 & Steel \\
\hline & 900-F4S-T129 & 189 & 49 & 463 & 40.9 & 10.5 & 30.4 & 0.26 & 3000000 & 6.48 & \\
\hline & & 520 & 0 & 463 & 112.3 & 0.0 & 112.3 & 0.00 & 1 & 0.00 & Flex. \\
\hline & 900-F5-T129 & 361 & 195 & 463 & 78.0 & 42.0 & 36.0 & 0.54 & 720000 & 5.86 & Steel \\
\hline & $900-F 6-T 129$ & 354 & 115 & 464 & 76.2 & 24.8 & 51.4 & 0.33 & 230000 & 5.36 & Steel \\
\hline & F1-CONT & 355 & 113 & 464 & 76.4 & 24.4 & 52.0 & 0.32 & 235000 & 5.37 & Steel \\
\hline
\end{tabular}

$\sigma_{s}=$ stress in tensile reinforcement at maximum moment location (MPa)

$f_{y}=$ measured yield strength in tensile reinforcement (MPa)

$\mathrm{R}=$ ratio of minimum $\sigma_{\mathrm{s}}$ to maximum $\sigma_{\mathrm{s}}$ during load cycle

$N=$ number of load cycles to failure 
Table 4.2. Load Data Based on Steel Strength (cont'd).

\begin{tabular}{|c|c|c|c|c|c|c|c|c|c|c|c|}
\hline \multirow[b]{2}{*}{ Series } & \multirow[b]{2}{*}{ Specimen } & \multicolumn{2}{|c|}{$\sigma_{s}$} & \multirow[b]{2}{*}{$f_{y}$} & \multicolumn{3}{|c|}{$\sigma_{s} / f_{y} \quad(\%)$} & \multirow[b]{2}{*}{$\mathbf{R}$} & \multirow[b]{2}{*}{$\mathbf{N}$} & \multirow[b]{2}{*}{$\log (N)$} & \multirow{2}{*}{$\begin{array}{l}\text { Failure } \\
\text { Mode }\end{array}$} \\
\hline & & $\overline{\max }$ & $\min$ & & $\max$ & $\min$ & $\max -\min$ & & & & \\
\hline Tepfers & $732-23$ & 393 & 107 & 637 & 61.7 & 16.8 & 44.9 & 0.27 & 703 & 2.85 & Bond \\
\hline \multirow[t]{20}{*}{ (1973) } & $732-25$ & 371 & 148 & 632 & 58.7 & 23.4 & 35.3 & 0.40 & 5524 & 3.74 & Bond \\
\hline & $732-26$ & 376 & 159 & 621 & 60.6 & 25.6 & 34.9 & 0.42 & 246895 & 5.39 & Bond \\
\hline & $732-27$ & 373 & 158 & 621 & 60.1 & 25.4 & 34.6 & 0.42 & 76553 & 4.88 & Bond \\
\hline & $732-33$ & 301 & 130 & 600 & 50.2 & 21.7 & 28.5 & 0.43 & 46510 & 4.67 & Bond \\
\hline & $732-79$ & 371 & 58 & 729 & 50.8 & 7.9 & 42.9 & 0.16 & 117743 & 5.07 & Bond \\
\hline & $732-81$ & 409 & 172 & 680 & 60.2 & 25.3 & 34.9 & 0.42 & 29720 & 4.47 & Bond \\
\hline & 732-82 & 371 & 173 & 664 & 55.9 & 26.1 & 29.8 & 0.47 & 82953 & 4.92 & Bond \\
\hline & $732-83$ & 371 & 173 & 733 & 50.6 & 23.6 & 27.0 & 0.47 & 7145330 & 6.85 & Bond \\
\hline & $732-91$ & 450 & 172 & 600 & 75.0 & 28.6 & 46.4 & 0.38 & 13320 & 4.12 & Bond \\
\hline & $732-92$ & 430 & 172 & 600 & 71.6 & 28.6 & 43.0 & 0.40 & 79090 & 4.90 & Bond \\
\hline & $732-93$ & 450 & 172 & 438 & 102.8 & 39.2 & 63.5 & 0.38 & 350 & 2.54 & Bond \\
\hline & $732-94$ & 432 & 173 & 438 & 98.7 & 39.5 & 59.2 & 0.40 & 520 & 2.72 & Bond \\
\hline & $732-95$ & 417 & 175 & 445 & 93.8 & 39.4 & 54.3 & 0.42 & 21970 & 4.34 & Bond \\
\hline & $732-96$ & 394 & 174 & 440 & 89.6 & 39.6 & 50.0 & 0.44 & 45610 & 4.66 & Bond \\
\hline & $732-97$ & 246 & 89 & 677 & 36.4 & 13.1 & 23.2 & 0.36 & 1250 & 3.10 & Bond \\
\hline & $732-99$ & 432 & 155 & 657 & 65.8 & 23.5 & 42.2 & 0.36 & 45960 & 4.66 & Bond \\
\hline & $732-162$ & 443 & 159 & 657 & 65.4 & 24.2 & 41.2 & 0.36 & 1680 & 3.23 & Bond \\
\hline & $732-164$ & 440 & 157 & 672 & 65.5 & 23.4 & 42.1 & 0.36 & 376520 & 5.58 & Steel \\
\hline & $732-165$ & 440 & 157 & 667 & 66.0 & 23.5 & 42.4 & 0.36 & 246890 & 5.39 & Bond \\
\hline & $732-166$ & 440 & 157 & 667 & 66.0 & 23.5 & 42.4 & 0.36 & 8920 & 3.95 & Bond \\
\hline
\end{tabular}

$\sigma_{\mathrm{s}}=$ stress in tensile reinforcement at maximum moment location (MPa)

$f_{y}=$ measured yield strength in tensile reinforcement (MPa)

$R=$ ratio of minimum $\sigma_{s}$ to maximum $\sigma_{s}$ during load cycle

$\mathrm{N}=$ number of load cycles to failure 
resulted from bond fatigue, the predicted static splice strength was the most fitting reference base $\left(\sigma_{\mathrm{s}} / \sigma_{\text {static }}\right.$, Table 4.1). However, for those specimens that failed from fatigue of the tensile reinforcing bars, it was appropriate to reference their performance to the measured yield strength of the reinforcing steel $\left(\sigma_{\mathrm{s}} / \mathrm{f}_{\mathrm{y}}\right.$, Table 4.2).

The anticipated static splice strength $\left(\sigma_{\text {static }}\right)$ for each test beam was based on the related static test performed for each series and then adjusted according to actual concrete strengths at the time of testing, the actual amount of confinement provided and the actual yield strengths of the stirrups (see Appendix A.3). The resulting predicted static strength of the splice for some of the beams was greater than the measured yield strength of the reinforcing steel. This was the effect of a higher concrete compressive strength for the actual beams as compared to the design value. However, this condition did not influence the test results because the peak fatigue stress was never above $77 \%$ of the predicted static splice strength and always equalled a value less than the reinforcing steel yield strength.

For the series of data from Tepfers' study the expected static lap splice strengths were extrapolated from Tepfers' static tests completed on specimens of similar reinforcing bar configurations and size.

The "\% Resistance" values presented in Table 4.1 indicate the proportions of the total bond strength which, based on the ACI 408 design procedure under static loading conditions, is provided by the concrete confining the lap and the confinement provided by the stirrups enclosing the lap. The specimens considered from Tepfers' study did not contain any transverse reinforcement along the lap splice. Therefore, only the concrete strength, the confinement provided by the concrete and the lap length were variables used 
in the ACI Committee 408 design recommendations to determine the estimate of the static strength.

\subsection{Description of Specimen Failures:}

The specimen 975-ST1-T244 was tested statically with a steadily increasing load of 10 $\mathrm{kN}$ intervals until failure of the lap splice occurred. The ultimate static strength of the specimen was found to be $103.3 \mathrm{kN}$. The failed specimen is shown in Fig. 4.1.

The first specimen to be tested under a fatigue loading was specimen 975-F1-T244. This beam was subjected to an extreme overload due to an error with the MTS control unit. The beam was consequently dynamically loaded to failure during its first load cycle. Because of the sudden and unexpected occurrence of this failure, neither the data acquisition system nor the MTS was prepared to begin recording data from any of the measuring instruments; thus, no data was compiled for this specimen. This specimen is not included in Tables 4.1 and 4.2.

Specimen 975-F2-T244 was subjected to a sinusoidal loading with stresses in the main tensile reinforcement ranging from $75.5 \%$ to $24.9 \%$ of the measured yield strength of the steel (Table 4.2). During the first load cycle and then again later during the midpoint of the fatigue test for approximately 5 cycles, the set maximum test load was exceeded to values of $86.3 \%$ and $83.3 \%$ respectively. As previously indicated, the loading range used in all current test specimens was approximately $75 \%$ to $25 \%$ of the measured yield

strength of the reinforcement. As this specimen failed in bond, the more relevant loading range is $72.7 \%$ to $24.0 \%$ of the static strength as presented in Table 4.1 . The specimen (see Fig. 4.2) failed after 720 cycles when bond fatigue resulted in failure of the lap splice. In addition to the unintentional overloading, it is suspected that the heavy 


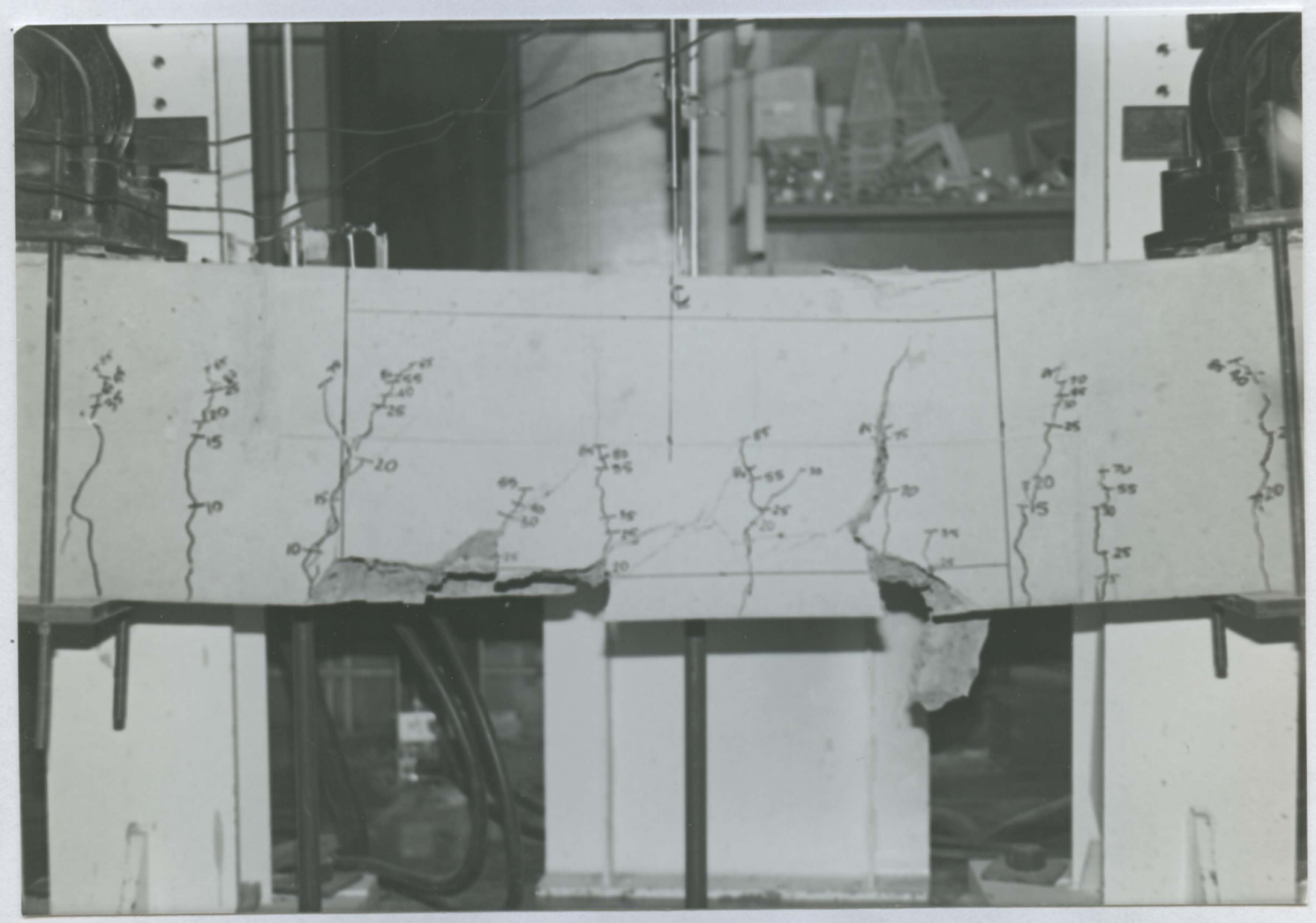

Figure 4.1. Specimen 975-ST1-T244.

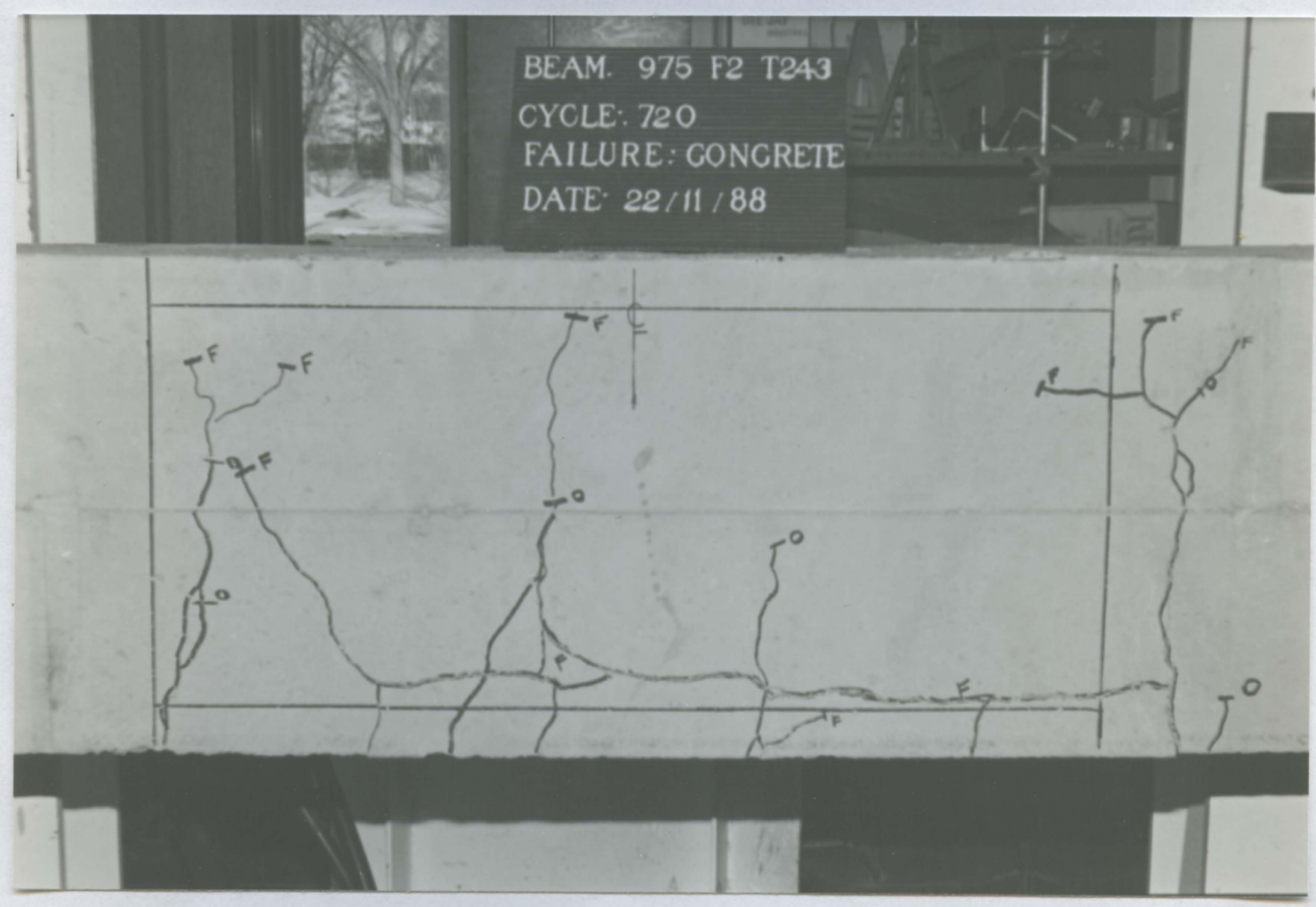

Figure 4.2. Specimen 975-F2-T244. 


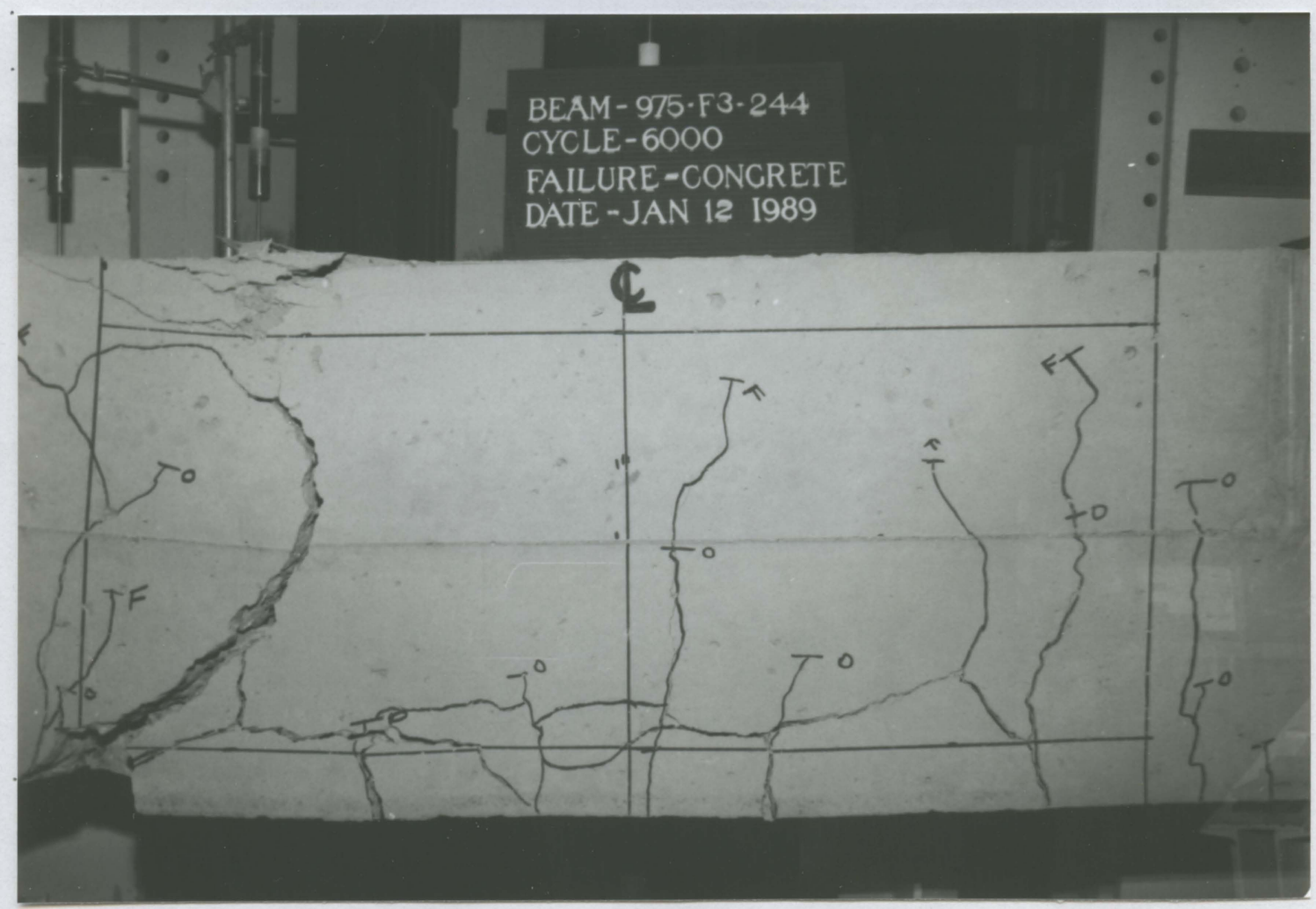

Figure 4.3. Specimen 975-F3-T244.

protection material applied to the strain gauges reduced the bond resistance and, may have contributed to the very low fatigue life for this specimen.

The third fatigue specimen, 975-F3-T244, was cycled between a stress range of $77.1 \%$ and $27.3 \%$ of the expected static strength of the specimen. The concrete strength of this specimen was $25.7 \mathrm{MPa}$ at the start of the testing period, significantly lower than the target strength. Failure of the specimen occurred after 6600 cycles when splitting and delamination of the concrete cover, reduced the bond capacity to such a degree that fatigue of the lap splice took place. The specimen, after failure of the splice, is shown in Fig. 4.3.

Specimen $900-\mathrm{F} 4-\mathrm{T} 129$ was subjected to stresses ranging from $75.3 \%$ to $24.5 \%$ of the 


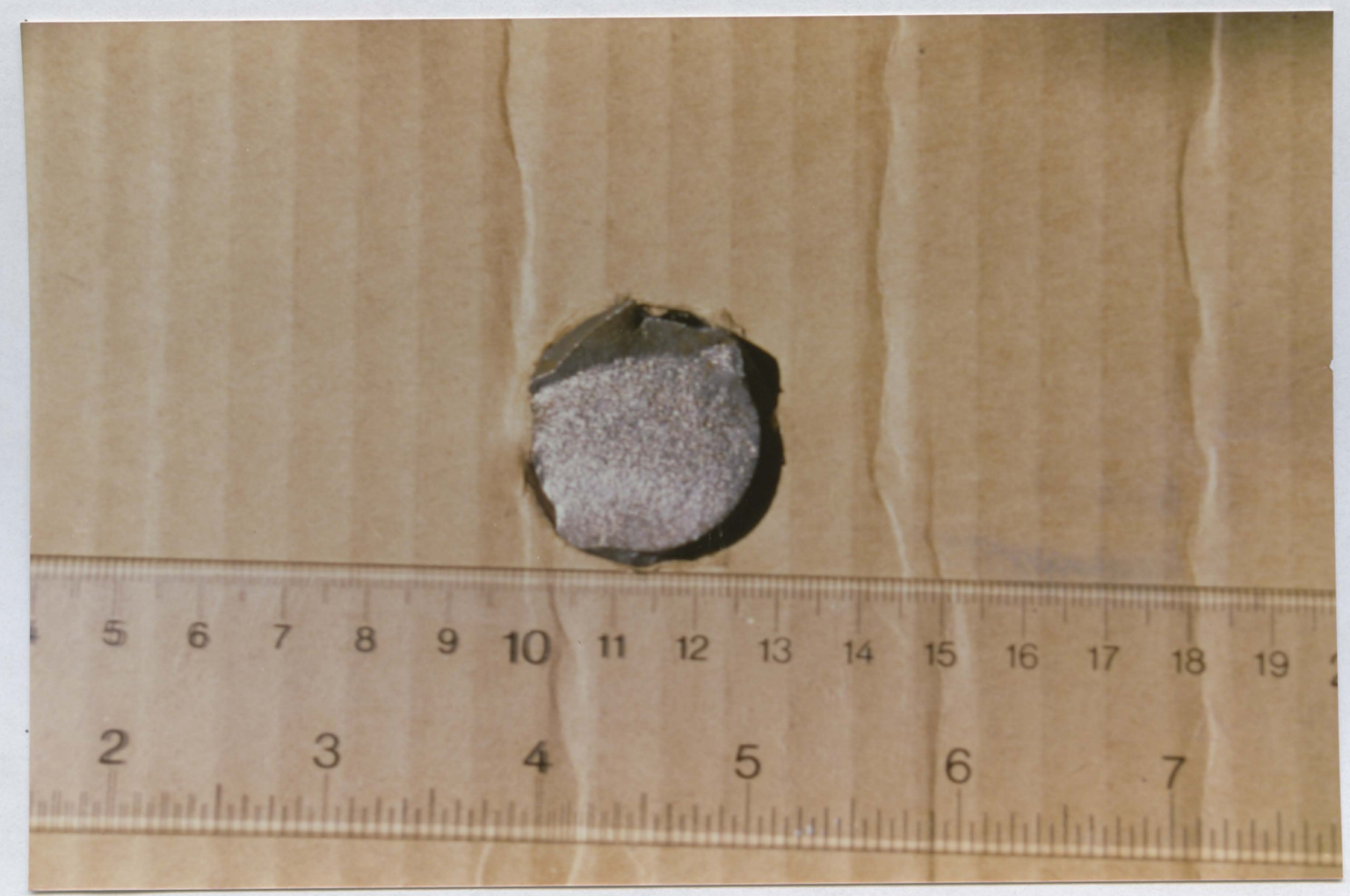

Figure 4.4. Reinforcing Steel Fatigue Crack - 900-F4-T129.

measured yield strength of the reinforcing steel. The failure of this specimen occurred when a tensile reinforcing bar fractured from fatigue at 334000 cycles. Difficulties connected with the MTS control unit resulted in eight shutdown periods during the testing of this specimen. The length of these rest periods was estimated on the basis of a clock which recorded the time the MTS pump was in operation. Therefore, the total number of cycles to failure was believed to be quite accurate. The location of the fracture in the reinforcing bars, which resulted in failure, was situated at the continuous end of the lap splice area. The cross sectional area of the fractured bar where the fatigue crack was located is shown in Fig. 4.4. The crack initiated from a deformation formed by the joining of a longitudinal and diagonal rib. The failed specimen is shown in Fig. 4.5.

Specimen $975-\mathrm{F} 5-\mathrm{T} 244$ was cycled using a stress range $75.1 \%$ to $24.3 \%$ of the steel reinforcing measured yield strength. The concrete strength of this specimen was tested at 


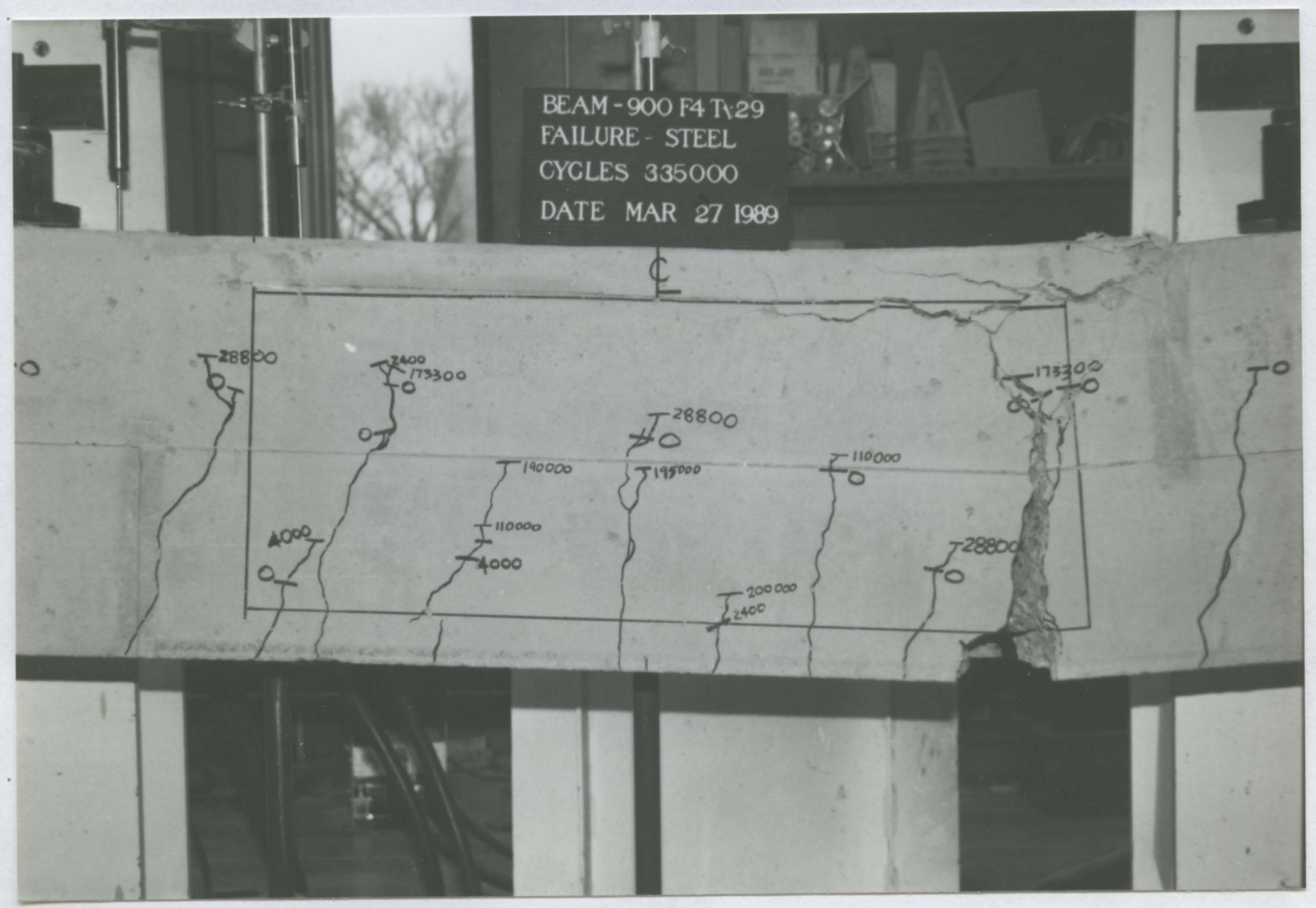

Figure 4.5. Specimen 900-F4-T129.

37.4 MPa well above the target strength for this program. The specimen had a fatigue life of 250000 cycles that ended with a failure of a tensile reinforcing bar near the end of the lap splice area. The failed beam is shown in Fig. 4.6. After the steel failure on the one side of the beam, the total loading was applied to opposite side of the beam causing failure of the concrete side cover. The failure surface of the reinforcing steel is shown in Fig. 4.7. The crack initiated from a deformation formed by the joining of a longitudinal and diagonal rib. Similar to specimen 900-F4-T129, shutdowns of the MTS resulted in four rest periods during the beam's fatigue life.

The sixth and seventh fatigue specimens, 975-F6-T195 and 975-F7-T195, were similar in construction and both failed in a similar manner. Fig. 4.8 and Fig. 4.9 show the outcome of the fatigue testing for each specimen. The splitting and delamination of the concrete 


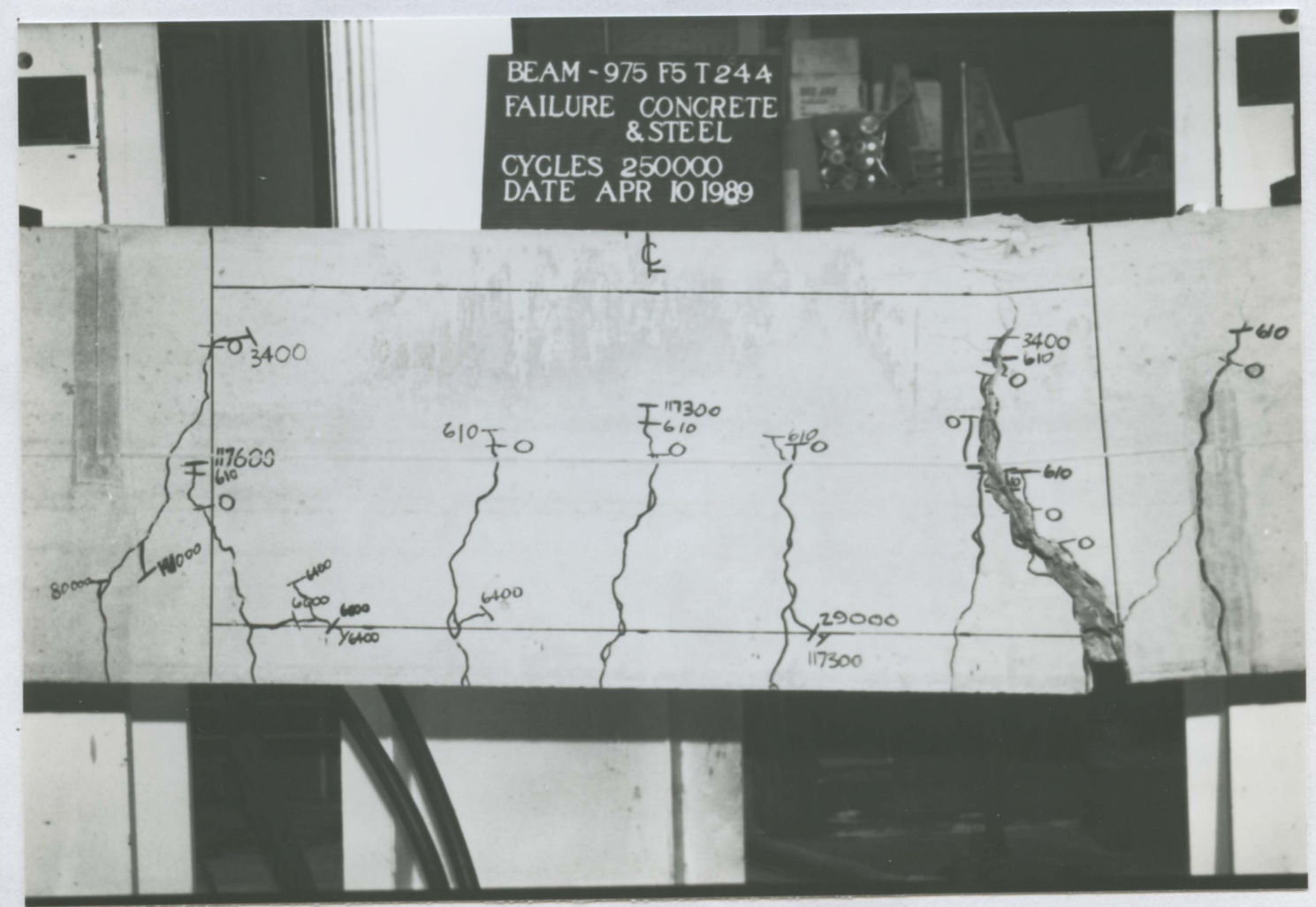

Figure 4.6. Specimen 975-F5-T244.

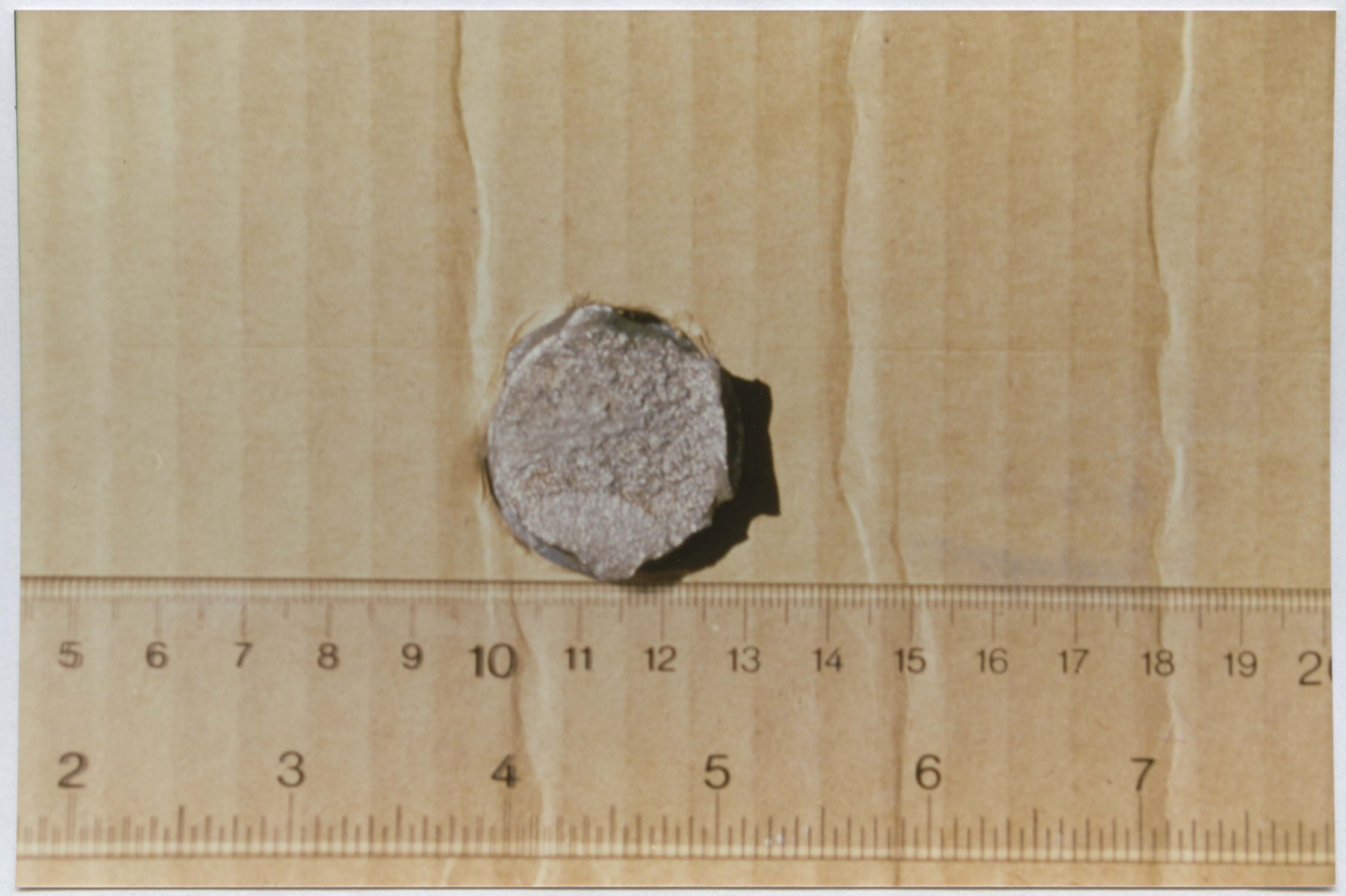

Figure 4.7. Reinforcing Steel Fatigue Crack - 975-F5-T244 


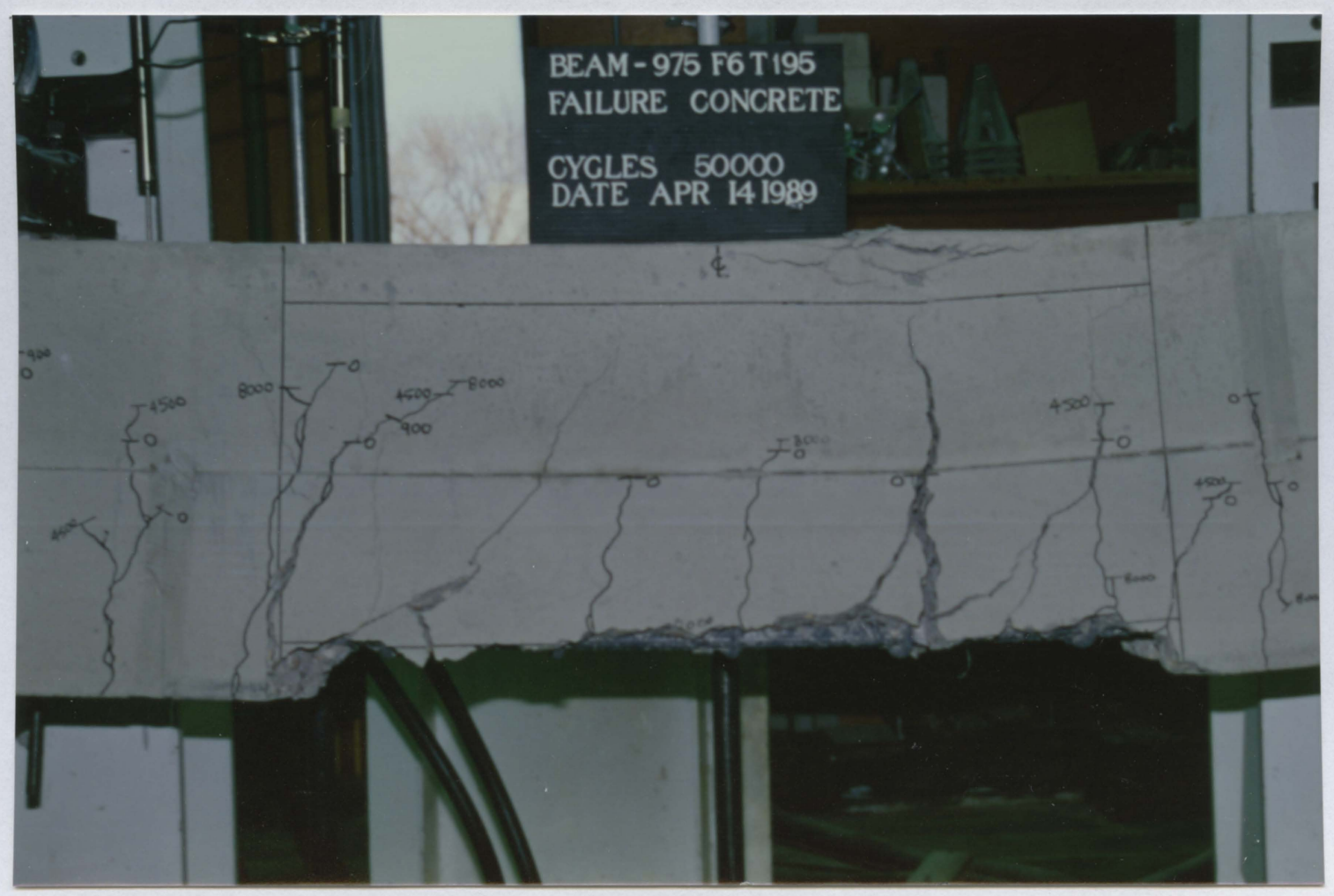

Figure 4.8. Specimen 975-F6-T195.

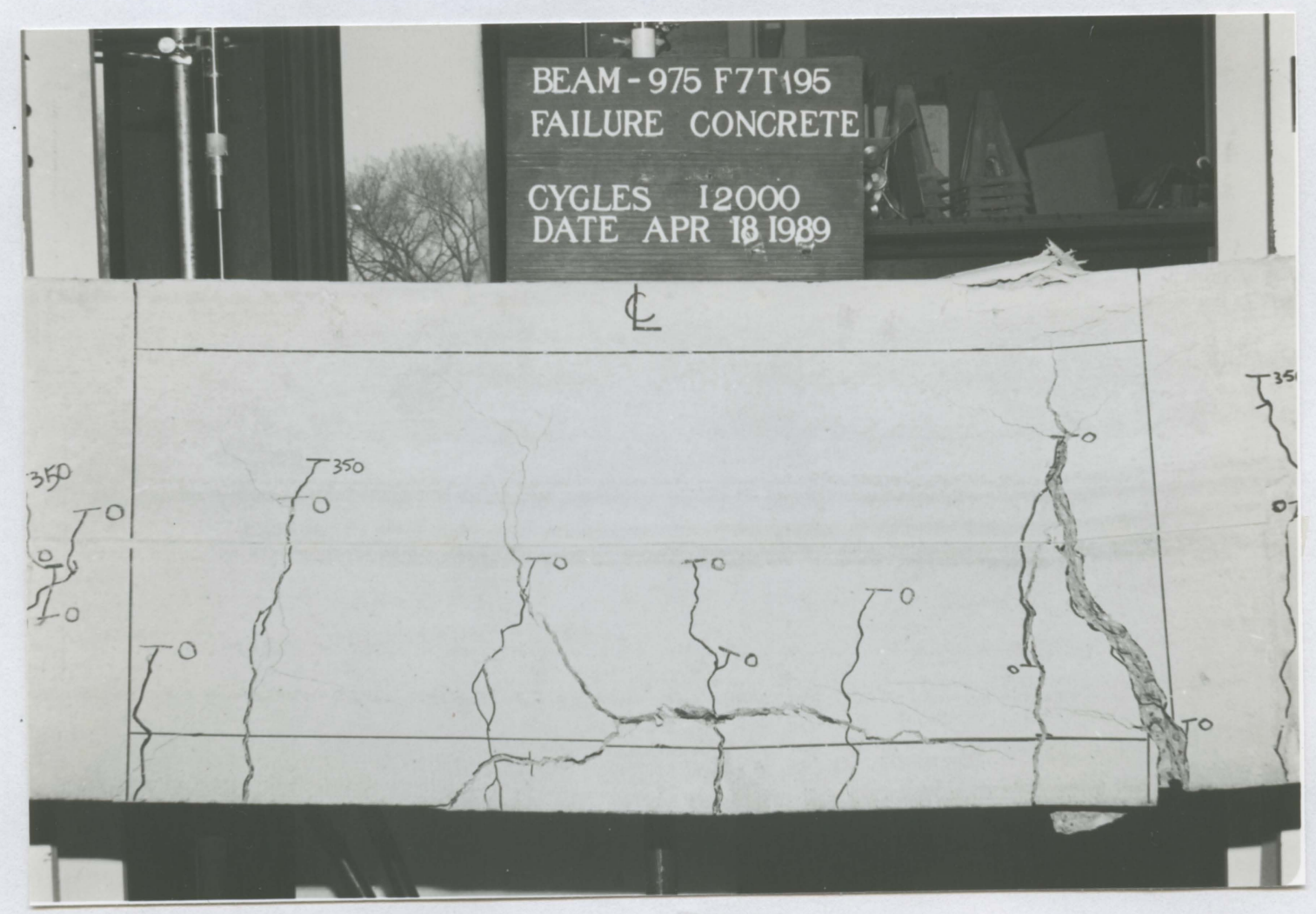

Figure 4.9. Specimen 975-F7-T195. 


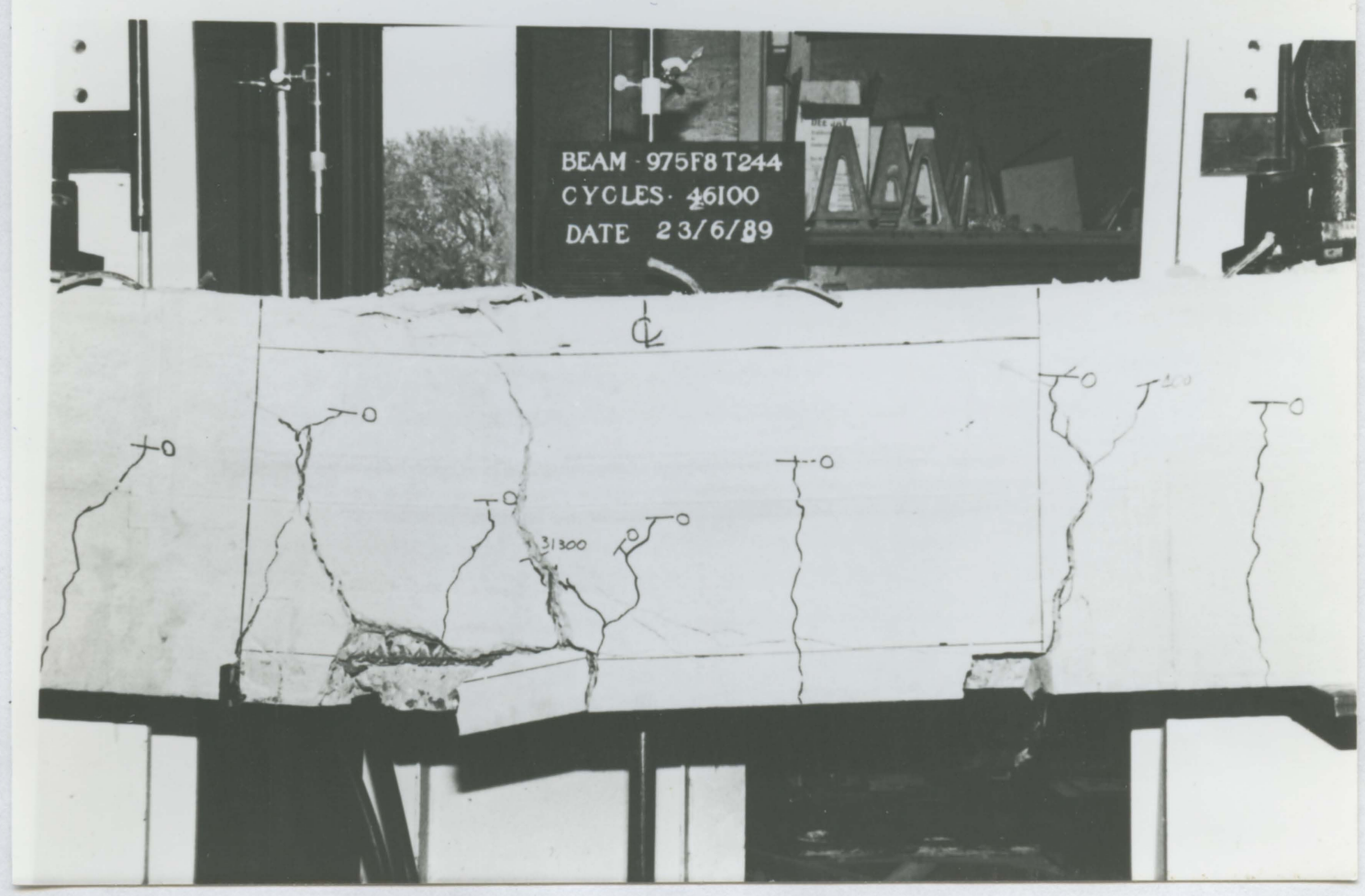

Figure 4.10. Specimens 975-F8-T244.

within the zones of bar cover and spacing, resulted in lap splice failure due to a reduced bond strength. Specimen 975-F6-T195 had a fatigue life of 49000 cycles after being cycled between $76.6 \%$ and $25.3 \%$ of the predicted static strength. The initial concrete strength for this specimen was determined as $24.8 \mathrm{MPa}$, below the expected strength. Specimen 975-F7-T195 at the start of testing, had a concrete strength of $25.7 \mathrm{MPa}$ and failed after 12000 cycles from stresses ranging between $75.2 \%$ and $24.9 \%$ of the expected static strength.

Specimen $975-$ F8-T244 was cycled between $72.5 \%$ and $24.0 \%$ of the specimen's predicted static strength. Failure occurred after 46000 cycles because of a reduction in bond from longitudinal splitting that resulted in lap splice fatigue. Fig. 4.10 shows the beam and the failed lap splice region. 
Specimen $900-\mathrm{F} 9-\mathrm{T} 129$ was cycled from $74.8 \%$ to $24.8 \%$ of the measured yield strength of the steel reinforcing. Failure occurred after 385000 cycles due to fatigue of the tensile reinforcing steel near the end of the lap splice area. The failure surface of the reinforcing steel is shown in Fig. 4.11. The crack initiated from a deformation formed by the joining of a longitudinal and diagonal rib. The failed specimen is shown in Fig. 4.12.

\subsection{Discussion of Results:}

The mode of failure for each specimen is indicated in Tables 4.1 and 4.2. As the data indicates, the lap splice designed for heavy confinement (i.e. $\mathrm{s}=129 \mathrm{~mm}$ ) and shorter lap length $\left(l_{s}=900 \mathrm{~mm}\right)$ was strong enough to prevent splice fatigue resulting in failure in the reinforcing steel. However, for those specimens with a nominal stirrup confinement $(s=$ 244 or $195 \mathrm{~mm})$ and a longer splice $\left(l_{\mathrm{s}}=975 \mathrm{~mm}\right)$ design, failure typically occurred from bond fatigue along the splice. Influence on the specimens' fatigue strength from the major variable parameters, such as the amount of transverse confinement and the concrete strengths, must be considered.

The specimens that were used from Tepfers' program did not have any stirrups along the splice; thus, all the lap splice confinement was supplied by the concrete. Failure occurred due to bond fatigue for all the specimens except one in which the tensile reinforcing steel fatigued. The specimens were stressed through a variation of ranges in this study, and the concrete and steel strengths fluctuated significantly between beams. The large variation in the specimens' concrete and steel strengths may be responsible for the large scatter in the test results. Even with the large scatter, Tepfers' data does not seem to be out of line with the data of Series A and B.

The test data in Tables 4.1 and 4.2 is presented in Figs. 4.13-4.17. 


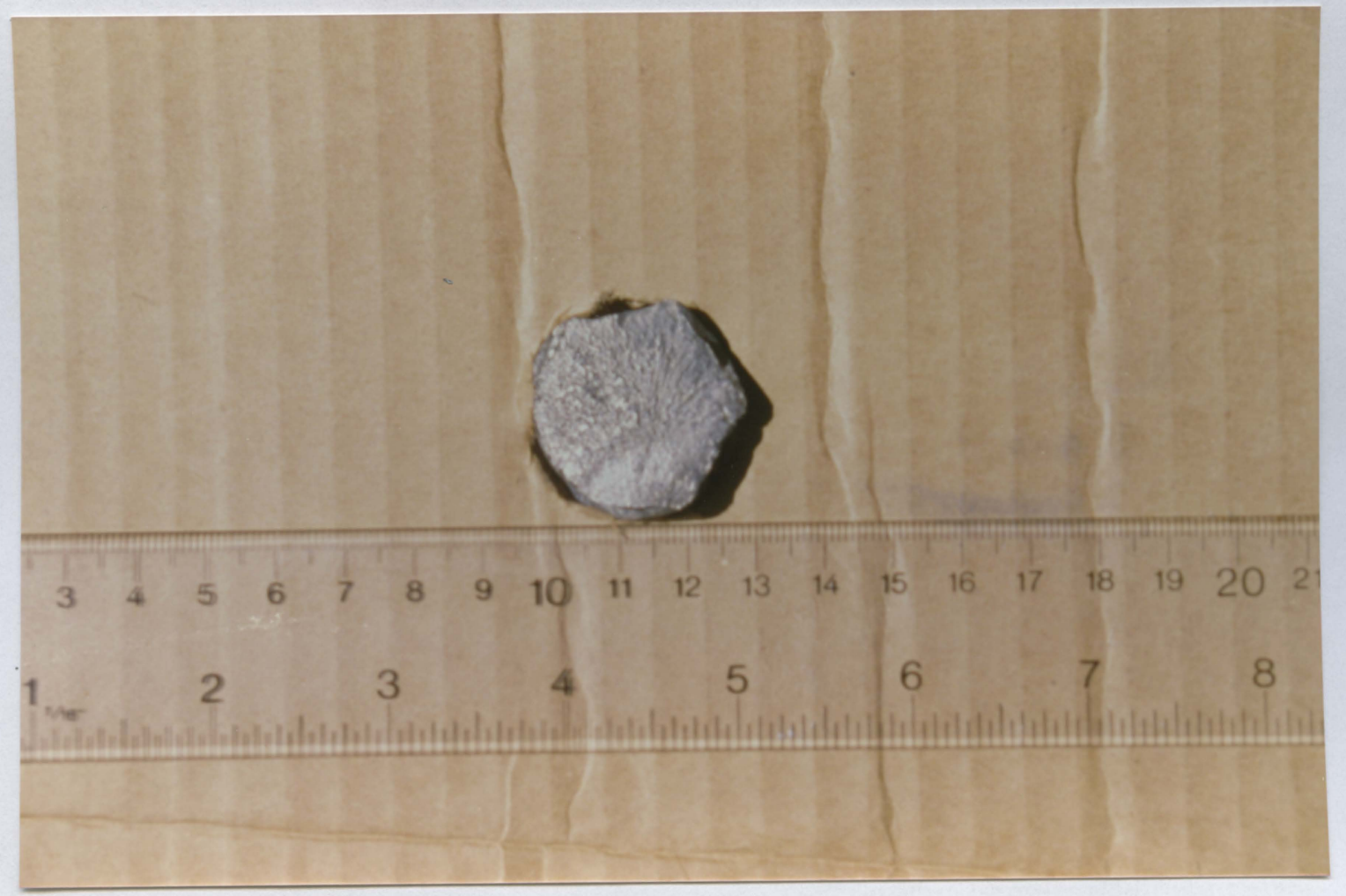

Figure 4.11. Reinforcing Steel Fatigue Crack - 900-F9-T129.

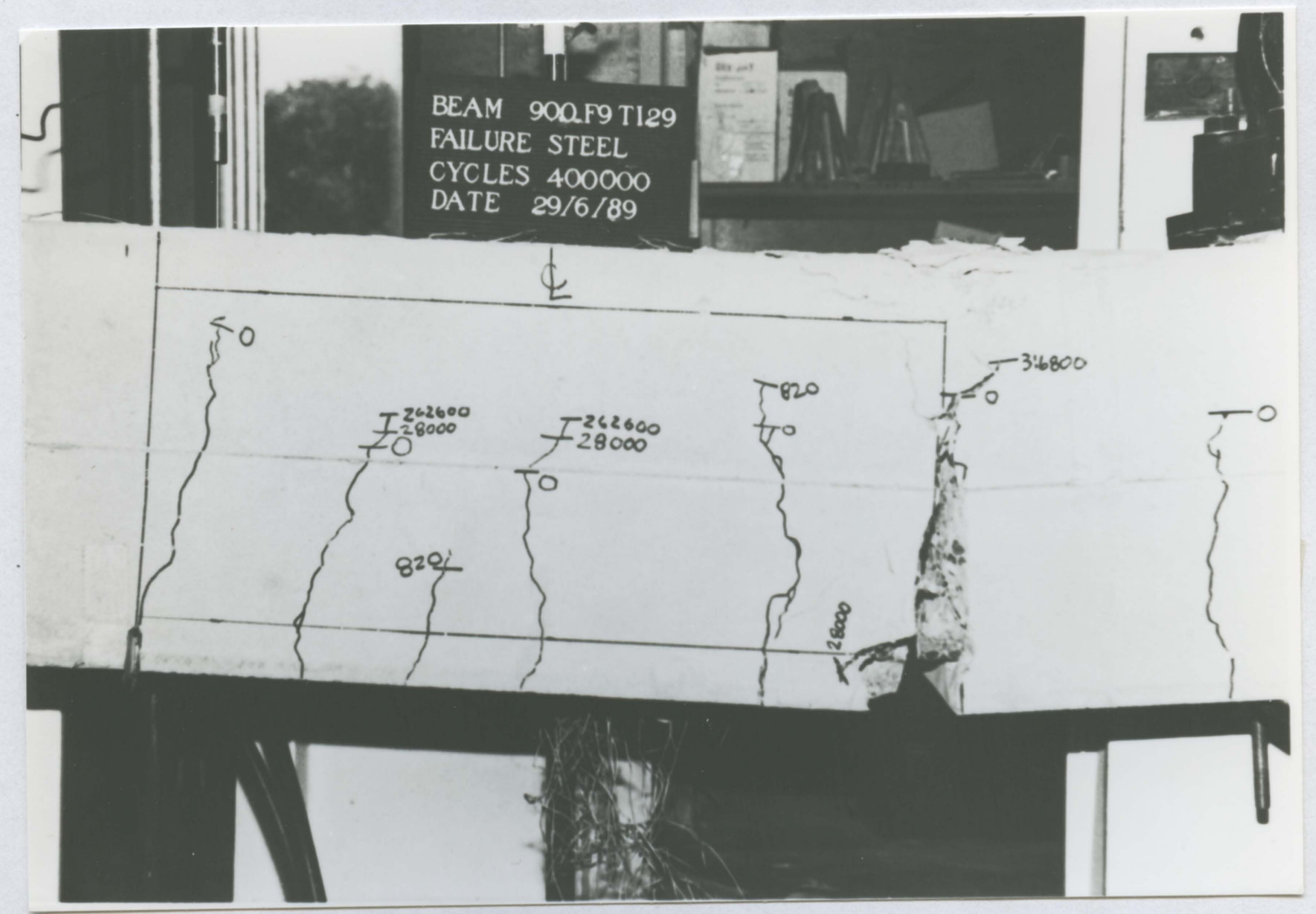

Figure 4.12. Specimens 900-F9-T129. 


\subsubsection{Bond Failure Results:}

Series A and Series B specimens, as listed in Table 4.1, are plotted in Fig. 4.13 (a). An S-N regression curve based on the specimens that failed from bond fatigue along the lap splice length is also plotted with these series of data points. The basis for this curve was Equation [2.16] developed by Aas-Jakobsen (1979) for concrete fatigue under compressive loading.

The failure of a lap splice by bond fatigue is one of tensile splitting and delamination of the surrounding concrete. Tepfers' (1973) expansion of Aas-Jakobsen's equation, showing that it was applicable to concrete in tension, established that Equation [2.16] may also be relevant to a bond type failure. Tepfers came to this conclusion from an analysis of splices without confining reinforcement that failed from tensile splitting of the surrounding concrete. For splices that are provided with transverse reinforcement, however, the resistance to bond fatigue is provided by two variables; concrete confinement and stirrups. The amount of contribution to the total bond static strength by each of the two confining parameters is indicated by the "\% Resistance" values in Table 4.1. Because the fatigue strength of a lap splice is defined by the bond resistance, the stress parameter within Equation [2.16] would be more appropriately represented by those variables that govern the bond strength rather than the compressive or tensile strength of the concrete alone. So, rather than using the performance ratio of $\sigma_{\mathrm{cmax}} / \mathrm{f}_{\mathrm{c}}{ }_{\mathrm{c}}$ as in Equation [2.16] to describe the bond resistance, the ratio of the reinforcing bar stresses, representing the bond fatigue strength along the splice, to the specimen's 


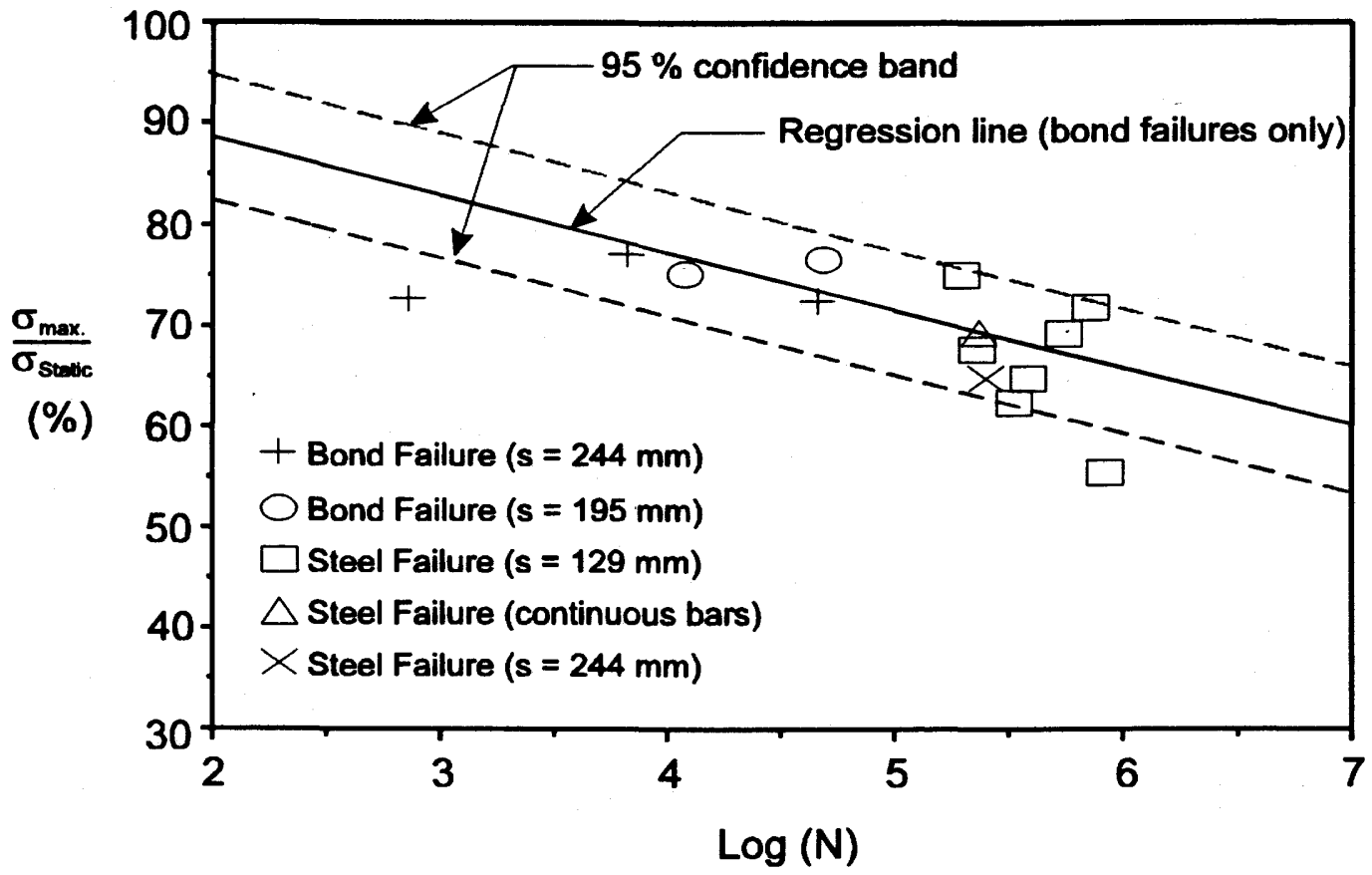

(a) U of S Data

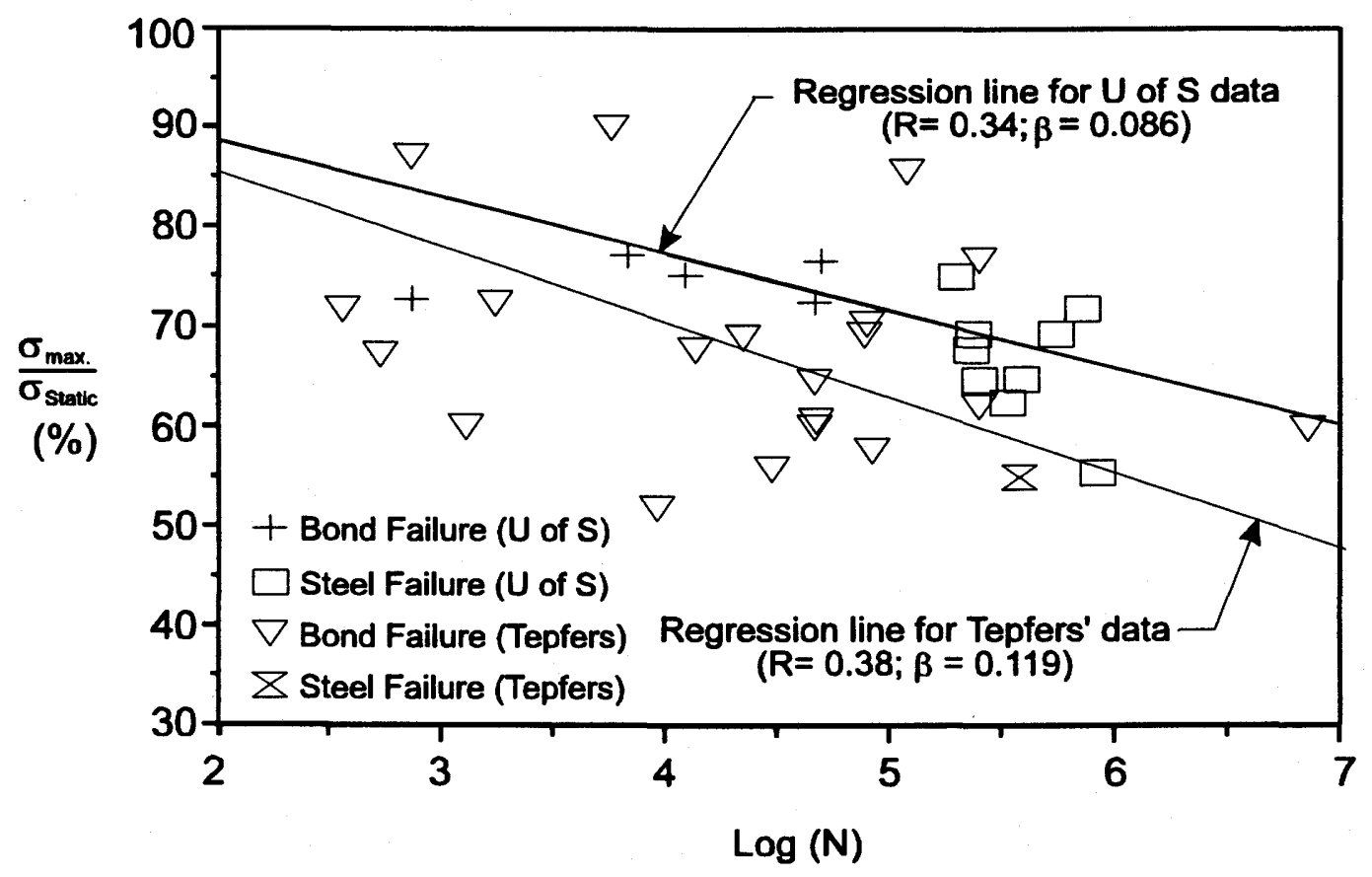

(b) All Data

Figure 4.13. Maximum Stress vs Number of Cycles to Failure. 
predicted static strength $\left(\sigma_{\mathrm{s} \max } / \sigma_{\text {static }}\right)$ were used as in the following equation:

$$
\begin{array}{ll}
\frac{\sigma_{\text {smax }}}{\sigma_{\text {static }}}=1-\beta(1-R) \log (N) & \beta=\text { regression constant } \\
& R=\sigma_{\min } / \sigma_{\max } .
\end{array}
$$

To determine the value of the regression coefficient $\beta$ equal to 0.086 , an average $R=$ 0.34 was determined from the bond fatigue failure specimens and then a regression analysis was performed. The regression analysis calculations are provided in Appendix B. Equation [4.1] as plotted in Fig. 4.13 (a) seems to provide a good representation of the test data failing from bond fatigue.

The data point for the specimen 975-F2-T244 was neglected when determining the S-N line of regression because of the uncertainty concerning the specimen's measured lap splice strength. This specimen was provided with a significant number of strain gauges and protection material along the length of the lap that may have resulted in a reduced bond resistance between the reinforcement and the surrounding concrete. Another reason for this specimen's unusually low cycles at failure may have been due to overloading during its fatigue life, as previously described. Such a load history condition may have caused extensive damage from increased cracking to the concrete confinement surrounding the lap splice, thus significantly reducing the subsequent bond fatigue resistance. Because it was suspected that the test results for this specimen may not be representative of the true fatigue lap splice strength, this data point was not used in the determination of the regression line so as not to distort the line from the more accurate results obtained from the other specimens. 
Fig. 4.13 (b) is similar to Fig. 4.13 (a) but includes the data points for all three series in Table 4.1. A second S-N curve was also plotted to represent Tepfers' data points. By using an average $R=0.38$, the regression analysis resulted in a coefficient $\beta$ equal to 0.119. Although it is difficult to compare Tepfers' results with the data from Series A and $B$ because of the large variability associated with Tepfers' specimens, there is a suggestion from this additional data that a poorer performance can be expected from lap splices with no stirrup confinement. This is indicated from the fact that all but one of Tepfers' specimens failed in bond, even in the beams that were tested at low stress levels.

\subsubsection{Influence of Transverse Reinforcement Confinement:}

From the data presented in Table 4.1 and plotted in Fig. 4.13 (a), the influence that the quantity of transverse reinforcement confining a lap splice has on the number of cycles to failure and the mode of failure can be recognized. For the specimens with a nominal stirrup spacing of $244 \mathrm{~mm}$ or $195 \mathrm{~mm}$, and a lap of $975 \mathrm{~mm}$, cycled loading with a maximum stress exceeding $72 \%$ of the static strength of the specimen was only sustained for around 50000 or fewer load cycles before bond failures occurred. With a heavier stirrup confinement (stirrup spacing of $129 \mathrm{~mm}$ ) and a lap length equal to $900 \mathrm{~mm}$, the maximum stress during cycling was held as high as $75 \%$ of the static strength without a bond fatigue failure in the splice. The number of load cycles required to produce a fatigue failure in the reinforcement for these specimens exceeded 200000 cycles.

Looking at the values associated with the \% Resistance heading in Table 4.1 a trend may be noticed. For the specimens with a heavy transverse reinforcement confinement, the contribution of the stirrups to the static splice resistance was determined as $33 \%$ from the ACI 408 equations. This amount decreased to approximately $20-25 \%$ for the specimens with a wider spacing of stirrups. This decrease in contribution, though small, 
was significant enough to change the failure mode from a reinforcing steel fatigue for the tightly spaced stirnups, to a bond fatigue for a majority of the specimens with fewer stirrups.

The above observations suggest that for resisting fatigue loading, a heavier confinement from stirrups with a shorter lap length is favoured over a nominal stirrup confinement and a longer length of lap splice.

\subsubsection{Influence of Concrete Strength:}

The effect that the concrete strength $\mathrm{f}_{\mathrm{c}}{ }_{\mathrm{c}}$ has on the fatigue life of the beams can be studied by examining the three test specimens, 975-F3-T244, 975-F5-T244, and 975-F8-T244 (see Fig. 4.14). All have the same beam configuration and a similar load history when referenced to the yield strength of the longitudinal reinforcing steel (Table 4.2). As the strength of the concrete increases from a low of $25.7 \mathrm{MPa}$ for 975-F3-T244 to a high of $37.4 \mathrm{MPa}$ for $975-\mathrm{F} 5-\mathrm{T} 244$, the mode of failure changes from a bond fatigue failure with the two specimen with weaker concrete to a fatigue failure of the reinforcing steel in specimen 975-F5-T244.

Because of the mechanism of bond, which includes bearing of the concrete against the reinforcement lugs and the tensile splitting of the concrete cover, it is reasonable to expect that the concrete strength would influence the bond strength of the lap splice. Although the loading ranges were kept similar, the static strengths were expected to vary with the concrete compressive strength, and the stress ranges when expressed as a percentage of the predicted static strength varied from a low of $44 \%$ for specimen 975-F5-T244 to a high of $50 \%$ for specimen $975-$ F3-T244. The low stress range of 


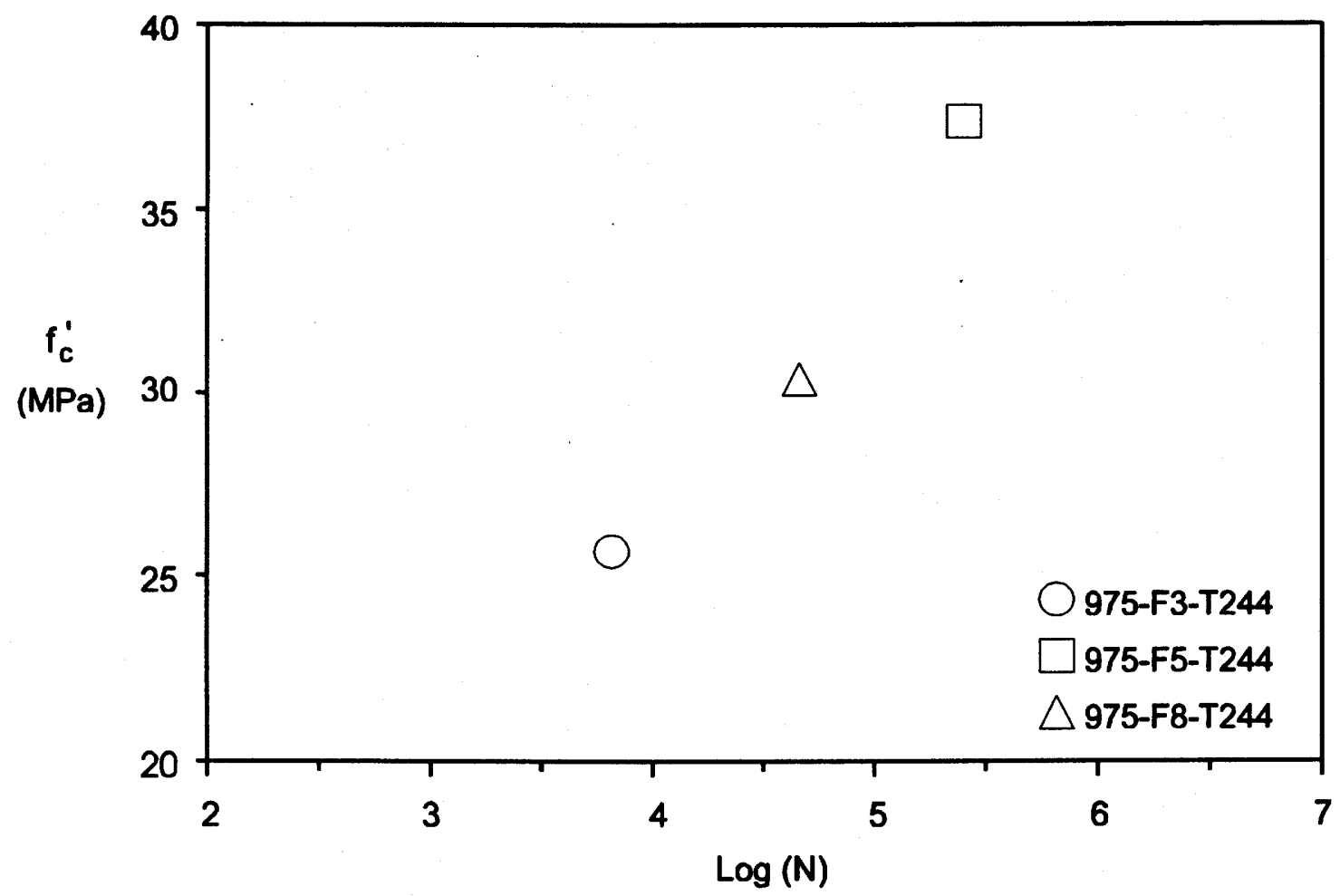

Figure 4.14. Concrete Compressive Strength vs Number of Cycles to Failure.

$44 \%$ of the static splice strength for Specimen 975-F5-T244 permitted sufficient cycling without causing a bond failure, so that the reinforcing steel finally fatigued. The stress range, when expressed as a function of the yield strength, was quite high at $51 \%$ for this specimen (Table 4.2). Thus, a change in failure mode ensued for the beam configuration containing nominal stirrups along the splice. Though the number of tests completed do not justify any firm conclusions on the effects of concrete strength on fatigue, higher values of concrete compressive strength will improve fatigue performance when failure occurs in the splice, and a sufficiently high concrete strength may change the failure mode from bond to reinforcing steel fatigue. This latter mode is the optimum that can be achieved as it is not limited by bond resistance.

As shown by Siemes (1983) and other researchers, the scatter of data associated with S-N curves of fatigue test results may be attributed to the variable nature of the static 
strength of concrete. Tepfers' data (Fig. 4.13 (b)) shows a large variability as compared with the data from Series A and B. As the beams chosen from Tepfers' program to be presented here did not contain any transverse reinforcement, the lap splice confinement depended exclusively on the concrete confining the splice for bond resistance. Because the tensile strength of the concrete, which plays a major role in bond resistance, is known to be more variable than the compressive strength even under controlled lab conditions, this variability would be expected.

\subsubsection{Steel Failure Results:}

Table 4.2 lists the specimen test results based on the measured yield strength of the tensile reinforcing bars: Fig. 4.15 (a) presents an S-N plot of this data. Within the current test program represented by the Series A test results, two specimens were designed with a heavy stirrup confinement (spacing $=129 \mathrm{~mm}$ ) similar to the beams tested under Series B. This was done to compare the performance obtained from the Series B specimens that were tested over a year prior to the beginning of this current study. The two Series A specimens showed results similar to those of the previous Series B specimens.

To provide a measure of the expected response for specimens that failed from fatigue of the reinforcing steel, the test results for Series A and B were plotted along with Equation [2.20] in Fig. 4.15 (a). Equation [2.20] was developed by Rabbat and Corley (1984) to describe the fatigue strength of the main longitudinal reinforcing steel within a reinforced

concrete beam. The curve is based on $f_{s u}=680 \mathrm{MPa}$ and $\sigma_{s \text { min }}=115 \mathrm{MPa}$, values which are representative of the majority of the specimens tested in Table 4.2. With the minimum stress held constant, this curve plots as a straight line. 


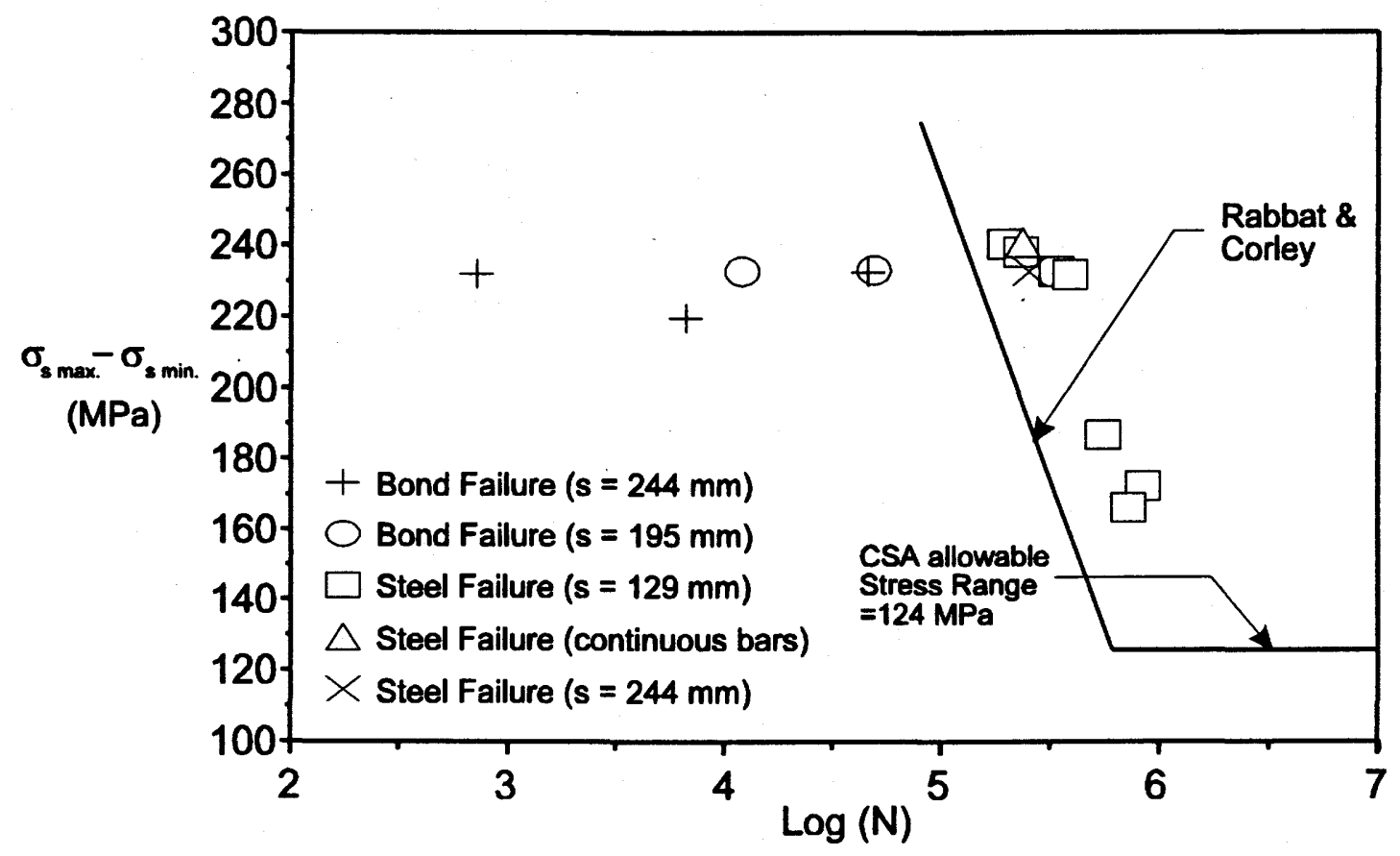

(a) U of S Data

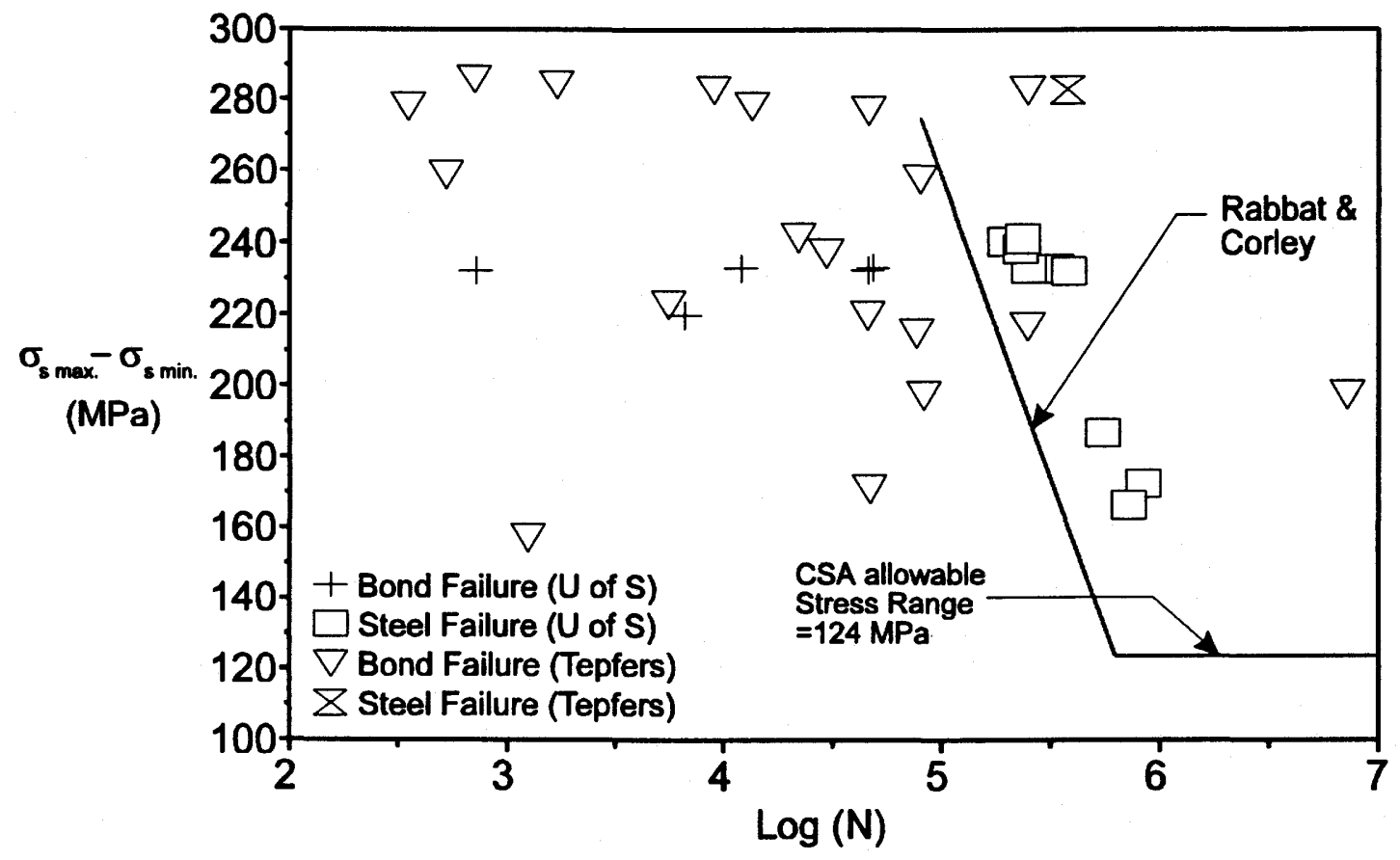

(b) All Data

Figure 4.15. Stress Range vs Number of Cycles to Failure. 
An endurance limit curve was also plotted in Fig. 4.15 (a) based on Equation [2.22] provided by CSA CAN3-S6-88 to limit the applied stress ranges for reinforced concrete structures. This equation was also established from the research of Rabbat and Corley. The curve plotted in Fig. $4.15(\mathrm{a})$ is based on $\sigma_{\mathrm{s} \min }=115 \mathrm{MPa}$. All of the specimens were tested with a value of $\sigma_{\mathrm{s}}>\sigma_{\mathrm{s} \text { min }}$.

A beam in Series B was tested with continuous reinforcement to provide a reference specimen for the steel fatigue fractures which were occurring. This specimen failed at a similar number of load cycles to those beams that contained a lap splice. As is shown in Fig. 4.15 (a), for all specimens failing from steel fatigue, failure occurred after reaching load cycles exceeding the lower bound curve proposed by Rabbat and Corley for beams with continuous reinforcement. Therefore, the lap splice proved not to be a weak link in the fatigue life of the beams, suggesting that the failure would have occurred even without the presence of the splice. At either end of the lap splices, the severe flexural cracks and stress concentrations that occurred due to the discontinuity in the longitudinal reinforcement did not seem to be detrimental to the fatigue resistance of the bar. The two curves plotted in Fig. 4.15 (a) and (b) provide a good lower bound for the beams that fail from fatigue of the longitudinal reinforcing steel.

\subsubsection{Analysis of Deflection Data:}

Deflection data for each specimen was collected using the Megadac Data Acquisition System from the LVDT's placed along the length of the beam between one load point and the midspan of the beam (see Fig. 3.3). The data which was gathered was found to have been greatly affected by noise within the Megadac System. This noise was later removed from the data during the analysis using the filtering process described in Appendix G.

Figs. 4.16-4.18 are plots showing the progression of the maximum midspan deflection as 
cycling of the specimen continued. In Appendix $\mathrm{H}$, plots of the individual LVDT deflections versus the number of accumulated load cycles are provided for each specimen.

A softening effect indicated by the gradual increase in deflection with increasing load cycles is evident in each of the specimens presented in Fig. 4.16. This degradation of stiffness may be attributed to accelerated creep-type deformation (Whaley and Neville 1973) resulting from cyclic loading (flexural cracking and crushing of concrete), as well as bond deterioration, where some bar slip and longitudinal cracking occur along the lap length.

For some of the specimens, namely 975-F3-T244, 975-F6-T195, and 975-F7-T195, the loss of stiffness or softening occurred at a faster rate as compared to the other specimens which did not show as great an increase in deflection until the accumulated cycles neared their fatigue life. The higher deterioration of stiffness may be the result of a weaker concrete compressive strength which was associated with the three specimens. This lower strength concrete would be subjected to greater cracking and crushing, thus allowing more slippage to take place throughout the life of the specimen along the lap length.

In Figs. 4.17 and 4.18, the shape of the curves may be an indication of the type of degradation occurring in the beams. Near the beginning of the specimens' life, a significant amount of deflection takes place that could be attributed in a large part to accelerated flexural creep from cycled loading. This deflection seems to level off during the mid-life of the specimens. Then, again near the end of the specimens' fatigue life a large increase in deflection occurs. This final increase in deflection could be the result of bar slippage due to bond deterioration along the splice. It would be expected there 


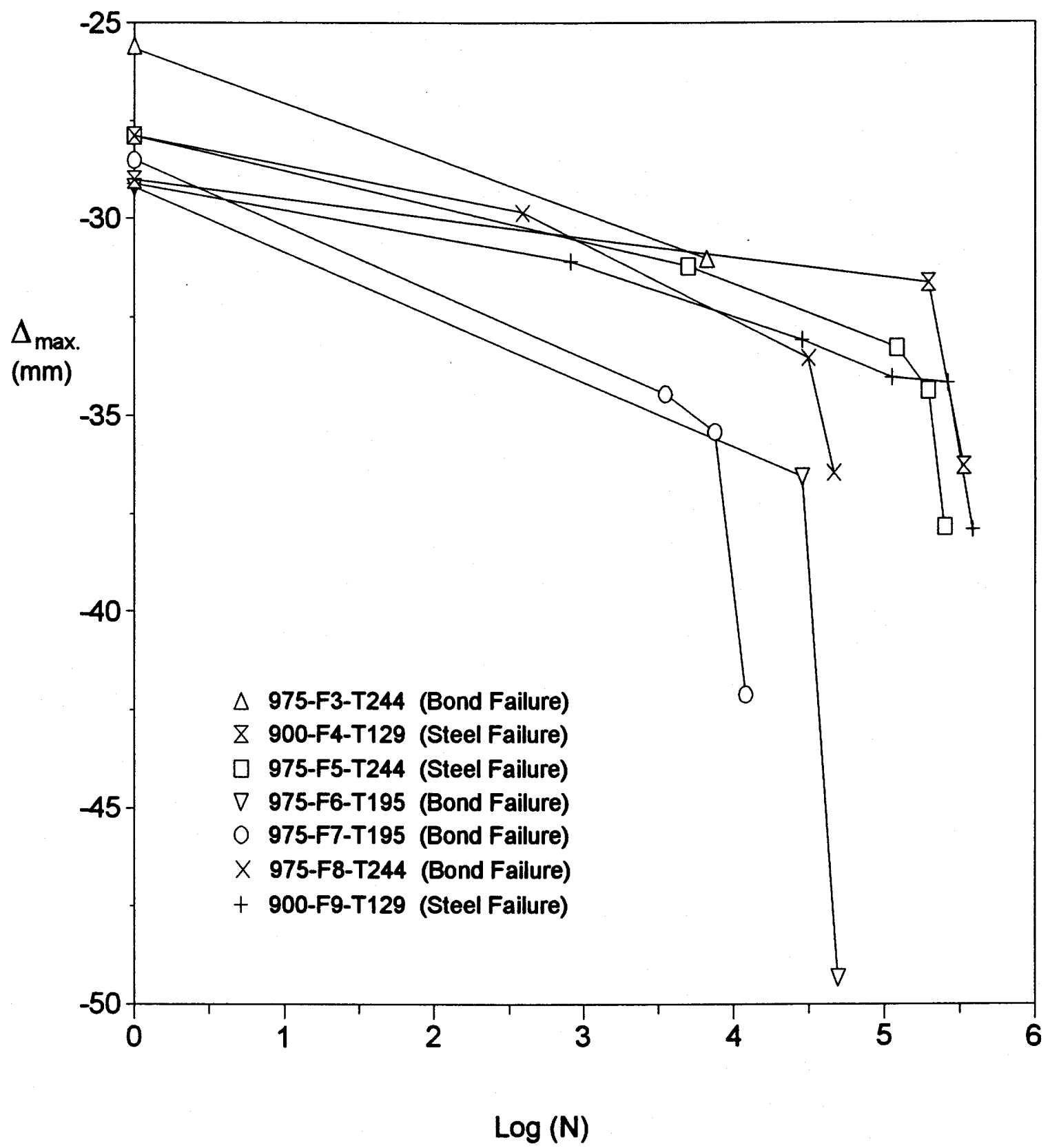

Figure 4.16. Specimens' Deflections: Maximum Midspan Deflection vs. $\log (\mathrm{N})$. 


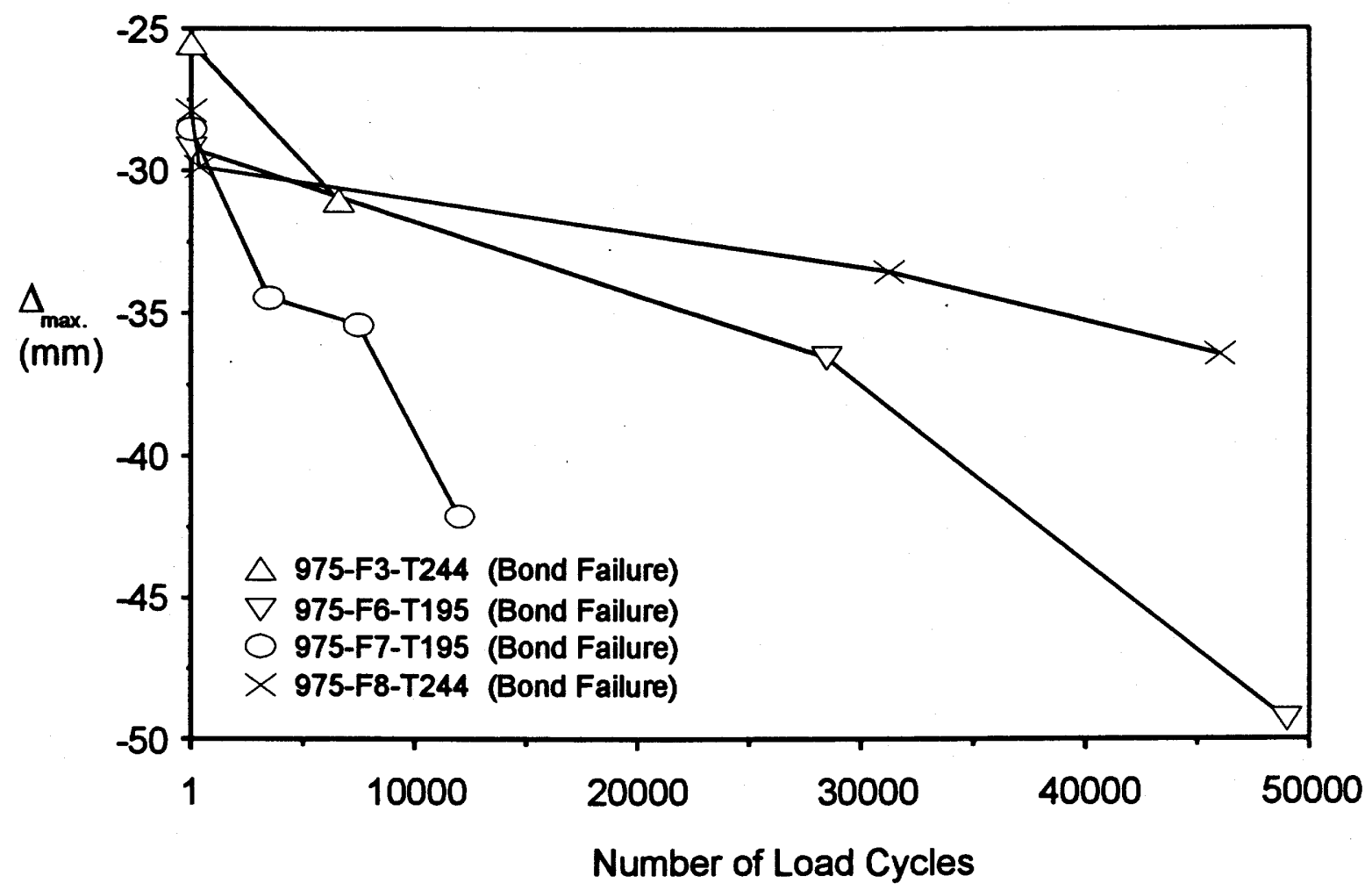

Figure 4.17. Bond Failure Deflections: Maximum Midspan Deflection vs. Load Cycles.

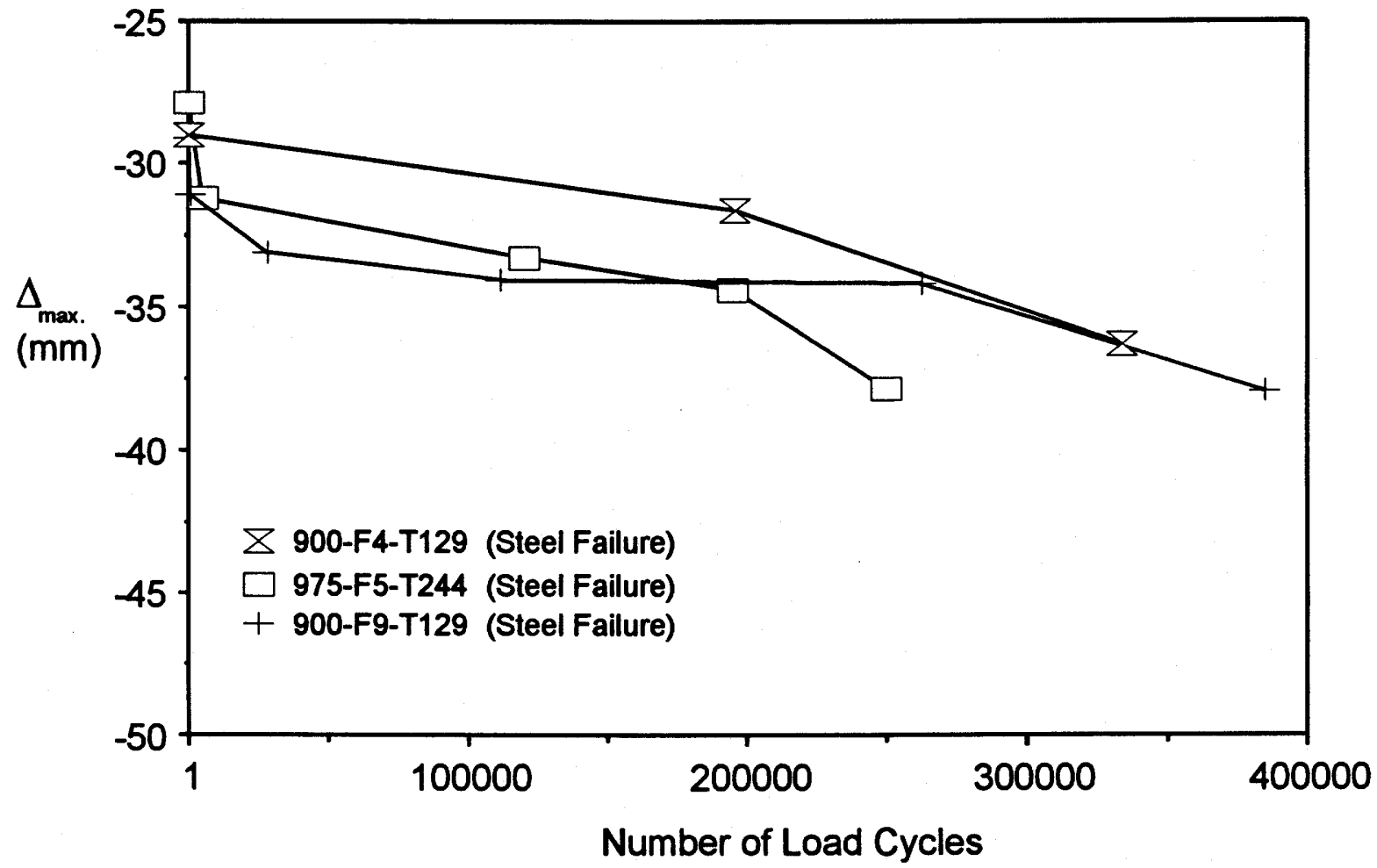

Figure 4.18. Steel Failure Deflections: Maximum Midspan Deflection vs. Load Cycles. 
would be less bond deterioration occurring in the specimens failing in steel fatigue than the specimens failing in bond. The plots seem to indicate this, as the bond deterioration occurring near the end of the fatigue life of the specimens failing in the steel (Fig. 4.18) is fairly insignificant when compared to the rate at which the increase in deformation occurs in the bond fatigued specimens (Fig. 4.17).

The plots presented in Appendix $\mathrm{H}$ were completed in an attempt to describe the curvature of the beam between load points. However, the data collected did not provide sufficient information from which to draw any conclusions as to the change in curvature over the fatigue life of the specimens.

\subsubsection{Discussion Summary:}

The S-N regression curve, described by Equation [4.1] and plotted in Fig. 4.13, seems to provide a good representation of the fatigue life of the test data failing in bond. As stated earlier, the fatigue life of concrete is affected by many different applied stress parameters. Fig. 4.19 is an S-N plot of the data listed in Table 4.1 using a stress parameter ratio of $\left(\sigma_{\text {smax }}-\sigma_{\text {smin }}\right) / \sigma_{\text {static }}$ along the ordinate. This figure does not present any additional conclusions, however it has been incorporated here as an alternate view of the test results.

From the data presented in Table 4.1, it was observed that heavy confinement from stirrups combined with a shorter lap length is preferable to a nominal stirrup confinement and a longer length of lap splice with respect to resisting fatigue loading. 


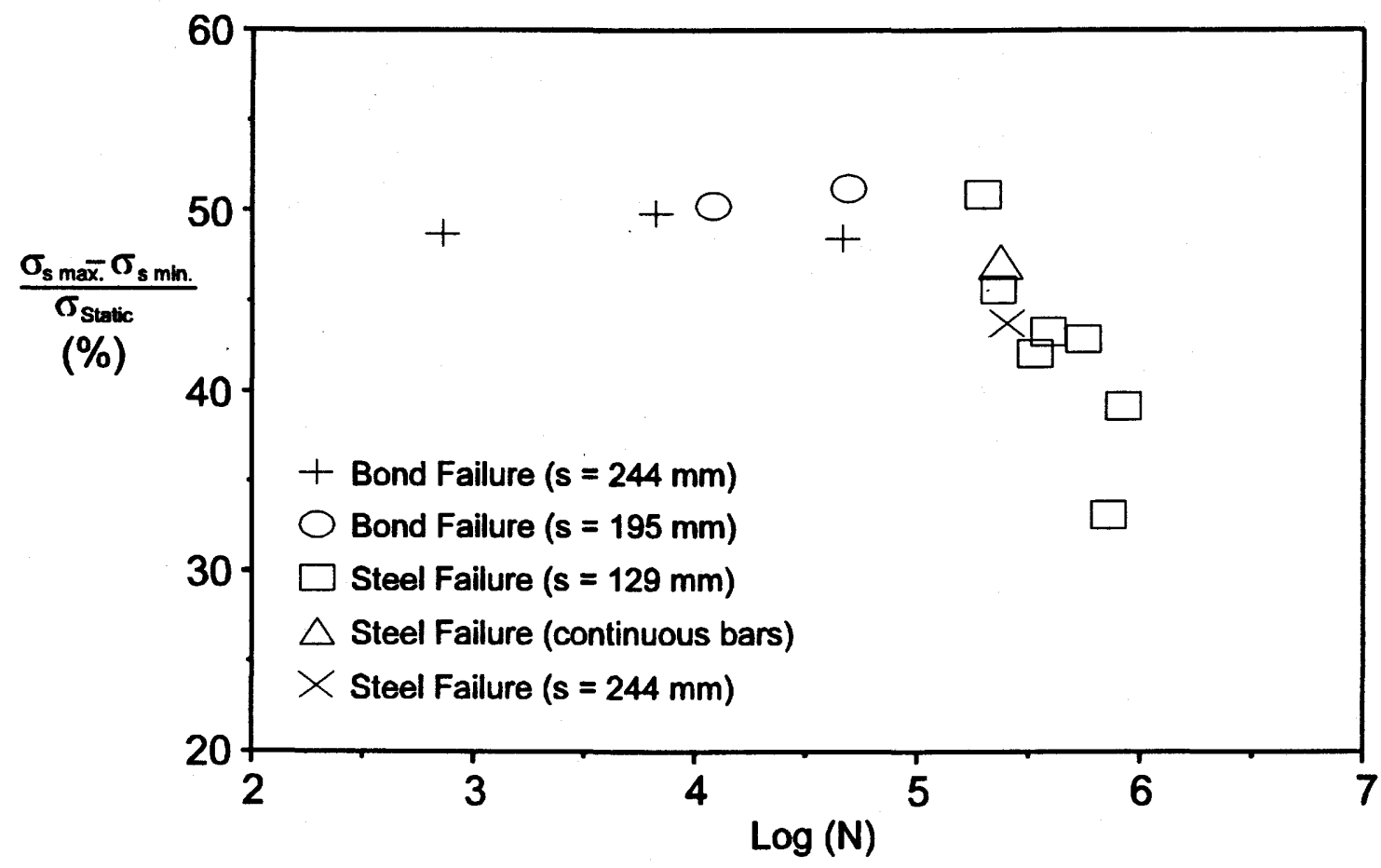

(a) U of S Data

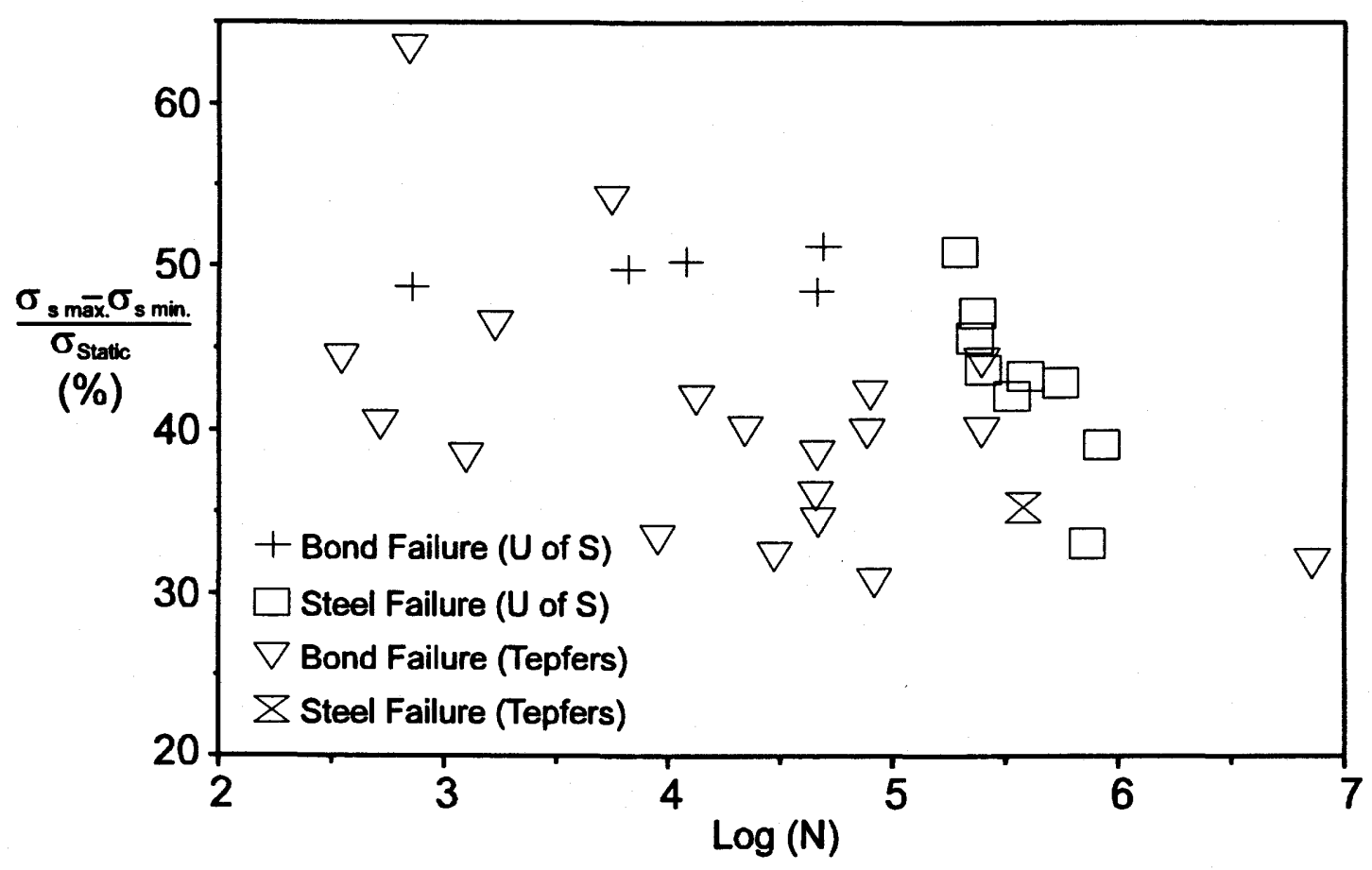

(b) All Data

Figure 4.19. Stress Range (\% of Static Lap Splice Strength)

vs Number of Cycles to Failure. 
The influence of the concrete strength was apparent in the test results, since higher values of concrete compressive strength appeared to improve the fatigue performance when failure occurred in the splice. When a sufficiently high concrete strength was present, a change in the mode of failure occurred from bond fatigue to reinforcing steel fatigue, the optimum fatigue strength that can be achieved.

The two curves plotted in Fig. 4.15 were determined from equations found in recent literature for predicting the fatigue performance of reinforcing steel without splices in concrete beams. These equations provided a good bound for the specimens with splices that failed from fatigue of the longitudinal reinforcing steel.

Deflection data at the midspan of each specimen (Fig. 4.16) indicated a gradual deterioration of the stiffness of the beams which could be attributed to accelerated creep type deformation as well as bond degradation along the lap length. Fig. 4.17 showed a greater rate of increase in deflection at a faster rate for the bond failures than the steel failed specimens that failed in the steel in Fig. 4.18. This may be an indication that bond deterioration is more significant in those specimens that ultimately fail in bond fatigue compared with the steel fatigued specimens. 


\section{CONCLUSIONS \& RECOMMENDATIONS}

\subsection{Conclusions:}

The variable nature of fatigue testing and the numerous parameters involved with bond fatigue performance would require a large number of specimens to be tested to obtain a good understanding of the performance of lap splices subjected to fatigue loading. However, financial and time constraints permitted only 10 specimens to be tested. As a consequence, the data obtained in this study was very limited. Only two different lap splice configurations and one bar size were considered. Therefore, the conclusions offered here must be restricted to the geometry and loading of the specimens of this study, supplemented by the results found in the two previous studies with which current data was considered. More extensive research in this area of study is needed before these conclusions can be confirmed. The following are the conclusions based on the information available from this study:

1) The specimens tested have shown that the fatigue resistance of lap splices designed for static conditions can be improved by providing a larger portion of the total bond resistance in the transverse reinforcement along the lap splice. Specimens with heavier transverse reinforcement along the splice and corresponding shorter lap length failed from fatigue of the longitudinal tensile reinforcing steel, thus proving that the lap splice bond fatigue strength was higher 
than the fatigue strength of the reinforcing bar. However, the majority of specimens that had fewer stirrups and a larger portion of the static strength being provided by the concrete confinement failed by bond fatigue along the lap splice. These results are in agreement with the conclusions found from seismic research, where splice confinement provided by large amounts of stirrups is required to offset the rapid deterioration of the concrete cover confinement resulting from the cyclic loading.

2) Two different types of lap splice configurations with equivalent static strengths were studied within the current program. One configuration had heavy transverse confinement spaced at one quarter of the effective beam depth $(1 / 4 \mathrm{~d})$ over a specific length of splice. The second arrangement had a longer lap length and fewer stirrups spaced at one half the effective beam depth $(1 / 2 d)$. The results of fatigue testing indicated that, for similar load intensities, the specimens with greater number of stirrups failed from steel fatigue in the longitudinal reinforcing steel while the nominally confined lap splices generally failed in bond fatigue.

3) The test results were compared with separate equations, representing the expected fatigue resistance of the specimens, for each of the two different fatigue failures which occurred during the testing. The equations for both failure conditions seemed to provide a good representation of test data. This may indicate that these equations could be used in the future for predicting the fatigue performance of reinforced concrete beams with lap splices. 


\subsection{Recommendations:}

1) Future codes, as compared to present specifications, may allow shorter lap lengths for lap splices in the static design of beams and slabs, even in the absence of transverse reinforcement confinement. Although the concrete cover confinement may be sufficient to provide the static strength, the fatigue resistance of these lap splices with no transverse reinforcement confinement may be inadequate. Bond fatigue resistance was reduced with a reduction in the portion of the static bond strength provided by the transverse reinforcing steel in the current test program. Results from a previous study on beams with no stirrups confining the lap splice showed a large scatter in the bond fatigue resistance; however, the specimens were not able to achieve the fatigue resistance of the main reinforcing steel, as bond fatigue failures controlled the number of load cycles producing failure. Further study is required on lap splices without transverse reinforcement confinement to determine the fatigue resistance of the relatively short lap length that may be permitted for static loading by future codes.

2) If the cyclic stress applied to a concrete beam containing a tensile lap splice is high enough, then the splice may fail in bond fatigue. If this load intensity is reduced, then the reinforcing steel could fail before failure of the splice. If the load is lowered further, and if enough cycles of load are applied, the beam may again fail from bond fatigue along the lap splice. This final change in failure mode, at stresses below the endurance limit of the steel, may occur since concrete is not believed to exhibit an endurance limit. Future research on concrete beams containing lap splices should investigate this possible mode of failure change for very low levels of cyclic loading. 
3) Further study will also be required to examine the effects of changes in specimen configurations. These may include variations in splice confinements, bar sizes, and beam sizes. Such modifications will allow a more complete understanding of how these variables affect the fatigue performance of tensile lap splices within concrete beams. 


\section{References:}

AAS-JAKOBSEN, K. 1970. Fatigue of concrete beams and columns. The Norwegian Institute of Technology, The University of Trondheim, Division of Concrete Structures, Trondheim. Bulletin No. 70-1: 148.

ALLEN, N. P., AND EARLY, C. C. 1956. Effect of phosphorus content on impact values of steel. Journal of Iron and Steel Institute. 182: 375-388.

AMERICAN CONCRETE INSTITUTE COMMITTEE 4081979 reaffirmed 1990. ACI 408.1R-90. Suggested development, splice and standard hook provisions for deformed bars in tension. American Concrete Institute, Detroit, MI.

AMERICAN CONCRETE INSTITUTE COMMITTEE 318 1989. ACI 318-89 and ACI 318R-89. Building code requirements for reinforced concrete and commentary. American Concrete Institute, Detroit, MI.

AMERICAN CONCRETE INSTITUTE COMMITTEE 215 1974. Considerations for design of concrete structures subjected to fatigue loading. Journal of the American Concrete Institute. 71(3): 97- 121.

AWAD, M. E. AND HILSDORF, H. K. 1963. Strength and deformation characteristics of plain concrete subjected to high repeated and sustained loads. Fatigue of Concrete SP-41. American Concrete Institute, Detroit, MI.

BAZANT, Z.P. 1985. Mechanics of fracture and progressive cracking in concrete structures. Fracture Mechanics of Concrete. Martinus Nijhoff Publishers, The Haugue, Netherlands.

BENNETT, E.W., AND MUIR, S.E. 1967. Some fatigue tests of high-strength concrete in axial compression. Magazine of Concrete Research, 19(59): 113-117

BROEK, D. 1982. Elementary Engineering Fracture Mechanics. Martinus Nijhoff Publishers, The Haugue, Netherlands.

BULlENS, D. K. 1948. Steel and its Heat Treatment. Vol. I, John Wiley \& Sons, Inc. New York.

CANADIAN STANDARDS ASSOCIATION 1984. Code for the design of concrete structures for buildings. CSA Standard CAN3-A23.3-M84, Rexdale, ON. 
CANADIAN STANDARDS ASSOCIATION 1988. Design of highway bridges. CSA Standard CAN/CSA-S6-88, Rexdale, ON.

CHANG T. S., KESLER, C. E. 1958. Fatigue behavior of reinforced concrete beams. Journal of the American Concrete Institute. 55(2): 245- 259.

ELFGREN, L. 1989. Fracture Mechanics of Concrete Structures (From theory to applications). Report of the Technical Committee 90-FMA Fracture Mechanics to Concrete -Applications, RILEM, Chapman and Hall, London.

FAGUNDO, F. E., GERGELY, P., AND WHITE, R. N. 1979. The behavior of lapped splices in reinforced concrete beams subjected to repeated loads. Report No. 79-1, Department of Structural Engineering, Cornell University, Ithaca, NY.

FERGUSON, P.M. AND BRICENO, J.E. 1969. Tensile lap splices, part 1: retaining wall type, varying moment zone. Research Report No. 113-2, Centre of Highway Research. The University of Texas at Austin.

GETTU, R., CHENGSHENG, O. AND SURENDRA, P. 1991. Fracture mechanics of concrete - a review. Fatigue and Fracture in Steel and Concrete Structures. ISFF '91 Proceedings, Oxford and IBH Publishing Co. Pvt. Ltd., New Delhi, India.

GLUCKLICH, J. 1965. Static and fatigue fractures of portland cement mortar in flexure. Proceedings of the First International Conference on Fracture, Vol. 3, The Japanese Society for Strength and Fracture of Materials, Sendai, Japan.

GYLLTOFT, K. 1983. Fracture mechanics models for fatigue in concrete structures. Doctoral thesis 1983:25D, Division of Structural Engineering, Luleå University of Technology, Luleå.

GOTO Y. 1971. Cracks formed in concrete around deformed tension bars. Journal of the American Concrete Institute. 68(4): 244-251.

HILLERBORG, A. 1983. Analysis of one single crack. Fracture Mechanics of Concrete, Elsevier Science Publishing Co. Inc., New York, NY.

HILSDORF, H. K., AND KESLER, C. E. 1966. Fatigue strength of concrete under varying flexural load. Journal of the American Concrete Institute. 63(10): 1059-1076.

HOLKMANN OLSEN, N. 1990. The strength of overlapped deformed tensile reinforcement splices in high strength concrete. Danmarks Tekniske Hojskole, Afdelingen for Baerende Konstruktioner - Series R No. 234.

HSU, T. T. C. 1981. Fatigue of plain concrete. Journal of the American Concrete Institute. 78(4): 292-305. 
HUNGSPREUG, S. 1981. Local bond between a reinforcing bar and concrete under intensity cyclic load. Report No. 81-6, Department of Structural Engineering, Cornell University, Ithaca, NY.

HWAN OH, B. 1986. Fatigue analysis of plain concrete in flexure. Journal of Structural Engineering. 112(2): 273-288.

INGRAFFEA, A. R., GERSTLE, W. H., GERGELY, P., AND SAOUMA, V. 1984. Fracture mechanics of bond in reinforced concrete. Journal of Structural Engineering. 110(4): 871-890.

JHAMB, J. C. AND MACGREGOR, J. G. 1963a. Effect of surface characteristics on fatigue strength of reinforcing steel. Fatigue of Concrete SP-41. American Concrete Institute, Detroit, MI.

JHAMB, J. C. AND MACGREGOR, J. G. 1963b. Stress concentrations caused by reinforcing bar deformations. Fatigue of Concrete SP-41. American Concrete Institute, Detroit, MI.

KAPLAN, M. F. 1961. Crack propagation and the fracture of concrete. Journal of the American Concrete Institute. 58(5): 591-609.

KENNEDY J. B. AND NEVILLE A. M. 1976. Basic Statistical Methods for Engineers and Scientists, Second Edition. Harper \& Row Publishers, Inc., New York, NY.

LUKOSE, K., GERGELY, P., AND WHITE, R. N. 1982. Behavior of reinforced concrete lapped splices for inelastic cyclic loading. Journal of the American Concrete Institute. 79(5): 355-365.

LUTZ, L. A. AND GERGELY, P. 1967. Mechanics of bond and slip of deformed bars in concrete. Journal of the American Concrete Institute. 64(11): 711-721.

MALLET, G. P. 1991. Fatigue of Reinforced Concrete. State of the Art Review 2, TRRL, HMSO, London.

McCALL, J. T. 1958. Probability of fatigue failure of plain concrete. Journal of the American Concrete Institute. 55(2): 233-243.

MINDESS, S. 1983. The application of fracture mechanics to cement and concrete: a historical review. Fracture Mechanics of Concrete, Elsevier Science Publishing Co. Inc., New York, NY.

MINDESS, S., AND YOUNG, J.F. 1981. Concrete. Prentice-Hall Canada Inc., Toronto, ON. 
MURDOCK, J. W., AND KESLER, C. E. 1958. Effect of range of stress on fatigue strength of plain concrete beams. Journal of the American Concrete Institute. 55(2): 221231.

NORBY, G. M. 1958. Fatigue of concrete - a review of research. Journal of the American Concrete Institute. 55(2): 191-220.

OLSSON, P.-A. 1985. A fracture mechanics and experimental approach on anchorage splitting. Nordic Concrete Research, Publication No. 4, The Nordic Concrete Federation, Oslo.

OPLE, F. S. AND HULSBOS, C. L. 1968. Probable fatigue life of plain concrete with stress gradient. Journal of the American Concrete Institute. 63(2): 59-81.

OPPENHEIM, A., WILLSKY, A. S. AND YOUNG I. T. 1983. Signals and Systems. PrenticeHall Canada Inc., Toronto, ON.

ORANGUN, C. O., JIRSA, J. O., AND BREEN, J. E. 1977. A Re evaluation of Test Data on Development Length and Splices. Journal of American Concrete Institute. 74(3):114-122.

ORFANDIS, S. J. 1985. Optimum Signal Processing: An Introduction. Macmillan Publishing Company, New York, NY.

PARK, Y. J. 1990. Fatigue of concrete under random loadings. Journal of Structural Engineering. 116(11): 3228-3235.

RABBAT, B.G., AND CORLEY, W.G. 1984. Long -time fatigue properties of high yield reinforcing bars. Materials of Construction. 17(19): 35-38.

RAMAKRISHNAN, V. AND LOKVIK B. J. 1991. Fatigue strength and endurance limit of plain and fibre reinforced concretes - a critical review. Fatigue and Fracture in Steel and Concrete Structures. ISFF '91 Proceedings, Oxford and IBH Publishing Co. Pvt. Ltd., New Delhi, India.

ROLFE, S.T., AND BARSOM, J.M. 1977. Fracture and Fatigue Control in Structures (Applications of Fracture Mechanics). Prentice-Hall Inc., Englewood Cliffs, NJ.

SAITO, M. 1987. Characteristics of microcracking in concrete under static and repeated tensile loading. Cement and Concrete Research. 17(2): 211-218.

SIEMES, A. J. M. 1983. Fatigue of concrete, Part 1: Compressive stresses IRO-MATS/ CUR Report No. 112.

SHAH, S. P. AND CHANDRA S. 1970. Fracture of concrete subjected to cyclic and sustained loading. Journal of the American Concrete Institute. 67(10): 816-825. 
SHAH, S. P. 1984. Predictions of cumulative damage for concrete and reinforced concrete. Materials of Construction. 17(97): 65-68.

SORETZ, S 1964. Contribution to fatigue strength of reinforced concrete. Fatigue of Concrete SP-41. American Concrete Institute, Detroit, MI.

SPARKS P. R. AND MENZIES J. B. 1973. The effect of rate of loading upon the static and fatigue strengths of plain concrete in compression. Magazine of Concrete Research. 25(83): 73-80.

SPARLING, B. AND REZANSOFF T. 1986. The effect of confinement on lap splices in reversed cyclic loading. Canadian Journal of Civil Engineering. 13(6): 681-693.

SWAMY, R. N. 1983. Linear elastic fracture mechanics parameters of concrete. Fracture Mechanics of Concrete, Elsevier Science Publishing Co. Inc., New York, NY.

TEPFERS, R 1982. Fatigue of plain concrete subjected to stress reversals. Fatigue of Concrete Structures SP-75. American Concrete Institute, Detroit, MI.

TEPFERS, R. 1973. A theory of bond applied to overlapped tensile reinforcement splices for deformed bars. Division of Concrete Structures, Chalmers University of Technology, Goteborg, Sweden. Publication 73.2.

TEPFERS, R. AND KUTTI, T. 1979. Fatigue strength of plain, ordinary and lightweight concrete. Journal of the American Concrete Institute. 76(5): 635-652.

TILLY, G.P. 1986. Dynamic behavior of concrete structures. Report of the RILEM 65 MDB Committee, Elsevier Science Publishing Inc., New York, NY.

TILLY, G.P. 1979. Fatigue of steel reinforcement bars in concrete: a review. Fatigue of Engineering Materials and Structures. 12:251-268.

TOCCI, A.D., GERGELY, P., AND WHITE, R. N. 1981. The behavior and strength of lapped splices in reinforced concrete beams subjected to cyclic loading. Report No. 811, Department of Structural Engineering, Cornell University, Ithaca NY.

TSUI, C. H. AND REZANSOFF T. 1982. The case for using stirrups to confine lap splices in reinforced concrete. Proceedings of the Annual Conference of the Canadian Society for Civil Engineering. Edmonton, Alta.. 21-38.

WHALEY, C.P., AND NEVILLE, A.M. 1973. Non-elastic Deformation of Concrete Under Cyclic Compression. Magazine on Concrete Research. 25(84):145-154. 
YOSHIMOTO, A., OGINO, S., KAWAKAMI, M. 1972. Microcracking effect on flexural strength of concrete after repeated loading. Journal of the American Concrete Institute. 69(23): 233-240.

ZACARUK, J. A. 1990. Performance of large size reinforced concrete beams containing a lap splice subjected to fatigue loads. MSc. Thesis, Department of Civil Engineering, University of Saskatchewan, Saskatoon, Sk.

ZIEGELDORF, S. 1983. Phenomenological aspects of the fracture of concrete. Fracture Mechanics of Concrete, Elsevier Science Publishing Co. Inc., New York, NY. 


\section{APPENDIX A. SPLICE DESIGN AND ANALYSIS}

\section{A.1 ACI Committee 408 Recommendations:}

ACI 408 provides the following equations for determining the basic development length of bars with clear covers greater than $50 \mathrm{~mm}$ and centre to centre bar spacing not less than $127 \mathrm{~mm}$ :

$$
\begin{array}{ll}
1_{d b}=\frac{23 d_{b}}{\phi} & \text { for bars smaller than } 20 \mathrm{M} \text { and } f_{c}^{\prime} \geq 20.7 \mathrm{MPa} \\
& d_{b}=\text { bar diameter }(\mathrm{mm}) \\
& \phi=\text { capacity reduction factor }=0.8
\end{array}
$$

$$
\begin{array}{ll}
l_{d b}=\frac{7.25 \mathrm{~A}_{b}}{\phi \sqrt{\mathrm{f}_{\mathrm{c}}^{\prime}}} & \text { for } 20 \mathrm{M} \text { bars or larger; } \\
& \mathrm{A}_{\mathrm{b}}=\text { area of bar }\left(\mathrm{mm}^{2}\right) ; \\
& \mathrm{f}_{\mathrm{c}}^{\prime}=\text { concrete compressive strength }(\mathrm{MPa}) .
\end{array}
$$

The Canadian code, CSA CAN3-A23.3-M84, utilizes an equation similar to Equation [A.2] for calculating basic development lengths. Analysis of research data has shown that the above equations are unsafe for determining the development of bars with small concrete covers, and spacing, a situation which normally results in splitting failure. Therefore the ACI 408 Committee developed the following equation for $60 \mathrm{ksi}$ (414 $\mathrm{MPa}$ ) reinforcement which accounts directly for the effects of confinement and bar spacing on development and splice length:

$$
\begin{aligned}
l_{\mathrm{db}}=\frac{460 \mathrm{~A}_{\mathrm{b}}}{\phi \mathrm{K} \sqrt{\mathrm{f}_{\mathrm{c}}^{\prime}}} \quad \mathrm{K}= & \text { smaller of } \mathrm{C}_{\mathrm{c}}+\mathrm{K}_{\mathrm{tr}}, \mathrm{C}_{\mathrm{s}}+\mathrm{K}_{\mathrm{tr}}, \text { or } 3 \mathrm{~d}_{\mathrm{b}} \\
\mathrm{C}_{\mathrm{c}}= & \text { thickness of concrete cover measured from } \\
& \text { extreme tension fibre to centre of bar }(\mathrm{mm}) ; \\
\mathrm{C}_{\mathrm{s}}= & \text { smaller of the cover to the centre of the bar } \\
& \text { measured along the line through the layer of } \\
& \text { bars, or half the centre-to-centre distance of } \\
& \text { the bars in a layer }(\mathrm{mm}) ; \\
\mathrm{K}_{\mathrm{tr}}= & \text { an index of the transverse reinforcement } \\
& \text { provided along the anchored bar }(\mathrm{mm}) ; \\
= & \left(\mathrm{A}_{\mathrm{tr}} \mathrm{f}_{\mathrm{y}}\right) /(10.5 \mathrm{~s})<\mathrm{d}_{\mathrm{b}} ; \\
\mathrm{f}_{\mathrm{yt}}= & \text { specified yield strength of transverse } \\
& \text { reinforcement }(\mathrm{MPa}) ; \\
\mathrm{A}_{\mathrm{tr}}= & \text { area of effective transverse reinforcement } \\
& \left(\mathrm{mm} \mathrm{m}^{2}\right) ; \\
\mathrm{s}= & \text { spacing of transverse reinforcement }(\mathrm{mm}) .
\end{aligned}
$$


The term $K$ is a function of the confinement provided, with the cover parameters $\left(C_{c}\right.$ and $\mathrm{C}_{\mathrm{s}}$ ) and the transverse reinforcement index $\mathrm{K}_{\mathrm{tr}}$ both contributing to the bond resistance. Figure A.1 defines the cover parameters, and Figure A.2 provides a description of effective transverse reinforcement. The value of $K_{t r}$ is bound to less than $d_{b}$ and $K$ is restricted to a value less than $3 d_{b}$ to account for the limited effectiveness of confinement when the bond failure mode changes from concrete splitting to bar pullout.

ACI 408 recommends the following modification factors to account for design situations which were not provided for in the design equations. The modification factors are to be applied to the basic development length to give in the development design length:

1) reinforcement having yield strength other than $60 \mathrm{ksi}$ $f_{y} / 60$

2) top horizontal reinforcement where more than 12 in of fresh concrete is cast in the member below the bar

3) lightweight aggregate to replace all or a portion of aggregate

4) reinforcement in a flexural member (not subjected to seismic loads) in excess of that required $\left(A_{\mathrm{sr}}=\right.$ area of steel required ; $A_{\mathrm{sp}}=$ area of steel provided )

The following are the design calculations for the different lap splice configurations considered for this research program. All calculations are based on the ACI 408 Committee recommendations. Figure A.3 presents the specimen configuration used in this study.

\section{A.1.1 Nominal Stirrup Confinement Configuration:}

The lap splice length and number of stirrups (transverse reinforcement) when No. 10 stirrups are provided at a spacing of approximately half the effective beam depth $(d / 2)$ were determined as follows for No. 30 grade $60 \mathrm{ksi}$ (414 MPa) reinforcing steel bars loaded in tension:

Given:

$$
\begin{array}{ll}
A_{t}=100 \mathrm{~mm}^{2} ; & f_{y t}=414 \mathrm{MPa} \\
f_{y}=414 \mathrm{MPa} ; & \phi=0.8 ; \\
A_{b}=700 \mathrm{~mm}^{2} ; & \\
f_{c}=25 \mathrm{MPa} &
\end{array}
$$

Solution:

$$
\begin{aligned}
& C_{c}=50 \mathrm{~mm}+29.9 \mathrm{~mm} / 2=65 \mathrm{~mm} \text { (Governs); } \\
& C_{s}=82.5 \mathrm{~mm}-29.9 \mathrm{~mm} / 2=67.5 \mathrm{~mm} \\
& \mathrm{~s}=\mathrm{d} / 2=443 \mathrm{~mm} / 2=221.5 \mathrm{~mm} .
\end{aligned}
$$



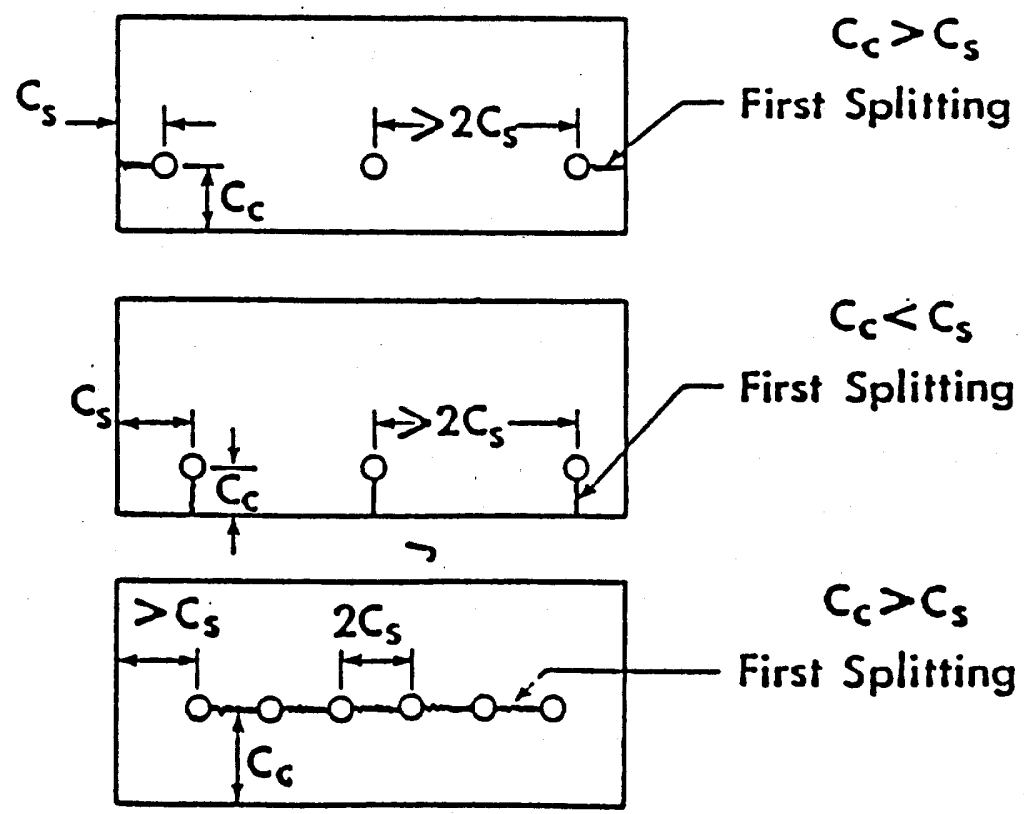

Figure A.1. Definition of Cover Parameters (ACl 4081979 and 1990).

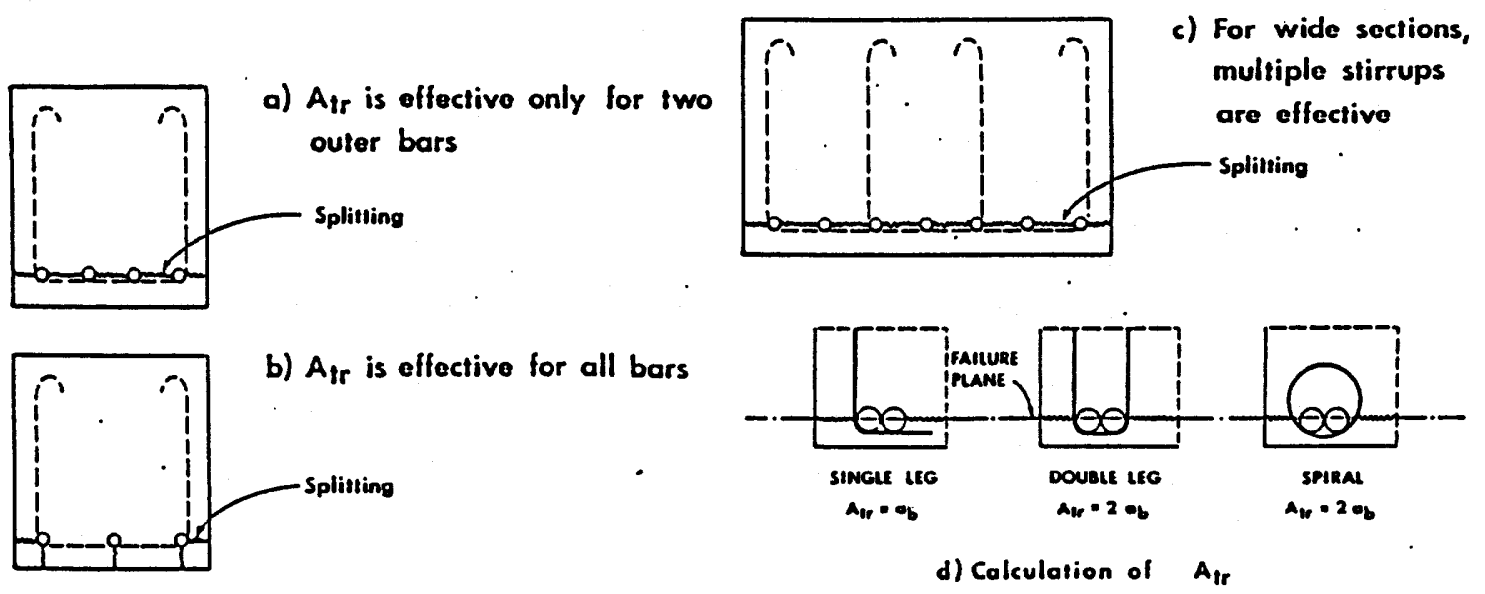

Figure A.2. Effective Transverse Reinforcement (ACl 4081979 and 1990). 


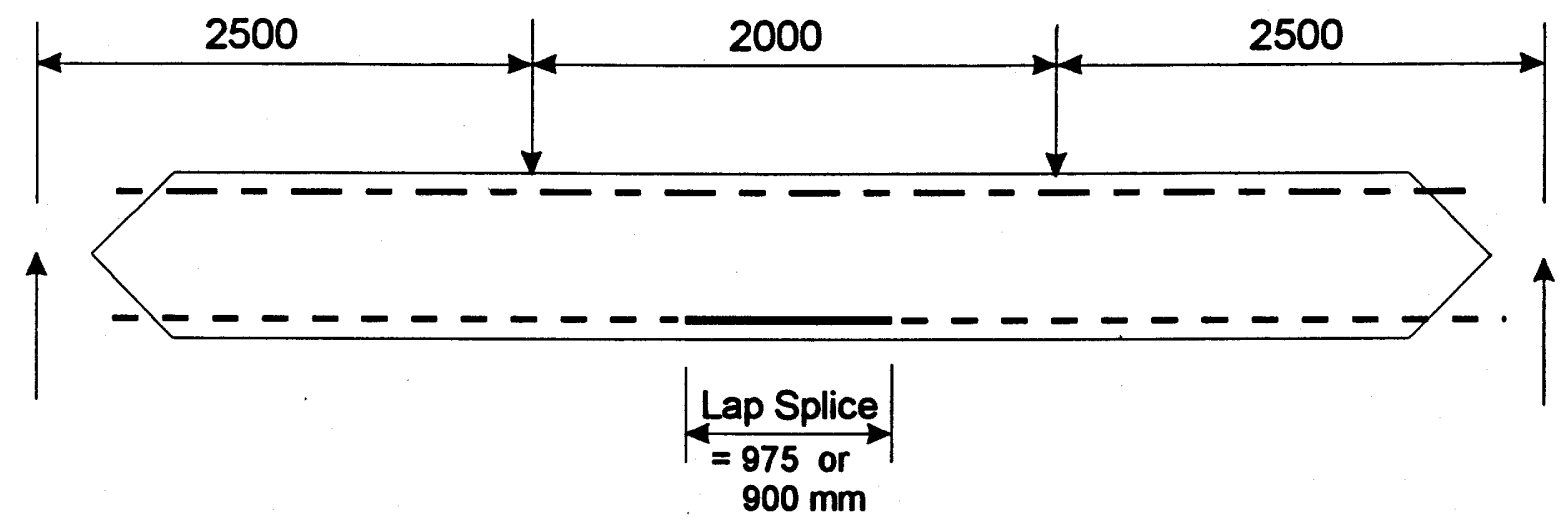

a) Elevation

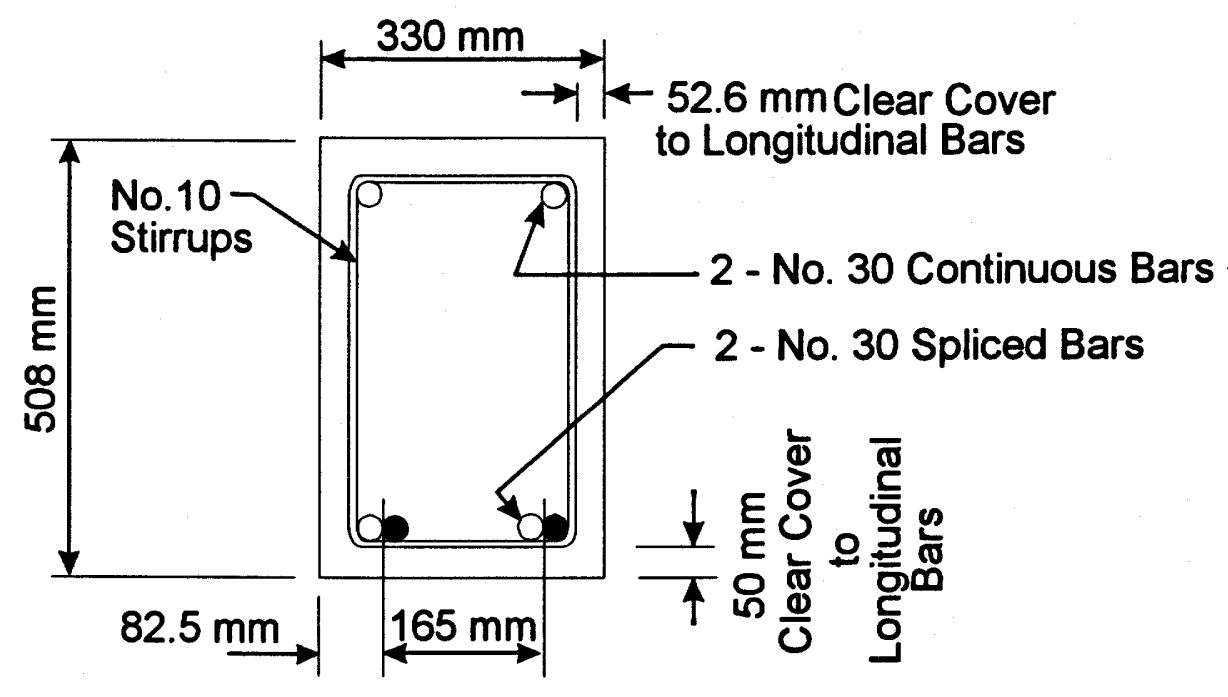

b) Cross Section

Figure A.3. Specimen Details. 


$$
\begin{aligned}
& \mathrm{K}_{\mathrm{tr}}=\frac{100 \mathrm{~mm}^{2}(414 \mathrm{MPa})}{10.5(221.5 \mathrm{~mm})}=17.8 \\
& \mathrm{~K}=65+17.8=82.8 \\
& \mathrm{I}_{\mathrm{d}}=\frac{460\left(700 \mathrm{~mm}^{2}\right)}{0.8(82.8) \sqrt{25 \mathrm{MPa}}}=972.2 \mathrm{~mm}
\end{aligned}
$$

$\therefore$ Assume a splice length of $975 \mathrm{~mm}$.

$$
\begin{aligned}
& \mathrm{K}=\frac{460\left(700 \mathrm{~mm}^{2}\right)}{(975 \mathrm{~mm})(0.8) \sqrt{25 \mathrm{MPa}}}=82.56 \\
& \mathrm{~K}_{\mathrm{tr}}=82.56-65=17.56 \\
& \mathrm{~s}=\frac{100 \mathrm{~mm}^{2}(414 \mathrm{MPa})}{10.5(17.56)}=224.5 \mathrm{~mm} \\
& \text { \# stirrups }=\frac{975 \mathrm{~mm}}{224.5 \mathrm{~mm}}=4.34
\end{aligned}
$$

So, two different quantities of stirrups were used for the nominal stirrup configuration:

1) 4 stirrups spaced at $243.75 \mathrm{~mm}$ o.c. over a splice length of $975 \mathrm{~mm}$;

2) 5 stirrups spaced at $195 \mathrm{~mm}$ o.c. over a splice length of $975 \mathrm{~mm}$;

\section{A.1.2 Heavy Stirrup Confinement Configuration:}

A design utilizing the largest amount of transverse reinforcement deemed effective for static load conditions was determined as follows:

Given: $\quad A_{t}=100 \mathrm{~mm}^{2} ; \quad f_{c}=25 \mathrm{MPa}$;

$$
\begin{array}{ll}
\mathrm{f}_{\mathrm{y}}=414 \mathrm{MPa} ; & \phi=0.8 ; \\
\mathrm{A}_{\mathrm{b}}=700 \mathrm{~mm}^{2} ; & \mathrm{f}_{\mathrm{yt}}=414 \mathrm{MPa}
\end{array}
$$

Solution:

$$
\begin{aligned}
& \mathrm{C}_{\mathrm{c}}=50 \mathrm{~mm}+29.9 \mathrm{~mm} / 2=65 \mathrm{~mm}(\text { Governs }) \\
& \mathrm{C}_{\mathrm{s}}=82.5 \mathrm{~mm}-29.9 \mathrm{~mm} / 2=67.5 \mathrm{~mm} ;
\end{aligned}
$$


The limiting value of $K_{t r}=d_{b}=29.9 \mathrm{~mm}$ will be used to determine the quantity of stirrups:

$$
\text { - solving for } s=\frac{100 \mathrm{~mm}^{2}(414 \mathrm{MPa})}{10.5(29.90)}=131.9 \mathrm{~mm}
$$

The total confinement parameter $K=\left(C_{c} \text { or } C_{s}\right)_{\min }+K_{t r} \leq 3 d_{b}$

$\therefore \mathrm{K}=65+29.9=94.9 \mathrm{~mm} \leq 3(29.9 \mathrm{~mm})=89.7 \mathrm{~mm}$

so $\mathrm{K}=89.7 \mathrm{~mm}$

Based on a $\mathrm{K}=89.7 \mathrm{~mm}$, the development length is:

$$
l_{d}=\frac{460\left(700 \mathrm{~mm}^{2}\right)}{0.8(89.7) \sqrt{25 \mathrm{MPa}}}=897.4 \mathrm{~mm}
$$

Choose $l_{d}=900 \mathrm{~mm}$, maintaining $K_{t r}=d_{b}(s=131.9 \mathrm{~mm})$

$$
\therefore \text { \# stirrups }=\frac{900 \mathrm{~mm}}{131.9 \mathrm{~mm}}=6.8
$$

$\therefore$ use 7 stirrups at $129 \mathrm{~mm}$ o.c. over a splice length of $900 \mathrm{~mm}$.

\section{A.1.3 No Stirrup Confinement Configuration:}

Given:

$$
\begin{array}{ll}
A_{t}=0 \mathrm{~m}^{2} ; & f_{y}=414 \mathrm{MPa} \\
A_{b}=700 \mathrm{~mm}^{2} ; & \phi=0.8 \\
f_{c}=25 \mathrm{MPa} ; &
\end{array}
$$

Solution:

$$
\begin{aligned}
& \mathrm{C}_{\mathrm{c}}=50 \mathrm{~mm}+29.9 \mathrm{~mm} / 2=65 \mathrm{~mm} \text { (Governs); } \\
& \mathrm{C}_{\mathrm{s}}=82.5 \mathrm{~mm}-29.9 \mathrm{~mm} / 2=67.5 \mathrm{~mm} ; \\
& \mathrm{K}_{\mathrm{tr}}=0 \\
& \mathrm{~K}=0+65=65 \\
& \mathrm{l}_{\mathrm{d}}=\frac{460\left(700 \mathrm{~mm}^{2}\right)}{0.8(65) \sqrt{25 \mathrm{MPa}}}=1239 \mathrm{~mm}
\end{aligned}
$$




\section{A.2 Determination of Lap Splice Lengths Based on CSA CAN3-A23.3-M84:}

The current Canadian code determines the length of tension lap splices based a calculation of a basic development length in tension which is then modified by a class factor (A, B or C) to provide the required splice length. The class factor depends on the level of stress in the reinforcement and the amount of reinforcement spliced at the splice location.

The following is the calculation of the lap splice length for the beam configuration used in the current study utilizing the CSA CAN3-A23.3-M84 design equations:

[A.4]

$$
1_{d b}=\frac{0.019 A_{b} f_{y}}{\sqrt{f_{c}^{\prime}}}>0.058 d_{b} f_{y}
$$

Given:

$$
\begin{aligned}
& d_{b}=29.9 \mathrm{~mm} ; \\
& A_{b}=700 \mathrm{~mm} ; \\
& f_{c}=25 \mathrm{MPa} ; \\
& f_{y}=400 \mathrm{MPa} ;
\end{aligned}
$$

Solution:

1) determine the basic development length:

$$
\begin{aligned}
& l_{\mathrm{db}}=\frac{0.019\left(700 \mathrm{~mm}^{2}\right)(400 \mathrm{MPa})}{\sqrt{25 \mathrm{MPa}}}>0.058(29.9 \mathrm{~mm})(400 \mathrm{MPa}) \\
& 1_{\mathrm{db}}=1064 \mathrm{~mm}>694 \mathrm{~mm}
\end{aligned}
$$

$\therefore$ use a basic development length of $1064 \mathrm{~mm}$ for a specified (nominal) yield strength $\mathrm{f}_{\mathrm{y}}$ $=400 \mathrm{MPa}$.

2) determine the splice length:

$-100 \%$ of bars are spliced at the location under consideration and the ratio of $\frac{A_{s \text { provided }}}{A_{s} \text { required }}$ is less than 2. Therefore the splice in question shall conform to a Class $\mathrm{C}$ tension lap splice which requires a modification factor of 1.7 (clause 12.15).

$$
-l_{s}=1064 \mathrm{~mm}(1.7)=1809 \mathrm{~mm}
$$


$\therefore$ use a lap splice length of $1809 \mathrm{~mm}$ for a specified (nominal) yield strength $\mathrm{f}_{\mathrm{y}}=400$ MPa.

To compare directly the lap length required by the Canadian code (A23.3) and the ACI 408 recommendations, modify the lap length calculated by the Canadian code for a specified yield strength $\mathrm{f}_{\mathrm{y}}=60 \mathrm{ksi}(414 \mathrm{MPa})$ :

$$
1_{\mathrm{s}}=1809 \mathrm{~mm} \cdot \frac{414 \mathrm{MPa}}{400 \mathrm{MPa}}=1872 \mathrm{~mm}
$$

\section{A.3 Determination of the Specimens' Predicted Static Strength:}

1) Determine total confinement $K$ available using the measured yield strength $f_{y t}=431$ $\mathrm{MPa}$ for the No. 10 stirrups:

$$
\begin{aligned}
& \mathrm{K}_{\mathrm{tr}}=\frac{\mathrm{A}_{\mathrm{tr}} \mathrm{f}_{\mathrm{yt}}}{10.5 \mathrm{~s}}=\frac{100 \mathrm{~mm}^{2}(431 \mathrm{MPa})}{10.5(243.75 \mathrm{~mm})}=16.84 \mathrm{~mm} \\
& \therefore \mathrm{K}=\mathrm{K}_{\mathrm{tr}}+\min .\left(\mathrm{C}_{\mathrm{c}} \text { or } \mathrm{C}_{\mathrm{s}}\right)=16.84 \mathrm{~mm}+65 \mathrm{~mm}=81.84 \mathrm{~mm}
\end{aligned}
$$

2) Calculate the bar stress that the lap splice provided in the specimen is expected to develop:

- With $\phi$ set to 1.0 (no factor of safety) in the ACI 408 recommendations a splice calculated by Equation [A.3] is expected to develop the specified yield strength for U.S. grade $60 \mathrm{ksi}$ reinforcement $(60 \mathrm{ksi}=414 \mathrm{MPa})$. If a lap length other than that determined from Equation [A.3] is provided, the bar stress expected to be developed is:

$$
\sigma_{\mathrm{s}}=414 \mathrm{MPa} \cdot \frac{\text { splice length provided }}{\text { Equation }[\mathrm{A} .3]}
$$

Therefore, using the measured concrete strength $\mathrm{f}_{\mathrm{c}}=28.2 \mathrm{MPa}$, the splice in Specimen 975-ST1-T244 is predicted to develop a bar stress

$$
\sigma_{\mathrm{s} \text { predicted }}=\frac{414 \mathrm{MPa}(975 \mathrm{~mm})(81.84 \mathrm{~mm}) \sqrt{28.2 \mathrm{MPa}}}{(460)\left(700 \mathrm{~mm}^{2}\right)}=544.8 \mathrm{MPa} .
$$


The bar stress calculated at splice failure during static testing is:

$$
\sigma_{\mathrm{s}}=462 \mathrm{MPa}
$$

$\therefore$ the measured static strength of specimen $975-\mathrm{ST} 1-\mathrm{T} 244$ is significantly weaker (18\%) than the predicted static strength.

Using the recommended $\phi$ factor $=0.8$ in design would provide a splice length $25 \%$ longer $(1 / 0.8=1.25)$ and should result in attaining the specified yield strength.

3) Determine predicted static strengths of fatigue specimens based on the measured static strength $\sigma_{\mathrm{s}}$ of reference specimen $975-\mathrm{ST} 1-\mathrm{T} 244$ as follows:

[A.6]

$$
\sigma_{\text {static }}=\sigma_{s \text { reference }} \sqrt{\frac{f_{c}^{\prime}}{f_{c \text { reference }}^{\prime}}} \cdot \frac{K}{K} \cdot \frac{l_{d}}{l_{d \text { reference }}}
$$

Table A.1 lists the results of Equation [A6] for each of the fatigue specimens.

\section{A.4 Analysis of Fatigue Data for Tepfers' Specimens:}

\section{A.4.1 Description of Tepfers' Specimens:}

The study completed by Tepfers' involved fatigue and static testing of numerous specimens with many different lap splices, beam cross sectional configurations, and material properties. Only those specimens that had a similar lap splice reinforcement arrangement to the current program's specimens were selected. The beams selected did not contain any transverse reinforcement confining the lap splice, and had the following configurations and material properties:

Beam Series: 732

Beam Type: A1

Tensile Reinforcement: 2- $16 \mathrm{~mm} \phi$

Lap Length: $520 \mathrm{~mm}$

Beam Size: $160 \mathrm{~mm} \times 200 \mathrm{~mm}(\mathrm{~b} \mathrm{x} \mathrm{h})$

Concrete Cover:

- Side: $30 \mathrm{~mm}$

- Bottom: $20 \mathrm{~mm}$

Conc. Comp. Strength: 20 to $40 \mathrm{MPa}$

Reinforcing Steel Strength: 354 to $733 \mathrm{MPa}$

All of Tepfers' fatigue tested specimens resulted in a bond failure of the lap splice. 
Table A.1. Predicted Specimen Static Strengths.

\begin{tabular}{ccccc} 
Specimen & $\mathrm{I}_{\mathrm{d}}(\mathrm{mm})$ & $\mathrm{K}(\mathrm{mm})$ & $\mathrm{f}_{\mathrm{c}}^{\prime}(\mathrm{MPa})$ & $\sigma_{\text {static }}(\mathrm{MPa})$ \\
\hline 975-ST1-T244 & 975 & 81.84 & 28.2 & - \\
975-F2-T244 & 975 & 81.84 & 30.0 & 477 \\
975-F3-T244 & 975 & 81.84 & 25.7 & 441 \\
900-F4-T129 & 900 & 96.81 & 33.9 & 553 \\
975-F5-T244 & 975 & 81.84 & 37.4 & 532 \\
975-F6-T195 & 975 & 86.05 & 24.8 & 455 \\
975-F7-T195 & 975 & 86.05 & 25.7 & 463 \\
975-F8-T244 & 975 & 81.84 & 30.4 & 480 \\
900-F9-T129 & 900 & 96.81 & 31.8 & 535 \\
\hline
\end{tabular}

\section{A.4.2 Determination of Predicted Static Strengths for Tepfers' Fatigue Specimens:}

Since the fatigue specimens which were considered from Tepfers' study did not contain any transverse reinforcement their predicted static strengths should be based on experimental static beams which did not contain any transverse reinforcement. The variables used in predicting the static strength of the splice include the strength of the concrete, the quantity of concrete confinement (concrete cover and bar spacing), and the lap length. Table A.2 lists some statically tested specimens from Tepfers' study which have a similar beam configuration as Tepfers' fatigue specimens which were considered for the current program.

Since only the concrete cover provided the confinement to the lap splice for the statically tested beams from Tepfers' program, it is possible to determine the efficiency $(\eta)$ of this confinement relative to the strength predicted by the recommendations of ACI Committee 408 (Equation [A.3] ). Knowing the efficiency of the concrete confinement for the static specimens, the static strength of the fatigue specimens can then be predicted.

The following demonstrates the calculation of the estimated static strengths for the fatigue specimens of Tepfers' study :

1) Determine $K$ using the measured material properties from Tepfers' study and Equation [A.3], for each of Tepfers' static specimen:

$$
\begin{aligned}
& -l_{s}=520 \mathrm{~mm} ; \\
& -A_{b}=200 \mathrm{~mm}^{2} ; \\
& -\phi=1.0 \\
& \mathrm{~K}=\frac{460 \mathrm{~A}_{\mathrm{b}}}{\phi \sqrt{\mathrm{f}_{\mathrm{c}}^{\prime}} \mathrm{l}_{\mathrm{s}}} \cdot \frac{\sigma_{\text {static }}}{414 \mathrm{MPa}}=\frac{460\left(200 \mathrm{~mm}^{2}\right)}{1.0 \sqrt{\mathrm{f}_{\mathrm{c}}^{\prime}}(520 \mathrm{~mm})} \cdot \frac{\sigma_{\text {static }}}{414 \mathrm{MPa}}
\end{aligned}
$$


Table A.2. Tepfers' Unconfined Static Test Specimens' Data

\begin{tabular}{|c|c|c|c|c|c|c|}
\hline Specimen & $f_{y}(M P a)$ & $\mathrm{f}_{c}^{\prime}(\mathrm{MPa})$ & $\sigma_{\text {static }}(\mathrm{MPa})$ & $\mathrm{K}(\mathrm{mm})$ & $C_{c}(\mathrm{~mm})$ & $C_{s}(\mathrm{~mm})$ \\
\hline $732-2$ & 607.1 & 22.2 & 392 & 35.81 & 32 & 24 \\
\hline $732-3$ & 613.0 & 35.5 & 493 & 35.53 & 26 & 24 \\
\hline $732-9$ & 588.6 & 20.3 & 488 & 46.51 & 31 & 26 \\
\hline $732-10$ & 588.6 & 26.8 & 511 & 42.44 & 30 & 30 \\
\hline $732-15$ & 422.6 & 27.8 & 411 & 33.53 & 31 & 20 \\
\hline $732-16$ & 420.7 & 32.5 & 441 & 33.19 & 34 & 19 \\
\hline $732-35$ & 588.6 & 37.3 & 551 & 38.81 & 27 & 24 \\
\hline $732-51$ & 504.6 & 25.3 & 389 & 33.19 & 27 & 24 \\
\hline $732-52$ & 504.6 & 24.0 & 380 & 33.31 & 27 & 25 \\
\hline \multirow[t]{2}{*}{$732-54$} & 482.2 & 40.6 & 459 & 30.99 & 25 & 24 \\
\hline & & & AV & 36.33 & 29 & 24 \\
\hline
\end{tabular}

Substituting in the appropriate the material properties for each specimen, the value $\mathrm{K}$ is resolved. The results of this calculation for each of Tepfers' static specimens are listed in Table A.2.

2) Determine efficiency of concrete cover confinement for Tepfers' static tests:

$\mathrm{K}=\mathrm{K}_{\mathrm{tr}}+\left(\mathrm{C}_{\mathrm{s}} \text { or } \mathrm{C}_{\mathrm{c}}\right)_{\min }$

For the beam configuration under consideration $\mathrm{K}=\mathrm{K}_{\mathrm{tr}}+\mathrm{C}_{\mathrm{c}}$ governs and $\mathrm{K}_{\mathrm{tr}}=0$.

$\therefore$ theoretically $\mathrm{K}=\mathrm{C}_{\mathrm{s}}$

So, from Table A.2 the efficiency of the concrete cover $\left(\mathrm{C}_{\mathrm{s}}\right)$ with respect to the total lap splice confinement resistance can be determined as follows:

$$
\begin{aligned}
& \mathrm{K}=\frac{36.33}{24} \mathrm{C}_{\mathrm{s}}=1.5214 \mathrm{C}_{\mathrm{s}} \\
& \therefore \eta=1.5214
\end{aligned}
$$

so, $\mathrm{K} \approx 1.5 \mathrm{C}_{\mathrm{s}}$ for Tepfers' static test specimens.

2) Determine predicted static strengths for Tepfers' fatigue tests from Equation [A.5] using Specimen 732-23 as an example:

$$
\begin{array}{ll}
l_{s}=520 \mathrm{~mm} ; & A_{b}=201.1 \mathrm{~mm}^{2} ; \quad \phi=1.0 ; \\
f_{c}=31.6 \mathrm{MPa} ; & \mathrm{f}_{\mathrm{y}}=414 \mathrm{MPa} ; \\
\mathrm{K}=1.5 \mathrm{C}_{\mathrm{s}}=1.5(23 \mathrm{~mm})=34.5 \mathrm{~mm}
\end{array}
$$


$\sigma_{\text {static }}=\frac{414 \mathrm{MPa}\left(\mathrm{K} \sqrt{\mathrm{f}_{\mathrm{c}}^{\prime}}\right) 1_{\mathrm{s}}}{460\left(\mathrm{~A}_{\mathrm{b}}\right)}=\frac{414 \mathrm{MPa}(34.5 \mathrm{~mm}) \sqrt{31.6 \mathrm{MPa}}(520 \mathrm{~mm})}{460\left(201.1 \mathrm{~mm}^{2}\right)}=451 \mathrm{MPa}$

Table A.3 shows the results of the calculations for the predicted static strength of all the specimens.

Table A.3. Predicted Static Strengths for Tepfers' Fatigue Test Specimens

\begin{tabular}{ccccc} 
Specimen & $C_{\mathbf{s}}(\mathrm{mm})$ & $K(\mathrm{~mm})$ & $\mathrm{f}_{\mathrm{c}}^{\prime}(\mathrm{MPa})$ & $\sigma_{\text {static }}(\mathrm{MPa})$ \\
\hline $732-23$ & 23 & 34.5 & 31.6 & 451 \\
$732-25$ & 21 & 31.5 & 31.6 & 412 \\
$732-26$ & 25 & 37.5 & 31.6 & 491 \\
$732-27$ & 27 & 40.5 & 32.7 & 539 \\
$732-33$ & 26 & 39.0 & 29.9 & 496 \\
$732-79$ & 20 & 30.0 & 38.4 & 433 \\
$732-81$ & 32 & 48.0 & 43.0 & 733 \\
$732-82$ & 30 & 45.0 & 37.7 & 643 \\
$732-83$ & 28 & 42.0 & 40.2 & 620 \\
$732-89$ & 28 & 42.0 & 46.2 & 664 \\
$732-91$ & 27 & 40.5 & 42.0 & 611 \\
$732-92$ & 27 & 40.5 & 44.3 & 627 \\
$732-93$ & 28 & 42.0 & 43.2 & 642 \\
$732-94$ & 26 & 39.0 & 44.3 & 604 \\
$732-95$ & 27 & 40.5 & 41.9 & 610 \\
$732-96$ & 30 & 45.0 & 15.3 & 410 \\
$732-97$ & 29 & 43.5 & 50.5 & 719 \\
$732-99$ & 26 & 39.0 & 45.6 & 613 \\
$732-162$ & 26 & 39.0 & 77.6 & 800 \\
$732-165$ & 22 & 33.0 & 85.1 & 708 \\
$732-166$ & 26 & 39.0 & 87.3 & 848 \\
\hline
\end{tabular}




\section{APPENDIX B. REGRESSION ANALYSIS OF BOND FAILURES}

A regression analysis was performed on the specimens which failed from bond fatigue. The regression line analysis was based on the following equation:

$$
\begin{aligned}
& \frac{\sigma_{\mathrm{s} \max }}{\sigma_{\text {static }}}=1-\beta(1-\mathrm{R}) \log (\mathrm{N}) \quad \beta=\text { regression constant; } \\
& \mathbf{R}=\sigma_{\mathrm{s} \min } / \sigma_{\mathrm{s} \max } \\
& \sigma_{\mathrm{s} \text { max }}, \sigma_{\mathrm{s} \text { min }}=\text { maximum and minimum } \\
& \text { stresses in tensile } \\
& \text { reinforcement of the } \\
& \text { specimen at the maximum } \\
& \text { moment location (MPa). }
\end{aligned}
$$

This is the form of a linear equation and may be represented as follows:

$$
\begin{array}{ll}
\mathrm{y}=\mathrm{mx}+\mathrm{b} & \mathrm{y}=\frac{\sigma_{\mathrm{s} \max }}{\sigma_{\mathrm{s} \min }} \\
\mathrm{m}=\operatorname{slope}=\beta(1-\mathrm{R}) & \mathrm{x}=\log (\mathrm{N}) ; \\
\mathrm{b} & =\mathrm{y} \text {-intercept }=1.00
\end{array}
$$

Which may also be written as:

$$
\begin{array}{ll}
x=m^{\prime} y+b^{\prime} & m^{\prime}=-\frac{1}{\beta(1-R)} ; \\
b^{\prime}=x \text {-intercept. }
\end{array}
$$

The first analysis included the data from Series A and B while a similar analysis was performed for the data obtain from Tepfers (1973).

\section{B.1. Regression Line Analysis of U of S Data:}

The line of regression of $x$ on $y$ (Equation [B.3]) was established with the use the Method of Least Squares as described by Kennedy and Neville (1976). The slope and $x$-intercept 
may be determined by the following equations:

$$
\begin{aligned}
& b^{\prime}=\frac{\sum y^{2} \sum x-\sum y \sum x y}{n \sum y^{2}-\left(\sum y\right)^{2}} \quad n=\text { number of samples; } \\
& m^{\prime}=\frac{n \sum y x-\sum y \sum x}{n \sum y^{2}-\left(\sum y\right)^{2}}
\end{aligned}
$$

In obtaining this line it is assumed that $y$ is the assigned variable, meaning it is essentially free from error, and the variable $\mathrm{x}$ is the observed quantity.

Kennedy and Neville (1976) show that Equations [B.2] and [B.3] describe the line which passes "...through the point whose coordinates are the appropriate means of all the observations...", $(\bar{x}, \bar{y})$. Also, the value of the y-intercept according to Equation [B.1] should be 1.00 , and therefore the regression line was forced through this intercept. This was accomplished by assuming the line passes through the point with coordinates of $(0,1)$. Thus using these two distinct points, $(\bar{x}, \bar{y})$ and $(0,1)$, and Equation [B.3], a "best" fit line could be defined for the test data by solving the two simultaneous equations. The results of these calculations are as follows:

$$
\begin{aligned}
& m^{\prime}=-17.60 \\
& b^{\prime}=17.60
\end{aligned}
$$

Using an average value of $R$ equal to $0.34, \beta$ in Equation [B.1] can be determined as 0.086 , thus providing the following regression line for the $U$ of $S$ data:

$$
\frac{\sigma_{\mathrm{smax}}}{\sigma_{\text {static }}}=1-0.086(1-0.34) \log (\mathrm{N}) \text {. }
$$

\section{B.2. Regression Line Analysis of Tepfers' Data:}

A similar procedure was performed on the data collected from Tepfers' study and this resulted in the following:

$$
\begin{aligned}
& m^{\prime}=-13.50 \\
& b^{\prime}=13.50
\end{aligned}
$$

then, solving for $\beta$ in Equation [B.1] the following regression line for the Tepfers' data 
Table B.1. Calculation of Residuals for $U$ of $S$ Data with Respect to Regression Line.

\begin{tabular}{|c|c|c|c|c|c|c|c|}
\hline & Specimen & $\mathbf{R}$ & $x$ & $y$ & $\left(y-y_{\text {mean }}\right)^{2}$ & e & $e^{2}$ \\
\hline & $\begin{array}{l}\text { 975-F3-T244 } \\
\text { 975-F6-T195 } \\
\text { 975-F7-T195 } \\
\text { 975-F8-T244 }\end{array}$ & $\begin{array}{l}0.35 \\
0.33 \\
0.33 \\
0.33\end{array}$ & $\begin{array}{l}3.82 \\
4.69 \\
4.08 \\
4.66\end{array}$ & $\begin{array}{l}0.77 \\
0.77 \\
0.75 \\
0.73\end{array}$ & & & $\begin{array}{l}3.035 \mathrm{E}-02 \\
3.669 \mathrm{E}-01 \\
6.581 \mathrm{E}-02 \\
1.924 \mathrm{E}-02\end{array}$ \\
\hline & $\begin{array}{r}\Sigma= \\
\text { Avg. }=\end{array}$ & $\begin{array}{l}1.35 \\
0.34\end{array}$ & $\begin{array}{l}17.25 \\
4.31\end{array}$ & $\begin{array}{l}3.01 \\
0.75\end{array}$ & & $\begin{array}{l}3.629 \mathrm{E}-02 \\
9.073 \mathrm{E}-03\end{array}$ & 1.206E-01 \\
\hline
\end{tabular}

results:

$$
\frac{\sigma_{\mathrm{s} \max }}{\sigma_{\text {static }}}=1-0.119(1-0.38) \log (\mathrm{N})
$$

\section{B.3. Calculation of the Confidence Limits for $\mathrm{U}$ of $\mathrm{S}$ Data:}

Kennedy and Neville defined the variance of $x$, estimated by the regression line of $x$ on $y$, as the sum of squares of deviations divided by the number of degrees of freedom $v$ available for calculating the regression line:

$$
\begin{aligned}
s_{x \mid y}^{2}=\frac{\sum \varepsilon_{i}^{2}}{v} \quad v & =n-2 ; \\
\varepsilon_{i} & =\text { residual }=y_{i}-\left(a+b x_{i}\right) ;
\end{aligned}
$$

To determine the confidence limits for $x_{i}$ corresponding to a specified value of $y_{i}$, the variance for the mean estimated value of $x_{i}$ needs to be determined as follows:

$$
s_{x i}^{2}=s_{x}^{2}\left[\frac{1}{n}+\frac{\left(y_{i}-\bar{y}\right)^{2}}{\sum(y-\bar{y})^{2}}\right] \quad \bar{y}=\frac{\sum y}{n}
$$

The confidence interval for the mean estimated value of $x_{i}$ is then:

$$
x_{i} \pm s_{x i}
$$

where the probability of being wrong is equal to the specified level of significance of the value of the normal distribution $t$. The distribution of $t$ can be found in the literature for different degrees of freedom and appropriate probabilities of error, $\alpha$.

The residuals of the $\mathrm{U}$ of $\mathrm{S}$ data with respect to the regression line were determined as shown in Table B.1. Then, using Equation B.6, a value for $\cdot \mathrm{s}_{\mathrm{yyx}}$ was calculated as 0.2411 . For a $95 \%$ confidence level $(\alpha=0.05)$, and the degrees of freedom $v=2(4$ specimens 2 ), the value of $t$ was determined as 4.303 (Kennedy and Neville 1976) and the 
Table B.2. Determination of Confidence Limits for $U$ of $S$ Data.

\begin{tabular}{ccccccc}
$\mathbf{y}(\%)$ & $\mathbf{y}$ & $\mathbf{x}$ & $\mathbf{s}_{\mathbf{x i}}$ & $\mathbf{s}_{\mathbf{x i}}{ }^{2}$ & $\mathbf{x}-\mathbf{t} \cdot \mathbf{s}_{\mathbf{x i}}$ & $\mathbf{x}+\mathbf{t} \cdot \mathbf{s}_{\mathbf{x i}}$ \\
\hline 100 & 1.0 & 0.00 & $6.90 E-02$ & $2.63 E-01$ & -1.13 & 1.13 \\
90 & 0.9 & 1.75 & $6.34 E-02$ & $2.52 E-01$ & 0.67 & 2.83 \\
80 & 0.8 & 3.49 & $6.06 E-02$ & $2.46 E-01$ & 2.43 & 4.55 \\
70 & 0.7 & 5.24 & $6.07 E-02$ & $2.46 E-01$ & 4.18 & 6.30 \\
50 & 0.5 & 8.73 & $6.95 E-02$ & $2.64 E-01$ & 7.59 & 9.86 \\
30 & 0.3 & 12.22 & $8.99 E-02$ & $3.00 E-01$ & 10.93 & 13.51
\end{tabular}

confidence lines were calculated as shown in Tables B.2.

\section{B.4 Rejection of Outliers:}

Kennedy and Neville (1976) discuss the rejection of outliers, which may be defined as an observation that does not fall within the expected range. They state that it would be reasonable under normal circumstances to reject an observation that differs from the mean by more than the confidence limits. They state that such a rejection is justified since the it may be of interest to only test representative samples and the sample containing such a large deviation is not representative. However, they also state that it is important not to reject indiscriminately observations that appear to be more widely scattered than would be liked.

In the above analysis, the Specimen 975-F2-T244 was not considered in the determination of the regression line due to the following reasons. This specimen was provided with a significant number of strain gauges and protection material along the length of the lap that may have resulted in a reduced bond resistance between the rebar and the surrounding concrete thus causing the specimen to fail in bond after only 720 number of cycles. Another possible reason for this specimen's unusually low cycles at failure may have been due to the overloading that it saw during the fatigue testing. Such an overloading condition may have caused extensive damage from increased cracking to the concrete confinement surrounding the lap splice, thus significantly reducing the subsequent bond fatigue resistance. Because it was suspected that the test results for this specimen may not be representative of the true fatigue lap splice strength, this data point was not used in the determination of the regression line so as not to distort the line from the more accurate results obtained from the other specimens. As Figure 4.13 shows the data point for Specimen 975-F2-T244 does not lie within the confidence limits for the regression line based on the analysis of the four remaining bond failures. This suggests that the rejection of this Specimen 975-F2-T244 from regression analysis is justified. 


\section{APPENDIX C. MOMENT - CURVATURE PROGRAM}

To obtain the theoretical load-deflection data for each of the specimens in the current study a computer program (Tsui and Rezansoff 1982) which applies beam momentcurvature relationships to determine stresses, strains and deflections based on "effective" moment of inertia principles, was used. Measured material properties and specimen dimensions were utilized with the program. Material properties included in the analysis were the stress-strain curve for the reinforcing steel found from static coupon tension tests, and the concrete compressive strength.

From the program's output data the maximum and minimum reinforcing steel stresses during testing were estimated for each specimen.

A sample of the output from the computer program for one of the specimens (975-F2T244) is presented on the following pages of this appendix. 
Table C.1. Computer Analysis Output for Specimen 975-F2-T244

Moment-Curvature-Steel Stress Relationships Based on Fully Cracked Concrete Section

\begin{tabular}{|c|c|c|c|c|}
\hline $\begin{array}{c}\text { Curvature } \\
\left(1 / \mathrm{m} \times 10^{-4}\right)\end{array}$ & $\begin{array}{l}\text { Moment } \\
(\mathrm{kN}-\mathrm{m})\end{array}$ & $\begin{array}{l}\text { Neu-Axis } \\
(\mathrm{mm})\end{array}$ & $\begin{array}{c}\text { Steel Stress } \\
(\mathrm{MPa})\end{array}$ & $\begin{array}{c}\text { Con-Stress } \\
\text { (MPa) }\end{array}$ \\
\hline 0 & 0.000 & 125.0 & 0.00 & 0.00 \\
\hline 5 & 16.965 & 118.9 & 30.26 & 1.74 \\
\hline 10 & 33.921 & 118.9 & 60.53 & 3.45 \\
\hline 15 & 50.773 & 119.3 & 90.65 & 5.11 \\
\hline 20 & 67.576 & 119.6 & 120.72 & 6.73 \\
\hline 25 & 85.686 & 121.1 & 153.26 & 8.39 \\
\hline 30 & 104.087 & 122.4 & 186.41 & 9.99 \\
\hline 35 & 122.430 & 123.6 & 219.49 & 11.56 \\
\hline 40 & 679.000 & 124.6 & 252.45 & 13.08 \\
\hline 45 & 157.972 & 125.1 & 283.67 & 14.49 \\
\hline 50 & 175.132 & 125.5 & 214.68 & 15.86 \\
\hline 55 & 191.853 & 125.9 & 344.93 & 17.17 \\
\hline 60 & 208.451 & 126.3 & 374.99 & 18.41 \\
\hline 65 & 224.657 & 126.6 & 404.37 & 19.6 \\
\hline 70 & 240.170 & 126.8 & 432.49 & 20.71 \\
\hline 75 & 254.829 & 126.8 & 459.04 & 21.72 \\
\hline 80 & 255.938 & 123.1 & 459.95 & 22.25 \\
\hline 85 & 256.988 & 119.7 & 460.87 & 22.75 \\
\hline 90 & 257.985 & 116.6 & 461.79 & 23.21 \\
\hline 95 & 258.941 & 113.8 & 462.72 & 23.66 \\
\hline 100 & 259.798 & 111.3 & 463.53 & 24.09 \\
\hline 105 & 260.596 & 108.9 & 464.29 & 24.48 \\
\hline 110 & 261.363 & 106.7 & 465.06 & 24.86 \\
\hline 115 & 262.108 & 104.6 & 465.82 & 25.24 \\
\hline 120 & 262.829 & 102.7 & 466.59 & 25.57 \\
\hline 125 & 263.481 & 101.0 & 467.27 & 25.90 \\
\hline 130 & 264.061 & 99.3 & 467.84 & 26.22 \\
\hline 135 & 264.624 & 97.7 & 468.42 & 26.51 \\
\hline 140 & 265.171 & 96.3 & 469.00 & 26.79 \\
\hline 145 & 265.707 & 94.9 & 469.58 & 27.06 \\
\hline 150 & 266.287 & 93.6 & 470.27 & 27.33 \\
\hline 155 & 267.006 & 92.4 & 471.23 & 27.56 \\
\hline 160 & 267.715 & 91.3 & 472.2 & 27.80 \\
\hline 165 & 268.416 & 90.2 & 473.16 & 28.03 \\
\hline 170 & 269.108 & 89.2 & 474.13 & 28.24 \\
\hline 175 & 269.864 & 88.3 & 475.23 & 28.43 \\
\hline 180 & 271.263 & 87.5 & 477.52 & 28.63 \\
\hline 205 & 278.255 & 84.2 & 489.15 & 29.42 \\
\hline 210 & 279.719 & 83.7 & 491.62 & 29.54 \\
\hline 215 & 281.178 & 83.1 & 494.1 & 29.65 \\
\hline 220 & 282.634 & 82.7 & 496.58 & 29.74 \\
\hline 225 & 284.081 & 82.2 & 499.05 & 29.81 \\
\hline
\end{tabular}


Table C.2. Computer Analysis Output for Specimen 975-F2-T244

\begin{tabular}{|c|c|c|}
\hline \multicolumn{3}{|c|}{ Load-Deflection Relationship } \\
\hline $\begin{array}{c}\text { Load } \\
\left(1 / \mathrm{m} \times 10^{-4}\right)\end{array}$ & $\begin{array}{l}\text { Moment } \\
(\mathrm{kN}-\mathrm{m})\end{array}$ & $\begin{array}{l}\text { Deflection } \\
(\mathrm{mm})\end{array}$ \\
\hline 0.0000 & 0.00000 & 0.000 \\
\hline 2.5000 & 6.24999 & 0.254 \\
\hline 5.0000 & 12.49997 & 0.508 \\
\hline 7.5000 & 18.74995 & 0.762 \\
\hline 10.0000 & 24.99994 & 1.016 \\
\hline 12.5000 & 31.24992 & 1.270 \\
\hline 15.0000 & 37.49991 & 1.524 \\
\hline 17.5000 & 43.74989 & 1.778 \\
\hline 20.0000 & 49.99988 & 2.032 \\
\hline 22.5000 & 56.24986 & 2.361 \\
\hline 25.0000 & 62.49985 & 3.118 \\
\hline 27.5000 & 68.74982 & 4.023 \\
\hline 30.0000 & 74.99981 & 5.024 \\
\hline 32.5000 & 81.24979 & 6.077 \\
\hline 35.0000 & 87.49978 & 7.152 \\
\hline 37.5000 & 93.74976 & 8.228 \\
\hline 40.0000 & 99.99975 & 9.294 \\
\hline 42.5000 & 106.24970 & 10.341 \\
\hline 45.0000 & 112.49970 & 11.368 \\
\hline 47.5000 & 118.74970 & 12.374 \\
\hline 50.0000 & 124.99970 & 13.359 \\
\hline 52.5000 & 131.24970 & 14.327 \\
\hline 55.0000 & 137.49970 & 15.277 \\
\hline 57.5000 & 143.74970 & 16.215 \\
\hline 65.0000 & 162.49960 & 18.953 \\
\hline 67.5000 & 168.74960 & 19.484 \\
\hline 70.0000 & 174.99960 & 20.735 \\
\hline 72.5000 & 181.24960 & 21.623 \\
\hline 75.0000 & 187.49960 & 22.506 \\
\hline 77.5000 & 193.74960 & 23.385 \\
\hline 80.0000 & 199.99960 & 24.261 \\
\hline 82.5000 & 206.24950 & 25.133 \\
\hline 85.0000 & 212.49950 & 26.008 \\
\hline 87.5000 & 218.74950 & 26.882 \\
\hline 90.0000 & 224.99950 & 27.754 \\
\hline 92.5000 & 231.24950 & 28.636 \\
\hline 95.0000 & 237.49950 & 29.519 \\
\hline 97.5000 & 243.74950 & 30.412 \\
\hline 100.0000 & 249.99950 & 31.313 \\
\hline 102.5000 & 256.24950 & 33.055 \\
\hline 105.0000 & 262.49940 & 39.025 \\
\hline
\end{tabular}


Table C.2. Computer Analysis Output for Specimen 975-F2-T244 (cont'd)

\begin{tabular}{ccc}
\multicolumn{3}{c}{ Load-Deflection Relationship } \\
\hline $\begin{array}{c}\text { Load } \\
\left(1 / \mathrm{m} \times 10^{-4}\right)\end{array}$ & $\begin{array}{c}\text { Moment } \\
(\mathrm{kN}-\mathrm{m})\end{array}$ & $\begin{array}{c}\text { Deflection } \\
(\mathrm{mm})\end{array}$ \\
\hline 107.5000 & 268.74950 & 47.428 \\
110.0000 & 274.99940 & 53.004 \\
112.5000 & 281.24940 & 58.184 \\
115.0000 & 284.08110 & 60.571 \\
\hline
\end{tabular}




\section{APPENDIX D. MTS LOAD - DEFLECTION PLOTS}

The following figures were created using the X-Y plotter connected to the MTS control units by intermittently placing the plotter pen on the paper during the testing of each specimen. For the static test of specimen 975-ST1-T244, the pen was allowed to plot during the whole testing procedure, thus providing a plot for the complete life of the specimen.

The plots represent the load-deflection curves at a MTS load cell location for the specimens and provided an indication of the progressive increase in deflection that was occurring in the specimens as the testing continued.

The loads and deflections that were plotted were adjusted to account for self-weight of the specimens. 


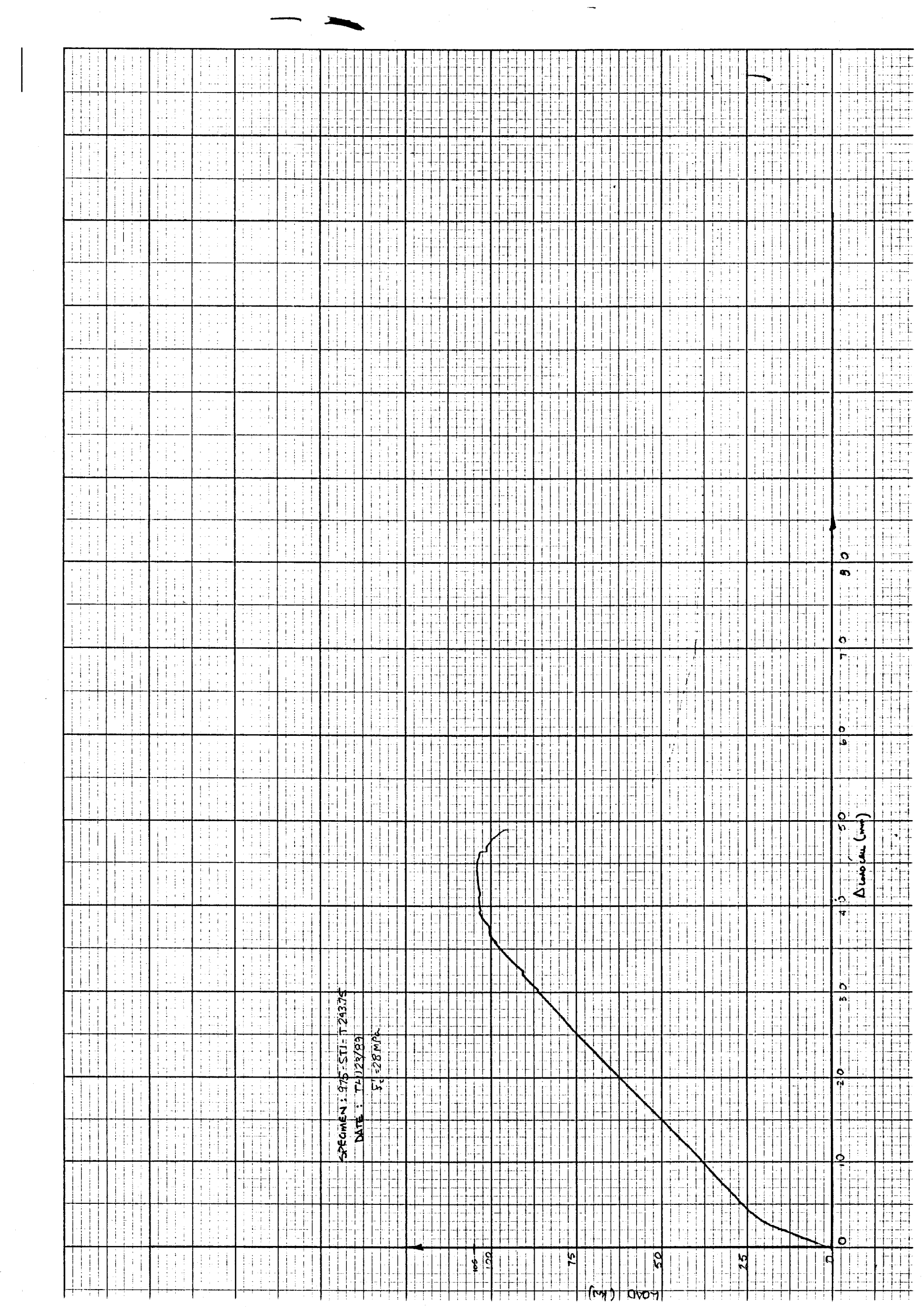




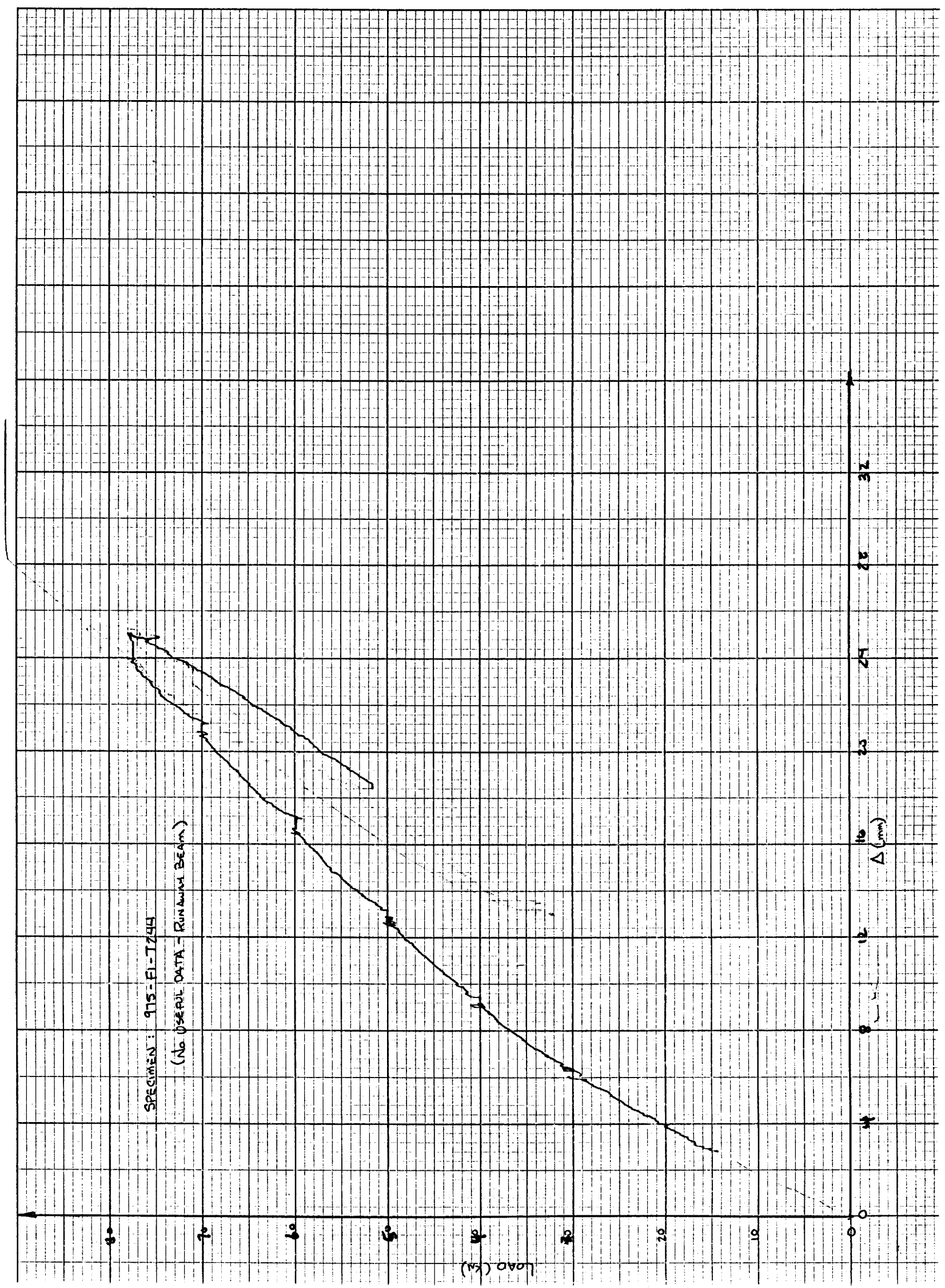




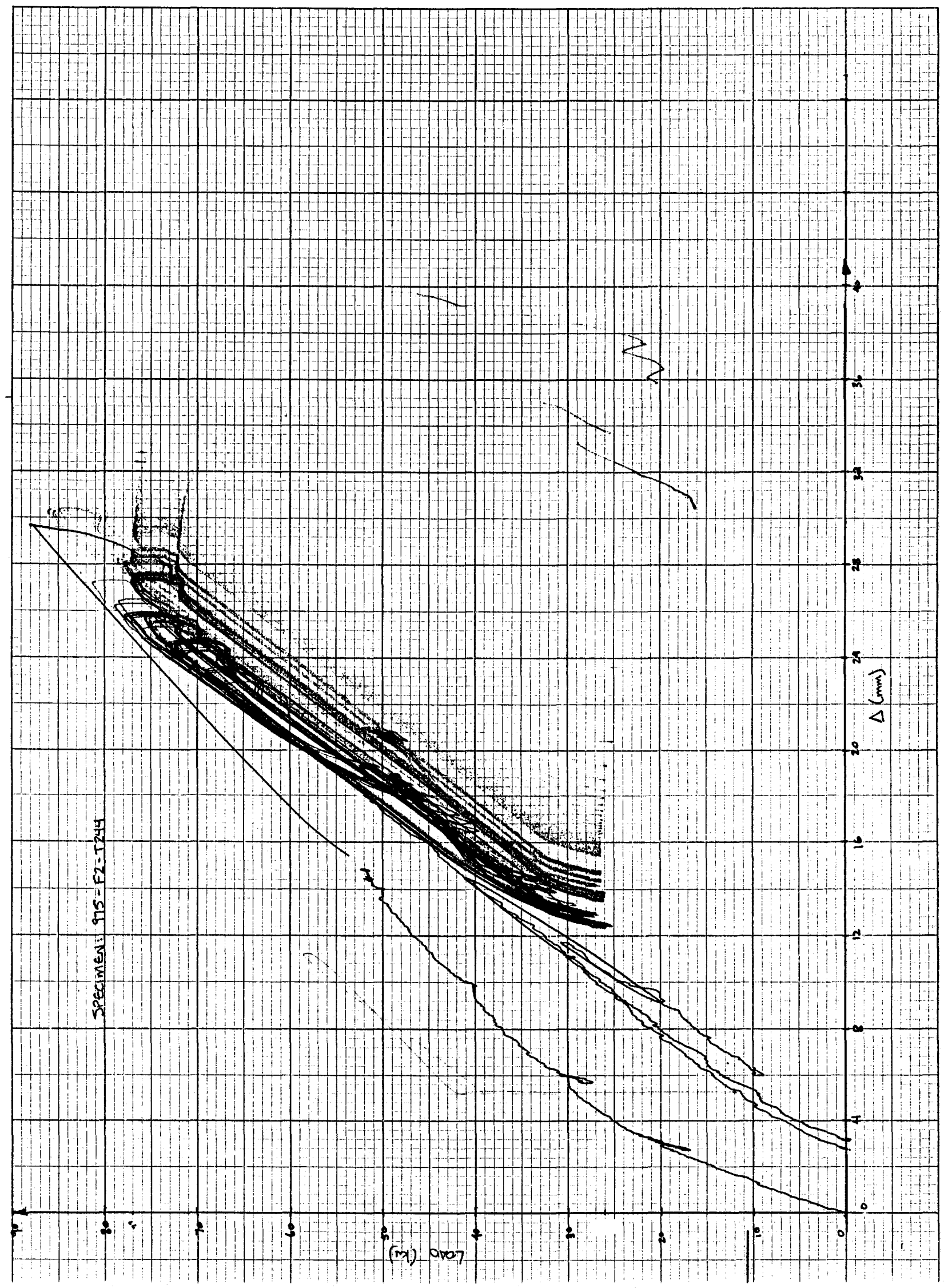




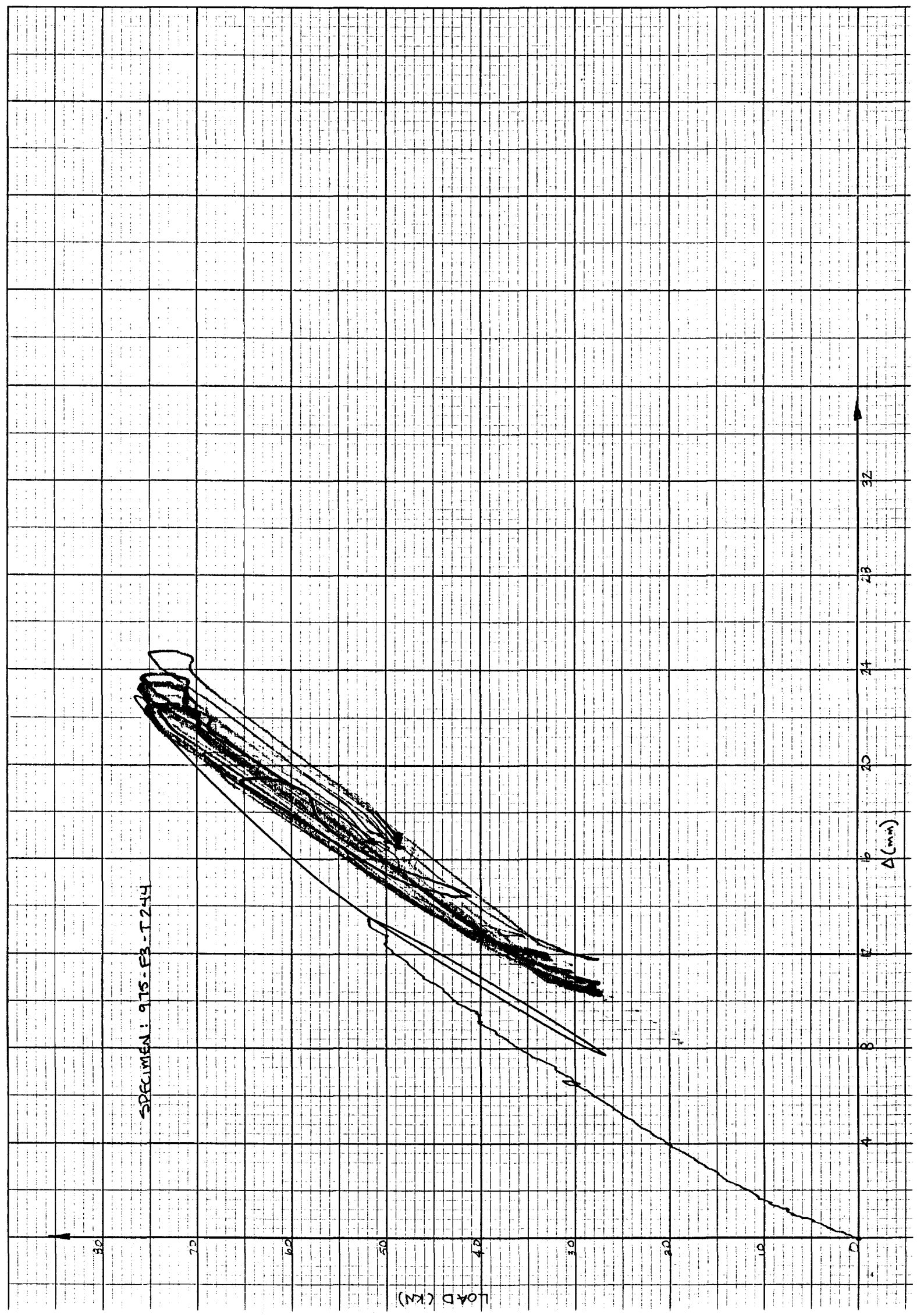




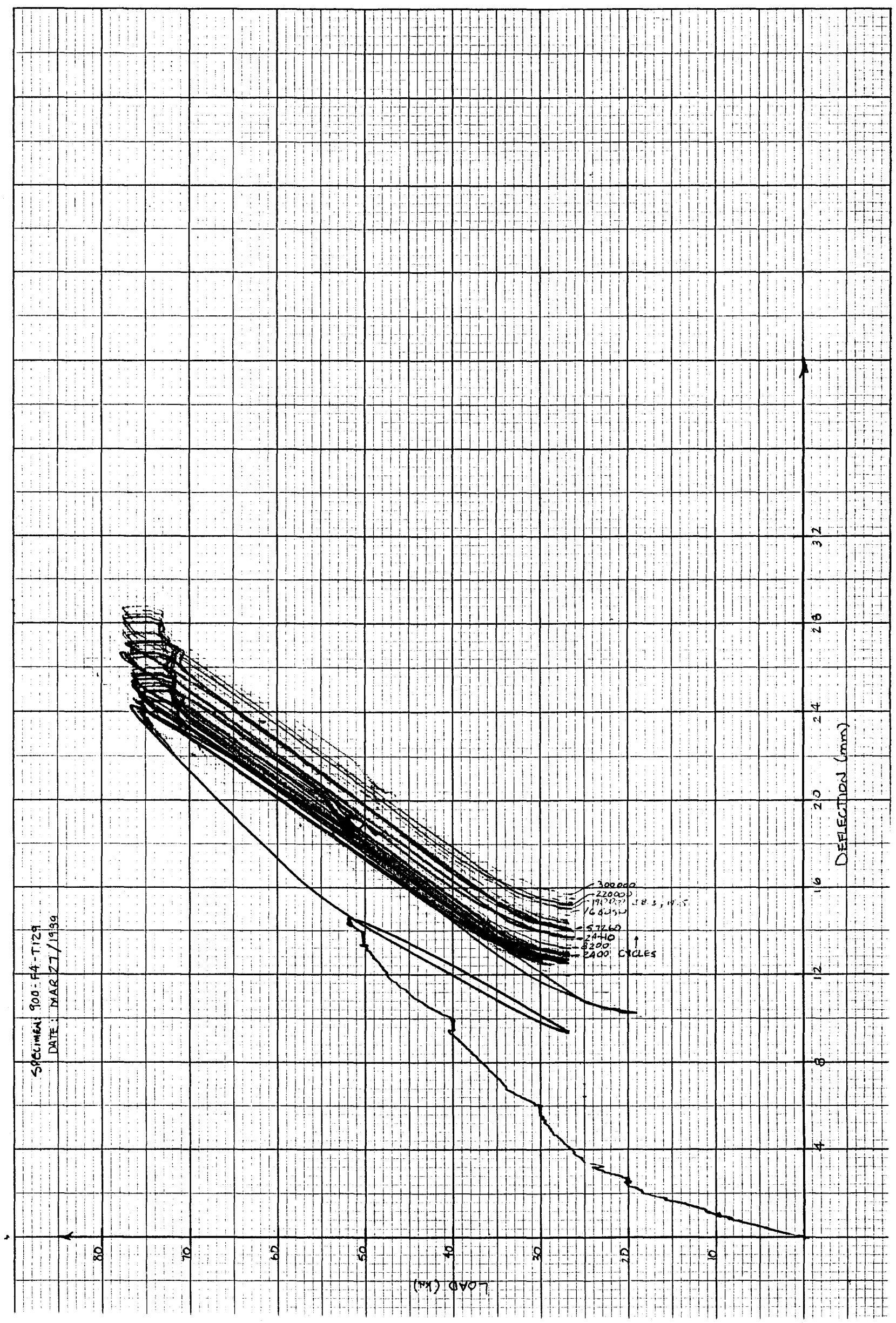




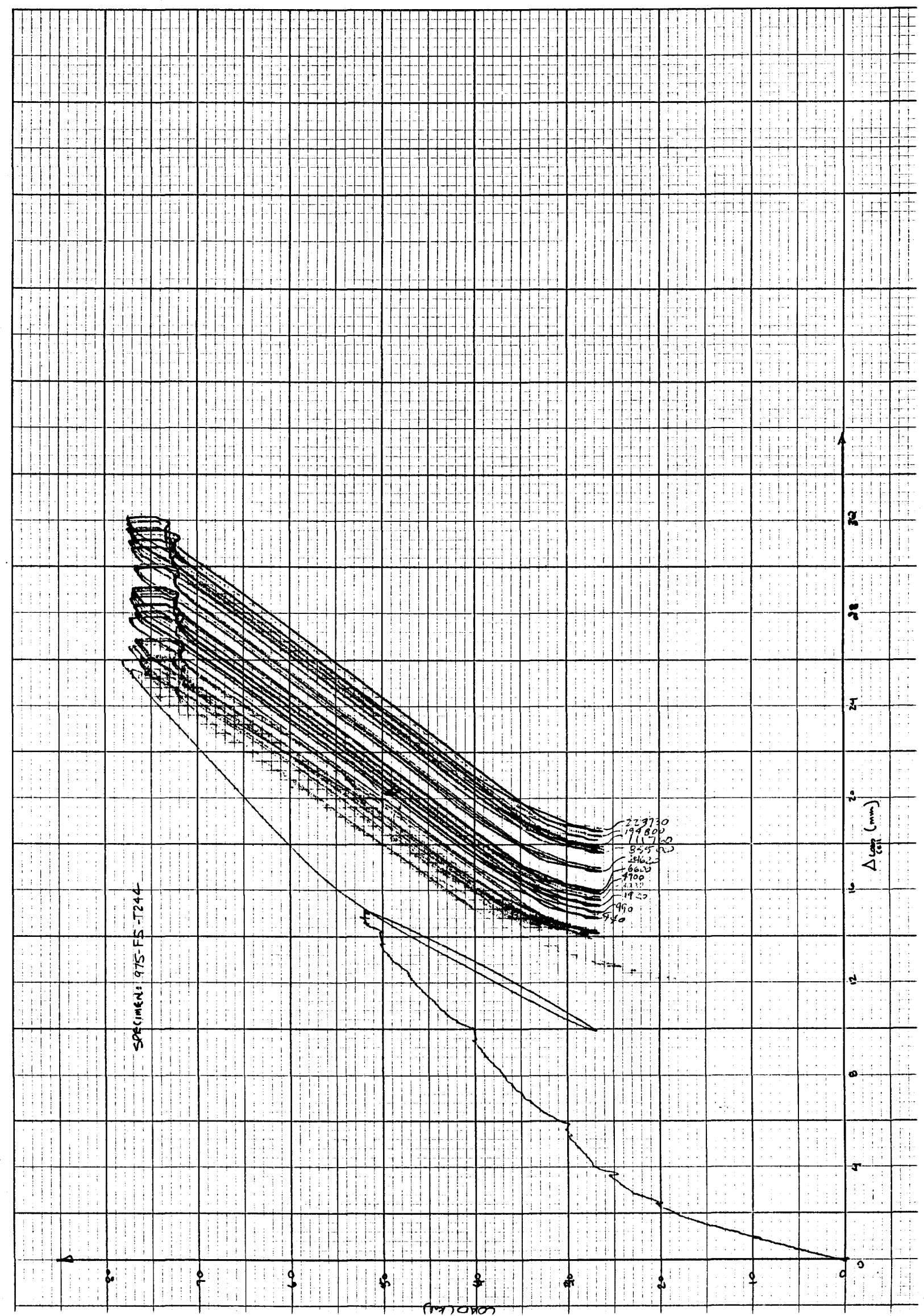




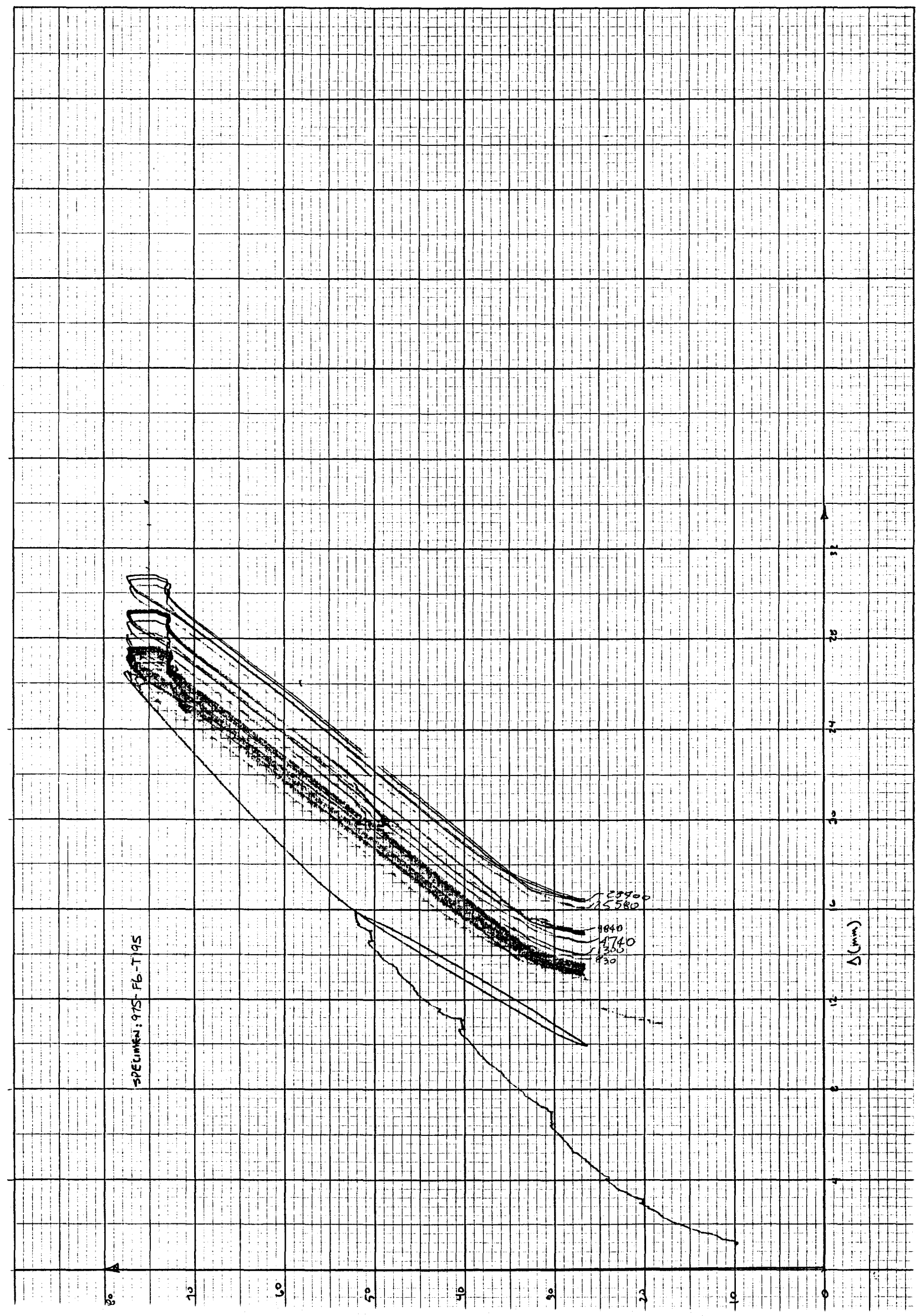




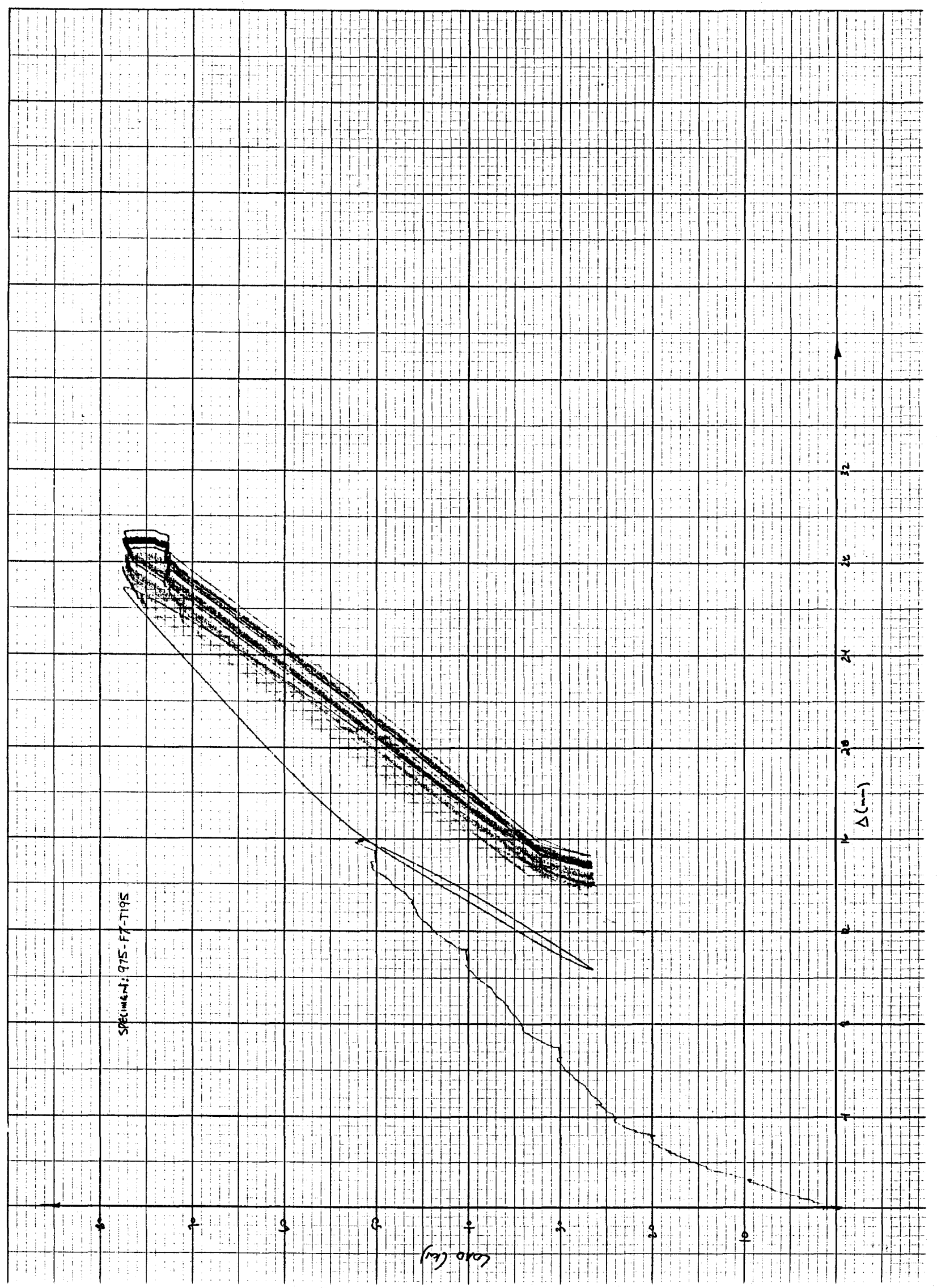




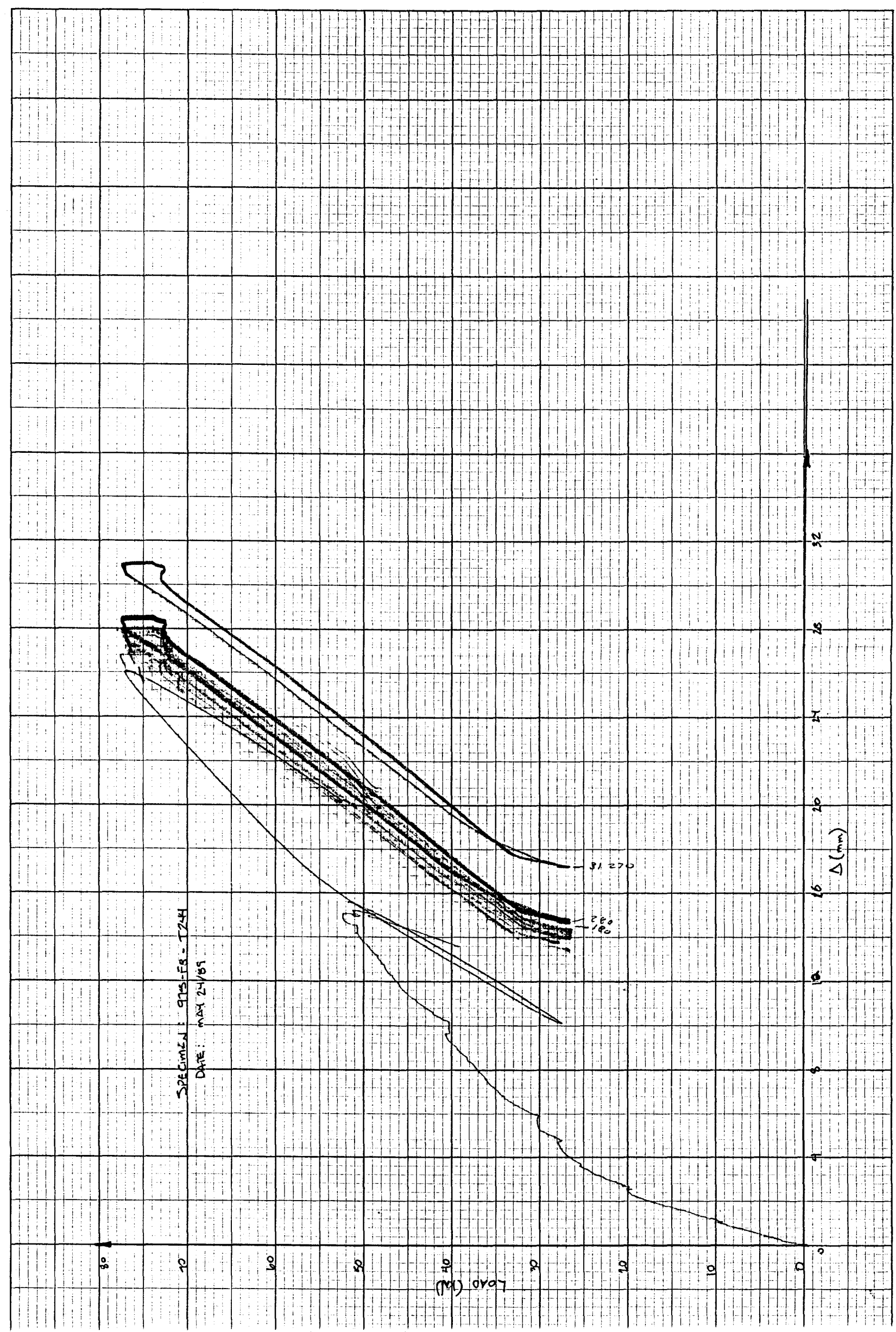




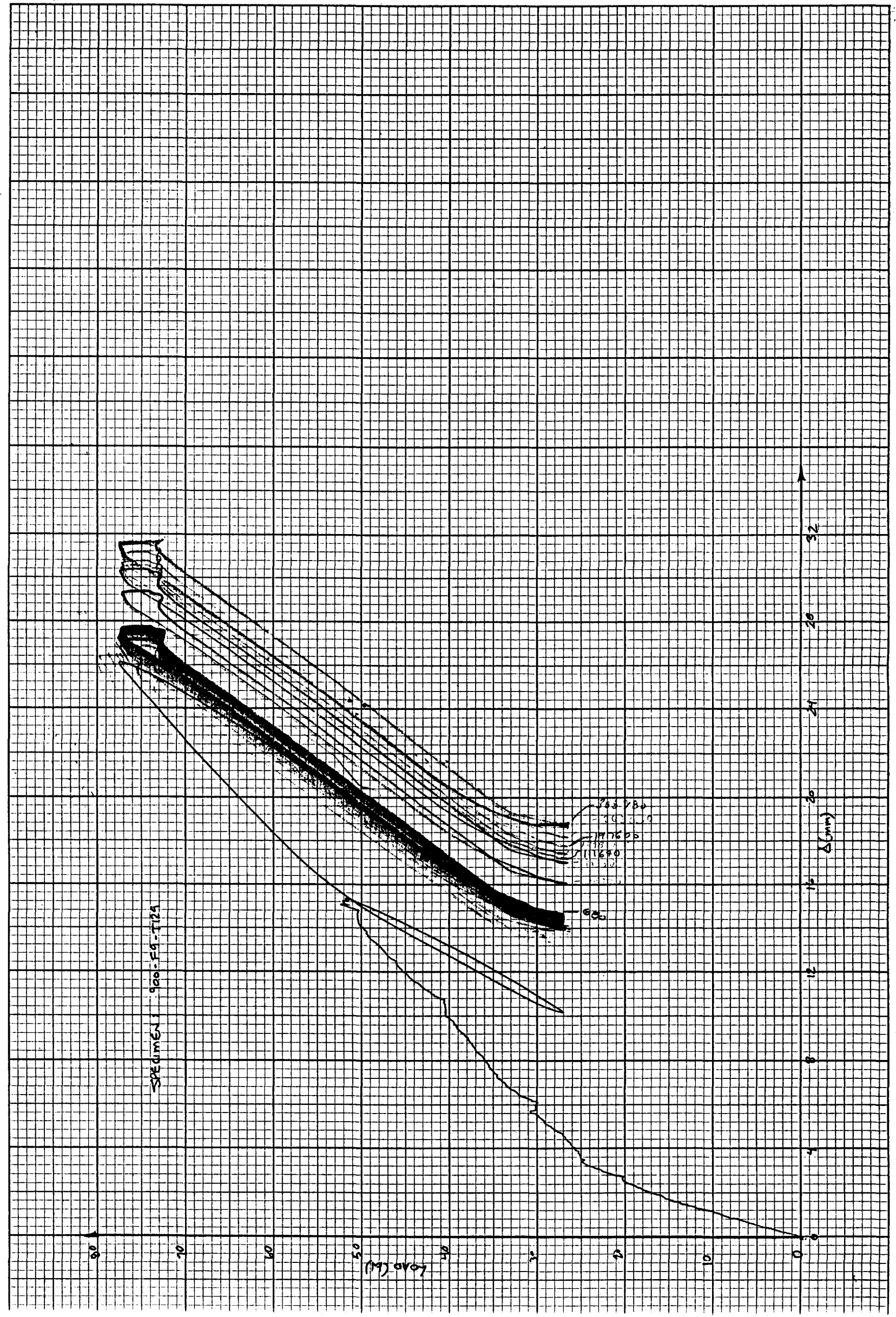




\begin{abstract}
APPENDIX E . STRAIN GAUGE LAYOUT
Four of the ten specimens tested in the current program were supplied with strain gauges bonded to the main tensile reinforcement and stirnups within the lap splice region. Before and during testing, problems developed with the gauges that resulted in many of them electrically failing and thus not providing any useful data.

The layout of the strain gauges used in each of the four specimens is shown in Figures E.1-E.4.
\end{abstract}




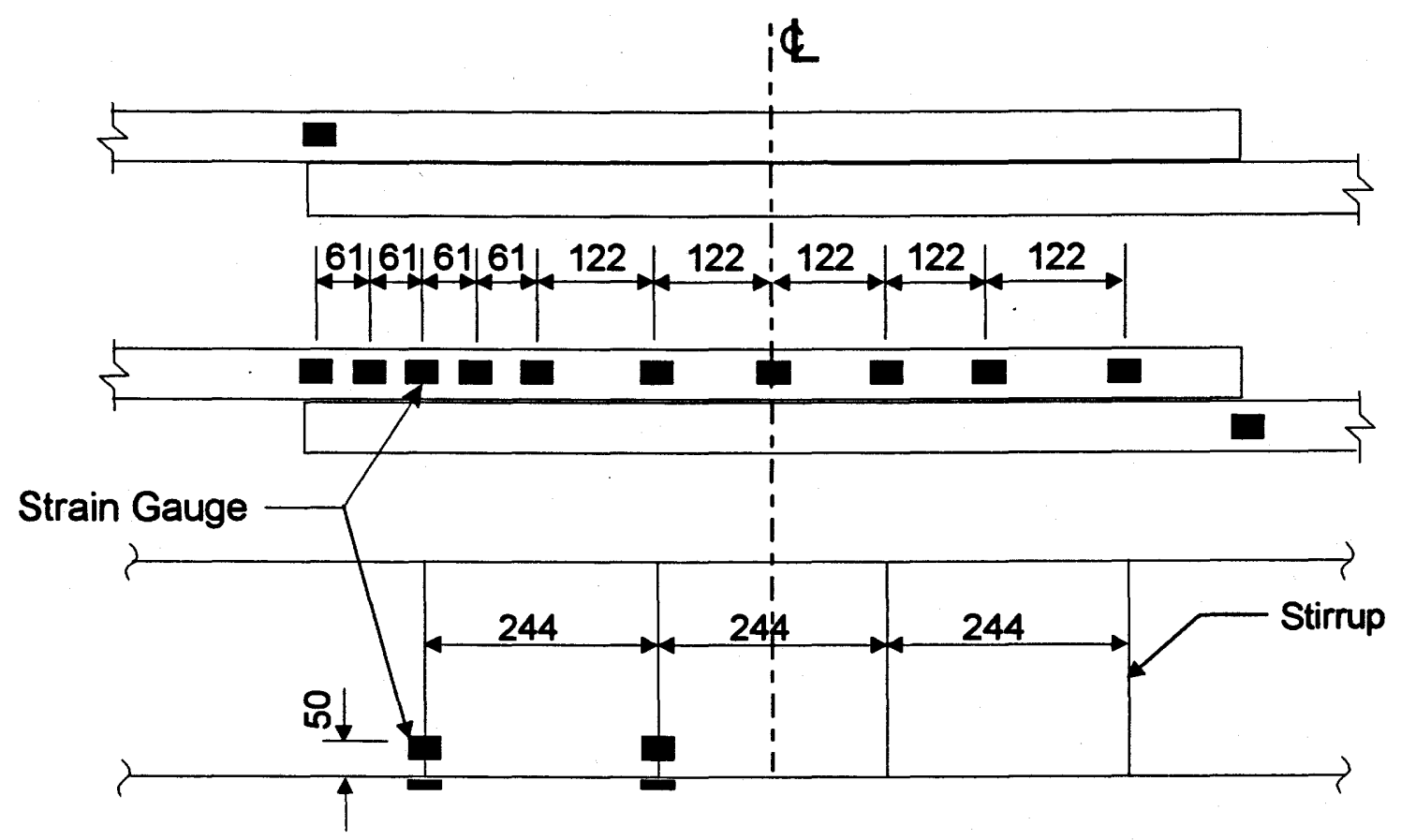

Figure E.1. Strain Guage Layout for Specimen 975-F1-T244.

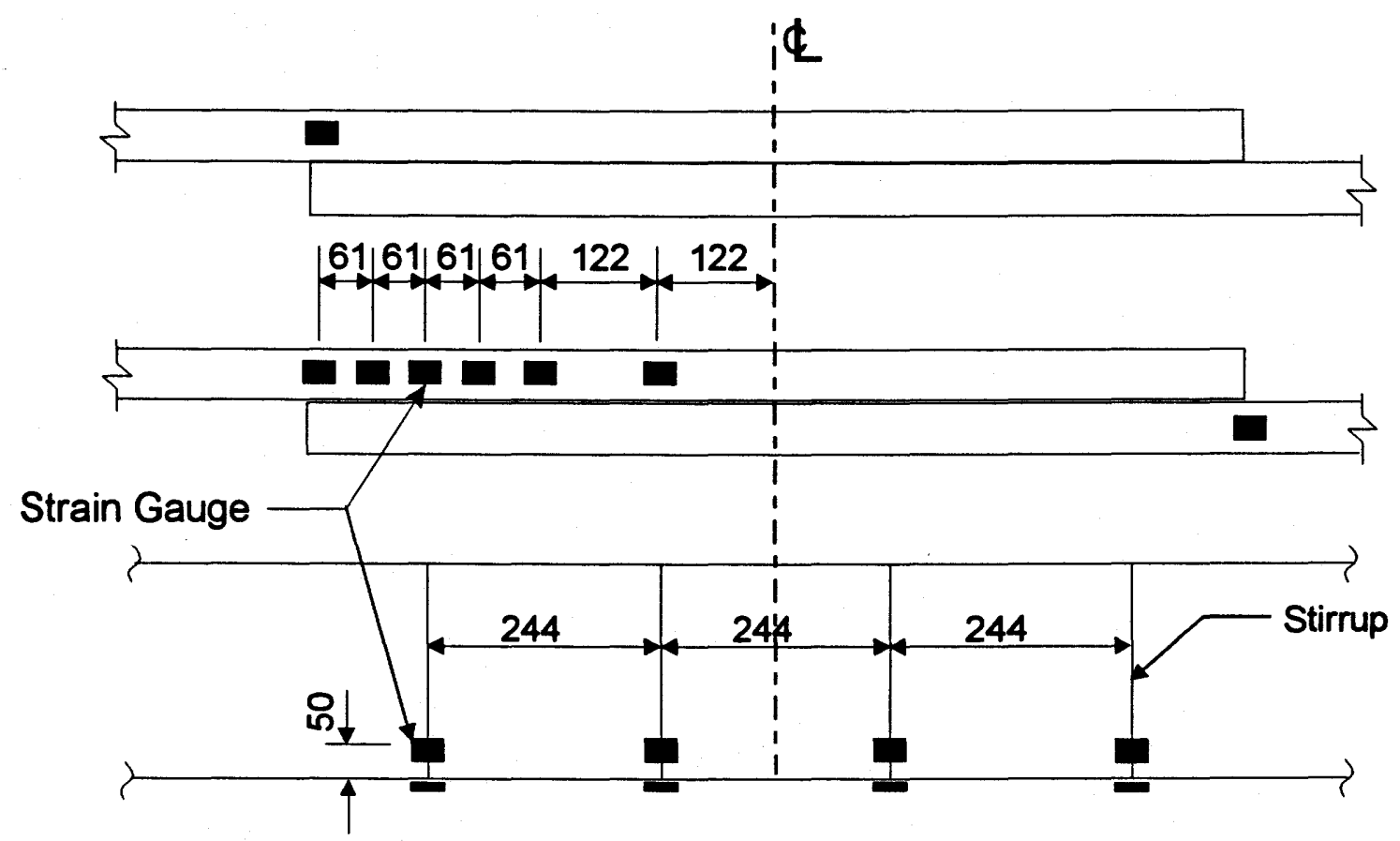

Figure E.2. Strain Guage Layout for Specimen 975-F2-T244. 


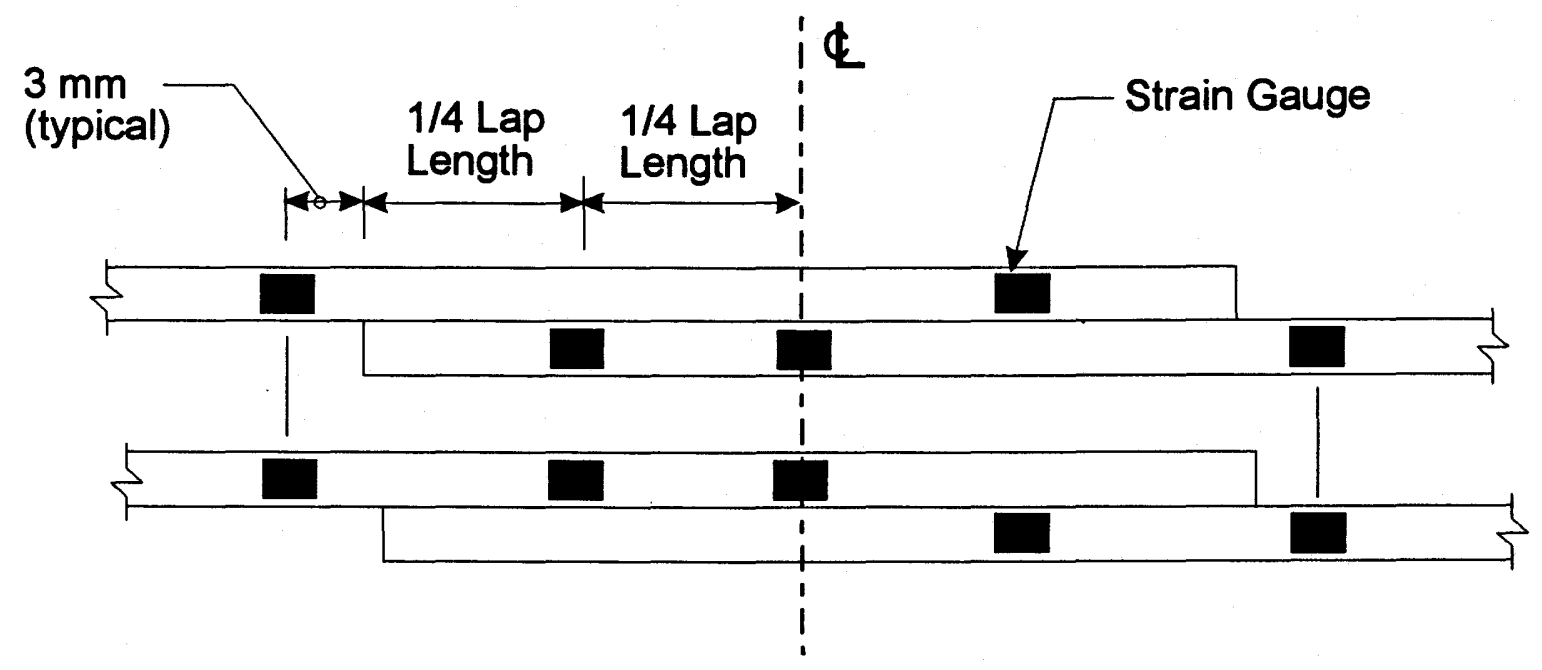

Figure E.3. Strain Gauge Layout for Specimen 975-F8-T244

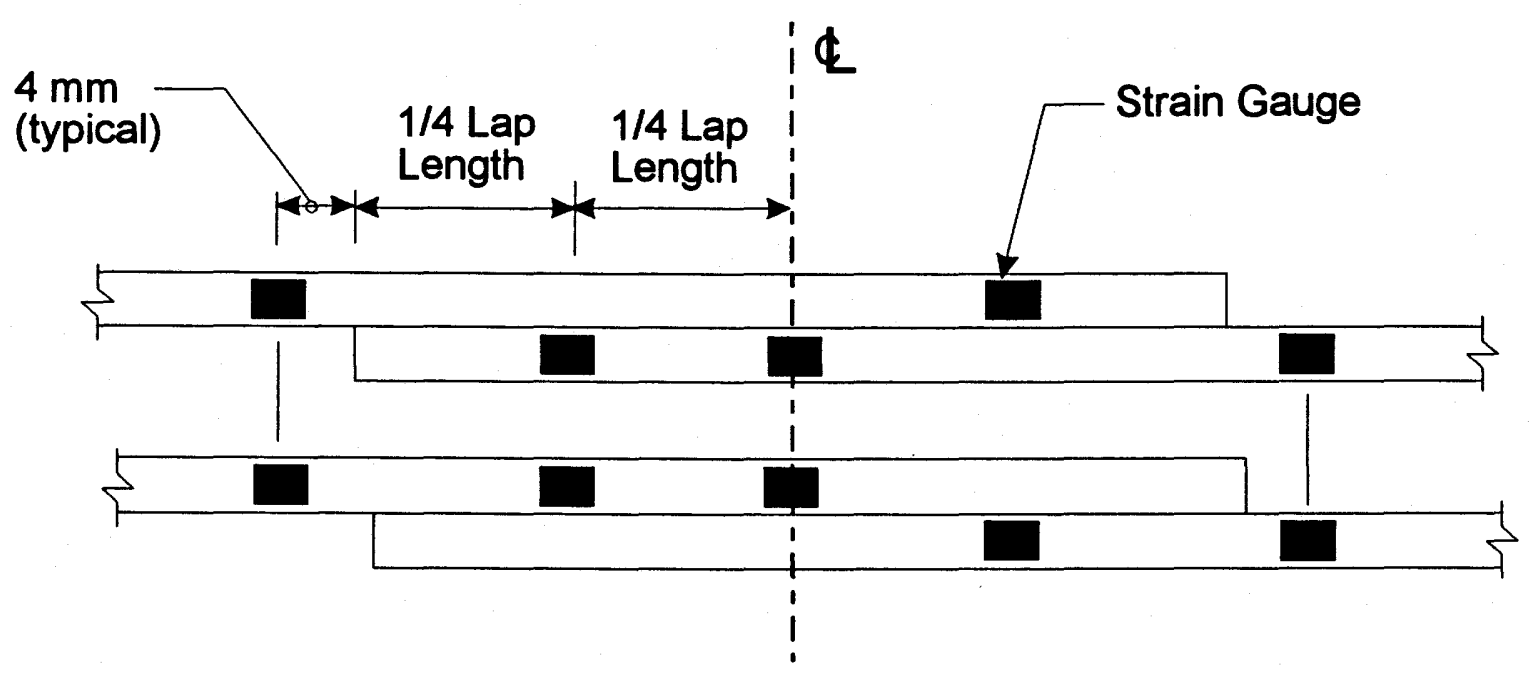

Figure E.4. Strain Gauge Layout for Specimen 900-F9-T129 


\section{APPENDIX F. TYPICAL MIX DESIGN}

A sample mix design was obtained from the ready mix supplier who prepared the concrete for all the specimens within this current program (Series A). The following are the concrete parameters which the supplier was to provide for Specimens 975-F6-T195 and 975-F7-T195 and subsequently a list of the proportions used in the concrete mix design for these specimens is presented:

Given:

- Cement Type: Portland - Normal Type 10

- Compressive Strength $=25 \mathrm{MPa}$ at 28 days

- Air Entertainment $=6 \% \pm 1 \%$

- Slump $=75$ to $100 \mathrm{~mm}$

- No other admixtures or cement replacements

- Vol. of concrete ordered $=2.75 \mathrm{~m}^{3}$

Mix Design:

\begin{tabular}{lll} 
Fine aggregate (sand) & $=$ & $800 \mathrm{~kg} / \mathrm{m}^{3}$ \\
Coarse aggregate (rock) & $=$ & $1100 \mathrm{~kg} / \mathrm{m}^{3}$ \\
Cement & $=310 \mathrm{~kg} / \mathrm{m}^{3}$ \\
Water & $=47 \mathrm{~kg} / \mathrm{m}^{3}$ \\
\hline Total & $=2257 \mathrm{~kg} / \mathrm{m}^{3}$
\end{tabular}

A similar mix design was used in the other specimens tested within this current program.

In the design of his specimens (Series B), Zacaruk (1990) specified $25 \mathrm{MPa}$ concrete compressive strength in the calculation of the required lap splice length, $1_{s}$. However, the concrete compressive strengths which were measured for each specimen prior to testing indicated strengths greater than or equal to $30 \mathrm{MPa}$, well above the design value. For the current study, the designs of the different lap splices were based on a compressive concrete strength of $25 \mathrm{MPa}$. However, because some of these specimens were of similar design to Zacaruk's specimens, and the specimens from his study were to be used in the analysis, it was decided that a concrete compressive strength of $30 \mathrm{MPa}$ would be targeted for the present study's beams. Previous research had shown that concrete strength is a significant factor in the fatigue resistance of a lap splice, therefore choosing this target value was an attempt to produce fatigue results which were comparable with the specimens from Zacaruk's program. 
In the analysis of the specimens, the differences between the design values and the measured quantities of the compressive concrete strength was not a issue. This is because the analysis of those specimens failing in bond was based on their predicted static strengths which were adjusted according to each specimen's measured concrete compressive strength (see Appendix A.3).

It should be noted that the concrete compressive strengths for the above two specimens were requested as $25 \mathrm{MPa}$ since for previous tests the targeted concrete strength of 30 MPa was being significantly surpassed at the start of each test (see Table 3.1). Therefore, in attempt to lower the concrete strength, closer to the target value at the start of testing, a reduced concrete strength at 28 days was requested. 


\section{APPENDIX G. DATA NOISE REDUCTION}

The raw data gathered by the Megadac Data Acquisition System was affected by discretization (purely random or white) noise caused by rounding errors each time the system took a sample. The noise was at a frequency equal to the sampling rate of the system ( 30 samples per second per sensor).

A filtering procedure was used to remove the noise from the data. The filter used is described as a non-recursive filter which assumes the noise to be gaussian (random) and is based on the present and previous input values. The filter is represented by the following equation (Orfandis 1985):

$$
\begin{aligned}
y_{n}^{\prime \prime}=a y_{n}+b y_{n-1} & y^{\prime \prime}=\text { filtered output value; } \\
& y_{n}=\text { present input value; } \\
& y_{n-1}=\text { previous input value; } \\
& a=\text { parameter selected depending on cutoff } \\
& \text { frequency chosen; } \\
& b=a-1 .
\end{aligned}
$$

For the current study the value of a was chosen as 0.25 which cuts out any noise above a frequency of approximately $18-25 \mathrm{~Hz}$. Multiple passes with the filter were needed to reduce the noise to the point where a smooth sine function resulted. However, the above filter caused the filtered data to be shifted to the right of the raw data. This displacement was expected of the above filter and the data was easily shifted back.

Figure G.1 shows some of the raw deflection data which was obtained from the Megadac System. Also shown is the resulting data after multiple passes through the above filter. 


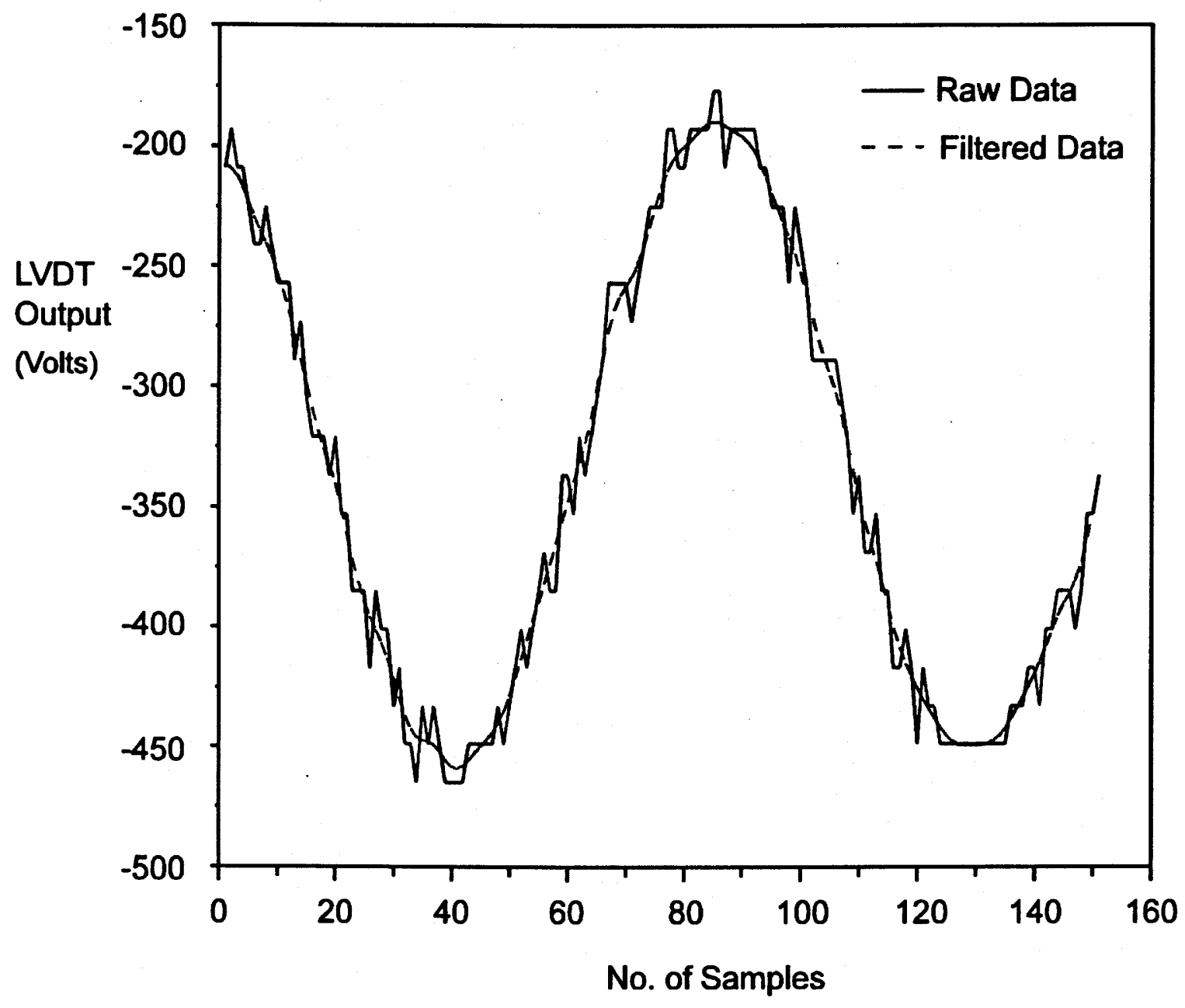

Figure G.1. LVDT Deflection Output vs. No. of Samples Collected 


\section{APPENDIX H . LVDT DEFLECTION DATA}

The figures following within this appendix are plots of the deflection data gathered from the Linear Variable Displacement Transducers (positioning of the LVDT's is as described in section 3.3) throughout the fatigue life of the specimens.

The plots indicate the degrading deflections occurring to each beam as the number of load cycles increases. This response is what would be expected as flexural creep occurs and the bond along the lap length deteriorates resulting in slippage of the lapped reinforcing bars. Fig. H.8 is a schematic indicating how the large flexural cracks occurring at the ends of the lapped bars might have influenced the overall deflection of the beam. If one of the flexural cracks opened up more than the other, the deflected shape of the beam may be similar to the first and second cases shown in Fig. H.8. This may have been what happened with Specimens 975-F6-T195 (Fig. H.4) and 975-F7-T195 (Fig. H.5) for example. However, if both cracks contributed equally to the beam deflection, a deflected shape similar to the third case in Fig. H.8 may have resulted. 


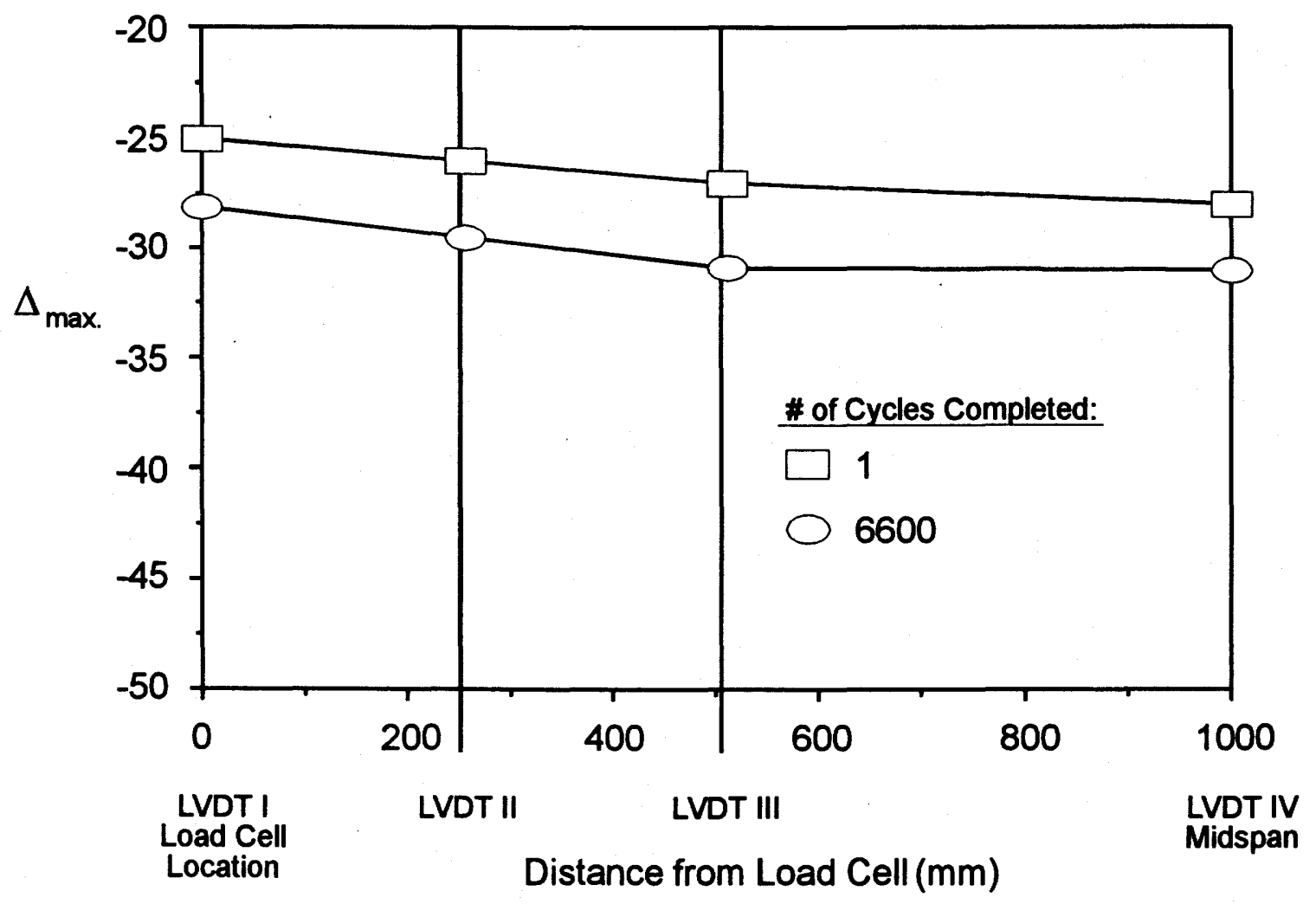

Figure H.1. Specimen 975-F3-T244: LVDT Deflections

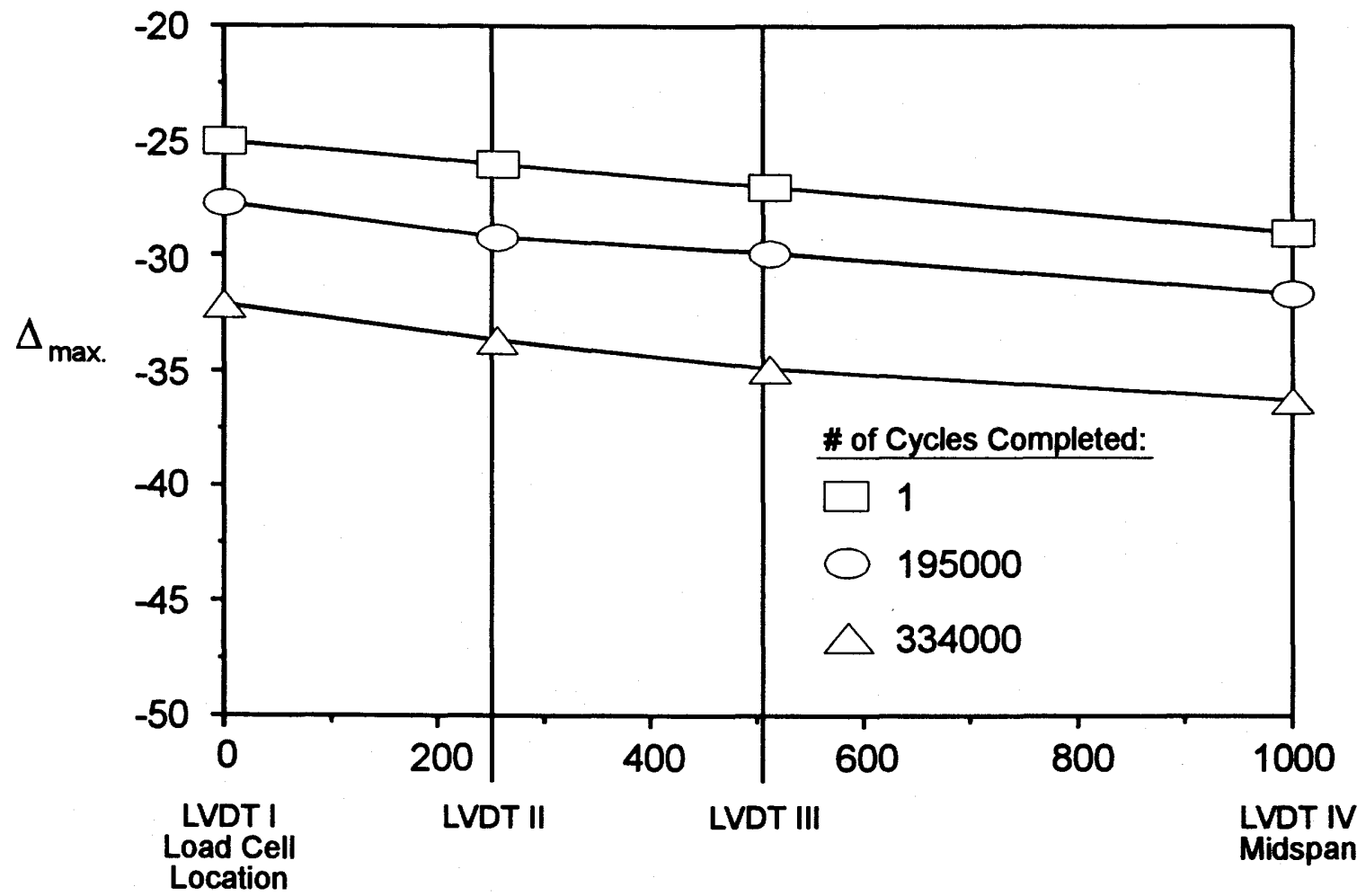

Distance from Load Cell ( $\mathrm{mm}$ )

Figure H.2. Specimen 900-F4-T129: LVDT Deflections 


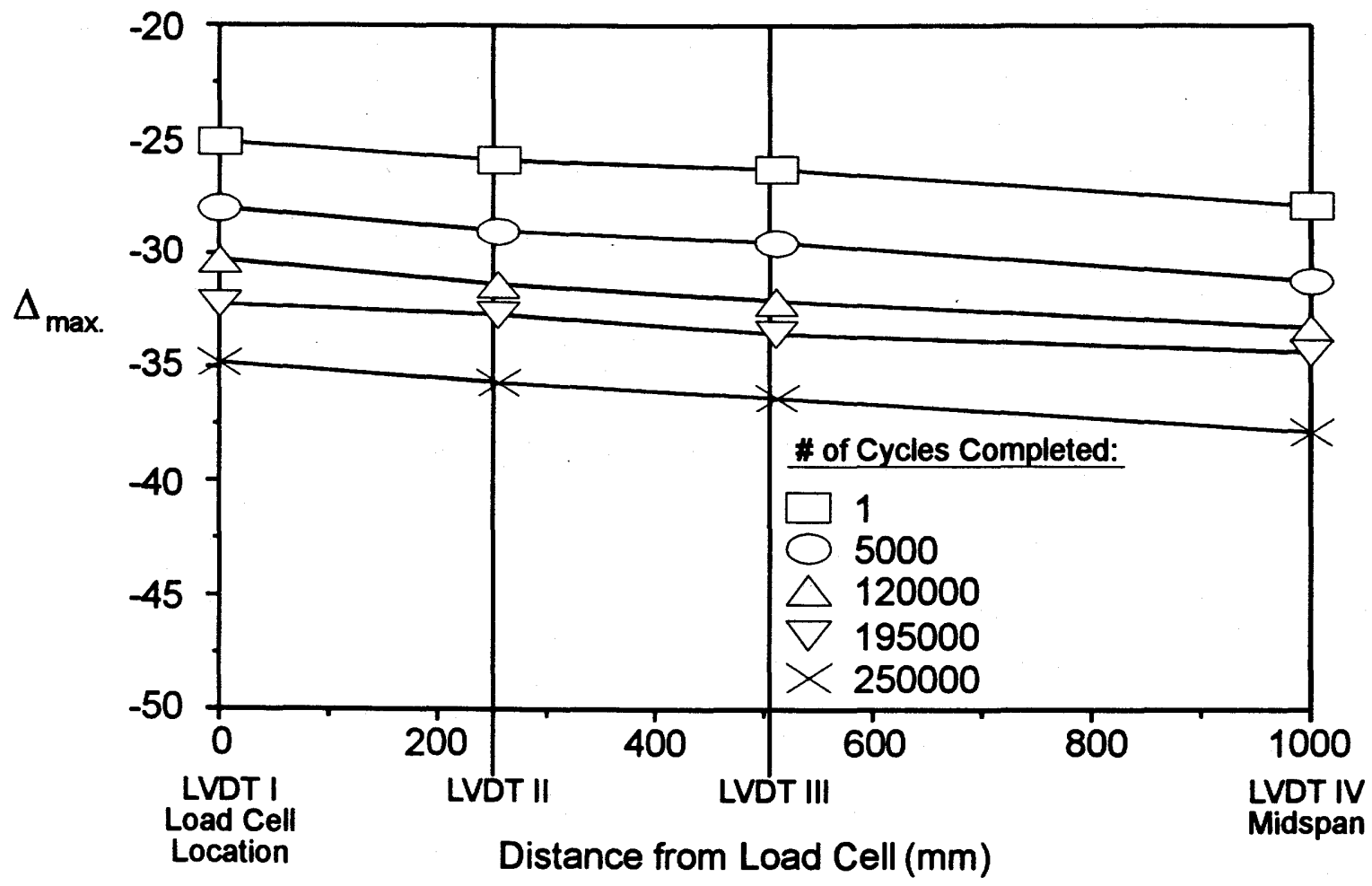

Figure H.3. Specimen 975-F5-T244: LVDT Deflections.

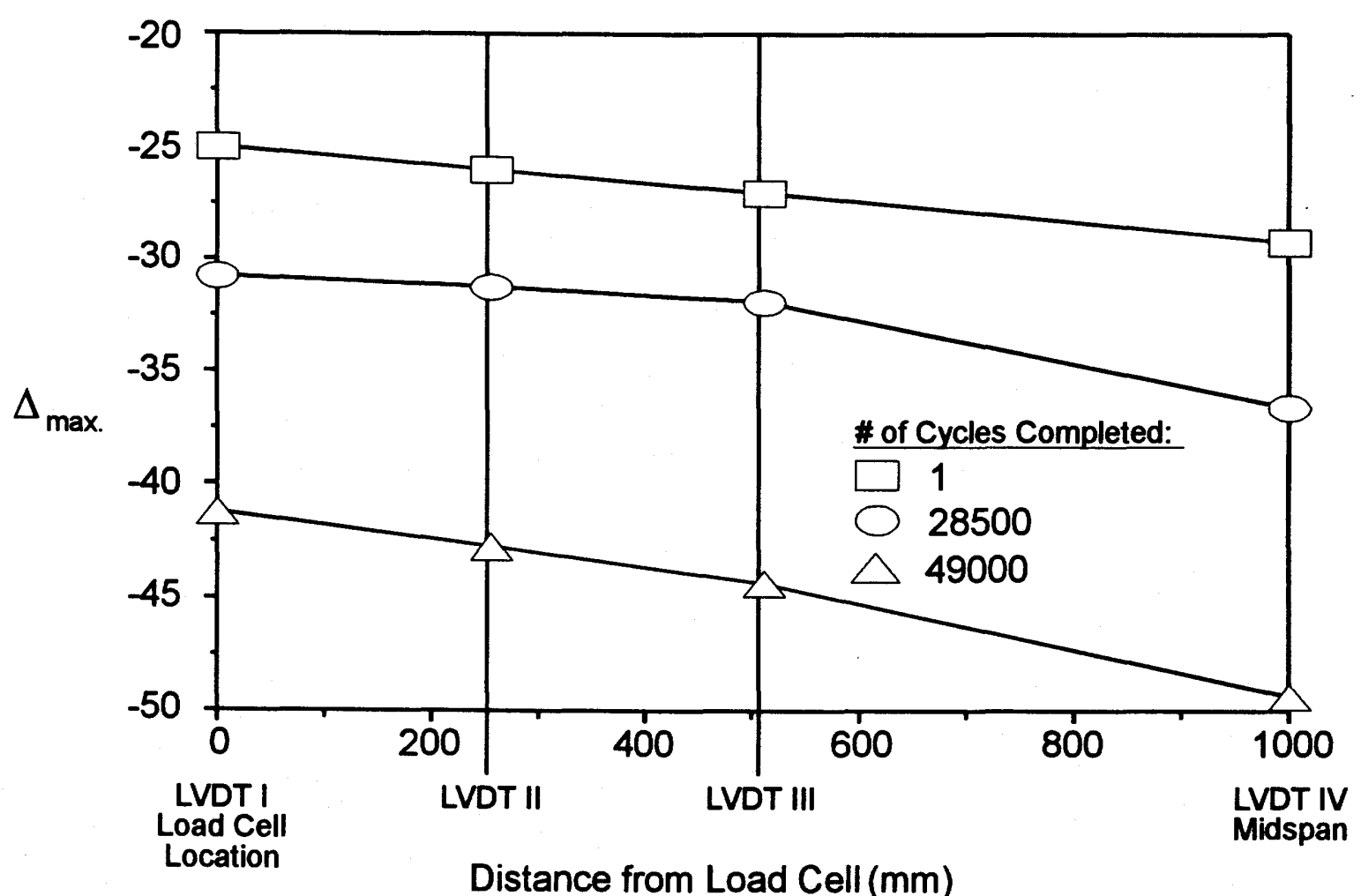

Figure H.4. Specimen 975-F6-T195: LVDT Deflections. 


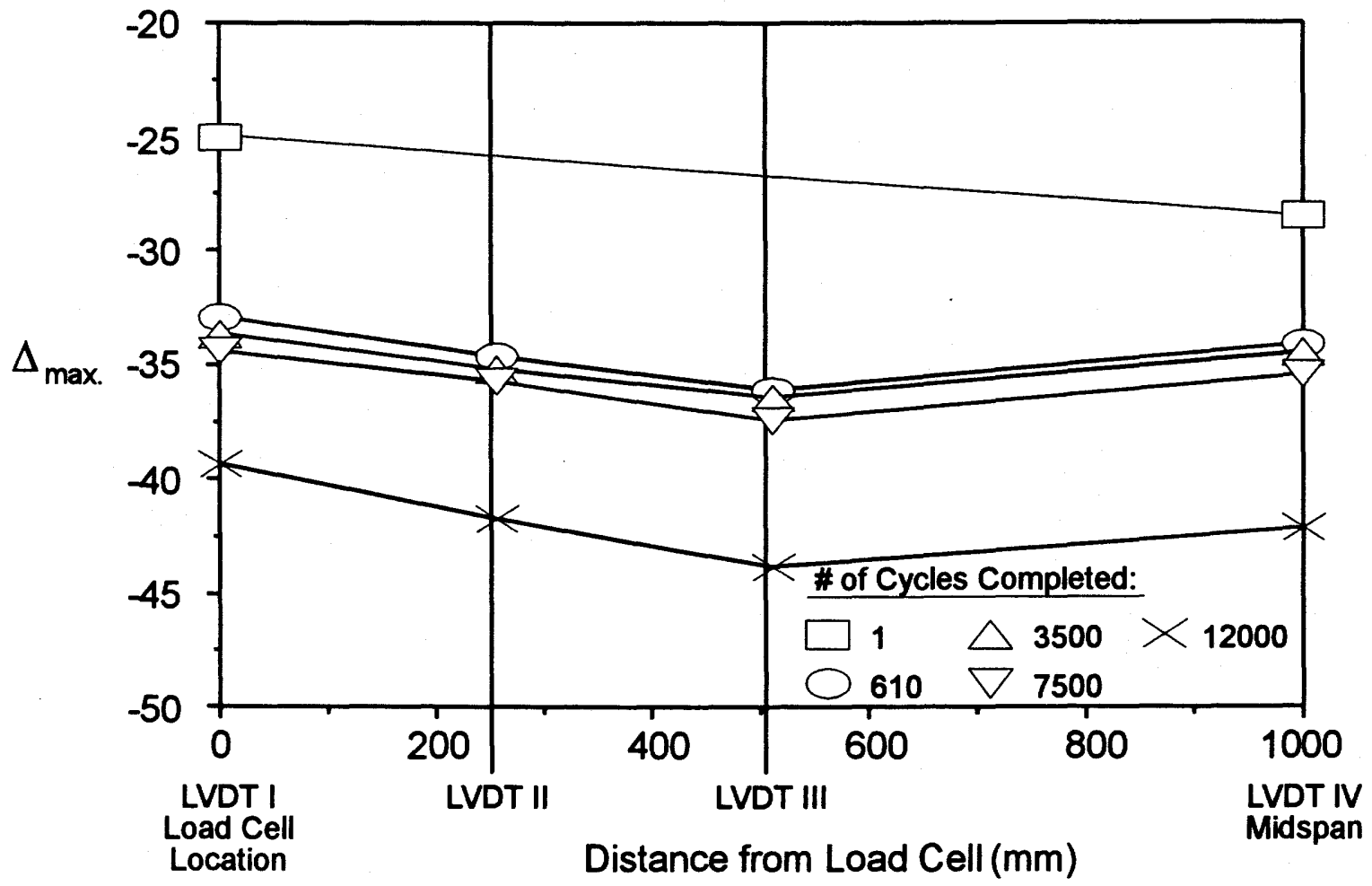

Figure H.5. Specimen 975-F7-T195: LVDT Deflections

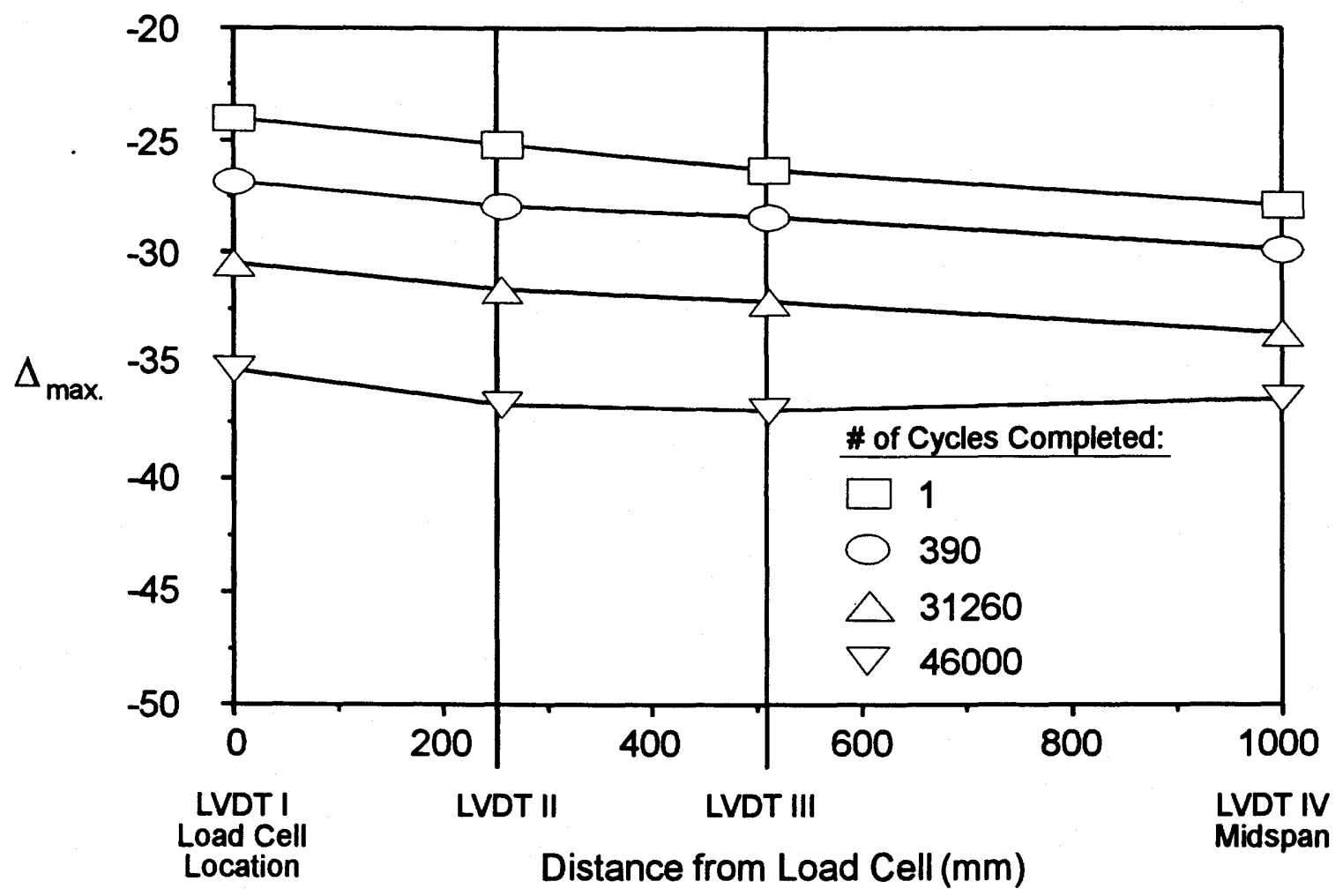

Figure H.6. Specimen 975-F8-T244: LVDT Deflections 


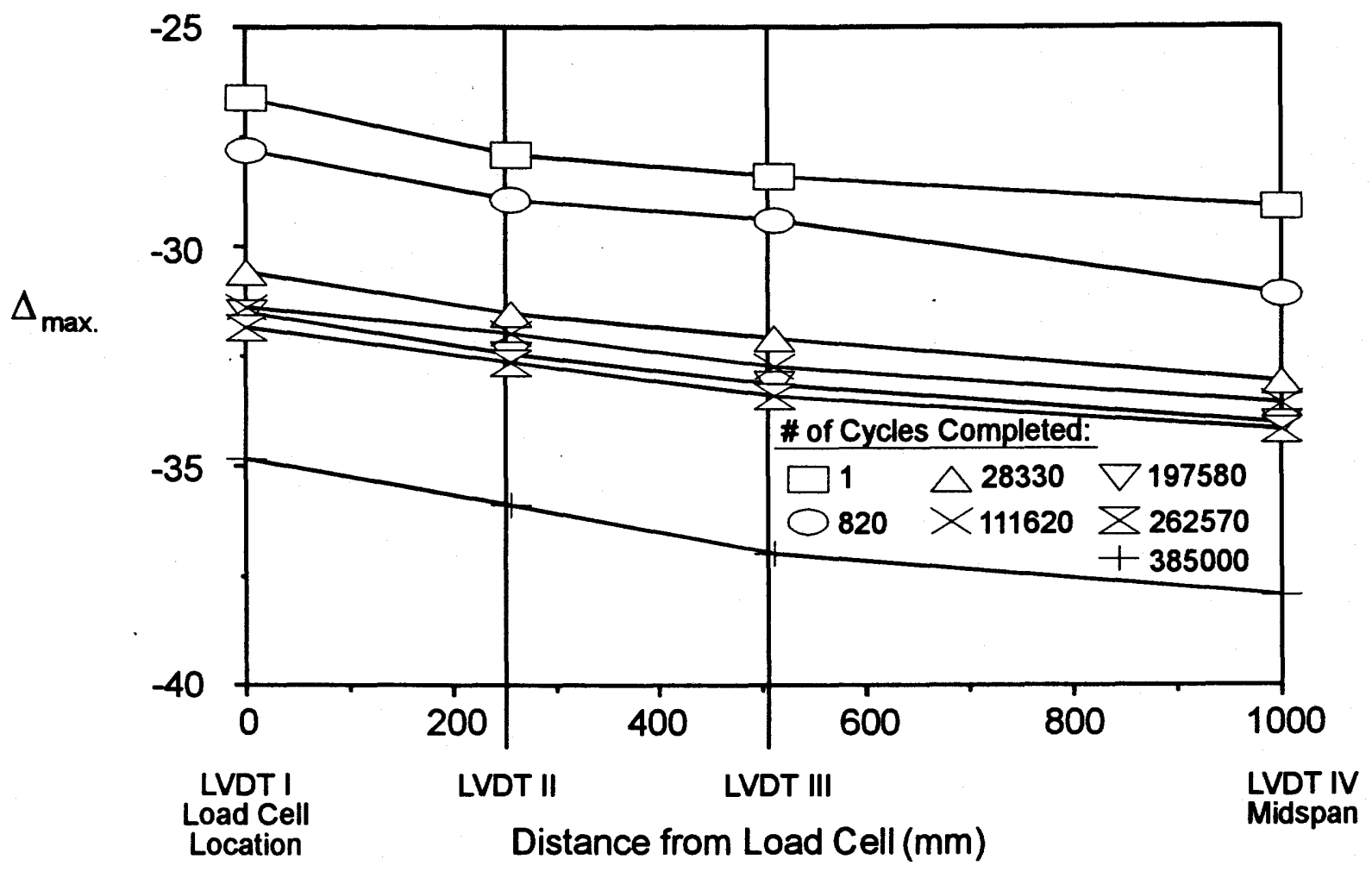

Figure H.7. Specimen 900-F9-T129: LVDT Deflections.

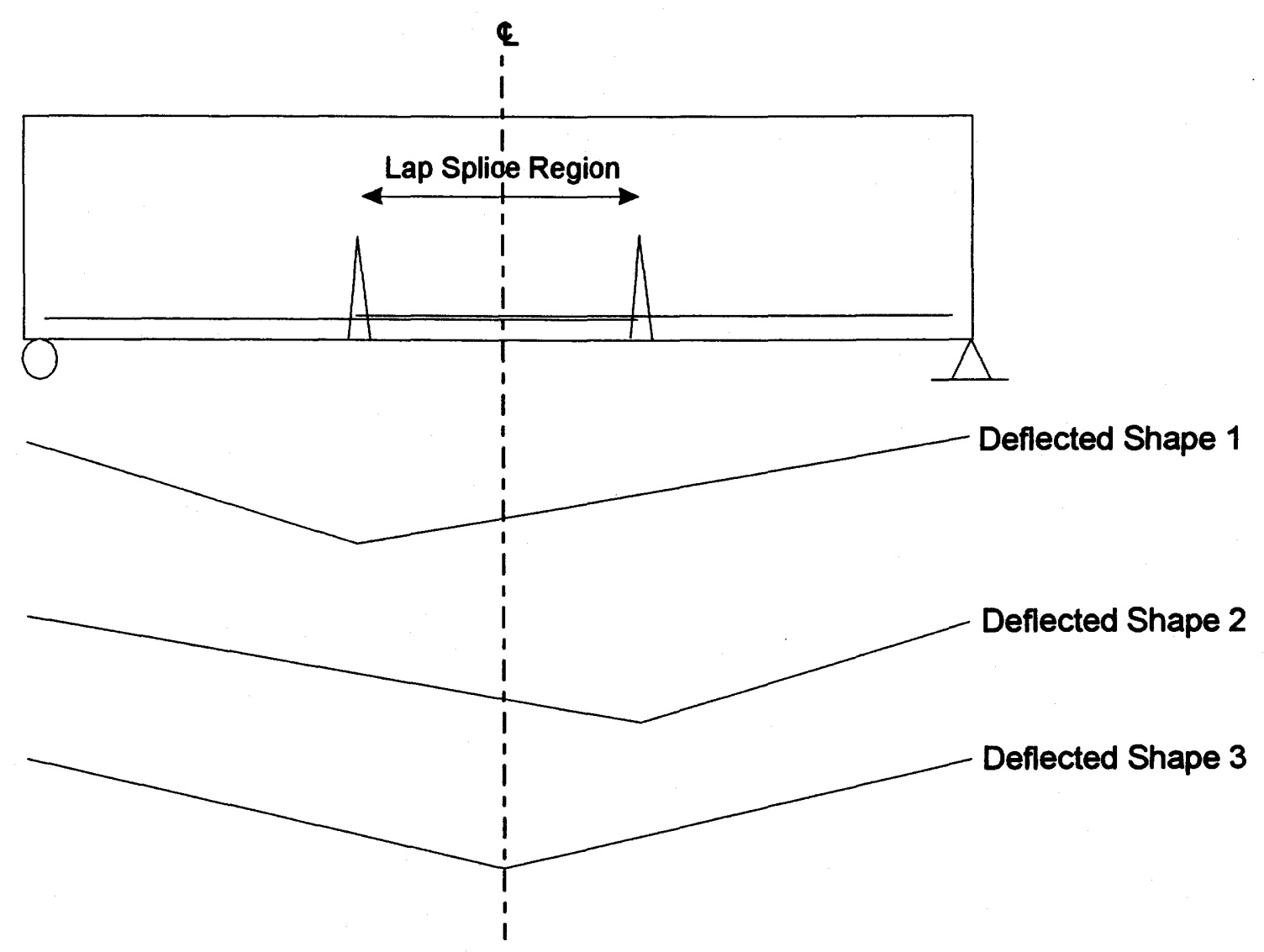

Figure H.8. Schematic of Beam Overall Deflected Shape. 